\title{
Nondestructive and destructive evaluation of FRP composite wrapped concrete cylinders with embedded debonds
}

\author{
Shasanka Shekhar Dutta \\ West Virginia University
}

Follow this and additional works at: https://researchrepository.wvu.edu/etd

\section{Recommended Citation}

Dutta, Shasanka Shekhar, "Nondestructive and destructive evaluation of FRP composite wrapped concrete cylinders with embedded debonds" (2010). Graduate Theses, Dissertations, and Problem Reports. 2945.

https://researchrepository.wvu.edu/etd/2945

This Dissertation is protected by copyright and/or related rights. It has been brought to you by the The Research Repository @ WVU with permission from the rights-holder(s). You are free to use this Dissertation in any way that is permitted by the copyright and related rights legislation that applies to your use. For other uses you must obtain permission from the rights-holder(s) directly, unless additional rights are indicated by a Creative Commons license in the record and/ or on the work itself. This Dissertation has been accepted for inclusion in WVU Graduate Theses, Dissertations, and Problem Reports collection by an authorized administrator of The Research Repository @ WVU.

For more information, please contact researchrepository@mail.wvu.edu. 


\title{
NONDESTRUCTIVE AND DESTRUCTIVE EVALUATION OF FRP COMPOSITE WRAPPED CONCRETE CYLINDERS WITH EMBEDDED DEBONDS
}

\author{
Shasanka Shekhar Dutta
}

\author{
DISSERTATION \\ Submitted to the \\ College of Engineering and Mineral Resources \\ at West Virginia University \\ in partial fulfillment of the requirements \\ for the degree of
}

\author{
Doctor of Philosophy \\ in \\ Civil Engineering
}

\author{
Udaya B. Halabe, Ph.D., P.E., Chair \\ Hota V. S. GangaRao, Ph.D., P.E. \\ Hema J. Siriwardane, Ph.D., P.E. \\ Powsiri Klinkachorn, Ph.D. \\ Ruifeng Liang, Ph.D.
}

Department of Civil and Environmental Engineering

Morgantown, West Virginia

2010

Keywords: Infrared Thermography, CFRP, GFRP, Debonds, Concrete Cylinder, Axial Strain, Circumferential Strain 


\section{ABSTRACT \\ Nondestructive and Destructive Evaluation of FRP Composite Wrapped Concrete Cylinders with Embedded Debonds}

\section{Shasanka Shekhar Dutta}

A major application of composite materials in the reinforced concrete industry is to wrap columns with Fiber Reinforced Polymer (FRP) composite fabric which results in increase in the columns' axial compressive strength and ductility. Presence of debonds between the FRP wrap and the underlying column surface inhibits the proper confinement of the column by the composite wrap.

The objectives of this research are: (a) to evaluate the feasibility of using Active Infrared Thermography for qualitative as well as quantitative evaluation of debonds in Fiber Reinforced Polymer (FRP) wrapped columns, (b) to understand of influence of heat flux, debond width and debond depth on various thermal response parameters, and (c) to study the effect of debonds on stress-strain behavior of FRP wrapped columns.

All laboratory tests were conducted on concrete cylinders of size 6" x 12" (152.4 mm x $304.8 \mathrm{~mm}$ ). Simulated air-filled debonds, water-filled debonds and debonds made from Teflon sheets of various sizes were placed on the concrete cylinder's surface prior to wrapping with FRP fabric. Active Thermography technique was used to locate these simulated debonds and to quantify the debond width and debond depth. Infrared thermography tests were conducted using a digital infrared camera capable of acquiring radiometric images with capture speed of up to 60 frames/s. In this research, the effect of debond area in terms of percentage of total area on the stresses and strains of concrete columns wrapped with FRP composite fabric was also studied using destructive compression testing.

The results reveal that Infrared Thermography is an effective nondestructive evaluation tool for qualitative and quantitative evaluation of subsurface debonds in concrete columns wrapped with Fiber Reinforced Polymer (FRP) composites. Also, a significant decrease in axial compressive strength with an increase in area of debonds was observed, and appropriate reduction factors have been proposed for use in strength computations. Both GFRP and CFRP composites were found to be effective in arresting the lateral dilation of the underlying concrete. Also, considerable ductility enhancement was evident due to the wrapping of cylinders with FRP composites, particularly with CFRP composites. 


\section{ACKNOWLEDGEMENTS}

At the outset, I would like to express my sincere gratitude to my academic and research advisor, Dr. Udaya B. Halabe for his guidance and encouragement during my Ph.D. program. I am thankful to Drs. Hota. V. S. GangaRao, Hema J. Siriwardane, Powsiri Klinkhachorn and Ruifeng Liang, members of my Advisory and Examining Committee, for their help during my research and studies.

I am thankful to all my friends especially Manab, Aneesh, Sourav, Ayman and Sandeep for their help during my research work. The help provided by Jerry Nestor, Mark Skidmore, Bill Comstock, Douglas Cutlip and David Turner during some of my laboratory work is gratefully acknowledged.

I thank my family who stood beside me and encouraged me to do my best. Lastly, I thank all of my friends for their help directly or indirectly in my research and for making my stay in Morgantown a memorable one. 


\section{DEDICATIONS}

I dedicate this dissertation to God and to my parents Dr. Kamaleswar Dutta and Dr. (Mrs.) Bharati Dutta. 


\section{TABLE OF CONTENTS}

ABSTRACT

ACKNOWLEDGEMENTS.............................................................iii

DEDICATIONS...............................................................

TABLE OF CONTENTS.........................................................v

LIST OF FIGURES.................................................................

LIST OF TABLES...........................................................xxii

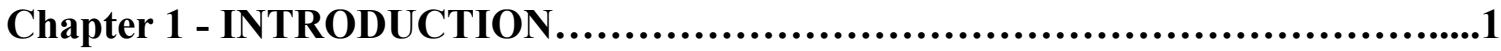

1.1 BACKGROUND........................................................1

1.2 RESEARCH OBJECTIVES AND SCOPE...............................

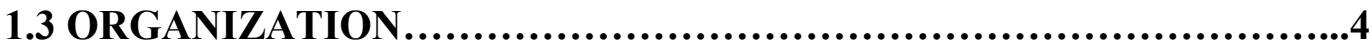

Chapter 2 - FUNDAMENTALS OF INFRARED THERMOGRAPHY..............5

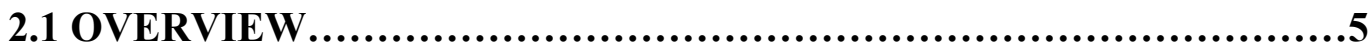

2.2 BASICS OF INFRARED THERMOGRAPHY ...........................5

2.2.1 Active Thermography and Passive Thermography......................9

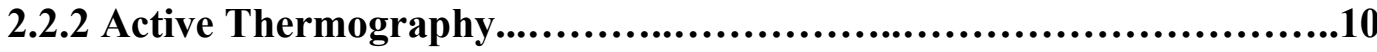

2.2.3 Testing Methods......................................................11

2.2.4 Quantitative Infrared Thermography $\ldots \ldots \ldots \ldots \ldots \ldots \ldots \ldots \ldots \ldots \ldots \ldots \ldots \ldots 11$

2.2.4.1 Estimation of Defect Width.......................................12

2.2.4.2 Estimation of Defect Depth.....................................13

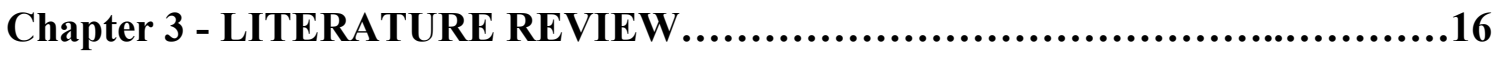

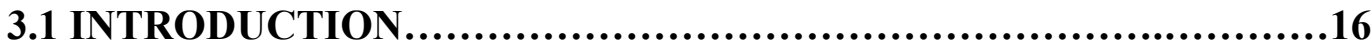




\subsection{STRESS STRAIN BEHAVIOR OF FRP COMPOSITE WRAPPED}

COLUMNS................................................................19

3.3.1 Theory of Confinement.................................................21

Chapter 4 - LABORATORY EQUIPMENT AND TEST SPECIMENS...............23

4.1 INFRARED THERMOGRAPHY EQUIPMENT_........................23

4.1.1 Infrared Camera .......................................................23

4.1.2 Quartz Tower Heater...................................................24

4.1.3 Heat Flux Meter.....................................................25

4.1.4 Thermal Conductivity Testing System................................26

4.2 SETUP FOR STATIC COMPRESSION TEST ...........................28

4.2.1 Universal Compression Testing Machine.................................28

4.2.2 Baldwin Machine......................................................28

4.2.3 Data Acquisition, Load Cell, LVDT and Strain Gages.................28

4.3 MAKING OF THE SPECIMENS.....................................29

4.3.1 Making of Debonds....................................................29

4.3.2 Wrapping of Cylinders.................................................31

Chapter 5 - EXPERIMENTAL RESULTS FROM INFRARED

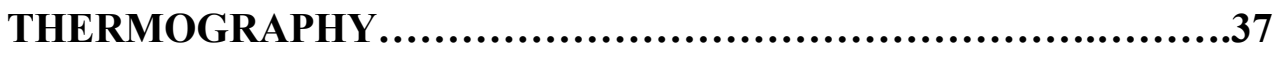

5.1 DETECTION OF DEBONDS BY IRT...................................37

5.1.1 Detection of Debonds in Cylinders Wrapped with GFRP

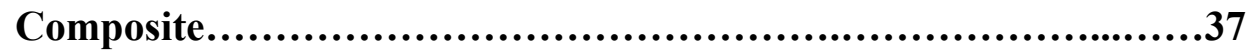

5.1.1.1 Detection of 1"' x 1" Air-Filled Debond...............................37

5.1.1.2 Detection of 1.4"' x 1.4" Air-Filled Debond............................40 
5.1.1.3 Detection of 2"' x 2"' Air-Filled Debond.............................43

5.1.1.4 Detection of 3" x 3" Air-Filled Debond..............................46

5.1.1.5 Detection of Water-Filled Debonds..................................48

5.1.2 Detection of Debonds in Cylinders Wrapped with CFRP Composite.............................................................50

5.1.2.1 Detection of 1.4" x 1.4" Air-Filled Debond...........................50

5.1.2.2 Detection of 2" x 2"' Air-Filled Debond............................52

5.1.2.3 Detection of 3" x 3" Air-Filled Debond.............................54

5.1.2.4 Detection of Water-filled Debond..................................56

5.1.3 Conclusions.....................................................58

5.2 PARAMETRIC STUDY USING INFRARED THERMOGRAPHY....58

5.2.1 Effect of Heat Flux..................................................59

5.2.2 Effect of Debond Width.............................................67

5.2.3 Effect of Debond Depth...............................................71

5.2.4 Conclusions..............................................................74

5.3 QUANTITATIVE CHARACTERIZATION RESULTS.................75

5.3.1 Estimation of Debond Width........................................76

5.3.2 Estimation of Debond Depth.........................................76

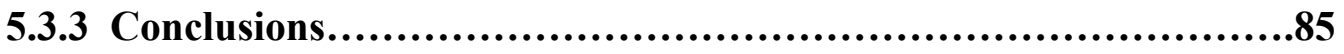

5.4 SURFACE TEMPERATURE CURVES................................85

Chapter 6 - EXPERIMENTAL RESULTS FROM DESTRUCTIVE TESTING..86 6.1 EFFECT OF DISCONTINUITY ON AXIAL COMPRESSIVE STRENGTH...........................................................86

6.1.1 Tensile Strength of Coupon Specimens..................................86

6.1.2 Axial Compressive Strength of Unwrapped Specimens...............87 
6.1.3 Axial and Circumferential Strain of Unwrapped Specimens

6.1.4 Axial Compressive Strength and Maximum Strain of Wrapped

Specimens..........................................................89

6.1.5 Axial Compressive Strength of Wrapped Specimens with Simulated

Debonds...............................................................90

6.1.5.1 Compressive Strength of GFRP Composite Wrapped Cylinders with Air-filled Debonds............................................91

6.1.5.2 Compressive Strength of GFRP Composite Wrapped Cylinders with Water-filled Debonds........................................91

6.1.5.3 Compressive Strength of GFRP Composite Wrapped Cylinders with Teflon Sheets................................................92

6.1.5.4 Maximum Strain of Cylinders GFRP Composite Wrapped Cylinders with Simulated Flaws..................................93

6.1.5.5 Volumetric strain and Axial Strain Relationship for GFRP Composite Wrapped Cylinders with Simulated Flaws.

6.1.5.6 Compressive Strength of CFRP Composite Wrapped Cylinders with Air-filled Debonds..............................................97

6.1.5.7 Compressive Strength of CFRP Composite Wrapped Cylinders with Water-filled Debonds........................................97

6.1.5.8 Compressive Strength of CFRP Composite Wrapped Cylinders with Teflon Sheets................................................98

6.1.5.9 Maximum Strain of Cylinders CFRP Composite Wrapped Cylinders with Simulated Flaws..................................99

6.1.5.10 Volumetric Strain and Axial Strain Relationship for CFRP Composite Wrapped Cylinders with Simulated Flaws...........101

6.1.6 Conclusions .102

6.2 DUCTILITY ENHANCEMENT .102

6.3 COMPARISON BETWEEN ANALYTICAL MODELS AND

EXPERIMENTAL RESULTS. 105

6.3.1 GFRP Composite Wrapped Cylinders. .105 
6.3.2 CFRP Composite Wrapped Cylinders...................................109

6.3.3 Relation between Debonded Area and Confined Compressive Strength.............................................................112

6.3.3.1 GFRP Composite Wrapped Cylinders.................................113

6.3.3.2 CFRP Composite Wrapped Cylinders.................................120

6.3.4 Conclusions........................................................122

6.4 REDUCTION FACTORS ….............................................127

6.5 FAILURE MODES............................................................128

6.5.1 Concrete Cylinders Wrapped with GFRP Composite.....................128

6.5.2 Concrete Cylinders Wrapped with CFRP Composite....................130

Chapter 7 CONCLUSIONS AND RECOMMENDATIONS.........................131

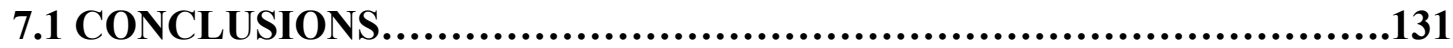

7.2 RECOMMENDATIONS FOR FUTURE RESEARCH......................133

REFERENCES..............................................................

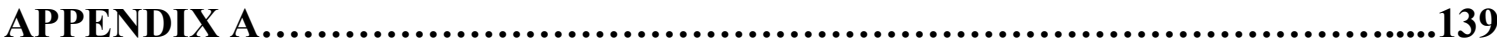

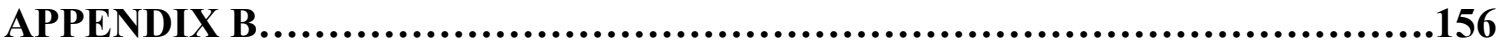




\section{LIST OF FIGURES}

Figure 2-1 Infrared region in electromagnetic spectrum (Kaplan 1999)................6

Figure 2-2 Blackbody curves at various temperatures (Kreith and Bohn 1993)... .....9

Figure 2-3 Surface temperature profile of a specimen with a simulated debond......12

Figure 3-1 Stress strain curves for concrete in triaxial compression (Mindness et al.

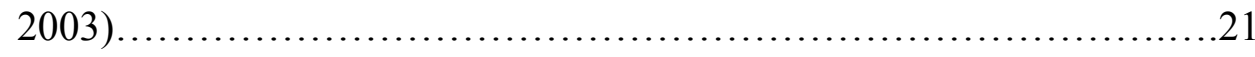

Figure 3-2 Confinement action (De Lorenzis et al. 2003)...........................22

Figure 4-1 ThermaCAM ${ }^{\mathrm{TM}} \mathrm{S} 60$ digital infrared camera..........................23

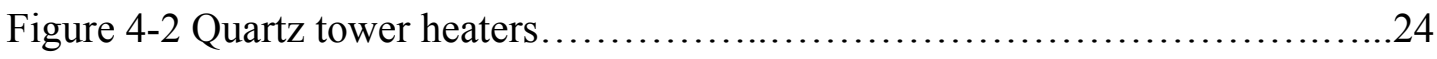

Figure 4-3 Infrared thermography setup in the laboratory.......................25

Figure 4-4 Heat flux meter and the galvanometer............................... 26

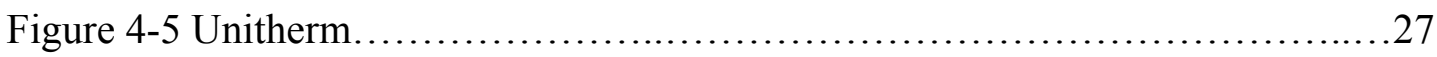

Figure 4-6 Schematic diagram of Unitherm 2022 (Hing 2006)......................27

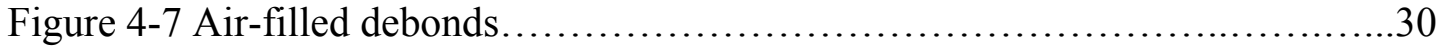

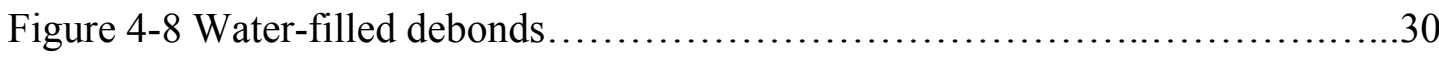

Figure 4-9 Tyfo S Saturant Epoxy (Type A and Type B).............................31

Figure 4-10 Mixing the two parts of the resin with a low speed mixer................32

Figure 4-11 Applying the mixed resin on FRP sheets..............................32

Figure 4-12 Wrapping the cylinders with FRP sheets...............................33

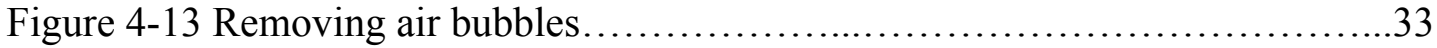

Figure 4-14 Curing the FRP composite wrapped cylinders........................32

Figure 4-15 Placement of debond in the cylinder maintaining diametrical symmetry before wrapping with composite...............................................................34

Figure 5-1 Infrared image of cylinder with 1" x 1" air-filled debond after 30 seconds of heating .............................................. 38

Figure 5-2 Infrared image of cylinder with 1" x 1" air-filled debond after 40

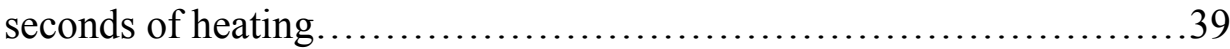

Figure 5-3 Infrared image of cylinder with 1" x 1" air-filled debond after 50 seconds of heating ...................................................

Figure 5-4 Infrared image of cylinder with 1" x 1" air-filled debond after 70 seconds of heating. 
Figure 5-5 Infrared image of cylinder with 1.4" x 1.4" air-filled debond after 30 seconds of heating.

Figure 5-6 Infrared image of cylinder with 1.4" x 1.4" air-filled debond after 40 seconds of heating.

Figure 5-7 Infrared image of cylinder with 1.4" x 1.4" air-filled debond after 50 seconds of heating

Figure 5-8 Infrared image of cylinder with 1.4" x 1.4" air-filled debond after 70 seconds of heating.

Figure 5-9 Infrared image of cylinder with 2" x 2" air-filled debond after 30 seconds of heating.

Figure 5-10 Infrared image of cylinder with 2" x 2" air-filled debond after 40 seconds of heating

Figure 5-11 Infrared image of cylinder with 2" x 2" air-filled debond after 50 seconds of heating.

Figure 5-12 Infrared image of cylinder with 2" x 2" air-filled debond after 70 seconds of heating.

Figure 5-13 Infrared image of cylinder with 3" x 3" air-filled debond after 30 seconds of heating. .46

Figure 5-14 Infrared image of cylinder with 3" x 3" air-filled debond after 40 seconds of heating.

Figure 5-15 Infrared image of cylinder with 3" x 3" air-filled debond after 50 seconds of heating.

Figure 5-16 Infrared image of cylinder with 3" x 3" air-filled debond after 70 seconds of heating. .48

Figure 5-17 Infrared image of cylinder with 1.4" x 1.4" water-filled debond after 70 seconds of heating

Figure 5-18 Infrared image of cylinder with 2" x 2" water-filled debond after 70 seconds of heating.

Figure 5-19 Infrared image of cylinder with 3" x 3" water-filled debond after 70 seconds of heating. .49 
Figure 5-20 Infrared image of cylinder with 1.4" x 1.4" air-filled debond after 30 seconds of heating..............................................

Figure 5-21 Infrared image of cylinder with 1.4" x 1.4" air-filled debond after 40 seconds of heating...............................................

Figure 5-22 Infrared image of cylinder with 1.4" x 1.4" air-filled debond after 50 seconds of heating.

Figure 5-23 Infrared image of cylinder with 1.4" x 1.4" air-filled debond after 70

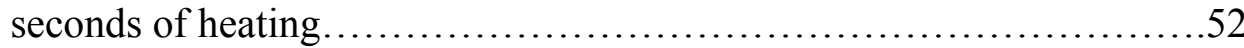

Figure 5-24 Infrared image of cylinder with 2" x 2" air-filled debond after 30

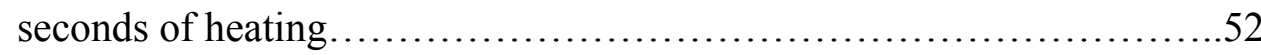

Figure 5-25 Infrared image of cylinder with 2" x 2" air-filled debond after 40 seconds of heating. .53

Figure 5-26 Infrared image of cylinder with 2" x 2" air-filled debond after 50 seconds of heating. .53

Figure 5-27 Infrared image of cylinder with 2" x 2" air-filled debond after 70 seconds of heating.

Figure 5-28 Infrared image of cylinder with 3" x 3" air-filled debond after 30 seconds of heating.................................................

Figure 5-29 Infrared image of cylinder with 3" x 3" air-filled debond after 40 seconds of heating. .55

Figure 5-30 Infrared image of cylinder with 3" x 3" air-filled debond after 50 seconds of heating

Figure 5-31 Infrared image of cylinder with 3" x 3" air-filled debond after 70 seconds of heating. .56

Figure 5-32 Infrared image of cylinder with 1.4" x 1.4" water-filled debond after 70 seconds of heating.

Figure 5-33 Infrared image of cylinder with 2" x 2" water-filled debond after 70 seconds of heating.

Figure 5-34 Infrared image of cylinder with 3" x 3" water-filled debond after 70 seconds of heating .58 
Figure 5-35 Effect of heat duration on maximum thermal difference for cylinders wrapped with GFRP composite..................................59

Figure 5-36 Effect of energy input on maximum thermal difference for cylinders wrapped with GFRP composite...............................60

Figure 5-37 Effect of heat duration on maximum thermal difference for cylinders wrapped with CFRP composite.

Figure 5-38 Effect of energy input on maximum thermal difference for cylinders wrapped with CFRP composite.

Figure 5-39 Effect of heat duration on maximum thermal contrast for cylinders wrapped with GFRP composite

Figure 5-40 Effect of energy input on maximum thermal contrast for cylinders wrapped with GFRP composite.

Figure 5-41 Effect of heat duration on maximum thermal contrast for cylinders wrapped with CFRP composite.

Figure 5-42 Effect of energy input on maximum thermal contrast for cylinders wrapped with CFRP composite

Figure 5-43 Effect of energy input on time for maximum thermal contrast for cylinders wrapped with GFRP composite

Figure 5-44 Effect of energy input on time for maximum thermal contrast for cylinders wrapped with CFRP composite.

Figure 5-45 Effect of energy input on time for maximum thermal difference for cylinders wrapped with GFRP composite.

Figure 5-46 Effect of energy input on time for maximum thermal difference for cylinders wrapped with CFRP composite.

Figure 5-47 Effect of energy input on increase in surface temperature above the debond for cylinders wrapped with GFRP composite.

Figure 5-48 Effect of energy input on increase in surface temperature above the debond for cylinders wrapped with CFRP composite.

Figure 5-49 Effect of debond width on maximum thermal difference for cylinders wrapped with GFRP composite. .68 
Figure 5-50 Effect of debond width on maximum thermal difference for cylinders wrapped with CFRP composite

Figure 5-51 Effect of debond width on time to achieve maximum thermal difference for cylinders wrapped with CFRP composite

Figure 5-52 Effect of debond width on time to achieve maximum thermal difference for cylinders wrapped with GFRP composite. .70

Figure 5-53 Effect of debond width on maximum surface temperature above the debond for cylinders wrapped with CFRP composite. . .70

Figure 5-54 Effect of debond width on maximum surface temperature above the debond for cylinders wrapped with GFRP composite.

Figure 5-55 Effect of debond depth on maximum thermal difference for cylinders wrapped with GFRP composite.

Figure 5-56 Effect of debond depth on time to achieve maximum thermal difference for cylinders wrapped with GFRP composite. .72

Figure 5-57 Effect of debond depth on maximum surface temperature above the debond for cylinders wrapped with GFRP composite.

Figure 5-58 Correlation between actual horizontal width and estimated horizontal width when measured by finding the inflection points of the temperature profile above the debond for cylinders wrapped with GFRP composite..77

Figure 5-59 Plot of depth of GFRP composite shell squared versus time to peak

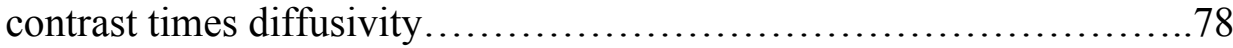

Figure 5-60 Plot of depth of GFRP composite shell squared versus time to peak slope of contrast times diffusivity.

Figure 5-61 Plot of depth of GFRP composite shell squared versus time for half of peak contrast times diffusivity

Figure 5-62 Curve fitting to find constants B and $n$ in equation 2.9 with peak contrast and time to peak contrast as the characteristic parameters 79

Figure 5-63 Curve fitting to find constants B and $n$ in equation 2.9 with peak slope of contrast and time to achieve peak slope of peak contrast as the characteristic parameters .80 
Figure 5-64 Curve fitting to find constants B and $\mathrm{n}$ in equation 2.9 with half of peak contrast and time to achieve half of peak contrast as the characteristic parameters.

Figure 6-1 Comparison between predicted compressive strength according to equation 6.17 and experimental compressive strengths.

Figure 6-2 Comparison between predicted compressive strength according to equation 6.18 and experimental compressive strengths.

Figure 6-3 Comparison between predicted compressive stress according to equation 6.17 and experimental compressive stress.

Figure 6-4 Comparison between predicted compressive stress according to equation 6.18 and experimental compressive stress

Figure 6-5 Comparison between predicted compressive strength according to equation 6.19 and experimental compressive strengths....

Figure 6-6 Comparison between predicted compressive strength according to equation 6.20 and experimental compressive strengths

Figure 6-7 Comparison between predicted compressive stress according to equation 6.19 and experimental compressive stress....

Figure 6-8 Comparison between predicted compressive stress according to equation 6.20 and experimental compressive stress.

Figure 6-9 Failure mode of GFRP composite wrapped concrete cylinder without any simulated debond.

Figure 6-10 Failure mode of GFRP composite $\left(0^{\circ} / 90^{\circ}\right)$ wrapped concrete cylinder with 1" x 1" and 2" x 2" air-filled debonds.

Figure 6-11 Failure mode of CFRP composite $\left(0^{\circ} / \pm 45^{\circ} / 90^{\circ}\right)$ wrapped concrete cylinder with 2" x 2" air-filled debond.

Figure A1 Heat Flux vs. time plot for 30 seconds heat duration.

Figure A2 Heat Flux vs. time plot for 40 seconds heat duration.

Figure A3 Heat Flux vs. time plot for 50 seconds heat duration. 140

Figure A4 Heat Flux vs. time plot for 70 seconds heat duration. 140

Figure A5 Surface temperature versus time curve for 3 layers of CFRP composite wrapped cylinder with 1.4" x 1.4" air-filled debond. 
Figure A6 Surface temperature versus time curve for 3 layers of CFRP composite wrapped cylinder with 2" x 2" air-filled debond...................... 141

Figure A7 Surface temperature versus time curve for 3 layers of CFRP composite wrapped cylinder with 3" x 3" air-filled debond.

Figure A8 Surface temperature versus time curve for 3 layers of CFRP composite wrapped cylinder with 1.4" x 1.4" water-filled debond.

Figure A9 Surface temperature versus time curve for 3 layers of CFRP composite wrapped cylinder with 2" x 2" water-filled debond.

Figure A10 Surface temperature versus time curve for 3 layers of CFRP composite wrapped cylinder with 3" x 3" water-filled debond

Figure A11 Surface temperature versus time curve for 3 layers of GFRP composite wrapped cylinder with 1" x 1" air-filled debond.

Figure A12 Surface temperature versus time curve for 3 layers of GFRP composite wrapped cylinder with 1.4" x 1.4" air-filled debond. 144

Figure A13 Surface temperature versus time curve for 3 layers of GFRP composite wrapped cylinder with 2" x 2" air-filled debond.

Figure A14 Surface temperature versus time curve for 3 layers of GFRP composite wrapped cylinder with 3" x 3" water-filled debond....................145

Figure A15 Surface temperature versus time curve for 3 layers of GFRP composite wrapped cylinder with 2" x 2" water-filled debond.

Figure A16 Surface temperature versus time curve for 3 layers of GFRP composite wrapped cylinder with 3" x 3" water-filled debond.

Figure A17 Surface temperature versus time curve for 1 layer GFRP composite wrapped cylinder with 2" x 2" air-filled debond.

Figure A18 Surface temperature versus time curve for 2 layers GFRP composite wrapped cylinder with 2" x 2" air-filled debond.

Figure A19 Surface temperature versus time curve for 4 layers GFRP composite wrapped cylinder with 2" x 2" air-filled debond.

Figure A20 Thermal difference versus time curve for 3 layers of CFRP composite wrapped cylinder with 1.4 " x 1.4" air-filled debond.... 148 
Figure A21 Thermal difference versus time curve for 3 layers of CFRP composite wrapped cylinder with 2" x 2" air-filled debond...

Figure A22 Thermal difference versus time curve for 3 layers of CFRP composite wrapped cylinder with 3" x 3" air-filled debond.

Figure A23 Thermal difference versus time curve for 3 layers of CFRP composite wrapped cylinder with 1.4" x 1.4" water-filled debond..................150

Figure A24 Thermal difference versus time curve for 3 layers of CFRP composite wrapped cylinder with 2" x 2" water-filled debond.....................150

Figure A25 Thermal difference versus time curve for 3 layers of CFRP composite wrapped cylinder with 3 " x 3 " water-filled debond.....................151

Figure A26 Thermal difference versus time curve for 3 layers of GFRP composite wrapped cylinder with 1" x 1" air-filled debond.

Figure A27 Thermal difference versus time curve for 3 layers of GFRP composite wrapped cylinder with 1.4" x 1.4" air-filled debond

Figure A28 Thermal difference versus time curve for 3 layers of GFRP composite wrapped cylinder with 2" x 2" air-filled debond.

Figure A29 Thermal difference versus time curve for 3 layers of GFRP composite wrapped cylinder with 3" x 3" air-filled debond.......................153

Figure A30 Thermal difference versus time curve for 3 layers of GFRP composite wrapped cylinder with 2" x 2" water-filled debond.

Figure A31 Thermal difference versus time curve for 3 layers of GFRP composite wrapped cylinder with 3" x 3 " water-filled debond

Figure A32 Thermal difference versus time curve for 1 layer of GFRP composite wrapped cylinder with 2" x 2" air-filled debond.....................154

Figure A33 Thermal difference versus time curve for 2 layers of GFRP composite wrapped cylinder with 2" x 2" air-filled debond.

Figure A34 Thermal difference versus time curve for 4 layers of GFRP composite wrapped cylinder with 2" x 2" air-filled debond.....................155

Figure B1 Tensile stress vs. tensile strain for GFRP $\left(0^{\circ} / 90^{\circ}\right)$ coupon specimen...156

Figure B2 Tensile stress vs. tensile strain for CFRP $\left(0^{\circ} / \pm 45^{\circ} / 90^{\circ}\right)$ coupon specimen 
Figure B3 Axial compressive stress vs. axial compressive strain for plain concrete cylinder number 1 .....

Figure B4 Axial compressive stress vs. strain for plain concrete cylinder number 2

Figure B5 Axial compressive stress vs. strain for defect free cylinder number 1 wrapped with GFRP composite $\left(0^{\circ} / 90^{\circ}\right)$

Figure B6 Volumetric strain vs. axial strain for defect free cylinder number 1 wrapped with GFRP composite $\left(0^{\circ} / 90^{\circ}\right)$ 158

Figure B7 Axial compressive stress vs. strain for defect free cylinder number 2 wrapped with GFRP composite $\left(0^{\circ} / 90^{\circ}\right)$

Figure B8 Volumetric strain vs. axial strain for defect free cylinder number 2 wrapped with GFRP composite $\left(0^{\circ} / 90^{\circ}\right)$ .159

Figure B9 Axial compressive stress vs. strain for defect free cylinder number 3 wrapped with GFRP composite $\left(0^{\circ} / 90^{\circ}\right)$ .160

Figure B10 Volumetric strain vs. axial strain for defect free cylinder number 3 wrapped with GFRP composite $\left(0^{\circ} / 90^{\circ}\right)$

Figure B11 Axial compressive stress vs. strain for cylinder with 1" x 1" air-filled debond wrapped with GFRP composite $\left(0^{\circ} / 90^{\circ}\right)$

Figure B12 Volumetric strain vs. axial strain for cylinder with 1" x 1" air-filled debond wrapped with GFRP composite $\left(0^{\circ} / 90^{\circ}\right)$

Figure B13 Axial compressive stress vs. strain for cylinder with 1.4” x 1.4" air-filled debond wrapped with GFRP composite $\left(0^{\circ} / 90^{\circ}\right)$

Figure B14 Volumetric strain vs. axial strain for cylinder with 1.4” x 1.4" air-filled debond wrapped with GFRP composite $\left(0^{\circ} / 90^{\circ}\right)$ 162

Figure B15 Axial compressive stress vs. strain for cylinder with 2" x 2" air-filled debond wrapped with GFRP composite $\left(0^{\circ} / 90^{\circ}\right)$

Figure B16 Volumetric strain vs. axial strain for cylinder with 2" x 2" air-filled debond wrapped with GFRP composite $\left(0^{\circ} / 90^{\circ}\right)$.

Figure B17 Axial compressive stress vs. strain for cylinder with 3" x 3" air-filled debond wrapped with GFRP composite $\left(0^{\circ} / 90^{\circ}\right)$ 164

Figure B18 Volumetric strain vs. axial strain for cylinder with 3" x 3" air-filled 
debond wrapped with GFRP composite $\left(0^{\circ} / 90^{\circ}\right)$ 164

Figure B19 Axial compressive stress vs. strain for cylinder with 1" x 1" water-filled debond wrapped with GFRP composite $\left(0^{\circ} / 90^{\circ}\right)$

Figure B20 Volumetric strain vs. axial strain for cylinder with 1" x 1" water-filled debond wrapped with GFRP composite $\left(0^{\circ} / 90^{\circ}\right)$

Figure B21 Axial compressive stress vs. strain for cylinder with 1.4" x 1.4" water-filled debond wrapped with GFRP composite $\left(0^{\circ} / 90^{\circ}\right)$

Figure B22 Volumetric strain vs. axial strain for cylinder with 1.4" x 1.4" water-filled debond wrapped with GFRP composite $\left(0^{\circ} / 90^{\circ}\right)$

Figure B23 Axial compressive stress vs. strain for cylinder with 2" x 2" water-filled debond wrapped with GFRP composite $\left(0^{\circ} / 90^{\circ}\right)$

Figure B24 Axial compressive stress vs. strain for cylinder with 3" x 3" water-filled debond wrapped with GFRP composite $\left(0^{\circ} / 90^{\circ}\right)$

Figure B25 Volumetric strain vs. axial strain for cylinder with 3" x 3" water-filled debond wrapped with GFRP composite $\left(0^{\circ} / 90^{\circ}\right)$ 168

Figure B26 Axial compressive stress vs. strain for cylinder with 1" x 1" Teflon sheet wrapped with GFRP composite $\left(0^{\circ} / 90^{\circ}\right)$

Figure B27 Volumetric strain vs. axial strain for cylinder with 1" x 1" Teflon sheet wrapped with GFRP composite $\left(0^{\circ} / 90^{\circ}\right)$

Figure B28 Axial compressive stress vs. axial strain for cylinder with 1.4" x 1.4" Teflon sheet wrapped with GFRP composite $\left(0^{\circ} / 90^{\circ}\right)$

Figure B29 Axial compressive stress vs. strain for cylinder with 2" x 2" Teflon sheet wrapped with GFRP composite $\left(0^{\circ} / 90^{\circ}\right)$

Figure B30 Volumetric strain vs. axial strain for cylinder with 2" x 2" Teflon sheet wrapped with GFRP composite $\left(0^{\circ} / 90^{\circ}\right)$

Figure B31 Axial compressive stress vs. strain for defect free cylinder number 1 wrapped with CFRP composite $\left(0^{\circ} / \pm 45^{\circ} / 90^{\circ}\right)$

Figure B32 Volumetric strain vs. axial strain for defect free cylinder number 1 wrapped with CFRP composite $\left(0^{\circ} / \pm 45^{\circ} / 90^{\circ}\right)$

Figure B33 Axial compressive stress vs. strain for defect free cylinder number 2 wrapped with CFRP composite $\left(0^{\circ} / \pm 45^{\circ} / 90^{\circ}\right)$ 
Figure B34 Volumetric strain vs. axial strain for defect free cylinder number 2

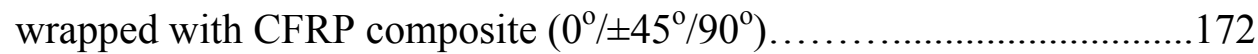

Figure B35 Axial compressive stress vs. strain for cylinder with 1" x 1" air-filled debond wrapped with CFRP composite $\left(0^{\circ} / \pm 45^{\circ} / 90^{\circ}\right) \ldots \ldots \ldots \ldots . . . \ldots 173$

Figure B36 Volumetric strain vs. axial strain for cylinder with 1" x 1" air-filled debond wrapped with CFRP composite $\left(0^{\circ} / \pm 45^{\circ} / 90^{\circ}\right)$

Figure B37 Axial compressive stress vs. strain for cylinder with 1.4" x 1.4" air-filled debond wrapped with CFRP composite $\left(0^{\circ} / \pm 45^{\circ} / 90^{\circ}\right)$

Figure B38 Volumetric strain vs. axial strain for cylinder with 1.4" x 1.4" air-filled debond wrapped with CFRP composite $\left(0^{\circ} / \pm 45^{\circ} / 90^{\circ}\right)$

Figure B39 Axial compressive stress vs. strain for cylinder with 2" x 2" air-filled debond wrapped with CFRP composite $\left(0^{\circ} / \pm 45^{\circ} / 90^{\circ}\right)$

Figure B40 Volumetric strain vs. axial strain for cylinder with 2" x 2" air-filled debond wrapped with CFRP composite $\left(0^{\circ} / \pm 45^{\circ} / 90^{\circ}\right)$ 175

Figure B41 Axial compressive stress vs. strain for cylinder with 3" x 3" air-filled debond wrapped with CFRP composite $\left(0^{\circ} / \pm 45^{\circ} / 90^{\circ}\right)$

Figure B42 Volumetric strain vs. axial strain for cylinder with 3" x 3" air-filled debond wrapped with CFRP composite $\left(0^{\circ} / \pm 45^{\circ} / 90^{\circ}\right) \ldots \ldots \ldots \ldots \ldots \ldots . \ldots 176$

Figure B43 Axial compressive stress vs. strain for cylinder with 1" x 1" water-filled debond wrapped with CFRP composite $\left(0^{\circ} / \pm 45^{\circ} / 90^{\circ}\right)$

Figure B44 Volumetric strain vs. axial strain for cylinder with 1" x 1" water-filled debond wrapped with CFRP composite $\left(0^{\circ} / \pm 45^{\circ} / 90^{\circ}\right)$

Figure B45 Axial compressive stress vs. strain for cylinder with 1.4" x 1.4" water-filled debond wrapped with CFRP composite $\left(0^{\circ} / \pm 45^{\circ} / 90^{\circ}\right)$ .178

Figure B46 Volumetric strain vs. axial strain for cylinder with 1.4" x 1.4" water-filled debond wrapped with CFRP composite $\left(0^{\circ} / \pm 45^{\circ} / 90^{\circ}\right) \ldots \ldots .178$

Figure B47 Axial compressive stress vs. strain for cylinder with 2" x 2" water-filled debond wrapped with CFRP composite $\left(0^{\circ} / \pm 45^{\circ} / 90^{\circ}\right) \ldots$

Figure B48 Volumetric strain vs. axial strain for cylinder with 2" x 2" water-filled debond wrapped with CFRP composite $\left(0^{\circ} / \pm 45^{\circ} / 90^{\circ}\right)$ 179

Figure B49 Axial compressive stress vs. strain for cylinder with 3" x 3" 
water-filled debond wrapped with CFRP composite $\left(0^{\circ} / \pm 45^{\circ} / 90^{\circ}\right) \ldots . .180$

Figure B50 Volumetric strain vs. axial strain for cylinder with 3" x 3"

water-filled debond wrapped with CFRP composite $\left(0^{\circ} / \pm 45^{\circ} / 90^{\circ}\right) \ldots \ldots .180$

Figure B51 Axial compressive stress vs. strain for cylinder with 1" x 1"

Teflon sheet wrapped with CFRP composite $\left(0^{\circ} / \pm 45^{\circ} / 90^{\circ}\right)$

Figure B52 Volumetric strain vs. axial strain for cylinder with 1" x 1"

Teflon sheet wrapped with CFRP composite $\left(0^{\circ} / \pm 45^{\circ} / 90^{\circ}\right)$

Figure B53 Axial compressive stress vs. strain for cylinder with 1.4" x 1.4"

Teflon sheet wrapped with CFRP composite $\left(0^{\circ} / \pm 45^{\circ} / 90^{\circ}\right)$

Figure B54 Volumetric strain vs. axial strain for cylinder with 1.4" x 1.4"

Teflon sheet wrapped with CFRP composite $\left(0^{\circ} / \pm 45^{\circ} / 90^{\circ}\right)$

Figure B55 Axial compressive stress vs. strain for cylinder with 2" x 2"

Teflon sheet wrapped with CFRP composite $\left(0^{\circ} / \pm 45^{\circ} / 90^{\circ}\right)$.

Figure B56 Volumetric strain vs. axial strain for cylinder with 2" x 2"

Teflon sheet wrapped with CFRP composite $\left(0^{\circ} / \pm 45^{\circ} / 90^{\circ}\right)$

Figure B57 Axial compressive stress vs. strain for cylinder with 3" x 3"

Teflon sheet wrapped with CFRP composite $\left(0^{\circ} / \pm 45^{\circ} / 90^{\circ}\right)$

Figure B58 Volumetric strain vs. axial strain for cylinder with 3" x 3"

Teflon sheet wrapped with CFRP composite $\left(0^{\circ} / \pm 45^{\circ} / 90^{\circ}\right)$ 


\section{LIST OF TABLES}

Table 2-1 Thermal properties of materials (Maldague 1993) ............................7

Table 4-1 Properties of TYFO S Saturant Epoxy (Fyfe Co. LLC 2000)....................31

Table 4-2 Thermal properties of CFRP and GFRP

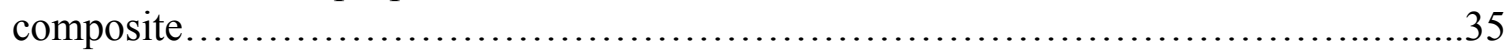

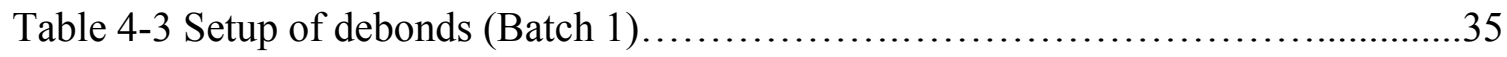

Table 4-4 Setup of debonds (Batch 2) .................................................

Table 5-1 Estimated and actual widths at best observation time........................81

Table 5-2 Comparison between widths estimated by equation (5.3) with actual

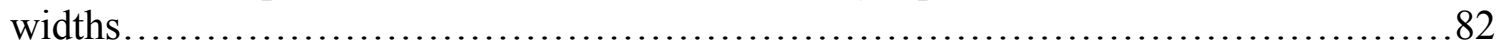

Table 5-3 Actual and estimated debond depths at different characteristic times..........83

Table 5-4 Actual and estimated debond depths at different characteristic times in

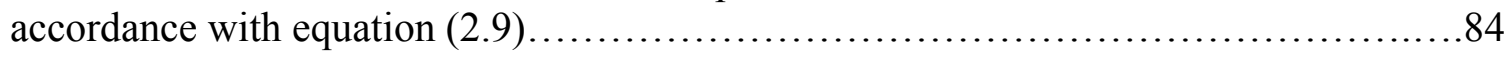

Table 6-1 Ultimate compressive strength of unwrapped cylinders......................88

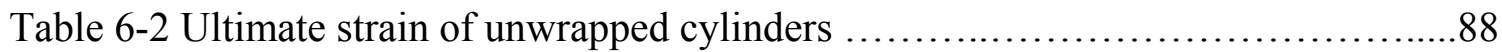

Table 6-3 Ultimate compressive strength of wrapped cylinders.........................89

Table 6-4 Ultimate strain of wrapped cylinders.................................... 90

Table 6-5 Setup of debonds and corresponding area..................................90

Table 6-6 Ultimate compressive strength of GFRP composite wrapped cylinders with air-

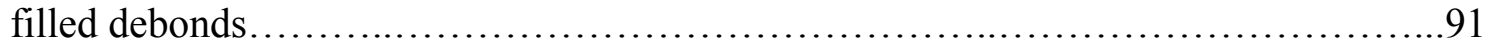

Table 6-7 Ultimate compressive strength of GFRP composite wrapped cylinders with

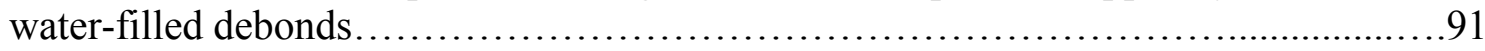

Table 6-8 Ultimate compressive strength of GFRP composite wrapped cylinders with

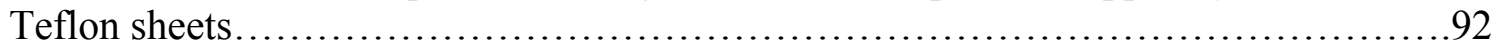

Table 6-9 Ultimate strain of GFRP composite wrapped cylinders with simulated flaws..94 Table 6-10 Circumferential strain values of GFRP composite wrapped cylinders with

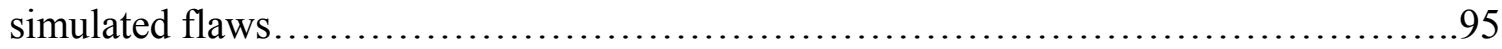

Table 6-11 Axial strain values at zero volumetric strain of GFRP composite wrapped

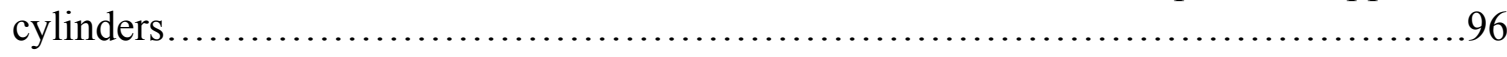

Table 6-12 Ultimate compressive strength of CFRP composite wrapped cylinders with

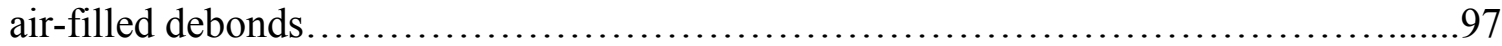

Table 6-13 Ultimate compressive strength of CFRP composite wrapped cylinders with

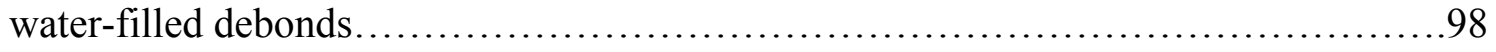

Table 6-14 Ultimate compressive strength of CFRP composite wrapped cylinders with

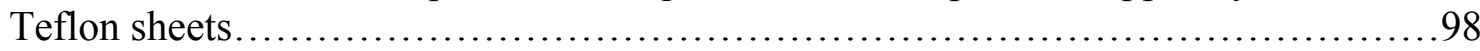


Table 6-15 Ultimate strain of CFRP composite wrapped cylinders with simulated flaws.

Table 6-16 Axial strain values at zero volumetric strain of CFRP composite wrapped cylinders

Table 6-17 Ductility enhancement of GFRP composite wrapped cylinders.............103

Table 6-18 Ductility enhancement of CFRP composite wrapped cylinders.

Table 6-19 Comparison between experimental and analytical compressive strength of concrete cylinders wrapped with CFRP composite.

Table 6-20 Comparison between experimental and analytical compressive strength of concrete cylinders wrapped with GFRP composite.

Table 6-21 Comparison between predicted compressive strength and experimental compressive strength for GFRP composite wrapped cylinders with air-filled debonds based on equation 6.17

Table 6-22 Comparison between predicted compressive strength and experimental compressive strength for GFRP composite wrapped cylinders with air-filled debonds based on equation 6.18

Table 6-23 Comparison between predicted compressive strength and experimental compressive strength for CFRP composite wrapped cylinders with Teflon sheets based on equation 6.19 .

Table 6-24 Comparison between predicted compressive strength and experimental compressive strength for CFRP composite wrapped cylinders with Teflon sheets based on equation 6.20 .

Table 6-25 Reduction Factors for GFRP wrapped Composite Cylinders with various Debonded Area.

Table 6-26 Reduction Factors for CFRP wrapped Composite Cylinders with various

Debonded Area... 128 


\section{CHAPTER 1 \\ INTRODUCTION}

\subsection{BACKGROUND}

Although the history of composite materials application to civil infrastructure is only three decades old, they are now being widely used in myriad of applications in all types of engineering structures. As far as construction industry is concerned, composite materials have heralded a new trend of cost effective applications in the area of repair, rehabilitation, replacement and new construction of infrastructure. The use of composite materials in civil engineering infrastructure can be attributed to many advantages it enjoys over other conventional structural materials. The spectrum of key properties includes lightweight, excellent corrosion and fatigue resistance, high strength, and impact resistance, just to name a few.

A major application of composite materials in the reinforced concrete industry is for repairing and strengthening existing reinforced concrete beams and columns. This can be achieved by wrapping the beam or column with Fiber Reinforced Polymer (FRP) composite wraps. In addition to increasing the load carrying capacity, wrapping the structural component with FRP fabrics enhances its ductility which is very important, especially in seismic regions.

A proper bond between the FRP composite wrap and the underlying concrete surface is of primary importance for appropriate functioning of the FRP composite wrap, i.e., for effective transfer of load from concrete to the wrap through confining action. Discontinuity between the wrap and the concrete surface could be developed during wrapping of the FRP sheets and during the service life of the column due to various reasons, such as presence of moisture, vehicular loads etc. Such a discontinuity is commonly referred to as a debond. Hence, periodic field monitoring through nondestructive testing methods becomes imperative in order to inspect and assess the condition of the debonds and the FRP composite wrapped component as a whole. Early

detection of deterioration makes the repair work less expensive and ensures continued structural integrity. 
Taking into view the development of infrastructure in the modern era, there is a need for an efficient and cost effective monitoring method to inspect and asses the condition FRP composite wrapped structural components. The method employed should not only detect the defect but should also throw light on its severity, type and location. Infrared Thermography (IRT) is a state-of-the-art technique that meets the criteria of a fast, reliable and cost-effective non destructive evaluation method. Infrared Thermography has the advantage of being a non-contact technique, i.e., it does not require a physical contact between the instrument and the object under study. This aspect is particularly important because in urban areas, inspecting the rehabilitated structures with IRT will not hinder the traffic. Although the history of IRT can be traced back to 1960 's, its use is qualitative in most of the cases. It means that IRT has been used just to detect the presence of subsurface defects. Quantitative characterization of the defect through IRT, i.e., extracting information regarding lateral size and depth of defect is an area of research which is of great importance. Such research has been carried out by several researchers for flat surfaces (Starnes 2002, Plotnikov 1999, Vavilov 2000) but not for a curved surface. This study focuses on the applicability of Actived Infrared Thermography (PIRT) in detecting and quantifying air-filled and water-filled debonds in concrete cylindrical columns wrapped with Fiber Reinforced Polymer (FRP) composites. Quantification of subsurface debonds in this study essentially means characterization of the debonds in terms of their width and depth.

It has been established in research previously conducted at West Virginia University (Dutta 2006) that IRT can be used as a nondestructive evaluation tool for detecting air-filled and water-filled debonds in concrete cylinders wrapped with FRP composites. It was found that in addition to air-filled debonds, water-filled debonds also appeared as "hot spots". The work by Dutta (2006) focused only on the qualitative aspect of IRT, i.e. only the surface temperature curves for air-filled and water-filled debonds were compared. Starnes (2002) performed thermographic parametric studies with the aid of finite element modeling for FRP layers bonded to flat concrete substrate. So, it is evident that there is a scarcity of research conducted to assess the performance of Actived thermography for qualitative as well for quantitative evaluation of FRP composite wrapped cylindrical columns, which have curved surfaces. 
It is also important to know the effect of the debonds on the stress-strain behavior of the wrapped members. Over the past decades, researchers have extensively performed studies in order to understand the stress-strain behavior of FRP composite wrapped concrete columns. While a number of studies are available on stress-strain behavior of defect-free members, no studies have been carried out till date to investigate the effect of debonds on stress-strain behavior of FRP composite wrapped columns. Dutta (2006) made an attempt to correlate the area of debonds and ultimate strength of FRP composite wrapped concrete columns without studying the full stress-strain behavior.

This research investigates the stress-strain behavior of FRP composite wrapped cylindrical specimens with embedded debonds. For specimens without embedded debonds, experimental results from this study has been compared with theoretical predictions from various models available in the published literature. Also, the effect of percentage area of the debonds on the stress-strain behavior of FRP wrapped concrete cylinders is investigated.

\subsection{RESEARCH OBJECTIVES AND SCOPE}

The primary objectives of this research are:

\section{(A) Quantification of debond parameters from IRT measurements}

- Investigate the effectiveness of IRT for detecting as well quantifying the size and depth of subsurface debonds in FRP wrapped concrete columns.

- Investigate the influence of heat flux, debond width and depth on thermal parameters.

- To establish surface temperature versus time curves, thermal difference versus time curves and thermal contrast versus time curves for different size debonds in concrete cylinders wrapped with CFRP and GFRP composites.

The above investigation has been carried out by creating air-filled and water-filled debonds of various lateral dimensions (1" x 1", 1.4" x 1.4", 2" x 2", 3" x 3") in 6" x 12" concrete cylindrical specimens wrapped with carbon fiber reinforced polymer (CFRP) fabric as well as E-glass fiber reinforced polymer (GFRP) fabric. A total of 16 concrete specimens were used for the IRT measurements. 


\section{(B) Investigation of the effect of debonds on stress-strain behavior of FRP composite wrapped concrete cylindrical specimens}

- Study the effect of percentage area of debonds on ultimate strength of FRP composite wrapped concrete cylindrical specimens.

- Study the effect of debonds on stress-strain behavior of FRP composite wrapped concrete cylindrical specimens.

- Compare the experimental ultimate strength with theoretical predictions from various models available in the published literature.

The above investigation was being carried out using CFRP and GFRP wrapped concrete cylindrical specimens with air-filled debonds, water-filled debonds and Teflon sheets of various lateral dimensions (1" x 1", 1.4” x 1.4", 2" x 2", 3" x 3"). A total of 30 concrete specimens were used for the destructive compression test in this part of the research.

\subsection{ORGANIZATION}

This dissertation is organized into seven chapters. Chapter 1 is devoted to background as well as objectives and scope of the study. Chapter 2 presents the basics of Infrared Thermography (qualitative and quantitative). Chapter 3 includes the literature review conducted as a part of this research. Chapter 4 describes various equipments as well as test specimens that were used in this research. The procedure for making the laboratory samples, i.e., casting of the cylinders, preparation of the simulated debonds, method of wrapping the cylinders, procedure to install strain gauges are also furnished in detail in this chapter. Chapter 5 presents the infrared thermography results obtained from laboratory tests that were conducted as a part of this study. Chapter 6 furnishes the analysis of the results of compression tests of FRP composite wrapped cylinders. Chapter 7 gives the conclusions and recommendations. This is followed by a listings of all the references cited in this research. Two appendices at the end include all the infrared thermography related curves (Appendix A) and the stress-strain curves obtained using compression testing of the cylindrical specimens (Appendix B). 


\section{CHAPTER 2}

\section{BASICS OF INFRARED THERMOGRAPHY}

\subsection{OVERVIEW}

Infrared Thermography (IRT) is a non-invasive scanning technique that can be used for mapping subsurface debonds in concrete bridges, pavements, and wooden components. This thesis investigates the use of IRT for detection and characterization of debonds in concrete columns wrapped with Carbon Fiber Reinforced Polymer (CFRP) fabric and Glass Fiber Reinforced Polymer (GFRP) fabric. This chapter gives a brief overview of the basic fundamentals of GPR and IRT.

\subsection{BASICS OF INFRARED THERMOGRAPHY}

Infrared Thermography is based on the principle that subsurface flaws or any other change in thermal properties affects the rate of heat flow which in turn causes surface temperature differentials. Measurement of this surface temperature differentials lead to the detection of the subsurface anomalies. Heat transfer from an object depends upon the thermal properties of the object. There are three modes of heat transfer namely conduction, convection and radiation. It's the radiation mode of heat transfer that the

principle of Infrared Thermography is based upon. All objects radiate energy in the infrared zone of the electromagnetic spectrum above absolute zero temperature. Infrared scanning devices measures the infrared radiation emitted from the target object (Kaplan 1999). Post processing of the data enables the measured infrared radiation levels to be converted into corresponding temperatures which in turn are recorded in the form of thermograms (Starnes et al.2003). Thermograms can be easily interpreted to locate a subsurface debond. Thermal conductivity and thermal diffusivity are two primary properties that influence the thermal behavior of a material. Thermal conductivity is the ease with which heat energy can flow from one point to another within a medium. Thermal diffusivity governs how fast heat propagates or diffuses through a material under transient conditions (Starnes et al. 2003). Thermal effusivity is another parameter that indicates the resistance of a particular material to increase in its temperature on application of heat (Shepard 2007). In general, thermal conductivity governs the thermal 
contrast between the defective and sound areas and thermal diffusivity influences the optimum detection time during a thermographic experiment (Starnes 2002).

The electromagnetic spectrum is shown in Figure 2-1. The infrared portion of the spectrum lies between from $0.75 \mu \mathrm{m}-100 \mu \mathrm{m}$. Radiative heat transfer takes place in the infrared spectrum although upper limit for practical measurement is $20 \mu \mathrm{m}$ (Kaplan 1999).

Table 2-1 gives thermal properties of some common materials (Maldague 1993).

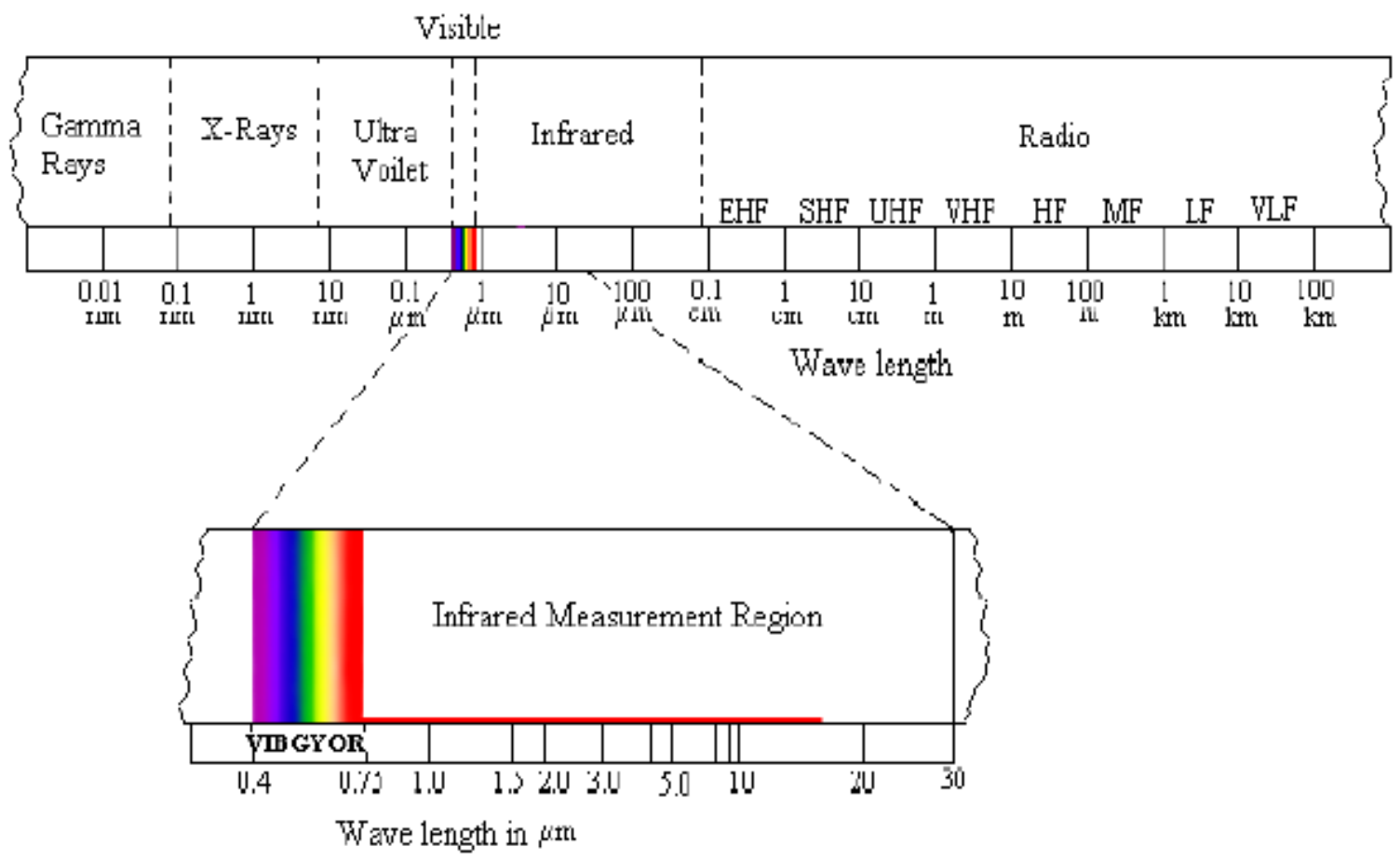

Figure 2-1 Infrared region in electromagnetic spectrum (Kaplan 1999) 
Table 2-1 Thermal properties of materials (Maldague 1993)

\begin{tabular}{|c|c|c|c|c|c|}
\hline Material & $\begin{array}{c}\text { Specific } \\
\text { Heat } \\
\mathrm{C} \\
\left(\mathrm{Jkg}^{-10} \mathrm{C}^{-1}\right)\end{array}$ & $\begin{array}{c}\text { Mass } \\
\text { Density } \\
\rho \\
\left(\mathrm{kg} \mathrm{m}^{-3}\right)\end{array}$ & $\begin{array}{c}\text { Heat } \\
\text { capacity } \\
\rho C \\
\left(J^{-3} \mathbf{~}^{-1}\right)\end{array}$ & $\begin{array}{c}\text { Thermal } \\
\text { Conductivity } \\
\mathbf{K} \\
\left(\mathbf{W} \mathbf{m}^{-10} \mathbf{C}^{-1}\right)\end{array}$ & $\begin{array}{c}\text { Thermal } \\
\text { Diffusivity }^{\mathrm{a}} \\
\delta \\
\left(\mathrm{m}^{2} \mathrm{~s}^{-1}\right)\end{array}$ \\
\hline Air (as defect) & 700 & 1.2 & $0.0008 \times 10^{6}$ & 0.024 & $33 \times 10^{-6}$ \\
\hline Aluminium & 880 & 2700 & $2.4 \times 10^{6}$ & 230 & $95 \times 10^{-6}$ \\
\hline $\begin{array}{c}\text { Brass }(65 \% \mathrm{Cu} \\
\text { and } 35 \% \mathrm{Zn})\end{array}$ & 380 & 8400 & $3.2 \times 10^{6}$ & 130 & $32 \times 10^{-6}$ \\
\hline $\mathrm{CFRP}^{\mathrm{b}}$ ( $(\mid$ ffibers $)$ & 1200 & 1600 & $1.9 \times 10^{6}$ & 0.8 & $0.42 \times 10^{-6}$ \\
\hline CFRP $^{\mathrm{b}}$ (\|fibers) & 1200 & 1600 & $1.9 \times 10^{6}$ & 7 & $3.7 \times 10^{-6}$ \\
\hline Concrete & 800 & 2400 & $1.9 \times 10^{6}$ & 1 & $0.53 \times 10^{-6}$ \\
\hline Copper & 380 & 8900 & $3.4 \times 10^{6}$ & 380 & $110 \times 10^{-6}$ \\
\hline Epoxy resin & 1700 & 1300 & $2.2 \times 10^{6}$ & 0.2 & $0.09 \times 10^{-6}$ \\
\hline Glass & 670 & 2600 & $1.7 \times 10^{6}$ & 0.7 & $0.41 \times 10^{-6}$ \\
\hline $\operatorname{GFRP}^{\mathrm{c}}(\mathrm{L} \mid$ fibers $)$ & 1200 & 1900 & $2.3 \times 10^{6}$ & 0.3 & $0.13 \times 10^{-6}$ \\
\hline GFRP $^{\mathrm{c}}(\|$ fibers $)$ & 1200 & 1900 & $2.3 \times 10^{6}$ & 0.38 & $0.17 \times 10^{-6}$ \\
\hline Lead & 130 & 11300 & $1.5 \times 10^{6}$ & 35 & $23 \times 10^{-6}$ \\
\hline Nickel & 440 & 8900 & $3.9 \times 10^{6}$ & 91 & $23 \times 10^{-6}$ \\
\hline Plexiglass ${ }^{\mathrm{TM}}$ & - & 1200 & - & 0.2 & $0.25 \times 10^{-6}$ \\
\hline Porcelain & 1100 & 2300 & $2.5 \times 10^{6}$ & 1.1 & $0.43 \times 10^{-6}$ \\
\hline Steel (mild) & 440 & 7900 & $3.5 \times 10^{6}$ & 46 & $13 \times 10^{-6}$ \\
\hline Steel (stainless) & 440 & 7900 & $3.5 \times 10^{6}$ & 25 & $7.1 \times 10^{-6}$ \\
\hline Teflon $^{\mathrm{TM}}$ & - & - & - & 0.42 & $1.59 \times 10^{-6}$ \\
\hline Titanium & 470 & 4500 & $2.1 \times 10^{6}$ & 16 & $7.6 \times 10^{-6}$ \\
\hline Uranium & 120 & 18700 & $2.2 \times 10^{6}$ & 27 & $12 \times 10^{-6}$ \\
\hline Water & 4180 & 1000 & $4.2 \times 10^{6}$ & 0.6 & $0.14 \times 10^{-6}$ \\
\hline Zircaloy 2 & 280 & 6600 & $1.8 \times 10^{6}$ & 13 & $11 \times 10^{-6}$ \\
\hline
\end{tabular}

(Vavilov 1980, p 182; Reynolds and Wells 1984, p 43; Tretout 1987, p 49; Touloukian and Dewitt 1970)

${ }^{a}$ Defined as $\delta=\mathrm{K} / \rho \mathrm{C}$, where $\mathrm{K}$ is the thermal conductivity, $\rho$ is mass density, $\mathrm{C}$ is the specific heat, and $\rho \mathrm{C}$ is the heat capacity.

${ }^{\mathrm{b}}$ Carbon fiber reinforced polymer.

${ }^{\mathrm{c}}$ Glass fiber reinforced polymer.

The radiant behaviour of an object is governed by two equations namely Stefan Boltzmann law and Wien's displacement law. Stefan Boltzmann law is given by

$$
W=\varepsilon \sigma T^{4}
$$


where, $W=$ Radiant intensity $\left(\frac{W}{m^{2}}\right)$

$\varepsilon=$ Emissivity of the object

$\sigma=$ Steafan-Boltzmann constant $\left(5.67 \times 10^{-8} \mathrm{Wm}^{-2} \mathrm{~K}^{-4}\right)$

$T=$ Absolute temperature $(K)$

Wien's displacement law is given by:

$$
\lambda_{\max }=\frac{b}{T}
$$

where, $b=$ Wien displacement constant $=2897 \frac{\mu m}{K}$

$$
\lambda_{\max }=\text { Wavelength of maximum radiation intensity }(\mu m)
$$

Emissivity is the ratio of actual emission from the object to that from a hypothetical source called a "black body" at the same temperature. As an object cools down, it starts to emit wavelengths in the infrared zone of the electromagnetic spectrum (Kaplan 1999). This also follows from Wein's displacement law. At room temperature the radiation emitted are in the infrared zone (Starnes et al. 2003). Infrared sensors can detect those invisible wavelengths and enable us to determine surface temperature of an object (Kaplan 1999). Essentially, the sensors measure the infrared radiation emitted from an object and converts it to an equivalent temperature value in accordance with the Stefan Boltzmann law (Kaplan 1999). Hence it is very important to accurately measure the emissivity of object surface. Figure 2-2 shows different blackbody curves at different temperatures. 


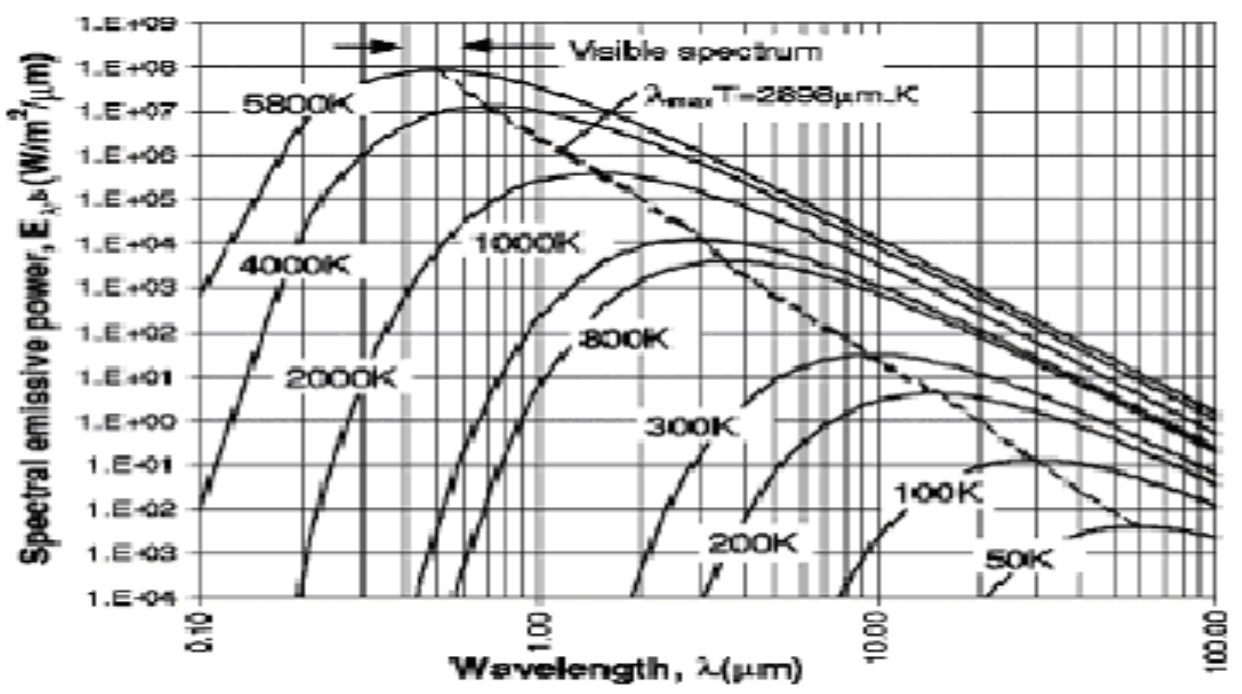

Figure 2-2 Blackbody curves at various temperatures (Kreith and Bohn 1993)

\subsubsection{Active Thermography and Passive Thermography}

Infrared Thermography is used in two schemes, active and passive. In active Infrared Thermography, external heating source such as lamp, heater, heating blanket are used to drive heat across the object of interest (Maldague 2000). The thermal gradients developed at the surface are observed through the infrared camera. Uniform heating is of utmost importance in this case since thermal gradients produced by non uniform heating can be mistaken for debonds (Steele 2001). Solar radiation can also be used as a heating source. In passive approach, the natural temperature differences on the surface due to subsurface anomalies are observed (Maldague 2000). In passive thermography what is measured is the temperature difference with respect to the surroundings, often referred to as the 'hotspot'. A temperature difference of $1-2{ }^{\circ} \mathrm{C}$ is taken as suspicious whereas a difference of $4{ }^{\circ} \mathrm{C}$ confirms the presence of an anomaly (Maldague 2000). Sometimes cooling source can also be used to develop the thermal gradient. Examples of cooling sources include cold water, liquid nitrogen, liquid carbon dioxide etc. The heat source can be of different type such as point heating source, line heating source or a plane heating source. Composites are thermally anisotropic because thermal conductivity value is higher in the direction parallel to the fibers than in the direction perpendicular to them. This effect of thermal anisotropy is evident when a point heating is used. For such a heat source, the heat flows laterally i.e along the fibers, instead of flowing perpendicular to 
them (Shepard 2007). Thus it becomes impossible to locate defects inside the test object. However, for a plane heating source, lateral heat flow occurs only at the edges of the heated area. In the regions directly below the heat source, thermal energy flows perpendicular to the fibers i.e. towards the surface thus making thermographic interrogation of the object possible (Shepard 2007). For this reason, use of point heating is generally avoided for thermographic investigation of composites. Nondestructive evaluation of civil engineering infrastructure often requires active thermography (Starnes et al. 2003). This is because unlike in the case of passive thermography, duration, intensity of the applied heat Active in active thermography can be regulated. Hence it is possible quantify the defect using the active thermography technique (Ghosh et al. 2006).

\subsubsection{Active Infrared Thermography}

Active theormography is a common active infrared thermography technique where the object of interest is first stimulated with a heat pulse of short duration and then the temperature decay curve of the specimen is then monitored and analyzed. The heat pulse is conducted through the material towards the colder regions as a result of diffusion The presence of subsurface defects results in a change of thermal conductivity value inside the material and it changes the rate of diffusion of the heat pulse. Therefore, the surface temperature above the flawed region will be different than the surface temperature of surrounding sound areas. In other words, the defects appear as in the infrared images either as "hot spots" or "cold spots" depending on the thermal conductivity value of the defect. The external heat source can be either cold or hot since the main objective of active infrared thermography is to create a temperature differential large enough to detect the defect (Ghosh et al. 2006) Polymer composites have intermediate thermal diffusivity values meaning thermal response of polymer composites is neither too fast nor too slow. Also low thermal effusivity values of polymer composites results in infrared signals that are above the noise level of the infrared camera making the signals easily detectable (Shepard 2007). Hence polymer composites make good test objects for investigations using active thermography. 


\subsubsection{Testing Methods}

Two testing methods namely transmission and reflection modes are currently being used in Active Thermography. In transmission mode, the specimen is heated or cooled from one side and images are taken from the other side so that any defect present in the base object results in hotter or colder zones in the other face (i.e. face nearer to the infrared camera) of the test object. In the reflection mode of infrared testing, the images are taken of the side which is subjected to thermal stimulus. It is evident that the thermal difference, i.e. the surface temperature difference between the zone above the defect and above the sound area in transmission mode strongly depends upon the depth of the defect or in other words the thermal resistance of the defect (Giorleo et al. 2002). Reflection mode of thermographic investigation yields greater resolution and requires the object thickness to be small (Starnes 2002). Also transmission mode is not suitable for quantitative analysis of defects (Starnes 2002). Hence, in this study, reflection mode of Active thermographic testing is used.

\subsubsection{Quantitative Infrared Thermography}

Quantitative measurement of debonds is based on the transient thermal evolution of the surface of the tested object. So it is required to record and analyze the spatial and temporal distribution of the surface temperature after the application of the heat flux. The surface temperature profile is dependent on debond size, debond depth and on the type of defects (Starnes 2002). A typical surface temperature profile of a specimen with a subsurface debond is shown in Figure 2-3. The surface temperature above the defect is high which gradually drops down towards the surrounding defect-free areas giving rise to a Gaussian type signal. This phenomenon occurs because the incident heat does not conduct efficiently through the subsurface defect in the radial direction and causes heat build up above the defect. However, the trapped heat between the surface and the underlying defect flows laterally from the center of the defect towards its edges which are cooler (Shepard et al. 1999). 


\section{surface temperature profile}

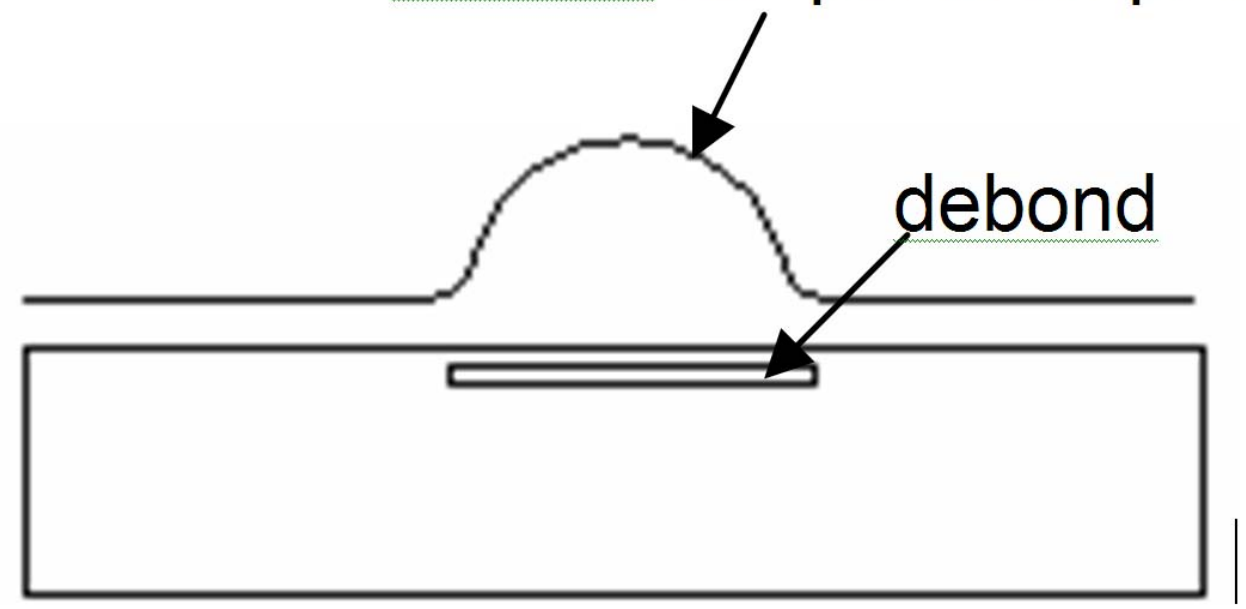

Figure 2-3 Surface temperature profile of a specimen with a simulated debond

\subsubsection{Estimation of Defect Width}

Vavilov (2000) proposed three methods to analyze the Gaussian like signal as explained above to determine the defect width. The first method requires the establishment of a threshold temperature value above the noise level. The disadvantage of this method is that it is noise and time dependant. The second method is called Full Width at Half Maximum (FWHM) measurement that determines the locations along the width of the defect where the temperature difference between the flawed and sound areas becomes half of the maximum value. The third method to estimate the defect width involves measuring the location of inflection points in the surface temperature profile. Mathematically,

$$
\frac{\partial^{2} T}{\partial x^{2}}=0 \text { at } x=x_{1} \text { and } x=x_{2}
$$


where $T$ is the surface temperature distribution across the width of the defect and $x_{1}$ and $x_{2}$ are the two roots of Eq. (2.3) which involves the second derivative of the temperature profile with respect to distance. It should be noted that for cylindrical specimens, $x$ is the distance measured along the circumferential direction. The width $w$ of the debond, as measured in the circumferential direction, is given by:

$$
w=x_{2}-x_{1}
$$

Similarly, the surface temperature distribution in the y-direction (i.e., along the length of the cylinder) can be analyzed to obtain the debond's dimension along the ydirection.

\subsubsection{Estimation of Defect Depth}

The surface temperature $\mathrm{T}$ of a sample at time $\mathrm{t}$ after pulse heating can be expressed as (Parker et al. 1961):

$$
T(t)=\frac{Q}{\rho C L}\left[1+2 \sum_{1}^{\infty} \exp \left(-\frac{n^{2} \Pi^{2}}{L^{2}} \alpha t\right)\right]
$$

where $\mathrm{Q}$ is the incident pulse thermal energy, $\rho$ is the density of the material, $\mathrm{C}$ is the specific heat capacity, $\mathrm{L}$ is the thickness of the sample and $\alpha$ is the thermal diffusivity of the material. Two empirical methods to quantify defect depth is to relate it to parameters namely peak contrast time and peak slope time. Contrast $(C)$ is defined as

$$
C=\frac{T_{\text {defect-free }}-T_{\text {defect }}}{T_{\text {defect }- \text { free }}}
$$

where $T_{\text {defect-free }}$ is the surface temperature above the sound area and $T_{\text {defect }}$ is the surface temperature above the flawed area. Knowing the fact that time to peak contrast is approximately proportional to the depth of the defect squared, it can be related to find the defect depth. Another parameter that can be correlated to defect depth is the time at which peak slope of the contrast curve is achieved. A disadvantage with these methods is 
that calculation of contrast involves the temperature of a sound region that should be known before the start of experiment. Also calculation of the peak slope involves finding derivative of the contrast profile that makes the data noisy (Sun 2006). Martin et al. (2003) showed that the transient thermal behavior of a specimen after the application of a instantaneous flash is linear in nature in logarithmic scale with a slope of -0.5. The time at which the surface temperature profile in the logarithmic scale deviates from its ideal behavior can be related to depth of defect. Shepard et al. (2003) concluded that there contains a peak time in second derivative of the surface temperature profile in logarithmic scale that can be related to defect depth (Sun 2006). According to Shepard et al. (1999), there is a time in the post flash surface temperature behavior of a specimen at which the surface temperature curve above the defect deviates from the surface temperature curve above the defect free region. This time defined as break time can also be used to determine defect depth. Other parameters that can be used to determine defect depth are contrast value at peak slope of the contrast curve, peak contrast value, peak slope value of the contrast curve, time to achieve half of the peak contrast in the ascending as well as in descending part of the curve etc. It can be noted that earlier is the characteristic time, less is its chance to get affected by multiple reflections of the thermal wave between the defect and the surface of the tested material (Favro et al. 1995)

Another formula that can be used to find defect depth can be stated as follows (Maldague 2001):

$$
z_{\text {def }}=A\left(C_{\max }\right)^{n} \sqrt{t}
$$

Taking the natural logarithm on both sides we get

$$
\begin{aligned}
& \ln z_{\text {def }}-\ln \sqrt{t}=\ln A+n \ln C_{\text {max }} \\
& \ln \left(\frac{z_{\text {def }}}{\sqrt{t}}\right)=B+n \ln C_{\text {max }} \\
& z_{d e f}=e^{\left(B+n \ln C_{\text {max }}\right)} \sqrt{t}
\end{aligned}
$$


where $z_{\text {def }}$ is the defect depth, $C_{\max }$ is the maximum contrast and $t$ is any characteristic time such as time to peak contrast, time to achieve half the peak contrast etc.

Since equation (2.7) is difficult to fit in standard mathematical packages, natural logarithm is taken and then manipulated to yield equation (2.8) which is the equation of a straight line. After finding the constants by curve fitting, we can get the defect depth with the help of equation (2.9). 


\section{CHAPTER 3 \\ LITERATURE REVIEW}

\subsection{INTRODUCTION}

This chapter discusses the literature review done as a part of this study. The review is divided into two parts. First part discusses the studies conducted regarding the use of Infrared Thermography (both qualitative and quantitative) in inspecting composite materials. The next part focuses on the previous studies made with regards to stress strain behavior of FRP composite wrapped concrete columns. Because of absence of research performed in the area of stress strain behavior of FRP composite wrapped concrete columns with debonds, this component of literature review mainly concentrates on stress strain behavior of FRP composite wrapped concrete columns without any simulated debonds. The principle behind the confinement effect of FRP composites on concrete columns is also briefly explained in this chapter.

\subsection{INFRARED THERMOGRAPHY}

Plotnikov (1999) simulated a $80 \mathrm{~mm}$ x $80 \mathrm{~mm}$ x $20 \mathrm{~mm}$ plate with an air defect of dimension $20 \mathrm{~mm} \times 20 \mathrm{~mm} \times 0.2 \mathrm{~mm}$ at depths varying from $1 \mathrm{~mm}$ to $19 \mathrm{~mm}$ to calculate several informative parameters related to depth estimation. The parameters included maximum thermal contrast, time of maximum contrast, time of peak slope in the contrast curve, the amplitude and phase of the Discrete Fourier Transform that was applied to the thermal evolution of the surface in the cooling cycle. It was established that time to peak slope of the contrast curve is influenced by planar size of the defect and thermal resistance of the defect. Hence time to peak slope is not a dependable parameter to estimate depth of the defect.

For quantitative evaluation of defects, it is of utmost importance that the specimen be heated uniformly. This is because thermal difference which is a parameter used in defect characterization depends on the selection of a reference point (i.e., a point in the defect-free area of the sample). Uneven heating can result in a change in both sign and 
magnitude of thermal difference and consequently can yield unexpected results (Vavilov 2000).

Favro et al. (1995) found that peak slope time of the contrast curve is not dependant on the planar size of defect. They also found that time of peak contrast increased with an increase in depth of defect.

Starnes (2002) stated that defects appear as round in the thermograms due to the three dimensional diffusion effects. The edges of the defects are well defined at the optimum observation time after which rounding effects becomes prominent. It can be noted here that the instant when thermal contrast is maximum is termed as optimum observation time.

Shepard (2006) pointed out that the cooling rate of a material does not depend on its thermomechanical properties such as effusivity, diffusivity etc. The author further stated that for any material, the temperature after a certain period of time will be the same percentage of the initial temperature of the surface.

Sun (2006) stated that since differentiation introduces noise in the data, order of the polynomial fitting the surface temperature decay curve should be given due consideration. Experimental system error stems from noise and linearity of the infrared detector. Although linearity can be corrected, data smoothing becomes inevitable to reduce noise. Data smoothing affects the magnitudes but the peak times remain unaltered. Hence, peak time rather than peak values are often used to predict defect depth. The ratio of the diameter to the depth of the defect governs whether a defect is detectable or not. Three-dimensional heat conduction dominates as the aspect ratio is decreased and reduces the possibility of detection of the defect. The author further established that peak slope time can be used to predict the defect depth with acceptable accuracy although the prediction becomes lower compared to the actual depth when the three dimensional heat conduction starts to dominate. On the other hand, peak slope value is highly sensitive to the smoothing routine and three dimensional heat conduction phenomena. The peak time in the second derivative of the temperature profile in the logarithmic scale can predict the depth with an accuracy that is similar to the accuracy of peak slope method. In addition to 
that, the last method of determining the depth does not require the prior knowledge of a defect free area and hence can be easily automated.

As the thickness of the defect increases, so does the thermal difference. But thermal difference decreases as the depth of the flaw increases. The time to maximum contrast increases as depth of the defect increases. To investigate the influence of various parameters on transient heat transfer phenomena, Starnes (2002) conducted finite element analysis of infrared thermography testing of FRP layers bonded to concrete using ANSYS 5.6. The major conclusions from the single factor parametric studies conducted are furnished below:

- The time for maximum signal depends on pulse duration and not on the applied heat flux.

- The magnitude of thermal contrast does not depend on heat flux and pulse duration.

- As heating time increases, so does the time for maximum contrast.

- Thermal parameters were not very sensitive to the change in thermal properties of FRP and concrete.

- The variation of maximum surface temperature with depth of flaw is non linear.

- Time of detection for debonds increases in a non linear manner with increasing debond depth.

- The maximum surface temperature does not depend much on thermal resistance of the flaw in case of debonds.

- Thermal signal and the time for maximum signal (or difference) increases with increasing thermal resistance.

- Very thin flaws may remain undetected.

Brown and Hamilton (2007) used three heating methods namely flash heating, scan heating and long pulse heating on FRP composite laid on concrete blocks that had simulated defects in the FRP-concrete interface. The authors found that well defined defects had a maximum temperature difference of more than $2 \mathrm{oC}$ and can be used for defect size determination. Scan heating produced more temperature difference than the other two heating methods. The heating was not uniform with long pulse heating method. 


\subsection{STRESS STRAIN BEHAVIOR OF FRP COMPOSITE WRAPPED COLUMNS}

$\mathrm{Au}$ et al. (2005) performed study regarding the effect of fiber orientation and ply mix on the stress strain behavior of FRP composite wrapped concrete cylinders. Three types of $\mathrm{E}$ glass fabric namely unidirectional fabric $\left(0^{\circ}\right)$, bidirectional fabric $\left(0^{\circ} / 90^{\circ}\right)$ and biangular fabric $\left( \pm 45^{\circ}\right)$ were used giving rise to a total of six wrap configurations. A term called kinking stress was defined which is the stress level at which reduction in axial stiffness occurs. It is also the point where failure of the concrete core occurs. Wrap configurations consisting of unidirectional fabrics (higher confinement stiffness) showed a system level strain hardening after a kinking stress level. They also showed a brittle failure mode. Wrap configurations with bidirectional fibers (lower confinement stiffness) demonstrated a strain softening behavior after kinking stress level. Angular fibers produced a ductile failure state due to fiber reorientation mechanism. Use of ply mix exhibited a mixed failure state as well as mixed load deformation behavior. Use of higher stiffness or higher thickness FRP composite yields a higher confinement pressure and subsequently kinking stress level.

Mirmiran et al. (1997) tested 30 concrete cylinders which included 6 unconfined plain concrete cylinders and 24 FRP tube wrapped concrete cylinders. The fiber used was unidirectional $\mathrm{E}$ glass fibers with $\pm 15^{\circ}$ winding angle. Three jacket thicknesses consisting of 6,10 and 14 plies were tested. Failure of the specimens occurred due to the fracture of the tube near midheight of the cylinder and shear failure was the primary failure mode of the composite tubes. An increase in strength and ductility of concrete due to wrapping was observed. Wrapping with FRP tubes also resulted in a curtailment of volumetric expansion of concrete.

Samaan et al. (1998) conducted a study in which 30 concrete cylinders were tested under uniaxial compression. Unidirectional $\mathrm{E}$ glass fiber with $\pm 75^{\circ}$ winding angle along with a polyester resin was used to make the composite tubes. They suggested the need to include the effect of stiffness of the confining device in order to completely describe the bilinear stress strain behavior of FRP wrapped concrete. The proposed model incorporates the dilation rate and stiffness of the wrap and completely describes the bilinear behavior of FRP wrapped concrete in both axial as well as in lateral direction. 
Toutanji (1999) tested 18 concrete cylinders in which 12 were wrapped with FRP composites and 6 were plain unconfined concrete. Three types of unidirectional FRP sheets consisting of two carbon sheets and one glass sheet were used in the study. It was found that compressive strength was doubled in specimens wrapped with glass sheets and tripled in case of specimens wrapped with carbon sheets. The study revealed that at the same stress level, axial and lateral strain values for cylinders wrapped with glass fabrics were approximately same. But in case of cylinders wrapped with carbon fabrics, lateral strain was always lower than the axial strain at the same stress level. A mathematical model was proposed in which equations to predict the stress strain behavior were developed separately for two regions. The first region of the stress strain curve corresponds to the region where lateral expansion of confined concrete was small. This is true till the unconfined strength of concrete is reached. The second region of the stress strain curve is the region beyond the stress level of unconfined concrete strength. This is the region where FRP wrap actually activates and starts producing the confining action.

Harries et al. (2003) investigated the effect of debonding and gaps between FRP composite wrap and concrete substrate. E glass fibers in conjunction with an epoxy was used to wrap $152 \mathrm{~mm}$ x $305 \mathrm{~mm}$ concrete cylinders. Three and nine layers of FRP composite wrap were used to confine the cylinders. Debonding was provided by wrapping the cylinder with plastic wrap. The cylinders wrapped with three layers of composite showed post peak ductility behavior as expected from a moderately confined system. The specimens confined with nine layers of composite showed a distinctive bilinear stress strain response in agreement with the behavior of an adequately confined system. The maximum compressive strength in case of debonded cylinders were found to be less than the maximum compressive strength of the cylinders without debonds. This happens because the concrete has to expand laterally to fill the gap created by the plastic wrap and engage the FRP shell in order make it fully activated. The authors concluded that the stress level at which concrete expands and makes contact with the outside FRP shell depends upon the size of the debond. The ultimate average strain values in debonded specimens did not differ much from the corresponding values in bonded cylinders. 
Saenz et al. (2007) divided the stress strain behavior of FRP confined concrete into three regions. The first region is linear elastic response region and is valid till microcracking starts to appear. The second region begins shortly after the initiation of volumetric contraction of concrete and goes until volumetric expansion of confined concrete begins to appear. The third region is the stress strain behavior of the confined till failure.

\subsubsection{Theory of Confinement}

When uniaxially loaded concrete is restrained from expanding in the radial direction, it results in increased strength of the concrete. When concrete wrapped with FRP fabrics is subjected to uniaxial compression, it is essentially being partially restrained. The ultimate compressive strength increases as the confining stress increases as evident from the stress strain curves for triaxial compression test (Figure 3-1).

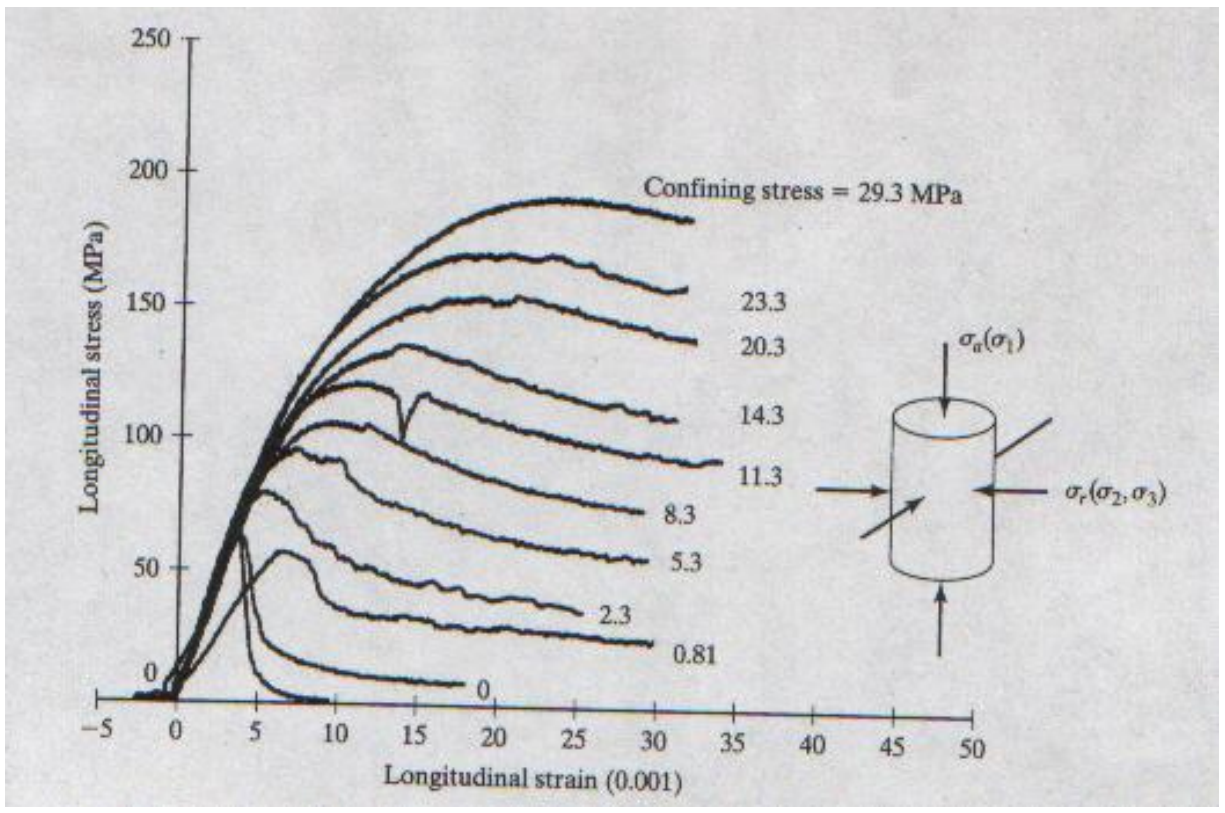

Figure 3-1 Stress strain curves for concrete in triaxial compression (Mindness et al. 2003)

The confinement action develops as the lateral expansion of concrete increases under axial load. The confinement device (e.g., FRP wraps) develops a hoop tensile stress which is in equilibrium with the radial confinement pressure that constrains the concrete 
from dilating laterally (De Lorenzis et al. 2003). The confinement action is shown in Figure 3-2.

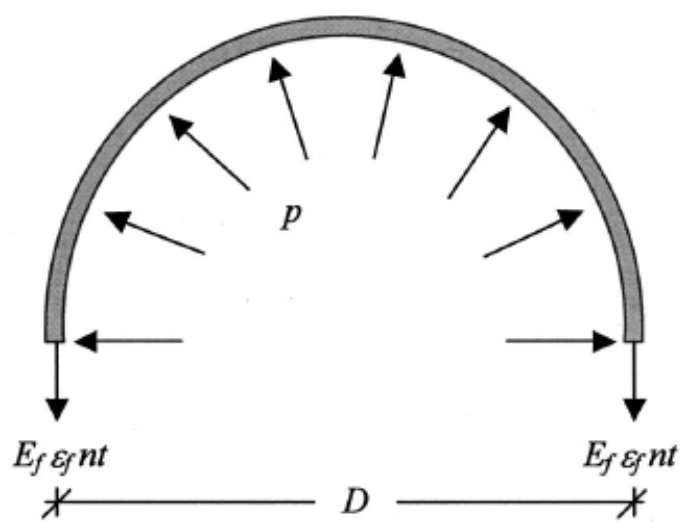

Figure 3-2 Confinement action (De Lorenzis et al. 2003)

The lateral strain $\varepsilon_{1}$ of the concrete should be equal to circumferential strain of FRP fabric $\varepsilon_{\mathrm{f}}$ under the assumption of deformation compatibility. From principle of equilibrium, we find the lateral force $\mathrm{p}$ that acts on concrete radially.

$\mathrm{p}=\mathrm{E}_{1} \varepsilon_{1}=\mathrm{E}_{1} \varepsilon_{\mathrm{f}}$

where $E_{1}=\left(2 E_{f} n t\right) / D$

Here $\mathrm{D}$ is diameter of the cylinder, $\mathrm{n}$ is the number of FRP layers, $\mathrm{t}$ is the thickness of each layer. The maximum confinement pressure $p_{u}$ that can be exerted by the confining device can be found by equating circumferential strain of FRP fabric to ultimate strain $\varepsilon_{\mathrm{fu}}$ of FRP fabric.

$p_{u}=E_{1} \varepsilon_{f u}=\left(2 f_{f u} n t\right) / D$, where $f_{f u}$ is the ultimate strength (per unit area) of FRP fabric.

The stress-strain response of FRP confined concrete columns is bilinear. At the point around the strength of unconfined concrete, the curve deviates from the initial portion with a decrease in stiffness value. 


\section{CHAPTER 4}

\section{LABORATORY EQUIPMENT AND TEST SPECIMENS}

This chapter discusses the laboratory equipment and experimental setup used in this study. Details of the test specimens are also included in this chapter.

\subsection{INFRARED THERMOGRAPHY EQUIPMENT}

\subsubsection{Infrared Camera}

The digital infrared camera that is used in the experiments is ThermaCAM ${ }^{\mathrm{TM}} \mathrm{S} 60$ by FLIR Systems. Figure 4-1Figure shows the digital picture of the Infrared camera.

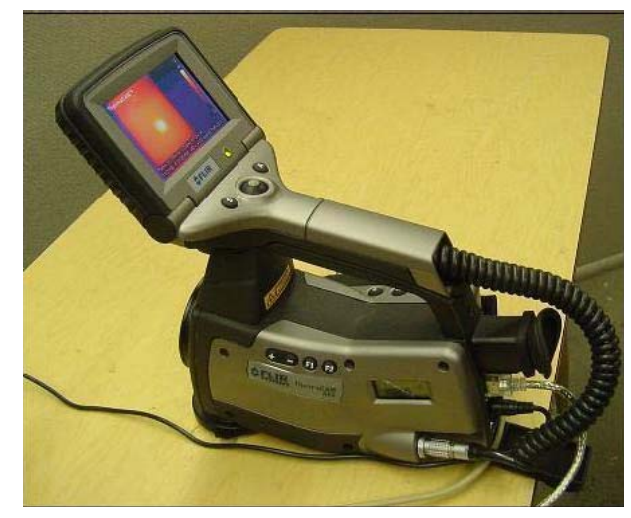

Figure 4-1 ThermaCAM ${ }^{\mathrm{TM}} \mathrm{S60}$ digital infrared camera

The camera is a lightweight one with a built in $24^{\circ}$ lens. It can detect infrared radiation in the spectral range of 7.5 to 13 microns. The different temperature ranges that the camera offers are 0 to $+500{ }^{\circ} \mathrm{C}\left(+32\right.$ to $\left.+932{ }^{\circ} \mathrm{F}\right),-40$ to $+120{ }^{\circ} \mathrm{C}\left(-40\right.$ to $\left.+248{ }^{\circ} \mathrm{F}\right)$ and +350 to $1500{ }^{\circ} \mathrm{C}\left(+662\right.$ to $\left.+2732{ }^{\circ} \mathrm{F}\right)$. Thermal sensitivity of the device at $30{ }^{\circ} \mathrm{C}$ is as low as $0.08{ }^{\circ} \mathrm{C}$. The imaging performance for the camera has a spatial resolution of $1.3 \mathrm{mrad}$ and the infrared image capture rate can go as high as 60 frames per second. It is possible to capture and store images on a removable flash card. The camera also features burst recording functionality that allows the user to record sequences of events into the internal RAM memory. The images that the camera produces can be analyzed either in the field by using the real-time measurement markers built into the camera software, or in a PC 
using FLIR Systems software (FLIR Systems 2002a). The software ThermaCAMTM Researcher 2002, which is used along with the camera, deals with the live IR images arriving through the camera interface. It can also receive IR images from other media, such as PC card hard disk from the camera. The analysis of the images can be made with the various analysis tools like isotherm, spotmeter, area and line. The temperature corresponding to any point can be obtained by using the spot temperature measurement option offered by the software. In other words, we can obtain detailed information at every pixel. Since the camera captures fully radiometric digital images, a reference image can be subtracted from the full image sequence to achieve better results in terms of detectability of defects and to conduct a quantitative analysis (FLIR Systems 2002b).

\subsubsection{Quartz Tower Heater}

Two $1500 \mathrm{~W}$ quartz tower heaters (Figure 4-2) were used to heat the specimens. The plan size of the heater is 17 " $\mathrm{9} 9$ " $(0.4318 \mathrm{~m} \times 0.2286 \mathrm{~m})$.

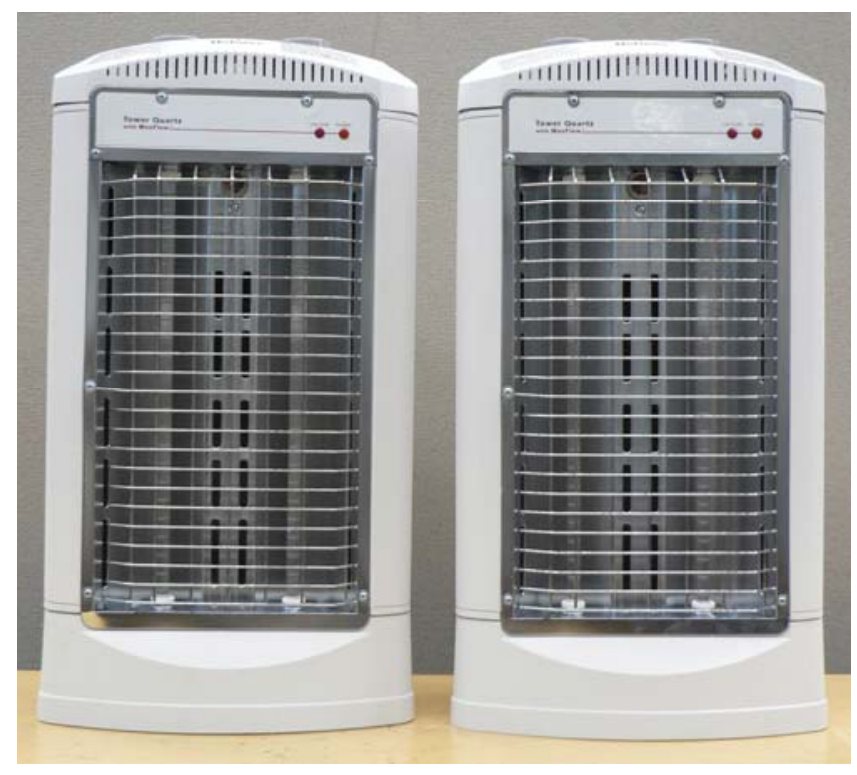

Figure 4-2 Quartz tower heaters

The safety features include automatic tip-over, caution light and overheat shut off. The basic Infrared Thermography setup for laboratory testing of wrapped cylinders is shown in Figure 4-3. The specimens were heated for a specified duration with two $1500 \mathrm{~W}$ quartz tower heaters that were placed on rotating tables. Data acquisition (capturing of infrared images) was initiated as soon as the heaters were turned on. At the 
end of the specified duration, the tables were rotated to other side so that the specimens were no longer exposed to the heat flow from the heaters. However, recording the images was allowed to continue for a couple of minutes after the heaters were rotated.

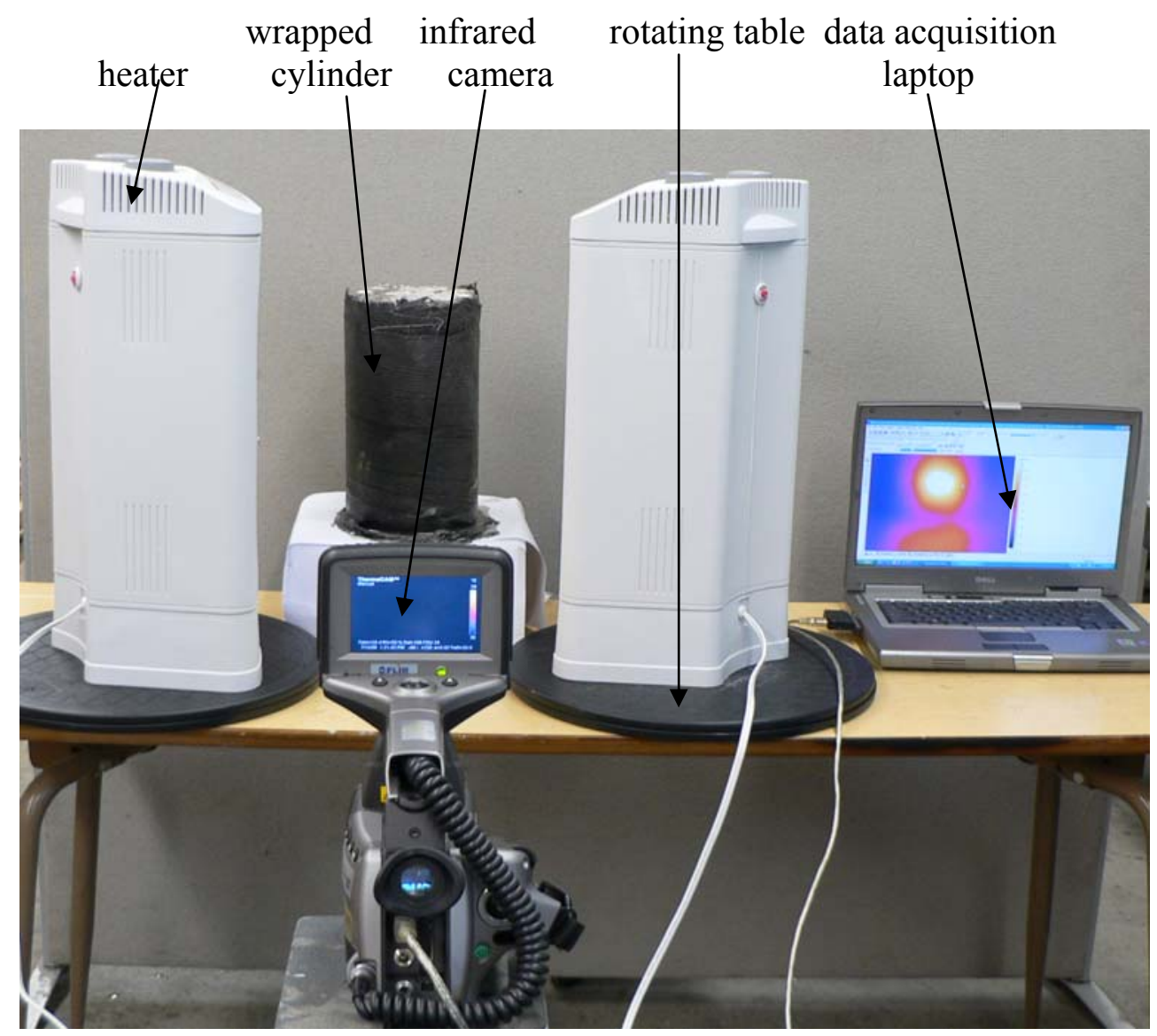

Figure 4-3 Infrared thermography setup in the laboratory

\subsubsection{Heat Flux Meter}

A heat flux meter together with a galvanometer (Figure 4-4) was used to measure the applied heat flux. The heat flux meter has a plan size of 4 " x 4 " $(0.1 \mathrm{~m} \mathrm{x} 0.1 \mathrm{~m})$ and a thickness of $0.055 "(0.001 \mathrm{~m})$. The temperature range through which the heat flux meter operates is $-425{ }^{\circ} \mathrm{F}\left(-253.9{ }^{\circ} \mathrm{C}\right)$ to $550{ }^{\circ} \mathrm{F}\left(287.8{ }^{\circ} \mathrm{C}\right)$. The meter had a accuracy of $1 \%$. 


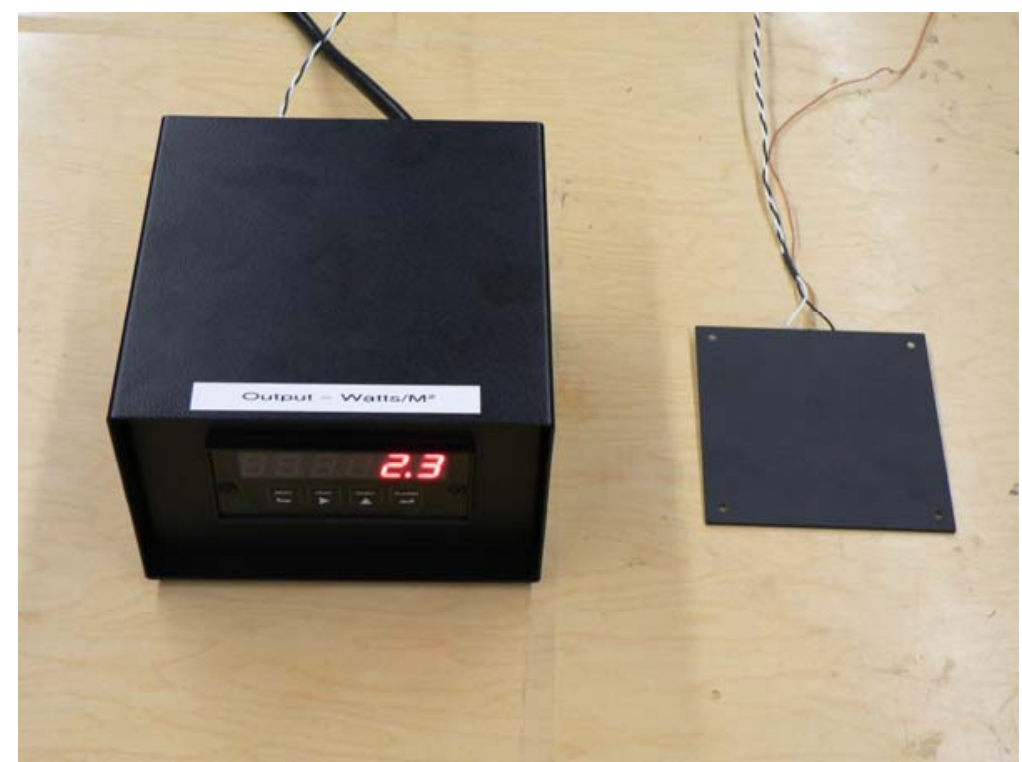

Figure 4-4 Heat flux meter and the galvanometer

\subsubsection{Thermal Conductivity Testing System}

Unitherm model 2022 (Figure 4-5) manufactured by ANTER Corp., Pittsburgh, PA was used to measure the thermal conductivity value of the FRP composites. The schematic diagram of the unit is illustrated in Figure 4-6. The machine measures thermal conductivity values within the range of 0.1 to $40 \mathrm{~W} / \mathrm{m} \cdot \mathrm{K}$ in accordance with ASTM E 1530. The samples are cut to a size of 2 inch diameter circular disks and placed between two polished surfaces. A pressure of $10 \mathrm{psi}$ is then applied on the top of the unit. The top and the bottom heaters help heat to flow steadily through the sample. 


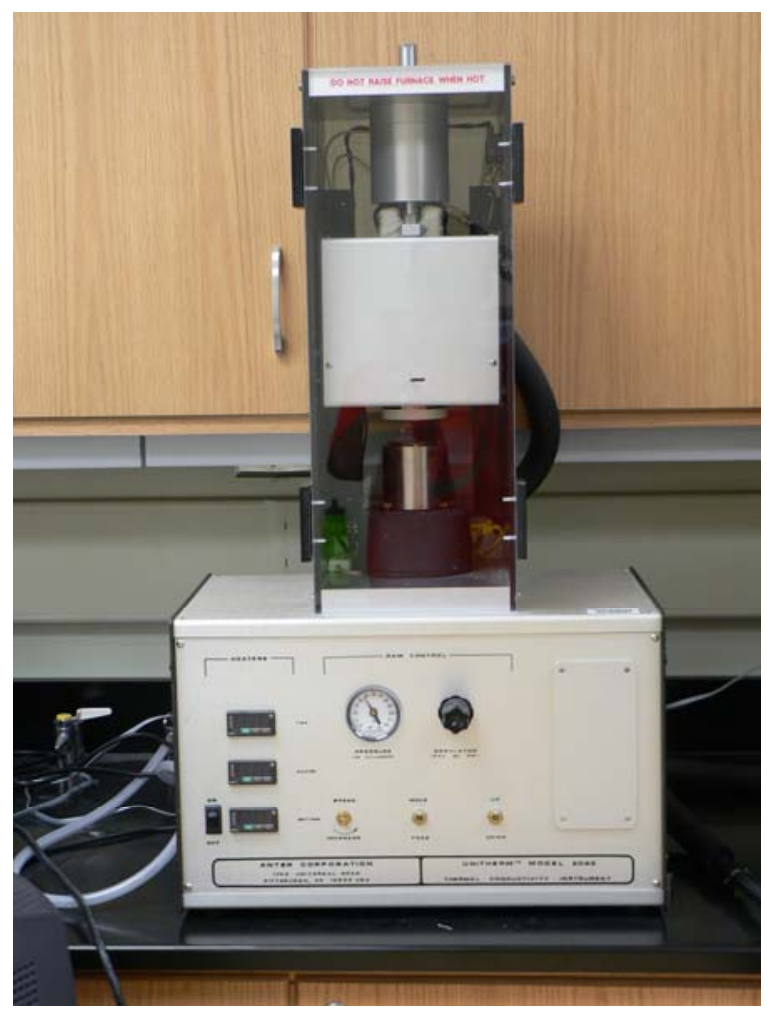

Figure 4-5 Unitherm 2022

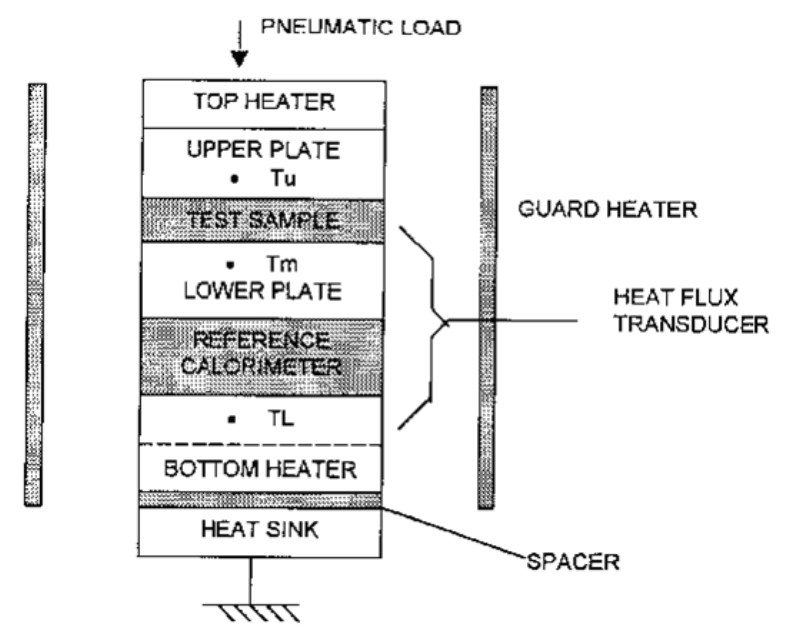

Figure 4-6 Schematic diagram of Unitherm 2022 (Hing 2006) 


\subsection{STATIC COMPRESSION TEST}

\subsubsection{Universal Compression Testing Machine}

The universal testing machine that has a two load indicator dials. The higher dial gauge of 350 kips was used in the testing as a higher load carrying capacity was anticipated due to the wrapping of the cylinder. The machine has a top plate that is stationary and a bottom platen that moves up. A load cell was used to record the load that was applied to the concrete specimens by the platens.

\subsubsection{Baldwin Machine}

The Baldwin machine has three loading scales and the lower scale with load capacity 100 kips was used to test the Carbon and Glass strips in tension. The highest scale with capacity 200 kips was used to test the concrete cylinders in compression. The advantage of this machine is that load cell is not required to read the load as an electrical signal outlet from the machine facilitates the reading of the applied load directly into the data acquisition system.

\subsubsection{Data Acquisition, Load Cell, LVDT and Strain Gages}

Test data was collected with the help of system 5000-scanner 5100 data acquisition manufactured by a US manufacturer. A load cell with a load capacity of 400 kips was used to record the load from the universal testing machine. Two types of strain gages were used in this study. The first set of strain gage used had a resistance of 350 ohms and a gage factor of $2.105 \pm 5 \%$. The gage length of the first set of strain gages was 0.75 inches. This set was used to measure the radial strain of the FRP composite wrapped cylinders. The second set of strain gages had a gage gage length of 4 inches and a gage factor of $2.110 \pm 5 \%$. This set was used to measure the both axial and radial of plain concrete cylinders. The Linear Variable Differential Transducers (LVDT) were used to measure the axial strain of the FRP composite wrapped cylinders. The strain gages were connected to the strain gage cards and LVDT were connected to the high level cards. 


\subsection{MAKING OF THE SPECIMENS}

Two sets concrete cylinders were caste for this research. While casting, demolding agent was applied inside the surface of the molds. The size of the cylinders was 6" x 12"' (152.4 mm x $304.8 \mathrm{~mm})$, which is a standard cylinder size specified by ASTM/ACI. Both sets of concrete used to cast the cylinders were provided by Hoy RediMix, Morgantown. The first set of concrete had a compressive strength of $3000 \mathrm{psi}$. The compressive strength of the second set of concrete was 2652 psi. Cylinders were cast at Hoy Redi-Mix plant in accordance with the ASTM standards and were left there to set in the mold for initial 48 hours. Cylinders were covered with plastic sheet in order to prevent moisture loss during initial curing. After two days, the cylinders were transported to the NDE laboratory, taken out from the molds and cured under ambient conditions $\left(\sim 70^{\circ} \mathrm{F}\right)$ by submerging in water tanks for 28 days. After 28 days of curing, the cylinders were taken out and allowed to dry for 7 days. It should be noted that all the cylinders used in this study were plain concrete cylinders without any internal reinforcement. Some of the cylinders were later wrapped with FRP fabrics prior to testing.

\subsubsection{Making of Debonds}

Various subsurface debonds were created between the FRP wraps and the underlying concrete cylinders to simulate debonded specimens. Debond refers to a defect that is present between the composite wrap and the underlying concrete surface. The cylinders with the debonds were nondestructively evaluated using Infrared Thermography and subsequently crushed to investigate the effect of debonds on axial compressive strength. Two types of debonds namely air-filled debond and water-filled debond were used in this study. Debonds were made into four plan sizes: 3' x 3' (76.2 mm x $76.2 \mathrm{~mm}), 2$ "' x 2"' (50.8 mm x $50.8 \mathrm{~mm}), 1.4$ '” x 1.4"' (35.56 mm x $35.56 \mathrm{~mm})$ and 1" x 1" (25.4 mm x $25.4 \mathrm{~mm})$. Thickness of all debonds were 1/10" (2.54 mm).

Air-filled debonds were made by cutting small stripes of plastic sheets and gluing them along the boundary as spacers. The spacers were then glued in between two plastic sheets of the same size so that an air pocket of desired thickness was enclosed between the two sheets. Curved plastic containers were used in this case so that the debonds would fit snuggly on the surface of the curved concrete cylinders. Water-filled debonds were 
made by filling water in custom made polyethylene pouches. As custom made pouch of size 1.4" x 1.4" (35.56 mm x $35.56 \mathrm{~mm}$ ) could not be procured, water-filled debond of that size was made from 3" x 3" size with the help of an impulse sealer. Although care was taken to fill the pouches with the amount of water that made them 1/10" $(2.54 \mathrm{~mm})$ thick, some air bubbles were trapped inside which could not be avoided. Figure 4-7 and Figure 4-8 show the air-filled debonds and the water-filled debonds, respectively. Some of the cylinders had also Teflon sheets glued to them before they were wrapped. These Teflon sheets were also cut in the sizes of 3" x 3" (76.2 mm x $76.2 \mathrm{~mm}), 2$ " x 2" (50.8 mm x $50.8 \mathrm{~mm}), 1.4$ " x 1.4" (35.56 mm x $35.56 \mathrm{~mm})$ and 1" x 1" (25.4 mm x $25.4 \mathrm{~mm})$. It can be noted that section 6.2 .3 of ACI 440.2R-02 states that inspection method should be able to detect delaminations that are $2 \mathrm{in}^{2}$ or greater. The debond sizes that were incorporated in this study were 1 in $^{2}$ (1" x 1"), 2 in $^{2}$ (1.4" x 1.4"), 4 in $^{2}$ (2" x 2") and 9 in $^{2}\left(3 " x 3^{\prime \prime}\right)$.

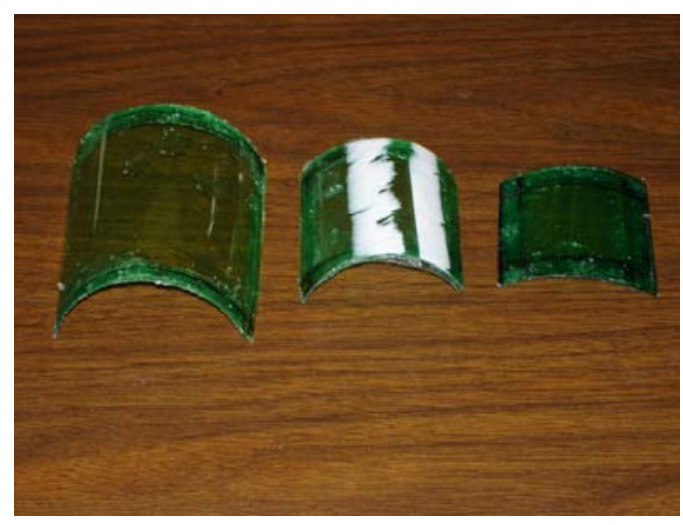

Figure 4-7 Air-filled debonds

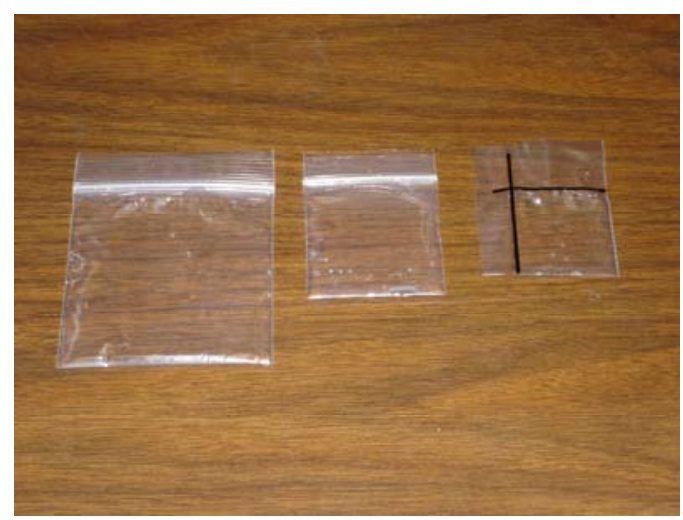

Figure 4-8 Water-filled debonds 


\subsubsection{Wrapping of Cylinders}

The surfaces of the cured concrete cylinders were cleaned with a brush so as to obtain a clean, dry surface. The fiber reinforced fabrics used to wrap the cylinders were of three types: two types of carbon FRP and one type of glass FRP. First set of CFRP fabric consisted of carbon fiber that were oriented in $\pm 45^{\circ}$. Second set of carbon fabric contained fibers with oriented in $0^{\circ}, \pm 45^{\circ}$ and $90^{\circ}$ direction.

In case of the Glass FRP fabric, the orientation of fibers was $0^{\circ} / 90^{\circ}$. An epoxy resin known as Tyfo S Saturant Epoxy manufactured by Fyfe Co. LLC was used as the matrix to bind the FRP wraps (both glass and carbon wraps) to the concrete surface. The adhesive had two parts: Part A (resin) and Part B (Hardener) (Figure 4-9).

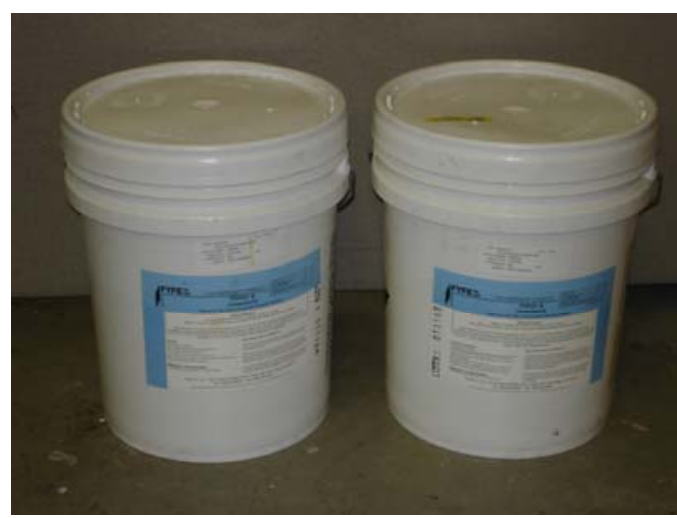

Figure 4-9 Tyfo S Saturant Epoxy (Type A and Type B)

The mix ratio for the two parts was 100 parts of component $A$ to 42 parts of component B by volume. Properties of the TYFO S Saturant Epoxy supplied by the manufacturer are furnished in Table 4-1.

Table 4-1 Properties of TYFO S Saturant Epoxy (Fyfe Co. LLC 2000)

\begin{tabular}{|c|c|}
\hline Property & Value \\
\hline \hline Tensile Strength & $10500 \mathrm{psi}$ \\
\hline Tensile Modulus & $461000 \mathrm{psi}$ \\
\hline Elongation percent & $5 \%$ \\
\hline Flexural Strength & $17900 \mathrm{psi}$ \\
\hline Flexural Modulus & $452000 \mathrm{psi}$ \\
\hline Curing time & 72 hours at $60^{\circ} \mathrm{C}$ \\
\hline
\end{tabular}


The wrapping procedure is explained below and is shown from Figure 4-10 to Figure 4-14.

- The FRP sheets were cut to cover the circumference of the cylinder with an extra overlap length of $\sim 3$ '".

- The epoxy component A and component B were mixed in the given ratio with a low speed mixer at 400-600 rpm until the components were mixed thoroughly.

- Epoxy was applied on both sides of the FRP wraps and also to the concrete surface with a brush. Extra epoxy was stroked off with a plastic trowel.

- FRP fabrics were wrapped around the cylinder and were gently pressed with a plastic trowel in order to remove any unwanted air bubbles.

- The cylinders were left to cure at room temperature for five days.

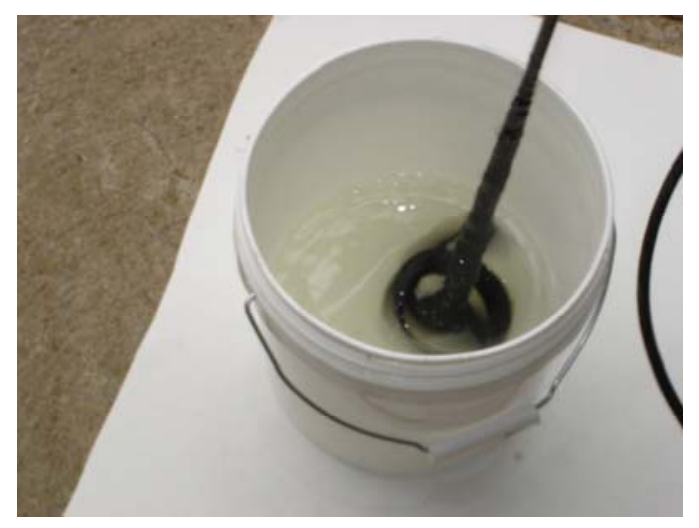

Figure 4-10 Mixing the two parts of the resin with a low speed mixer

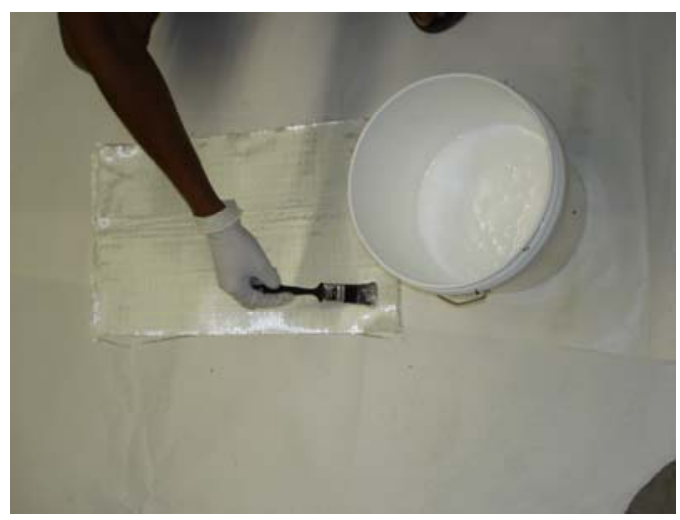

Figure 4-11 Applying the mixed resin on FRP sheets 


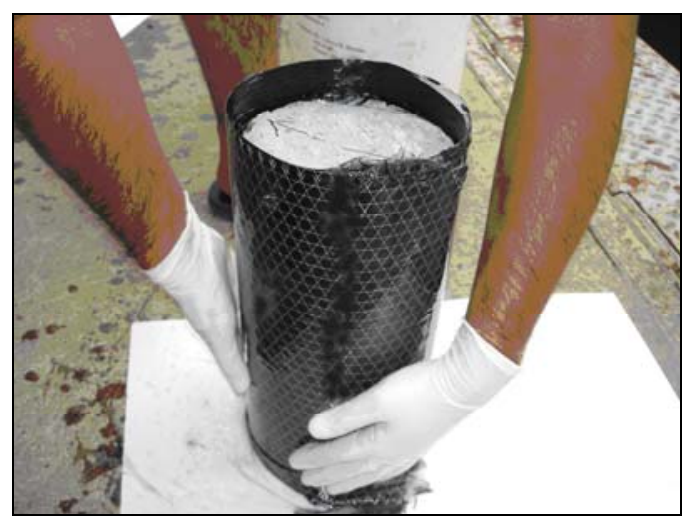

Figure 4-12 Wrapping the cylinders with FRP sheets

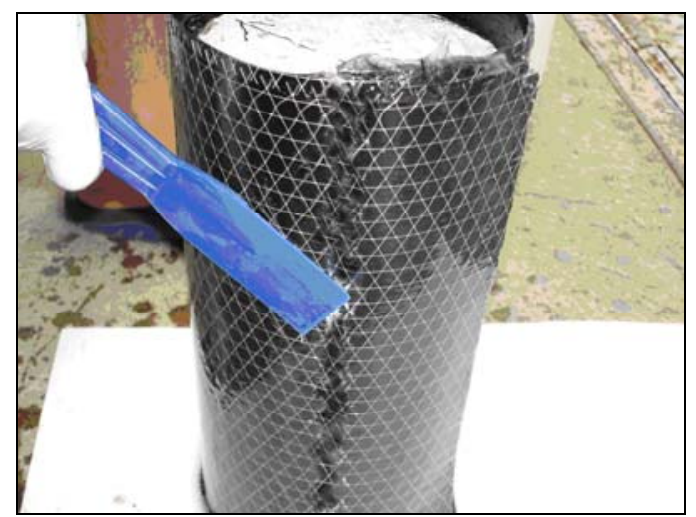

Figure 4-13 Removing air bubbles

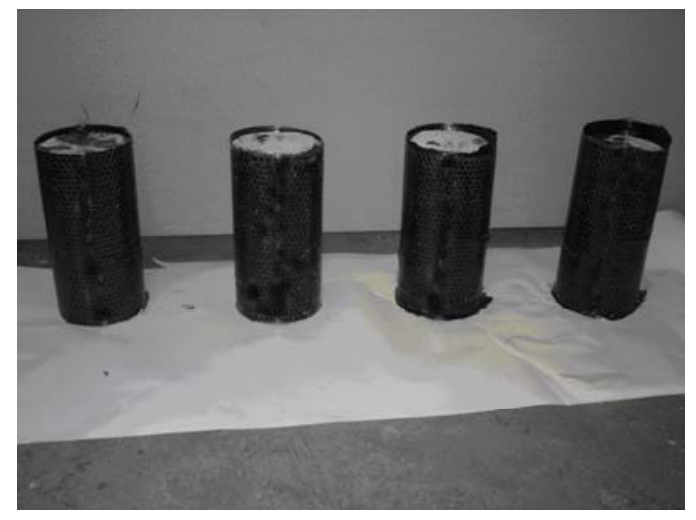

Figure 4-14 Curing the FRP composite wrapped cylinders 
Table 4-2 gives the different properties of the GFRP and first set of CFRP composite system that were used to wrap cylinders and subsequently tested to study the feasibility of infrared thermography in detection of subsurface debonds. It should be noted that properties summarized in this table are only relevant to testing with infrared thermography technique. Emissivity of the composite was measured in accordance with non-contact thermometer method given in ASTM E 1933-99a. Also, the thermal conductivity of the GFRP and CFRP wrap across the wrap thickness is similar because this property across the thickness is dominated more by the resins than by the fibers.

A total of two batches of concrete cylinders were cast. The first batch comprised of 16 cylinders used for experimenting with infrared thermography. The cylinders of the first batch were wrapped with 3 layers of GFRP composite and first set of CFRP composite. The second batch had 30 concrete cylinders. Out of these 30 specimens, 23 were wrapped with FRP composite with debond inserted between the FRP composite wrap and concrete surface and 5 were wrapped with FRP composites without debonds. These 5 cylinders were used as control specimen to measure the increase compressive strength of plain cylinders due to wrapping. Another two cylinders of this batch were used as control specimen to measure the compressive strength of plain (unwrapped) cylinders. The cylinders of this batch were wrapped with 3 layers of GFRP composite and second set of CFRP composite. Table 4-3 and Table 4-4 list the setup of debonds of the two batches. The debonds were inserted in diametrically opposite location maintaining diametrical symmetry (Figure 4-15).

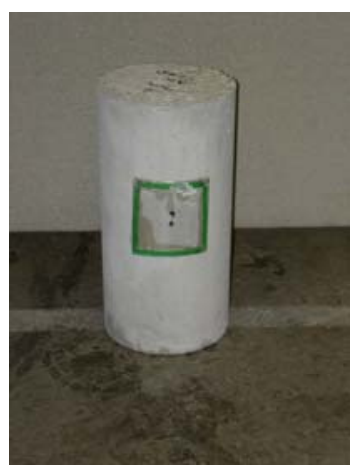

Figure 4-15 Placement of debond in the cylinder maintaining diametrical symmetry before wrapping with composite 
Table 4-2 Thermal properties of CFRP and GFRP composite

\begin{tabular}{|c|c|c|}
\hline Property & CFRP Composite & GFRP Composite \\
\hline Emissivity & 0.700 & 0.790 \\
\hline $\begin{array}{l}\text { Thermal conductivity } \\
\left(\mathbf{W m}^{-10} \mathrm{C}^{-1}\right) \\
\text { (along thickness) }\end{array}$ & $\begin{array}{c}0.169 \\
(0.154,0.171,0.183)\end{array}$ & $\begin{array}{c}0.172 \\
(0.160,0.172,0.185)\end{array}$ \\
\hline Density $\left(\mathrm{kg} / \mathrm{m}^{3}\right)$ & $\begin{array}{c}1344.15 \\
(1383.80,1221.70,1426.90)\end{array}$ & $\begin{array}{c}1800.41 \\
(1741.00,1890.29,1769.94)\end{array}$ \\
\hline Specific heat $\left(\mathrm{J} \mathrm{kg}^{-1}{ }^{\mathbf{0}} \mathrm{K}^{-1}\right)$ & $\begin{array}{c}1244.56 \\
(1272.80,1179.50,1281.30)\end{array}$ & $\begin{array}{c}1055.19 \\
(1009.40,1016.80,1139.30)\end{array}$ \\
\hline Thermal diffusivity $\left(\mathrm{m}^{2} / \mathrm{s}\right)$ & $1.012 \times 10^{-7}$ & $9.071 \times 10^{-8}$ \\
\hline Laminate thickness (m) & 0.000300 & 0.000628 \\
\hline
\end{tabular}

Table 4-3 Setup of debonds (Batch 1)

\begin{tabular}{|c|c|}
\hline Cylinder No & Setup of Debonds \\
\hline \hline \multicolumn{2}{|c|}{ Wrapped with GFRP Composite (3 layers) } \\
\hline 1 & one 1" x 1" air-filled debond on each side \\
\hline 2 & one 1.4"x 1.4" air-filled debond on each side \\
\hline 3 & one 2" x 2" air-filled debond on each side \\
\hline 4 & one 3" x 3" air-filled debond on each side \\
\hline 5 & one 1.4"x 1.4" water-filled debond on each side \\
\hline 6 & one 2" x 2" water-filled debond on each side \\
\hline 7 & one 3" x 3" water-filled debond on each side \\
\hline \multicolumn{2}{|c|}{ Wrapped with GFRP Composite } \\
\hline 8 & one 2" x 2" air-filled debond with 1 layer of composite wrap \\
\hline 9 & one 2" x 2" air-filled debond with 2 layers of composite wrap \\
\hline 10 & one 2" x 2" air-filled debond with 4 layers of composite wrap \\
\hline \multicolumn{2}{|c|}{ Wrapped with CFRP Composite (3 layers) } \\
\hline 11 & one 1.4"x 1.4" air-filled debond on each side \\
\hline 12 & one 2" x 2" air-filled debond on each side \\
\hline 13 & one 3" x 3" air-filled debond on each side \\
\hline 14 & one 1.4"x 1.4" water-filled debond on each side \\
\hline 15 & one 2" x 2" water-filled debond on each side \\
\hline 16 & one 3" x 3" water-filled debond on each side \\
\hline \multicolumn{2}{|}{} \\
\hline
\end{tabular}


Table 4-4 Setup of debonds (Batch 2)

\begin{tabular}{|c|c|}
\hline Cylinder No & Setup of Debonds \\
\hline \hline & Wrapped with GFRP Composite (3 Layers) \\
\hline 1 & one 1" x 1" air-filled debond on each side \\
\hline 2 & One 1.4" x 1.4" air-filled debond on each side \\
\hline 3 & one 2" x 2" air-filled debond on each side \\
\hline 4 & one 3" x 3" air-filled debond on each side \\
\hline 5 & one 1" x 1" water-filled debond on each side \\
\hline 6 & one 1.4" x 1.4" water-filled debond on each side \\
\hline 7 & one 2" x 2" water-filled debond on each side \\
\hline 8 & one 3" x 3" water-filled debond on each side \\
\hline 9 & one 1" x 1" Teflon on each side \\
\hline 10 & one 1.4" x 1.4" Teflon debond on each side \\
\hline 11 & one 2" x 2" Teflon debond on each side \\
\hline & Wrapped with CFRP Composite (3 Layers) \\
\hline 12 & one 1" x 1" air-filled debond on each side \\
\hline 13 & one 1.4" x 1.4" air-filled debond on each side \\
\hline 14 & one 2" x 2" air-filled debond on each side \\
\hline 15 & one 3" x 3" air-filled debond on each side \\
\hline 16 & one 1" x 1" water-filled debond on each side \\
\hline 17 & one 1.4" x 1.4" water-filled debond on each side \\
\hline 18 & one 2" x 2" water-filled debond on each side \\
\hline 19 & one 3" x 3" water-filled debond on each side \\
\hline 20 & one 1" x 1" Teflon on each side \\
\hline 21 & one 1.4" x 1.4" Teflon on each side \\
\hline 22 & one 2" x 2" Teflon on each side \\
\hline 23 & one 3" x 3" Teflon on each side \\
\hline
\end{tabular}

*Also, 2 plain concrete specimens, 3 with GFRP wraps and no debond, and 2 with CFRP wraps and no debond were tested and used as control specimens. 


\section{CHAPTER 5}

\section{EXPERIMENTAL RESULTS FROM INFRARED THERMOGRAPHY}

\subsection{DETECTION OF DEBONDS BY IRT}

The following sections describe the laboratory results for detecting debonds using Infrared Thermography. The experimental setup for the laboratory experiments using Infrared Thermography is already discussed in the previous chapter. In all the experiments, the setup described in the previous chapter was used to heat the specimen. The distance of the specimens from the infrared camera during the experiments was 3 feet. All data were processed with the help of ThermaCAM ${ }^{\mathrm{TM}}$ Researcher 2002 software and Matlab. Heating was done using two $1500 \mathrm{~W}$ quartz heaters at 1' distance (see Figure 4-3) for 30 seconds, 40 seconds, 50 seconds and 70 seconds for cylinder with air-filled debonds and for 70 seconds for cylinder with water-filled debonds. The reason is that water has a high specific heat capacity $\left(4180 \mathrm{~J} \mathrm{~kg}^{-1}{ }^{\circ} \mathrm{C}^{-1}\right.$ ) and hence needs higher amount of heat energy to produce the necessary thermal gradient. As soon as the heaters were turned on, heat was applied to the specimens and heat flux rate was measured. Therefore, the heat flux rate during the heating time was not constant. The total heat energy associated with 30 seconds, 40 seconds, 50 seconds and 70 seconds were 4833, 10985 , 20358 and $48928 \mathrm{~J} / \mathrm{m}^{2}$ (which is same as $\mathrm{Ws} / \mathrm{m}^{2}$ ) respectively. These heat energy values were determined by computing the area under the heat flux versus time curve. These curves are shown in Appendix A (Figures A1, A2, A3, and A4).

\subsubsection{Detection of Debonds in Cylinders Wrapped with GFRP Composite}

\subsubsection{Detection of 1" x 1" Air-Filled Debond}

Figure 5-1 to Figure 5-4 shows the infrared image taken after heating the debonded side for 30 seconds, 40 seconds, 50 seconds and 70 seconds respectively. The 1 " $\mathrm{x} 1$ ", air-filled debond as a region of higher temperature (reddish area in the infrared image) with respect to the surrounding defect-free regions for 50 seconds and 70 seconds heating time (Figure 5-3 and Figure 5-4). This is expected as air has a substantially lower 
thermal conductivity value $\left(0.024 \mathrm{Wm}^{-1} \mathrm{~K}^{-1}\right)$ compared to GFRP composite (see values in Table 4-2) and hence an air-filled debond acts as a thermal insulator. Since the heat can not conduct efficiently through the air-filled debond, the thermal energy gets trapped in the FRP layers above the debond which leads to higher surface temperature above the debonded area compared to the sound areas. It can be noted that 30 seconds and 40 seconds heating could not produce the necessary thermal difference in order to confirm the presence of an air-filled debond.

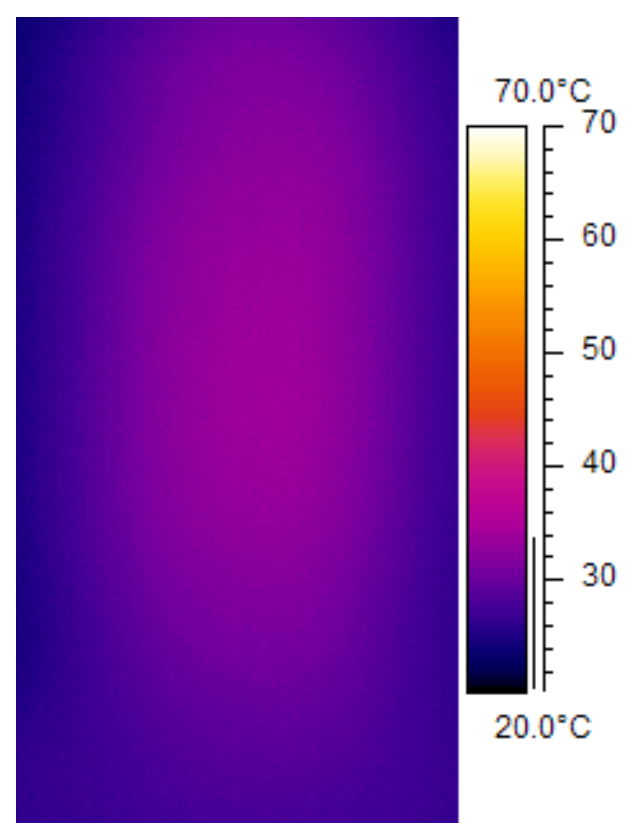

Figure 5-1 Infrared image of cylinder with 1" x 1" air-filled debond after 30 seconds of heating 


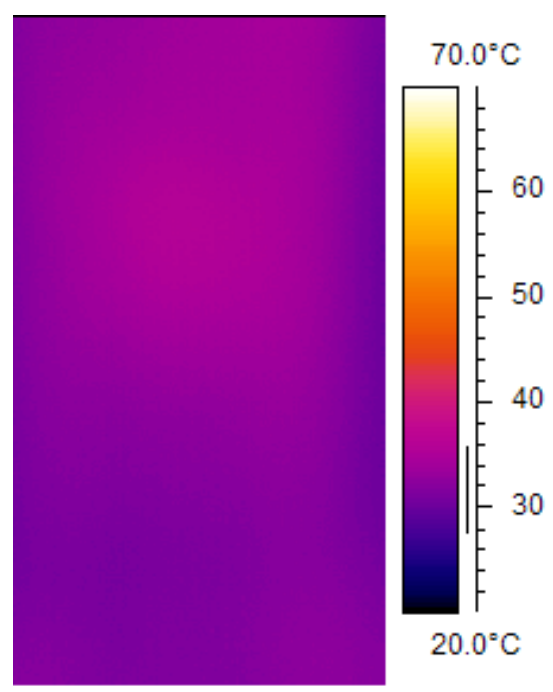

Figure 5-2 Infrared image of cylinder with 1" $x 1$ " air-filled debond after 40 seconds of heating
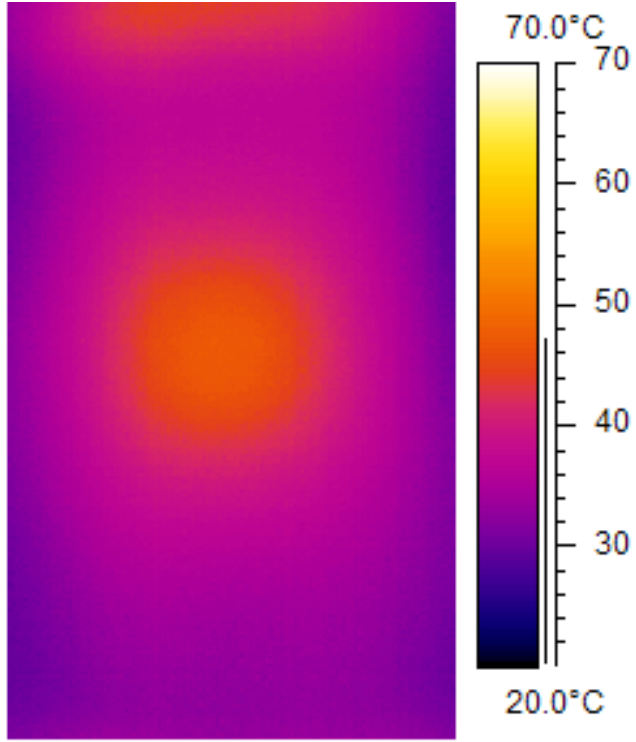

Figure 5-3 Infrared image of cylinder with 1" $x$ 1" air-filled debond after 50 seconds of heating 


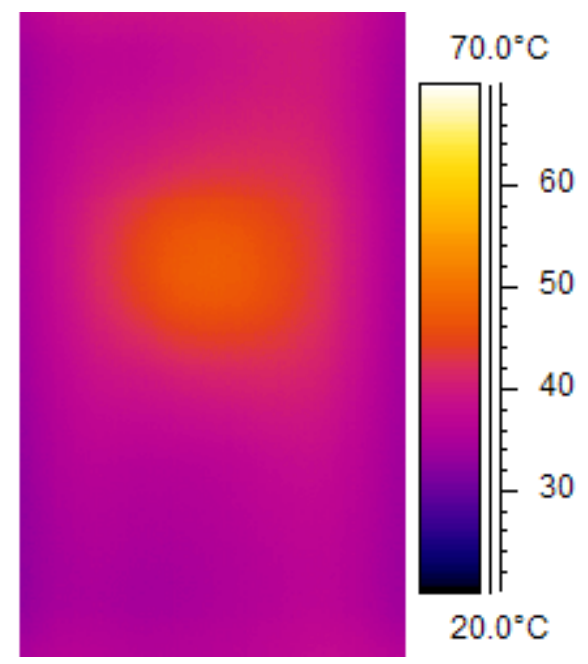

Figure 5-4 Infrared image of cylinder with 1" x 1" air-filled debond after 70 seconds of heating

\subsubsection{Detection of 1.4"' x 1.4"' Air-Filled Debond}

Figure 5-5 to Figure 5-8 shows the infrared image taken after heating the debonded side for 30 seconds, 40 seconds, 50 seconds and 70 seconds respectively. The 1.4 " x 1.4" air-filled debond appears as a region of higher temperature (reddish area in the infrared image) with respect to the surrounding defect-free regions for 70 seconds heating time (Figure 5-8). This is expected as air has a substantially lower thermal conductivity value $\left(0.024 \mathrm{Wm}^{-1} \mathrm{~K}^{-1}\right)$ compared to GFRP composite (see values in Table 4-2) and hence an air-filled debond acts as a thermal insulator. Since the heat can not conduct efficiently through the air-filled debond, the thermal energy gets trapped in the FRP layers above the debond which leads to higher surface temperature above the debonded area compared to the sound areas. It can be noted that 30 seconds, 40 seconds and 50 seconds heating could not produce the necessary thermal difference in order to confirm 


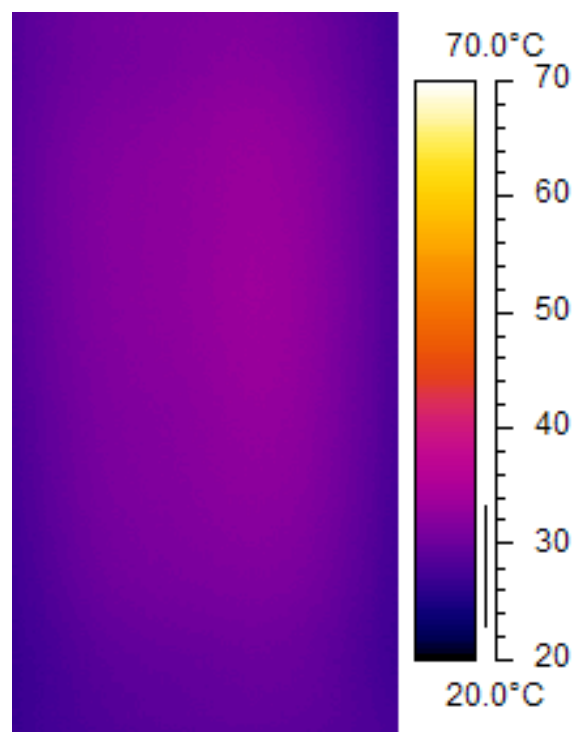

Figure 5-5 Infrared image of cylinder with 1.4" $x$ 1.4" air-filled debond after 30 seconds of heating 


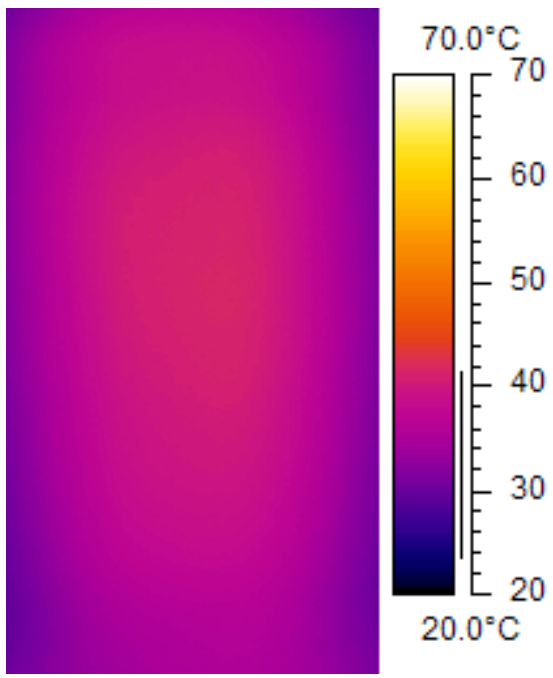

Figure 5-6 Infrared image of cylinder with 1.4" x 1.4" air-filled debond after 40 seconds of heating

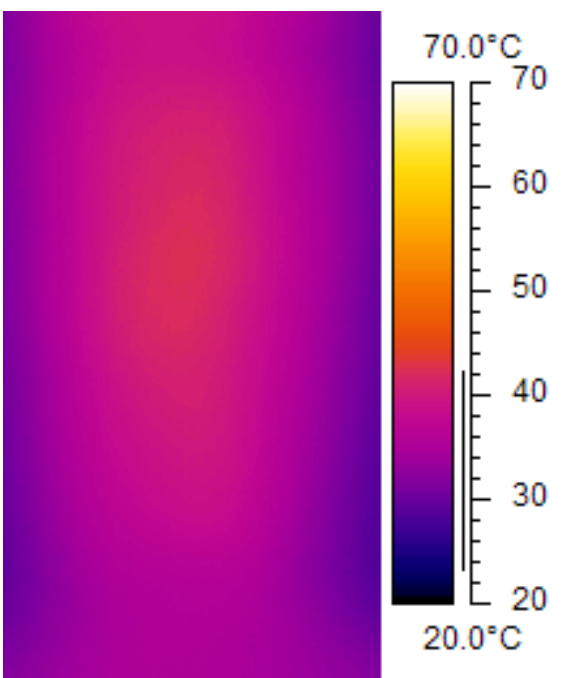

Figure 5-7 Infrared image of cylinder with 1.4" x 1.4" air-filled debond after 50 seconds of heating 


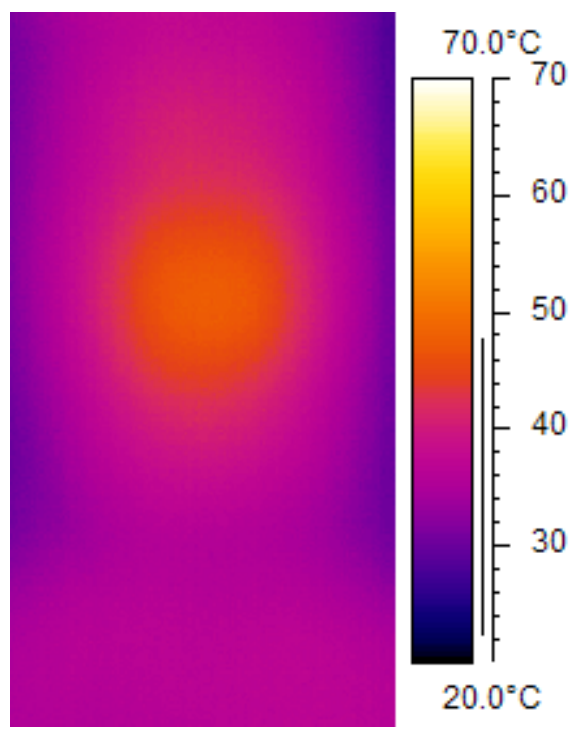

Figure 5-8 Infrared image of cylinder with 1.4" x 1.4" air-filled debond after 70 seconds of heating

\subsubsection{Detection of 2"' x 2"' Air-Filled Debond}

Figure 5-9 to Figure 5-12 shows the infrared image taken after heating the debonded side for 30 seconds, 40 seconds, 50 seconds and 70 seconds respectively. In this case also, the 2" x 2" air-filled debond was identified with ease in cacse of 70 second heating time. Fifty seconds heating also reveals the debond although to a lesser degree of clarity. The 2"' x 2", air-filled debond appears as a region of higher temperature (reddish area in the infrared images) with respect to the surrounding defect-free regions for 50 seconds and 70 seconds heating time (Figure 5-11 and Figure 5-12). This is expected as air has a substantially lower thermal conductivity value $\left(0.024 \mathrm{Wm}^{-1} \mathrm{~K}^{-1}\right)$ compared to GFRP composite (see values in Table 4-2) and hence an air-filled debond acts as a thermal insulator. Since the heat can not conduct efficiently through the airfilled debond, the thermal energy gets trapped in the FRP layers above the debond which leads to higher surface temperature above the debonded area compared to the sound areas. It can be noted that 30 seconds and 40 seconds heating could not drive enough heat into the specimen to produce the necessary thermal difference in order to confirm the presence of a debond. 


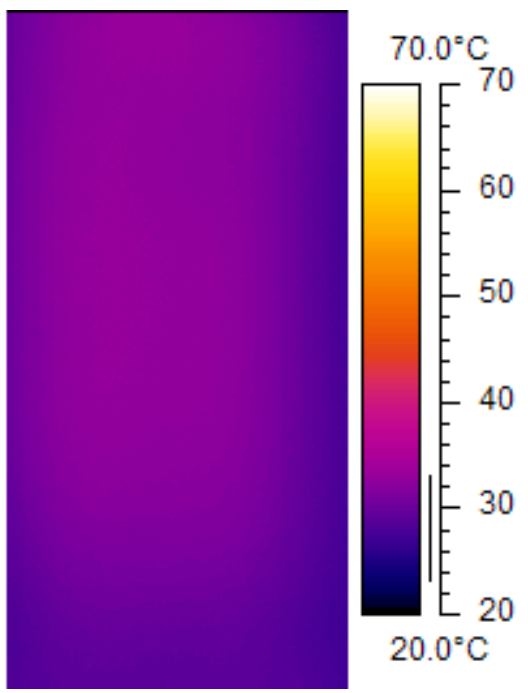

Figure 5-9 Infrared image of cylinder with 2" 12 2" air-filled debond after 30 seconds of heating

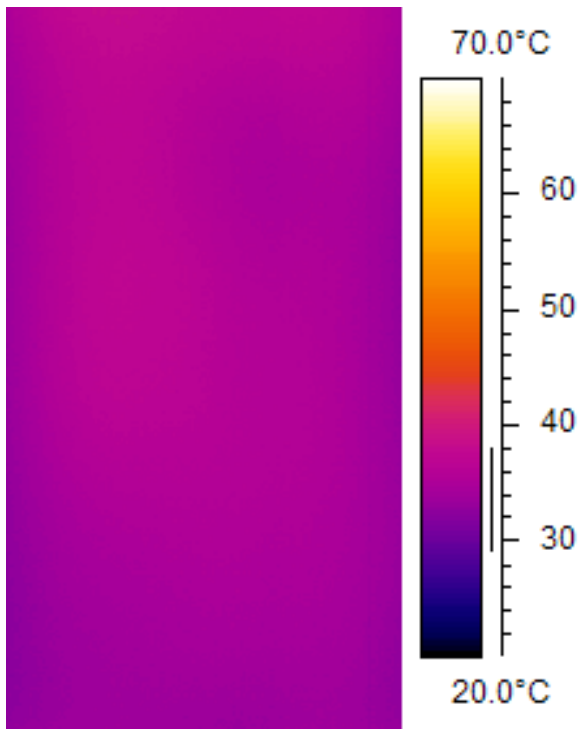

Figure 5-10 Infrared image of cylinder with 2" x 2" air-filled debond after 40 seconds of heating 


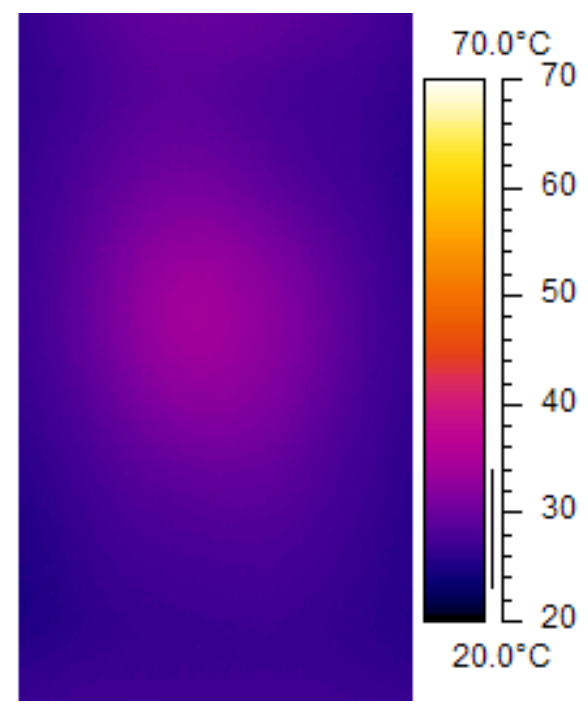

Figure 5-11 Infrared image of cylinder with 2" x 2" air-filled debond after 50 seconds of heating

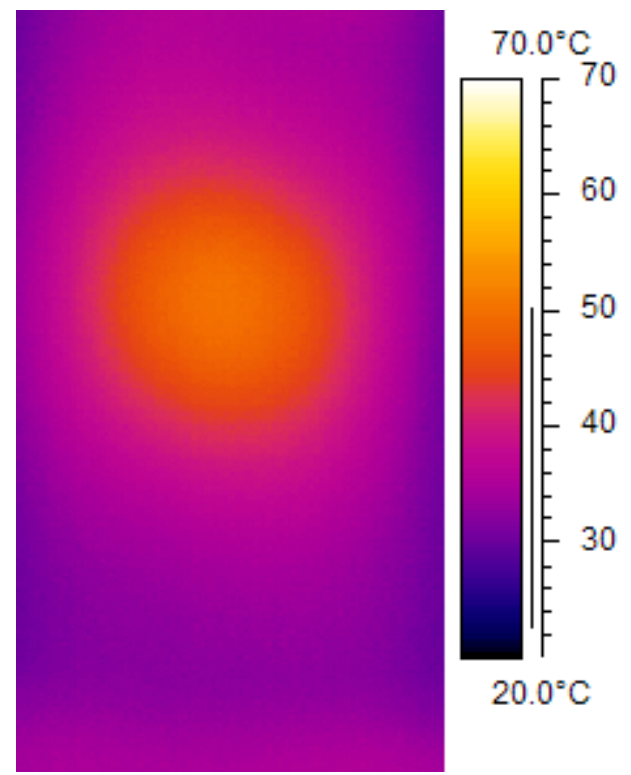

Figure 5-12 Infrared image of cylinder with 2" x 2" air-filled debond after 70 seconds of heating 


\subsubsection{Detection of 3"' x 3"' Air-Filled Debond}

Figure 5-13 to Figure 5-16 shows the infrared image taken after heating the debonded side for 30 seconds, 40 seconds, 50 seconds and 70 seconds respectively. In this case, the infrared images taken after heating the specimen 40 seconds, 50 seconds and 70 seconds (Figure 5-14, Figure 5-15 and Figure 5-16) shows the debond. Of the three infrared images, 70 seconds heating reveals the boundary of the 3"' $\mathrm{x} 3$ "' air-filled debond most clearly. Fifty seconds and 40 seconds heating also reveals the debond although to a lesser degree of clarity. The 3" x 3" air-filled debond appears as a region of higher temperature (reddish area in the infrared images) with respect to the surrounding defect-free regions for 50 seconds and 70 seconds heating time. The reason for this is already explained above.
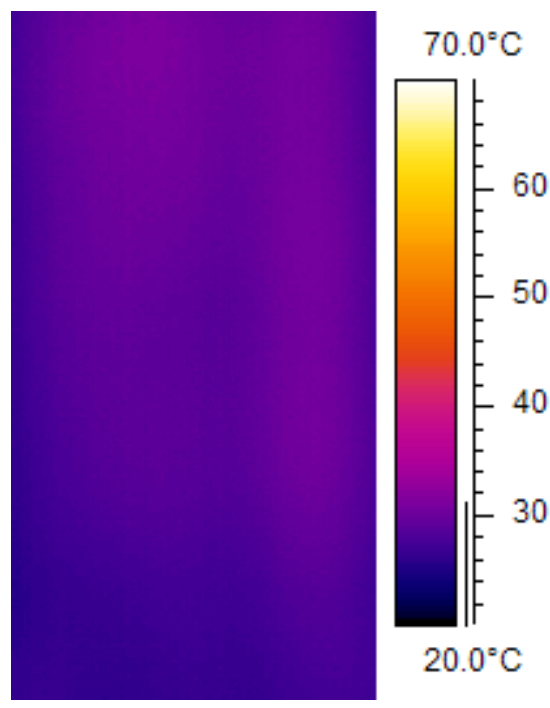

Figure 5-13 Infrared image of cylinder with 3" x 3" air-filled debond after 30 seconds of heating 


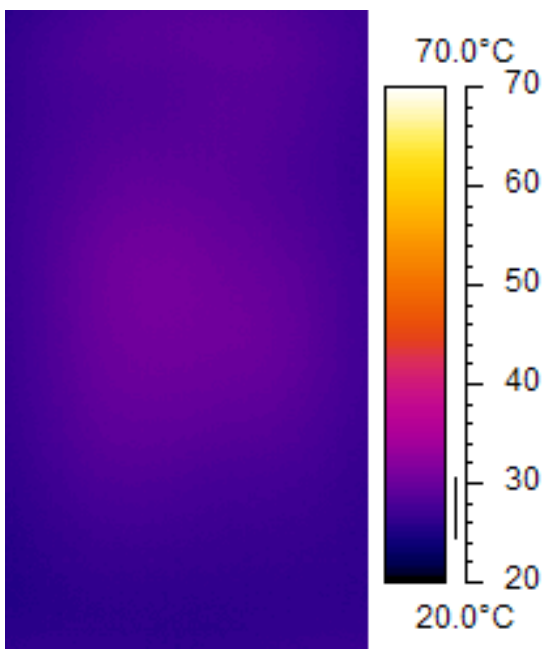

Figure 5-14 Infrared image of cylinder with 3" x 3" air-filled debond after 40 seconds of heating

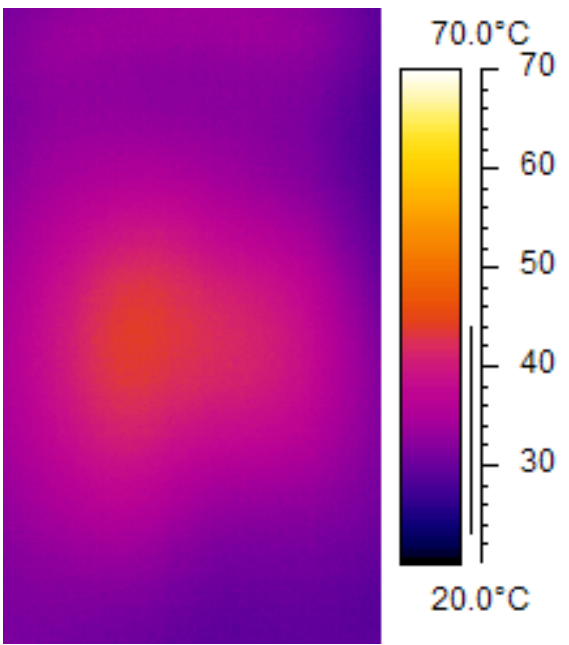

Figure 5-15 Infrared image of cylinder with 3" x 3" air-filled debond after 50 seconds of heating 


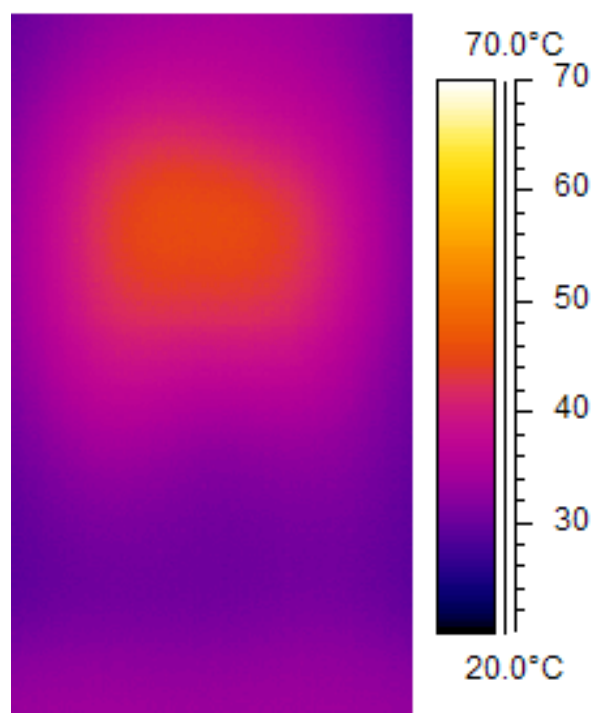

Figure 5-16 Infrared image of cylinder with 3" x 3" air-filled debond after 70 seconds of heating

\subsubsection{Detection of Water-Filled Debonds}

Water-filled debonds of the sizes i.e., 1.4' $x$ 1.4', 2'" x 2', and 3"' x 3'' could be detected by Infrared Thermography technique. As mentioned earlier, each cylinder had identical debonds placed in diametrically opposite locations to maintain symmetry. According to the principle of conductive heat transfer, a water-filled debond which has a high thermal conductivity $\left(\left(0.6 \mathrm{~W} \mathrm{~m}^{-1}{ }^{\circ} \mathrm{C}^{-1}\right)\right.$ compared to GFRP composite (see values in Table 4-2) should show up as a cold spot or in other words, surface temperature of the region above the water-filled debond should be lower compared to the surface temperature of the region above the defect-free areas. This is attributed to the fact that water has a higher thermal conductivity value $\left(0.6 \mathrm{~W} \mathrm{~m}^{-1}{ }^{\circ} \mathrm{C}^{-1}\right)$ compared to GFRP and hence conducts heat at a faster rate than the defect-free area. However, in our test, the water-filled debonds showed up as hot spots giving the indication of an air gap. This was again because of high specific value of water $\left(\left(4180 \mathrm{~J} \mathrm{~kg}^{-1}{ }^{\circ} \mathrm{C}^{-1}\right)\right.$ which meant that water stored a significant amount of heat after prolonged heating thus giving a false impression by appearing as an air-filled debond. Figure 5-17 to Figure 5-19 show the infrared images of the cylinders with water-filled debond sizes of $1.4^{\prime \prime} \times 1.4$ ', 2 '” $\mathrm{x} 2$ '' and 3' $\mathrm{x} 3$ ', where the water-filled debonds appear as "hot spots" with no clear boundary of the debonds. 


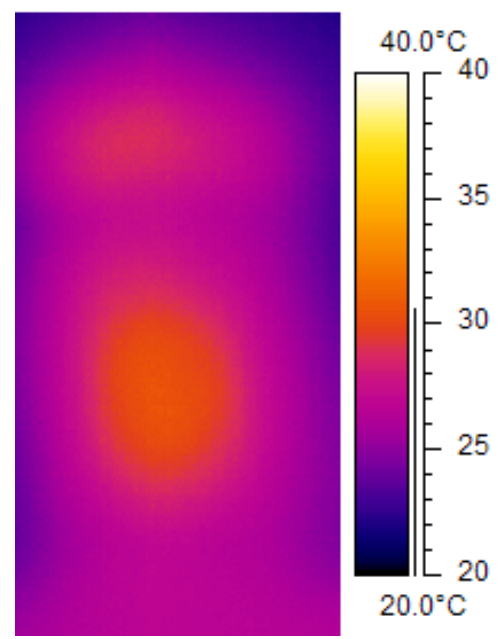

Figure 5-18 Infrared image of cylinder with 2" x 2" water-filled debond after 70 seconds of heating

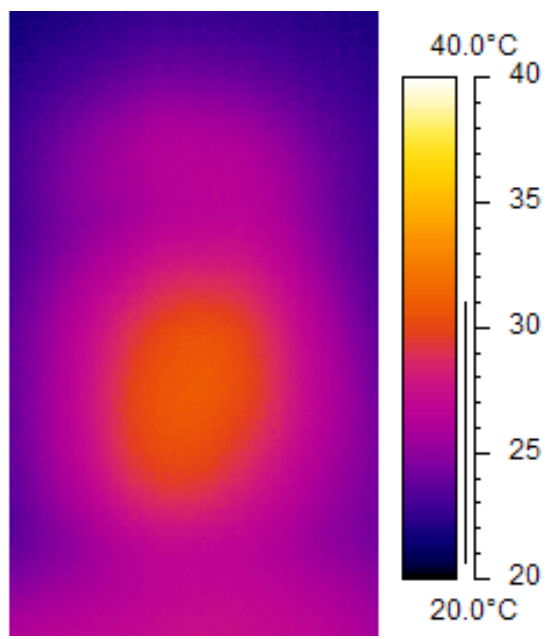

Figure 5-19 Infrared image of cylinder with 3" x 3" water-filled debond after 70 seconds of heating 


\subsubsection{Detection of Debonds in Cylinders Wrapped with CFRP Composite}

\subsubsection{Detection of 1.4' $x$ 1.4"' Air-Filled Debond}

Figure 5-20 to Figure 5-23 shows the infrared image taken after heating the debonded side for 30 seconds, 40 seconds, 50 seconds and 70 seconds respectively. Airfilled debond of size 1.4" x 1.4" inserted between the CFRP composite and concrete surface could be easily identified as a bright region (area with higher surface temperature compared to surrounding area) for 50 seconds and 70 seconds heating time. ). This is expected as air has a substantially lower thermal conductivity value $\left(0.024 \mathrm{Wm}^{-1} \mathrm{~K}^{-1}\right)$ compared to CFRP composite (see values in Table 4-2) and hence an air-filled debond acts as a thermal insulator. Since the heat can not conduct efficiently through the airfilled debond, the thermal energy gets trapped in the FRP layers above the debond which leads to higher surface temperature above the debonded area compared to the sound areas.

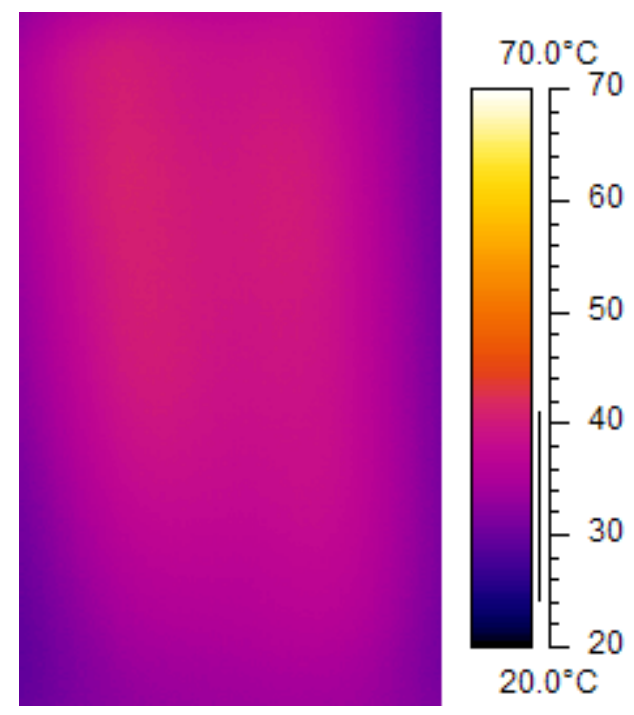

Figure 5-20 Infrared image of cylinder with 1.4" x 1.4" air-filled debond after 30 seconds of heating 

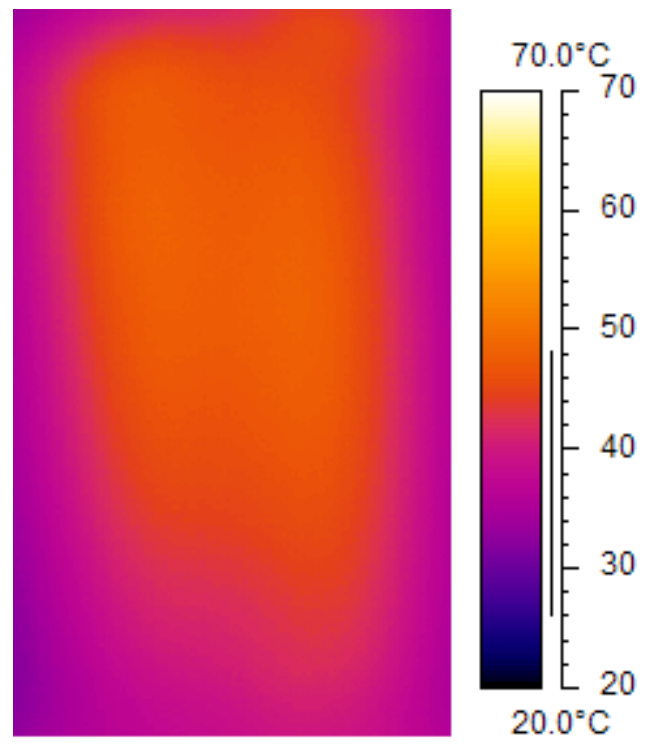

Figure 5-21 Infrared image of cylinder with 1.4" x 1.4" air-filled debond after 40 seconds of heating

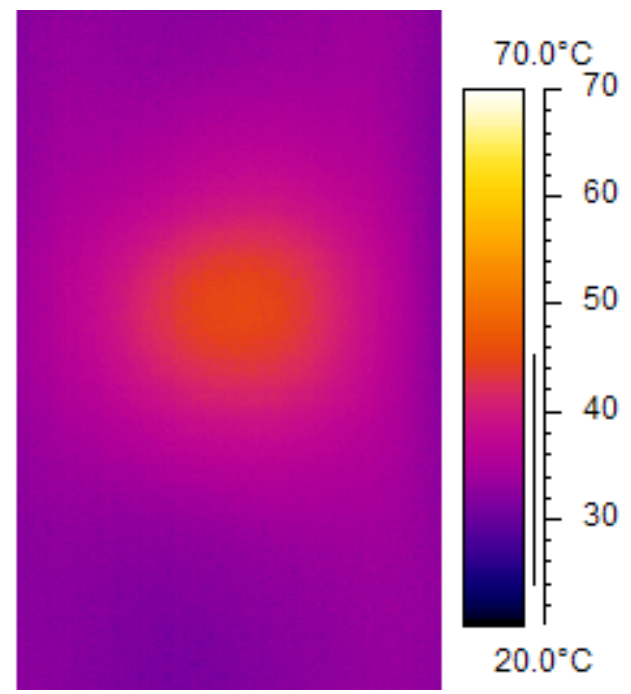

Figure 5-22 Infrared image of cylinder with 1.4" x 1.4" air-filled debond after 50 seconds of heating 


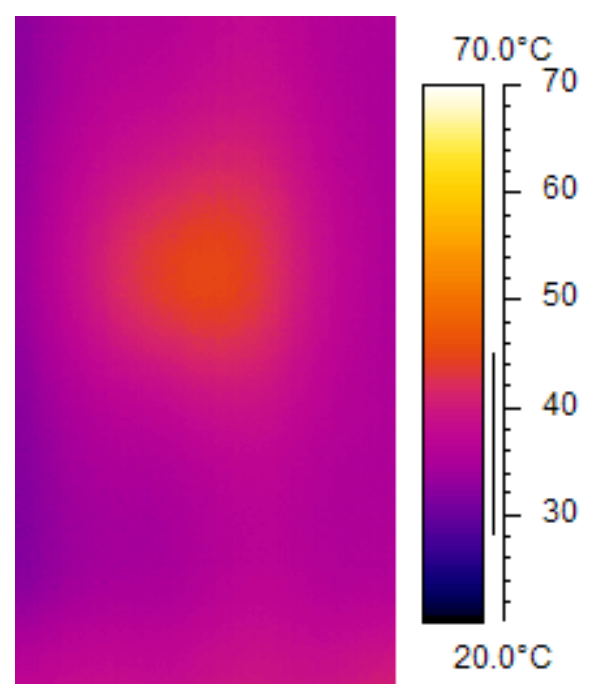

Figure 5-23 Infrared image of cylinder with 1.4" x 1.4" air-filled debond after 70 seconds of heating

\subsubsection{Detection of 2" $x$ 2" Air-Filled Debond}

Figure 5-24 to 5-27 represents the infrared images taken after heating the debonded side for 30 seconds, 40 seconds, 50 seconds and 70 seconds respectively. In this case also, only 50 seconds and 70 seconds heating time could produce the necessary thermal difference to specify the air-filled debond.
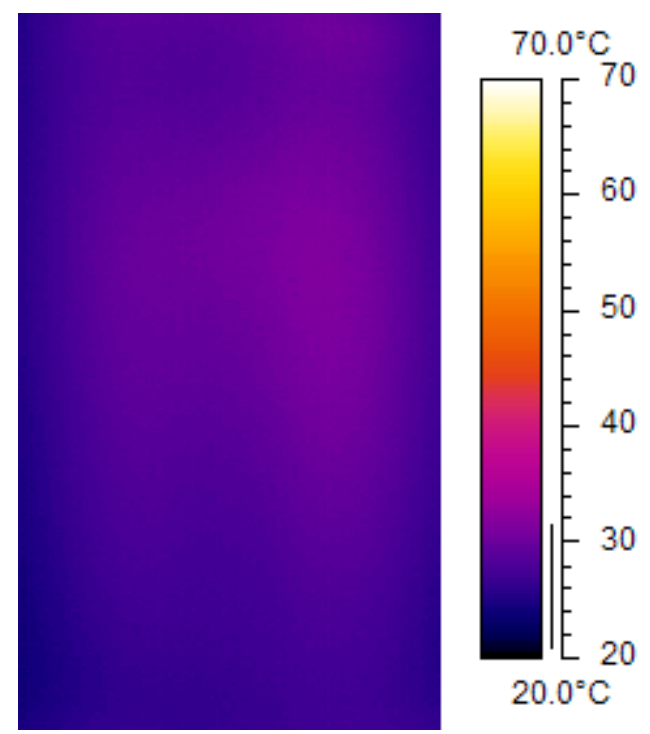

Figure 5-24 Infrared image of cylinder with 2" x 2" air-filled debond after 30 seconds of heating 


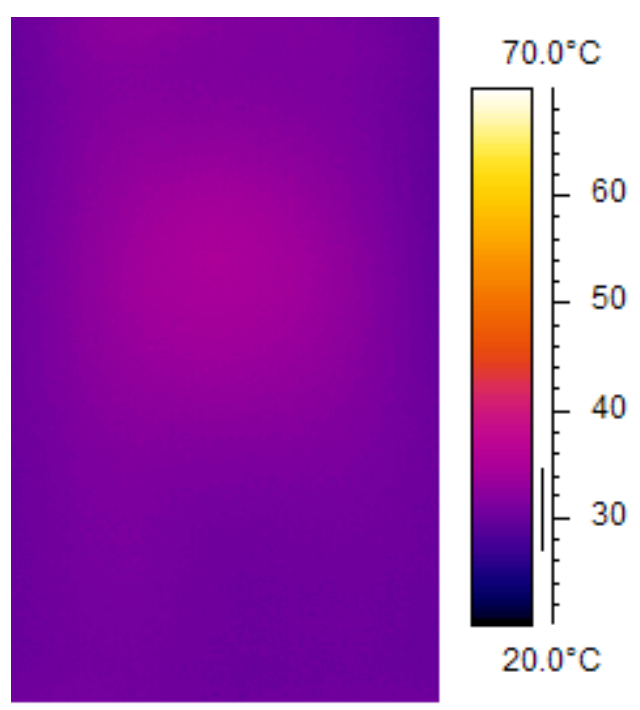

Figure 5-25 Infrared image of cylinder with 2" x 2" air-filled debond after 40 seconds of heating

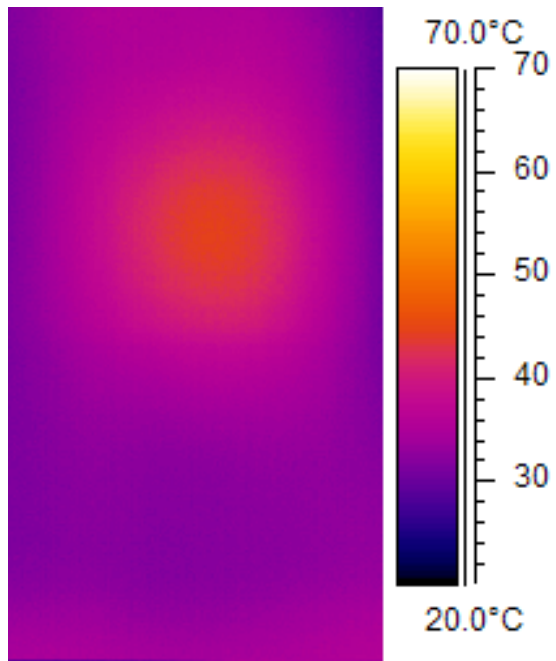

Figure 5-26 Infrared image of cylinder with 2" x 2" air-filled debond after 50 seconds of heating 


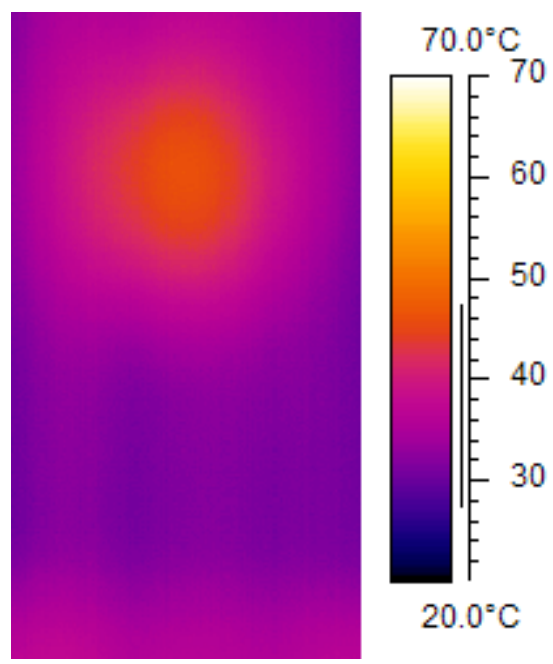

Figure 5-27 Infrared image of cylinder with 2" x 2" air-filled debond after 70 seconds of heating

\subsubsection{Detection of 3"' $x$ 3"' Air-Filled Debond}

Figure 5-28 to 5-31 represents the infrared images taken after heating the debonded side for 30 seconds, 40 seconds, 50 seconds and 70 seconds respectively. The 3" x 3" air-filled debond appears as a region of higher temperature (bright area in the infrared images) with respect to the surrounding defect-free regions for 50 seconds and 70 seconds heating time.
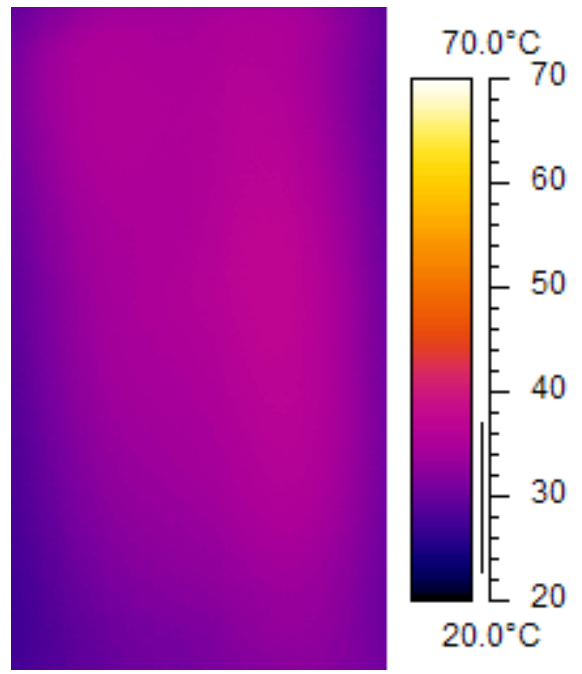

Figure 5-28 Infrared image of cylinder with 3" x 3" air-filled debond after 30 seconds of heating 


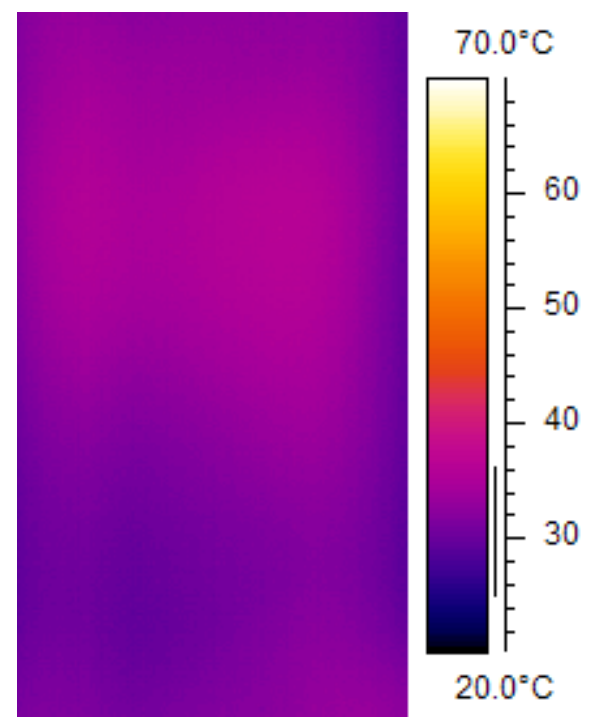

Figure 5-29 Infrared image of cylinder with 3" x 3" air-filled debond after 40 seconds of heating

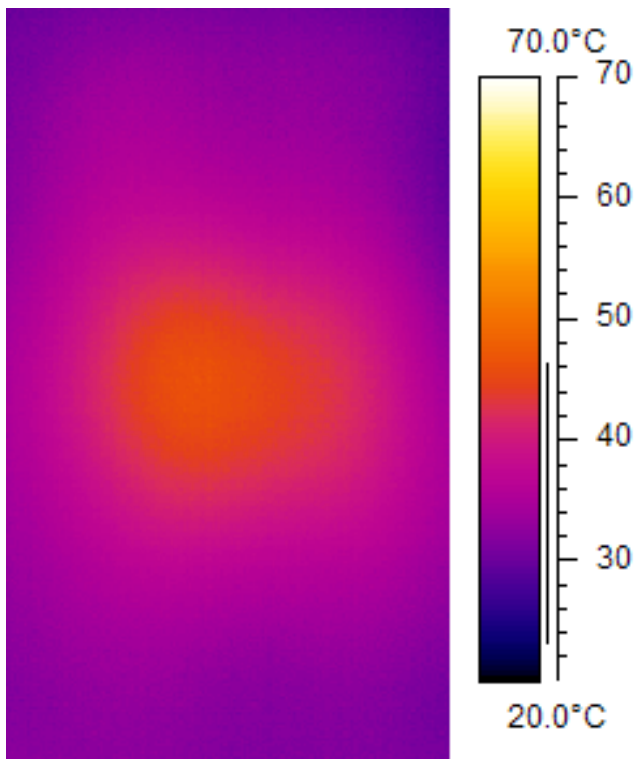

Figure 5-30 Infrared image of cylinder with 3" x 3" air-filled debond after 50 seconds of heating 


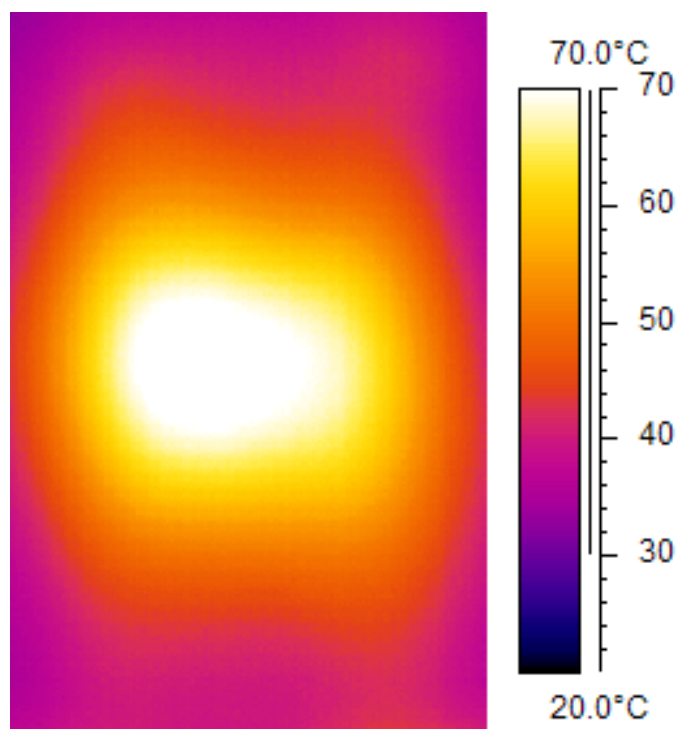

Figure 5-31 Infrared image of cylinder with 3" x 3" air-filled debond after 70 seconds of heating

\subsubsection{Detection of Water-Filled Debonds}

Water-filled debonds were also detected as "hot spots" by the Infrared Thermography technique. After the heating of 70 seconds, the water-filled debonds showed up as regions of higher temperature. This phenomenon was explained above and has more to do with water's high specific heat rather than its thermal conductivity.

Infrared images of cylinder no having water-filled debonds of sizes 1.4' $\mathrm{x} 1.4$ ', 2'" x 2'" and 3' x 3'" are shown from Figure 5-32 to 5-34 where the water-filled debonds appear as 'hot spots'. Also, in these CFRP wrapped cylinders, the observed "hot spot" is larger for the larger debond. For 70 seconds heating, the maximum surface temperature above the air-filled debonds of sizes 1.4" x 1.4", 2"' x 2'" and 3"' x 3"' were $91.3{ }^{\circ} \mathrm{C}, 89.4$ ${ }^{\circ} \mathrm{C}$ and $115.2{ }^{\circ} \mathrm{C}$ respectively. For the same heating time, the maximum surface temperature above the water-filled debonds of sizes 1.4" x 1.4", 2"' x 2"' and 3" x 3"' were $59{ }^{\circ} \mathrm{C}, 53.5{ }^{\circ} \mathrm{C}$ and $55.6{ }^{\circ} \mathrm{C}$ respectively. This clearly shows the effect of higher specific heat of water. 


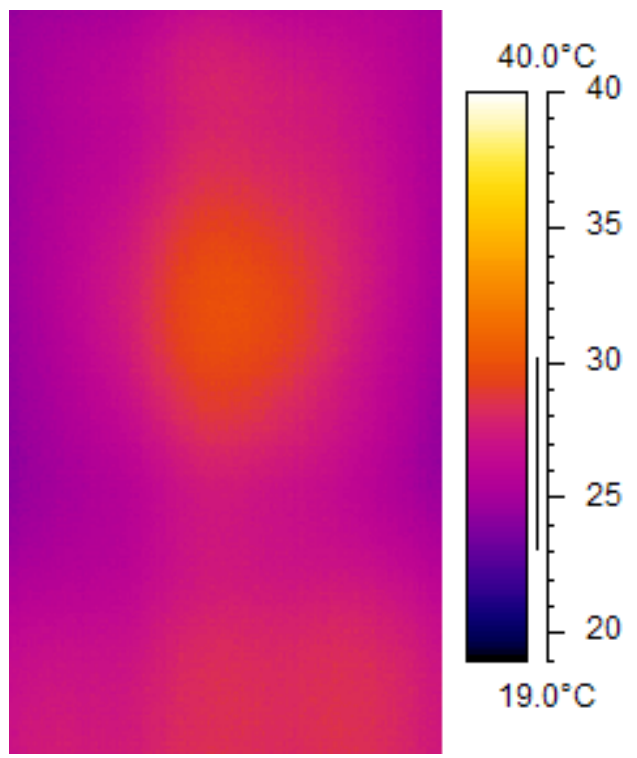

Figure 5-32 Infrared image of cylinder with 1.4" x 1.4" water-filled debond after 70 seconds of heating
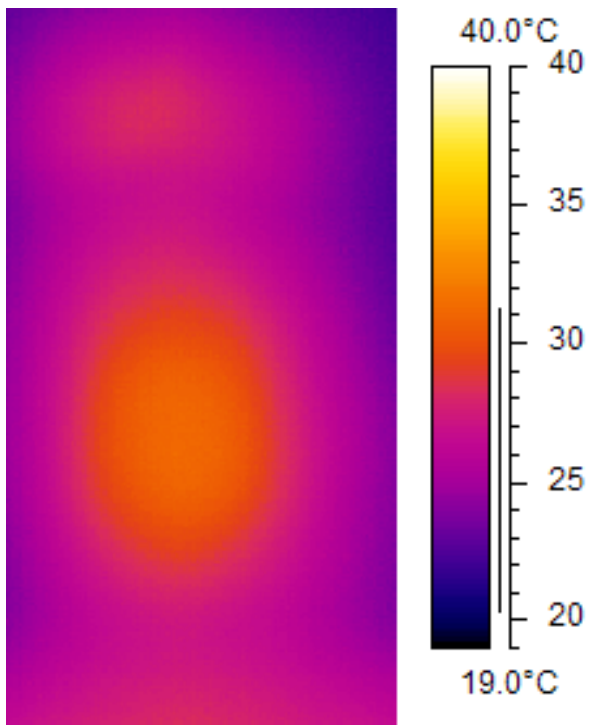

Figure 5-33 Infrared image of cylinder with 2" x 2" water-filled debond after 70 seconds of heating 


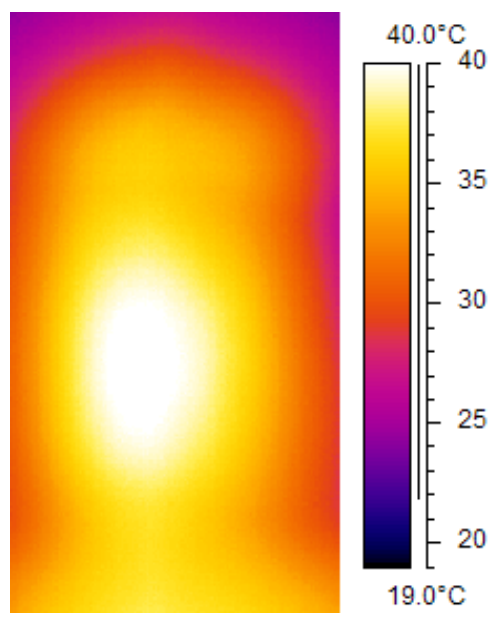

Figure 5-34 Infrared image of cylinder with 3" x 3" water-filled debond after 70 seconds of heating

\subsubsection{Conclusions}

Digital Infrared Thermography successfully detected the presence of air-filled debonds of sizes 3" x 3", 2" x 2", 1.4" x 1.4" and 1" x 1" in concrete columns wrapped with CFRP and GFRP composite. Fifty and seventy seconds heating proved to be adequate in detecting the debonds. Also, water-filled debonds appeared as air debonds or 'hot spots'. This is due to the fact that the thickness of the FRP wraps were very small and hence even a small amount of heat that was applied was quickly absorbed by waterfilled debonds, resulting in hot spots above the debond. It can be noted that if the size of the debond is larger than the field of view of the camera, the reference defect free area against which the relative temperature of debond is measured will no longer be available. Hence, such debonds could remain undetected.

\subsection{PARAMETRIC STUDY USING INFRARED THERMOGRAPHY}

The objective of this portion of the research was to evaluate the effect of various parameters in the transient heat transfer phenomenon. It is necessary in order to develop a proper understanding of the complex three dimensional heat transfer phenomenon and eventually to interpret the infrared thermography data effectively. The two most important parameters relevant to defect detection using infrared thermography are thermal difference and thermal contrast. Thermal difference is defined as

$$
\Delta \mathrm{T}=\mathrm{T}_{\text {defect-free }}-\mathrm{T}_{\text {debond }}
$$


where $\mathrm{T}_{\text {defect-free }}$ is the surface temperature above the defect-free area (reference area) and $\mathrm{T}_{\text {debond }}$ is the surface temperature above the debond.

Thermal contrast is defined as

$$
\mathrm{C}=\Delta \mathrm{T} / \mathrm{T}_{\text {defect-free }}
$$

where $\Delta \mathrm{T}$ is thermal difference and $\mathrm{T}_{\text {defect-free }}$ is surface temperature above the defect-free area (reference area)

\subsubsection{Effect of Heat Flux}

The effect of heat flux for both CFRP and GFRP composite wrapped cylinders was evaluated using the cylinders having a 2" x 2" air-filled debond. Figure 5-35 and Figure 5-36 represents effect of heat duration and energy input on maximum thermal difference in case of GFRP composite wrapped cylinder respectively. As seen from the graphs, maximum thermal difference increases as heat flux increases. This is because more the amount of heat driven into the specimen, the defective region stores more heat within it resulting in increased value of maximum thermal difference. Also we can see that variation of maximum thermal difference is sharper in GFRP composite wrapped cylinders than in CFRP composite wrapped cylinders because diffusivity value of CFRP composite is higher than GFRP composite.

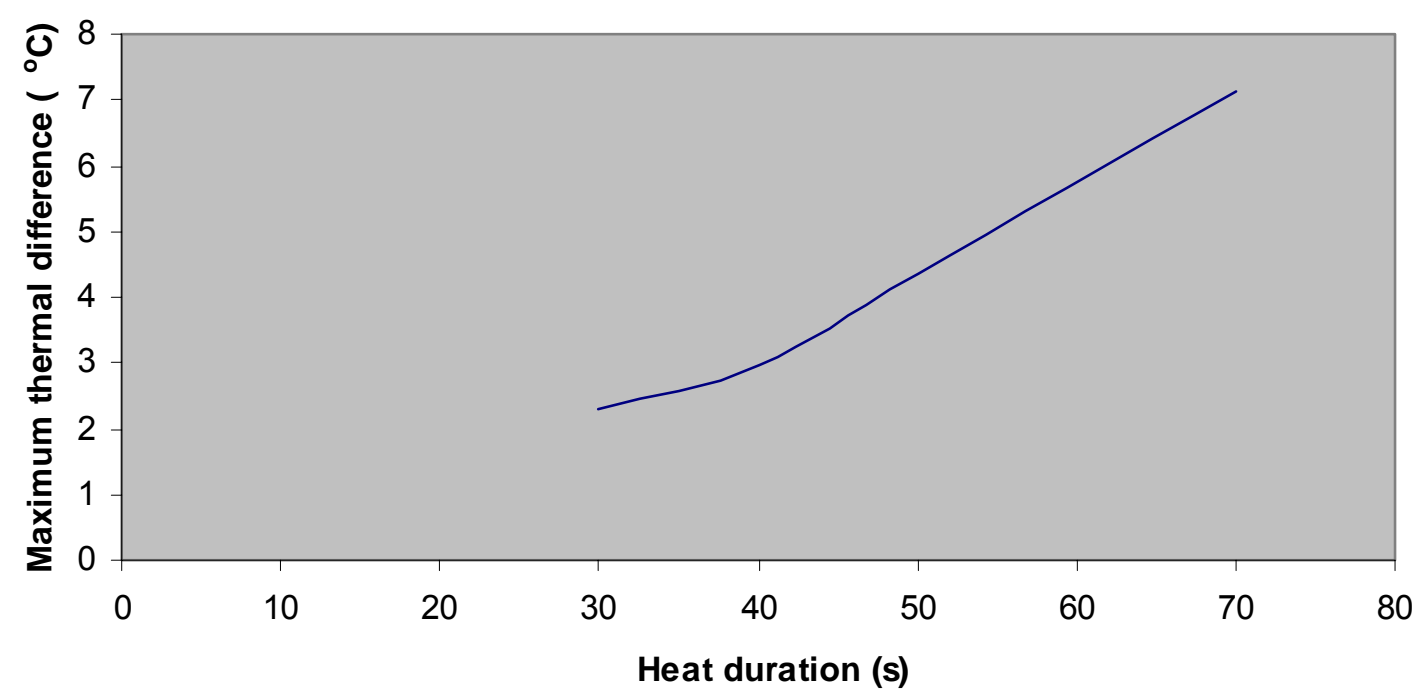

Figure 5-35 Effect of heat duration on maximum thermal difference for cylinders wrapped with GFRP composite 


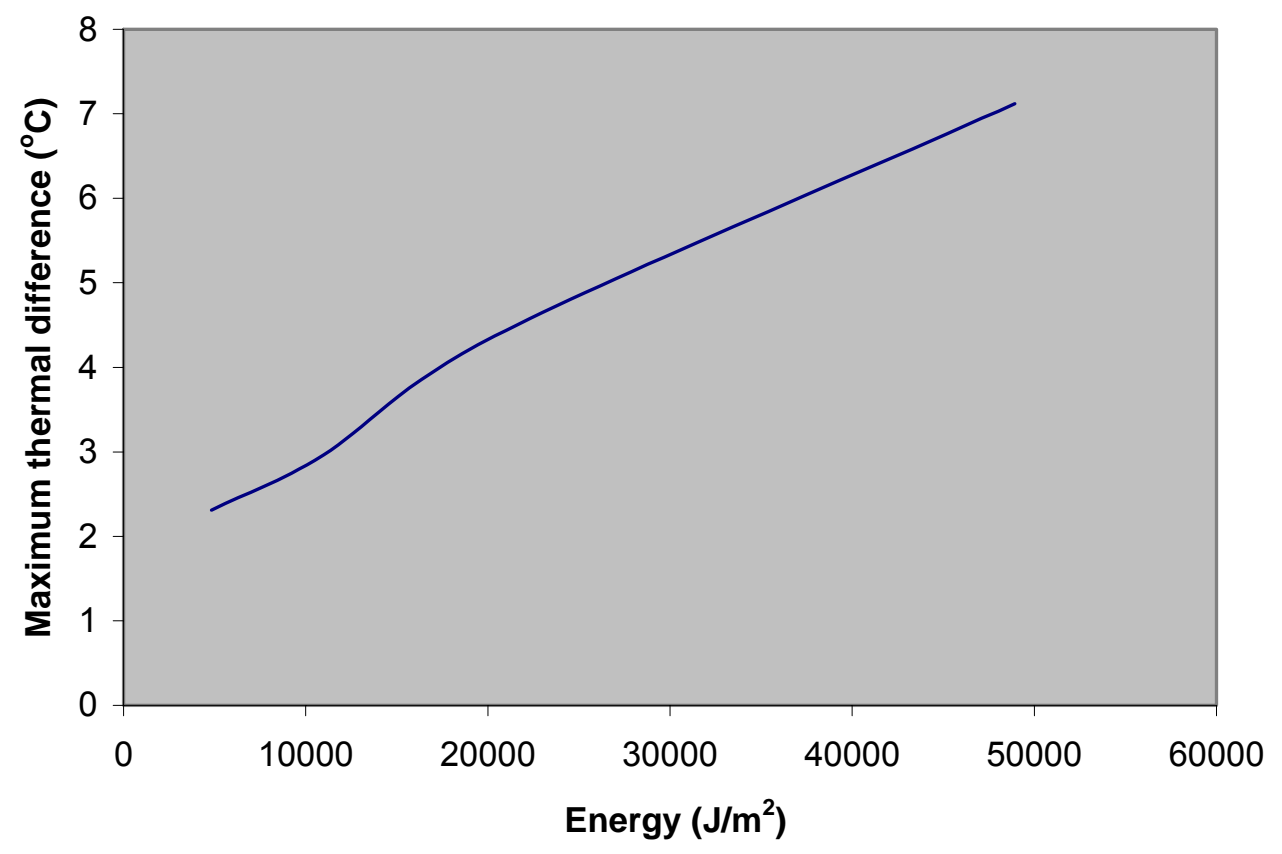

Figure 5-36 Effect of energy input on maximum thermal difference for cylinders wrapped with GFRP composite

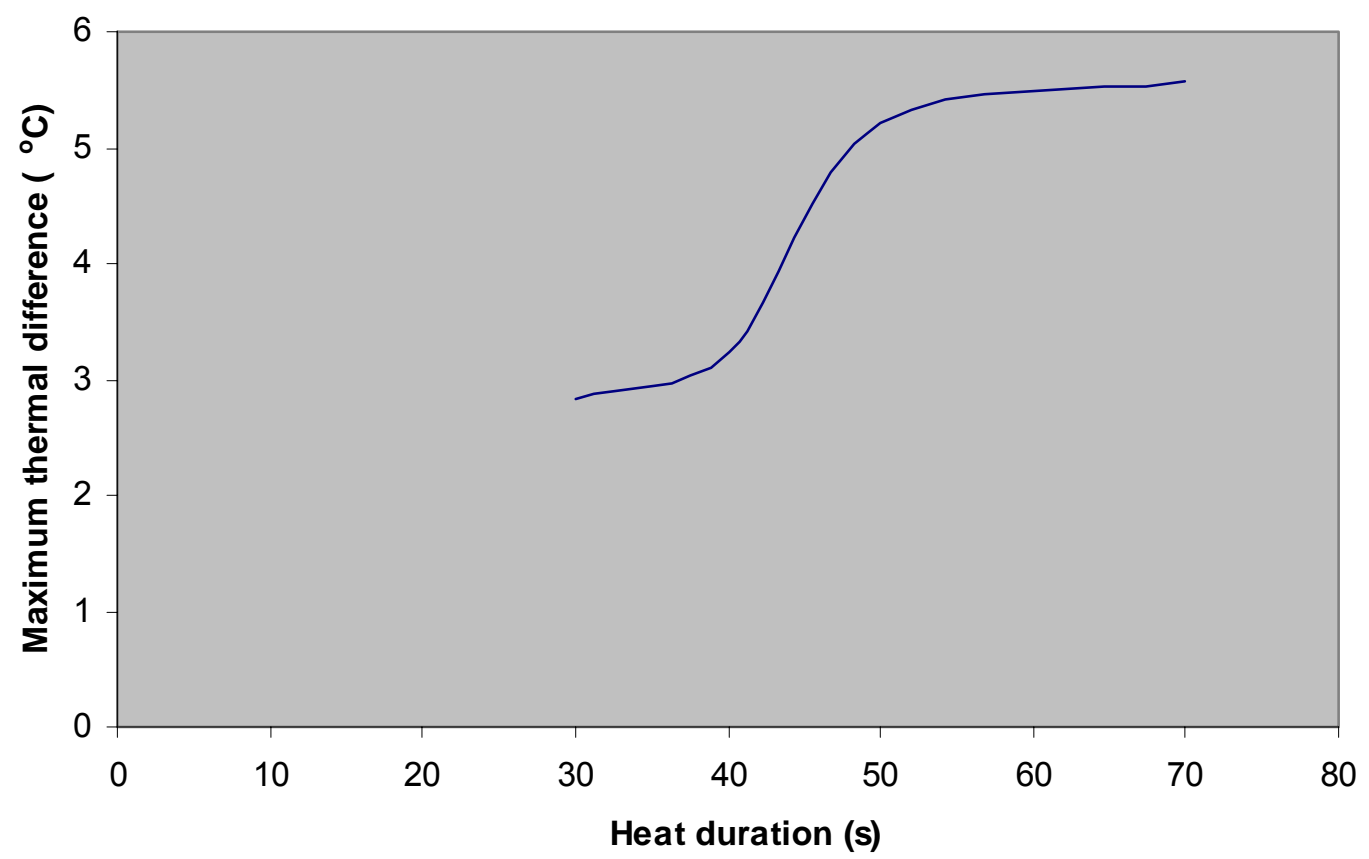

Figure 5-37 Effect of heat duration on maximum thermal difference for cylinders wrapped with CFRP composite 


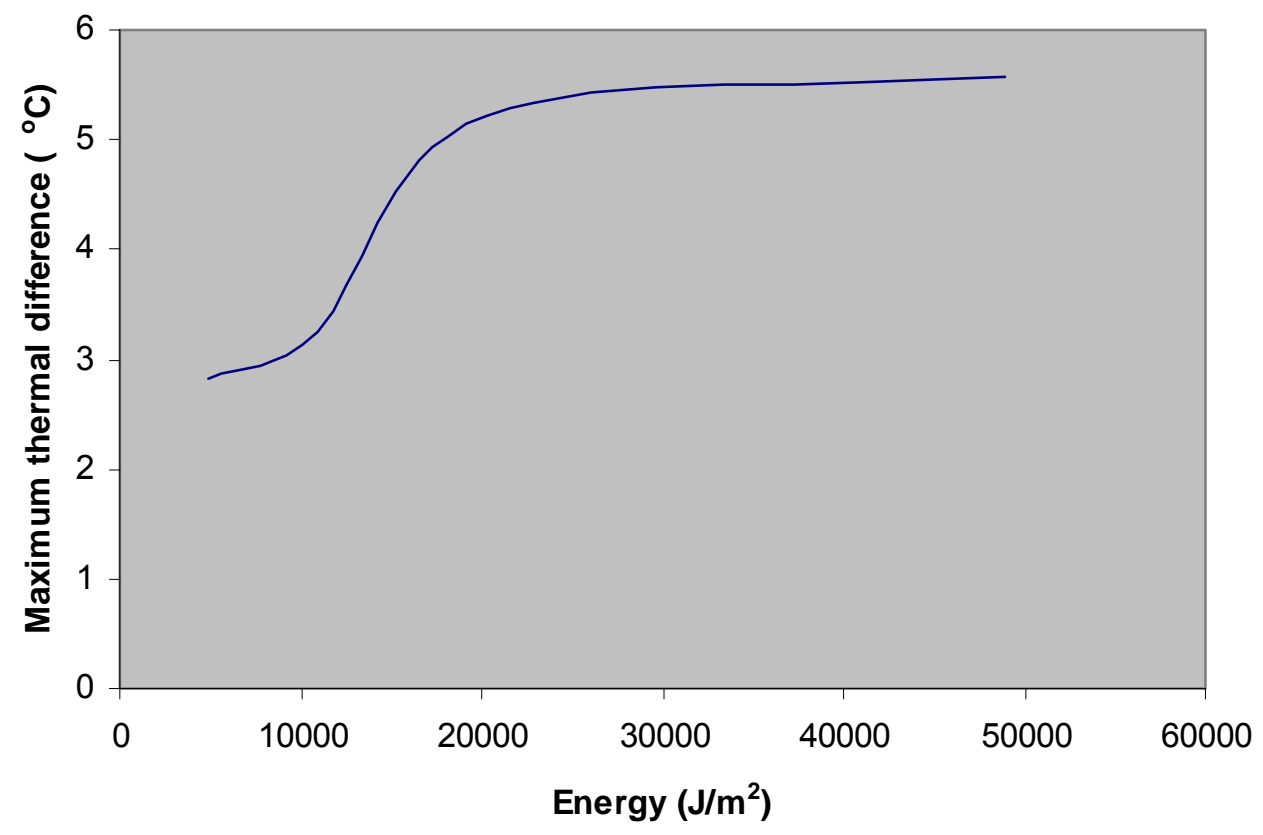

\section{Figure 5-38 Effect of energy input on maximum thermal difference for cylinders wrapped with CFRP composite}

Figure 5-37 and Figure 5-38 shows the effect of heat duration and energy input on maximum thermal difference in case of CFRP composite wrapped cylinder respectively. For both the cases we see that maximum thermal difference increases with the heat duration and energy input. Figure 5-39 and Figure 5-40 shows the influence of heat duration and energy input on maximum thermal contrast in case of GFRP composite wrapped cylinder respectively. As evident from the graphs, maximum thermal contrast also increases with increase in heat duration and energy input. Figure 5-41 and Figure 542 shows the how maximum thermal contrast depends on heat duration and energy input in case of CFRP composite wrapped cylinder respectively. As we see, the maximum thermal contrast also increases with increase in heat duration and energy input except for the 50 seconds heat duration and the corresponding energy input. 


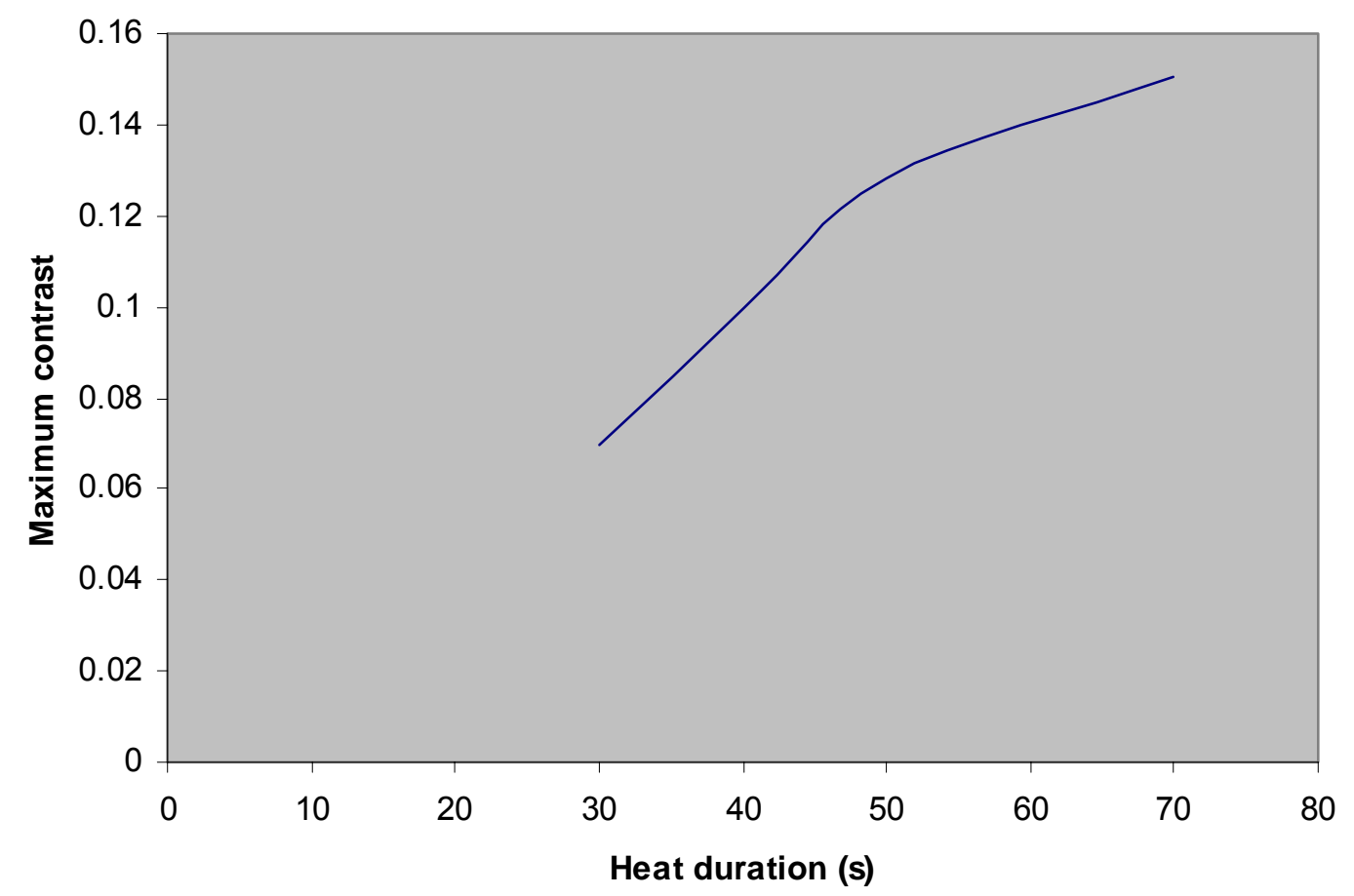

Figure 5-39 Effect of heat duration on maximum thermal contrast for cylinders wrapped with GFRP composite

Figure 5-43 and Figure 5-44 shows the variation of time for maximum contrast with energy for GFRP and CFRP composite wrapped cylinders respectively. As evident from the curves, the variation is almost linear for both the cases. In almost all cases in this study, maximum thermal difference and maximum thermal contrast occurred not immediately after the removal of the heat source but after a while. This is because immediately after removal of the heat source the diffusion of heat from the defect free and defective region is almost the same. But after sometime the diffusion of heat at the defect free region becomes greater than the defective region because of the obstruction of heat by the flaw. Hence the time for maximum contrast increases with an increase in input flux. Also we can see that time for maximum contrast is more for cylinders wrapped with GFRP composite than the ones wrapped with CFRP composite. This is because of the higher thermal diffusivity value of CFRP composite. 


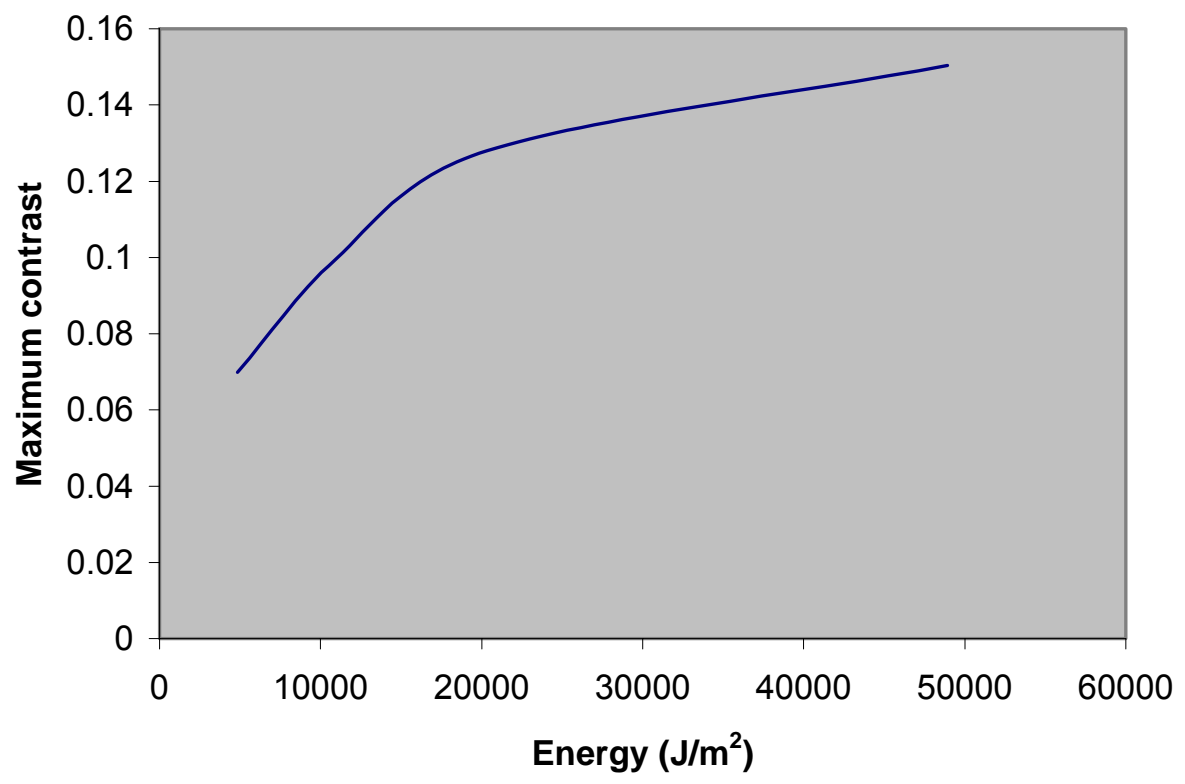

Figure 5-40 Effect of energy input on maximum thermal contrast for cylinders wrapped with GFRP composite

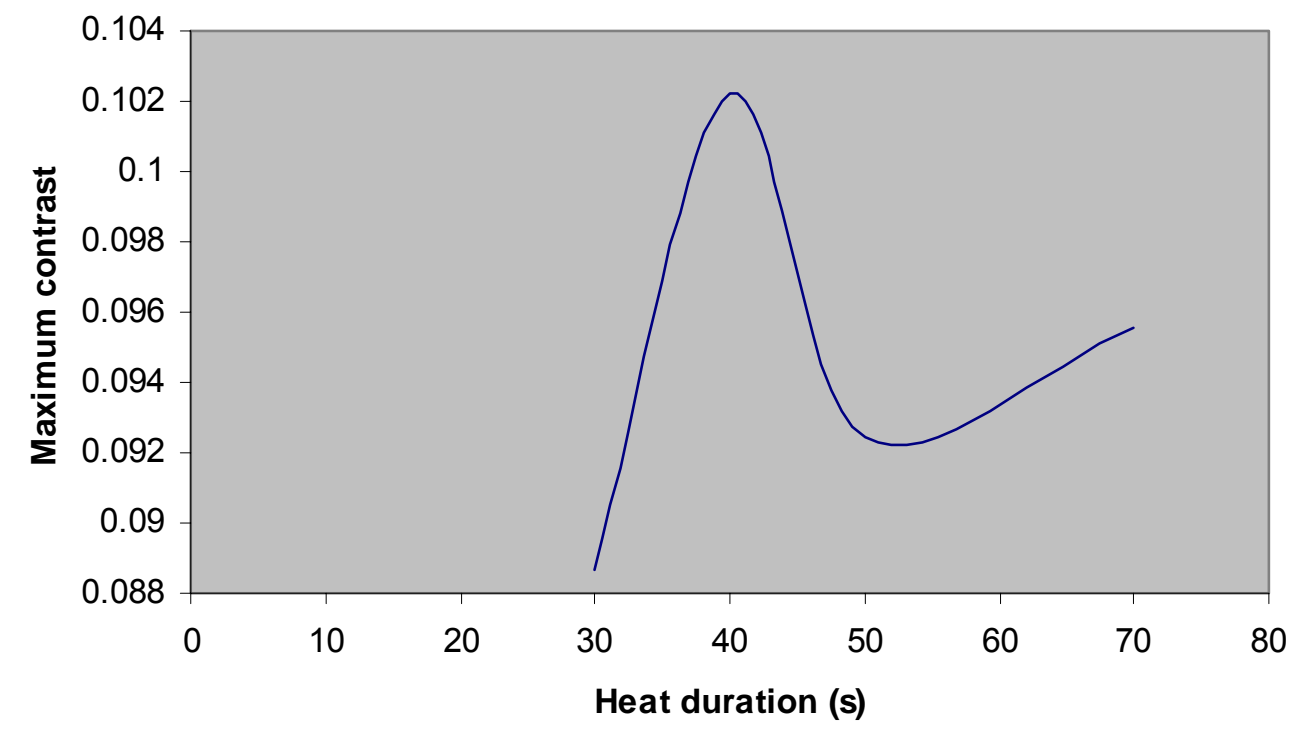

Figure 5-41 Effect of heat duration on maximum thermal contrast for cylinders wrapped with CFRP composite 


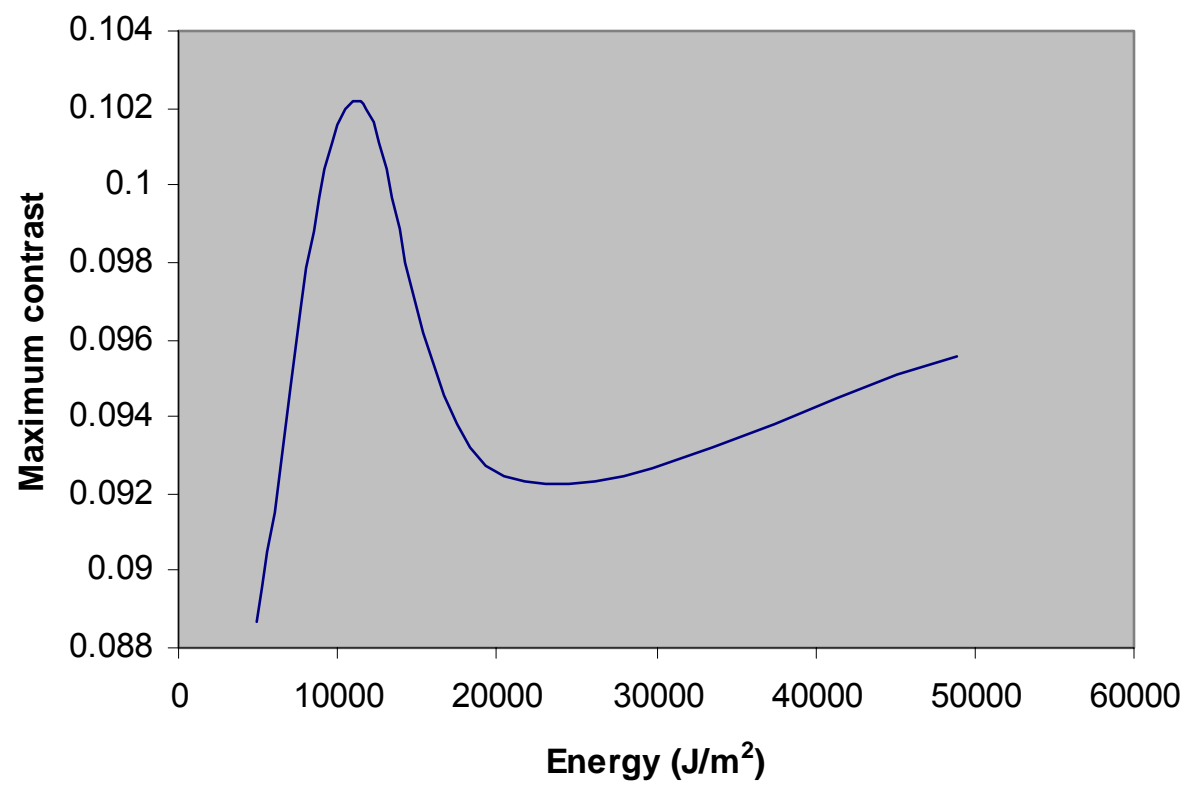

Figure 5-42 Effect of energy input on maximum thermal contrast for cylinders wrapped with CFRP composite

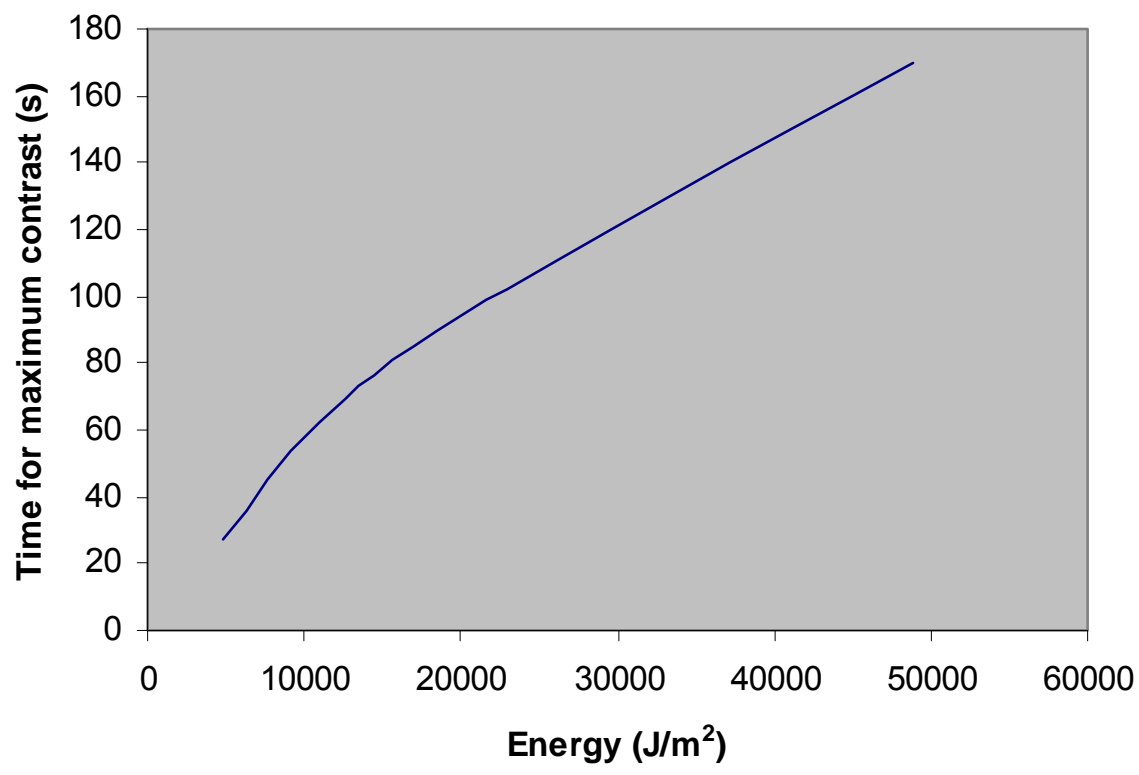

Figure 5-43 Effect of energy input on time for maximum thermal contrast for cylinders wrapped with GFRP composite 


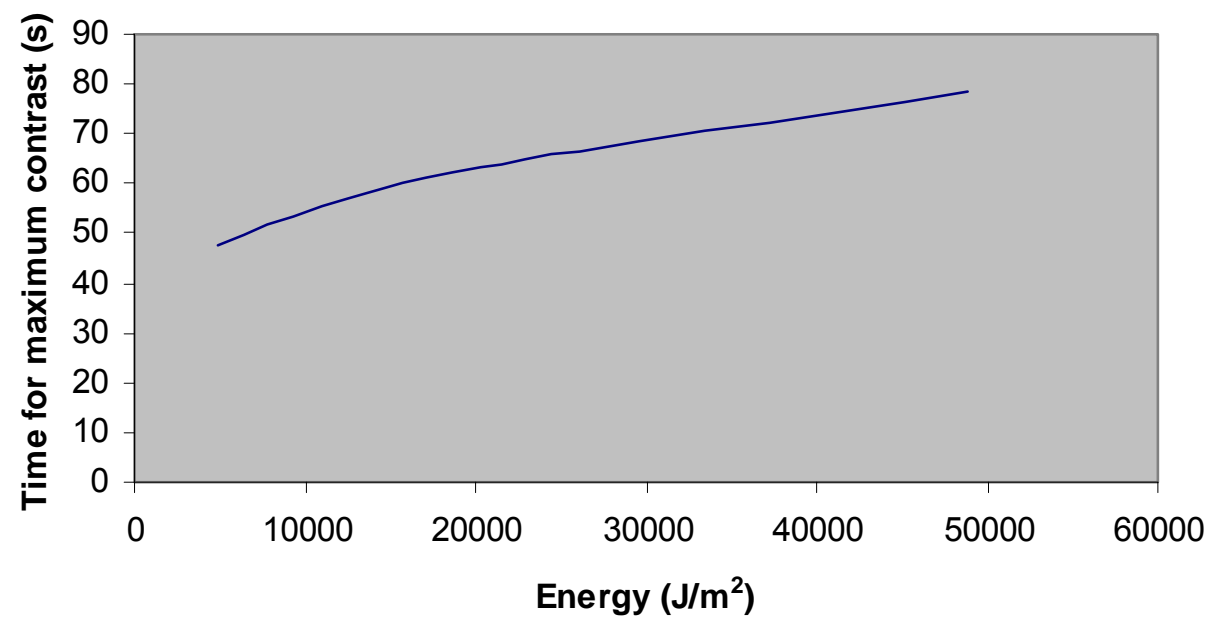

Figure 5-44 Effect of energy input on time for maximum thermal contrast for cylinders wrapped with CFRP composite

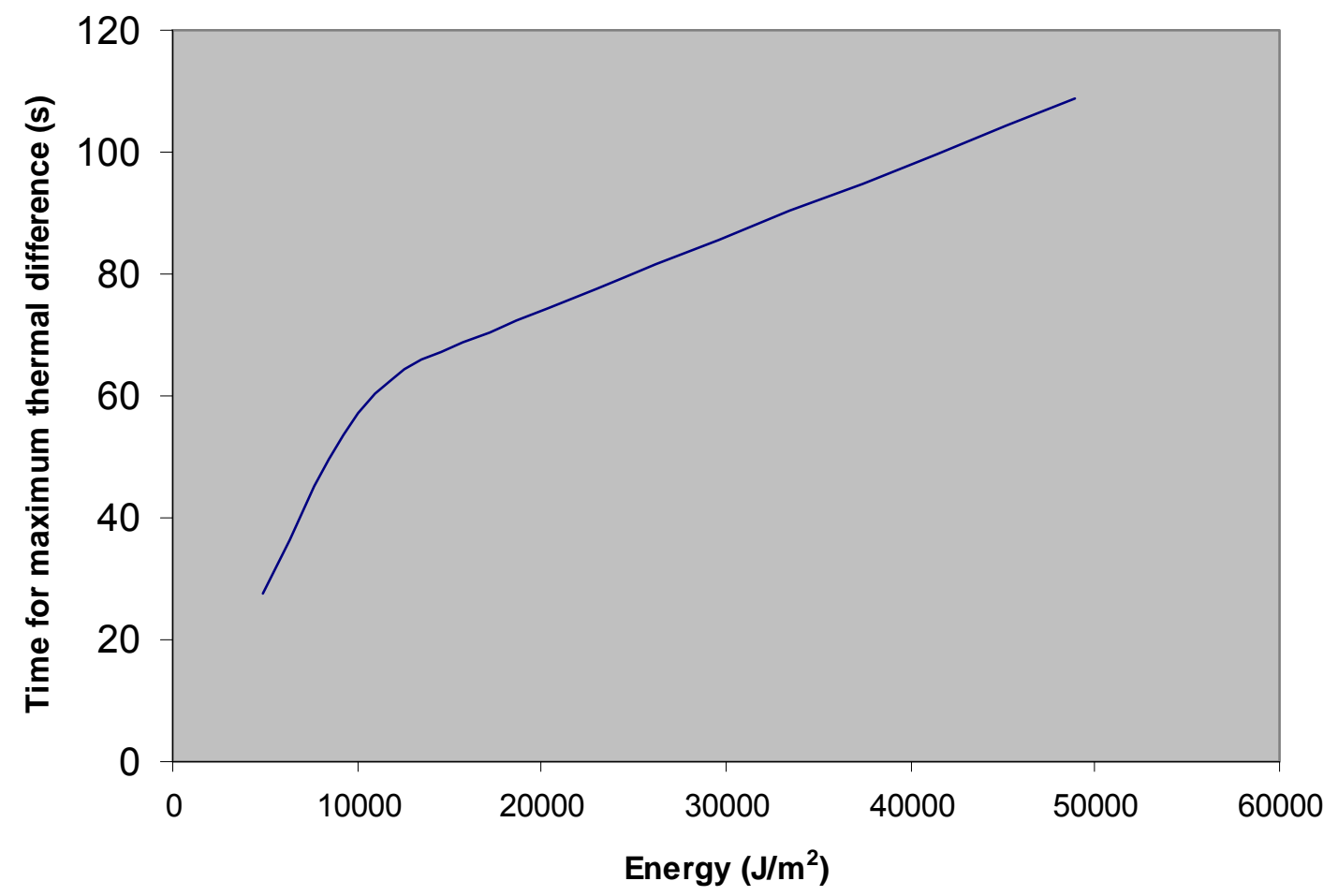

Figure 5-45 Effect of energy input on time for maximum thermal difference for cylinders wrapped with GFRP composite 


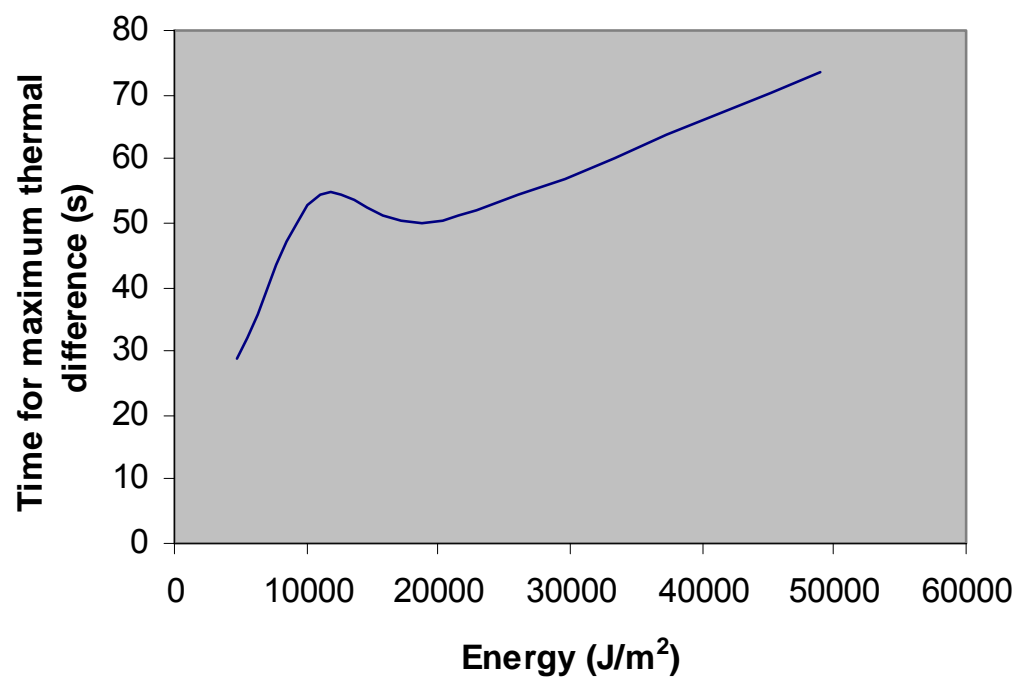

Figure 5-46 Effect of energy input on time for maximum thermal difference for cylinders wrapped with CFRP composite

Figure 5-45 and Figure 5-46 shows the influence of energy input on time for maximum thermal difference cylinders wrapped with GFRP and CFRP composites respectively.

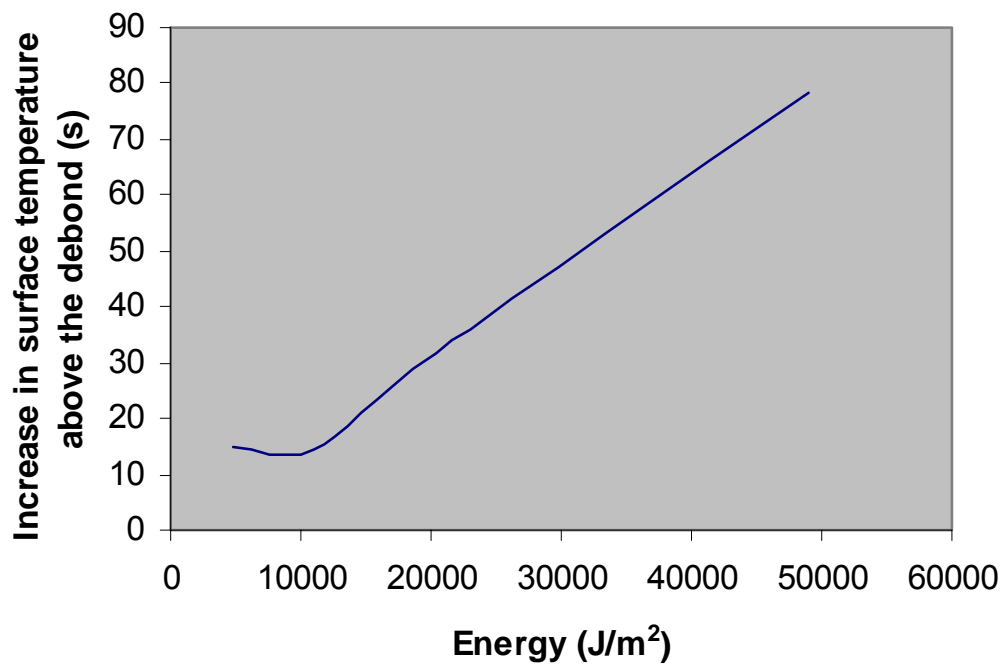

Figure 5-47 Effect of energy input on increase in surface temperature above the debond for cylinders wrapped with GFRP composite 


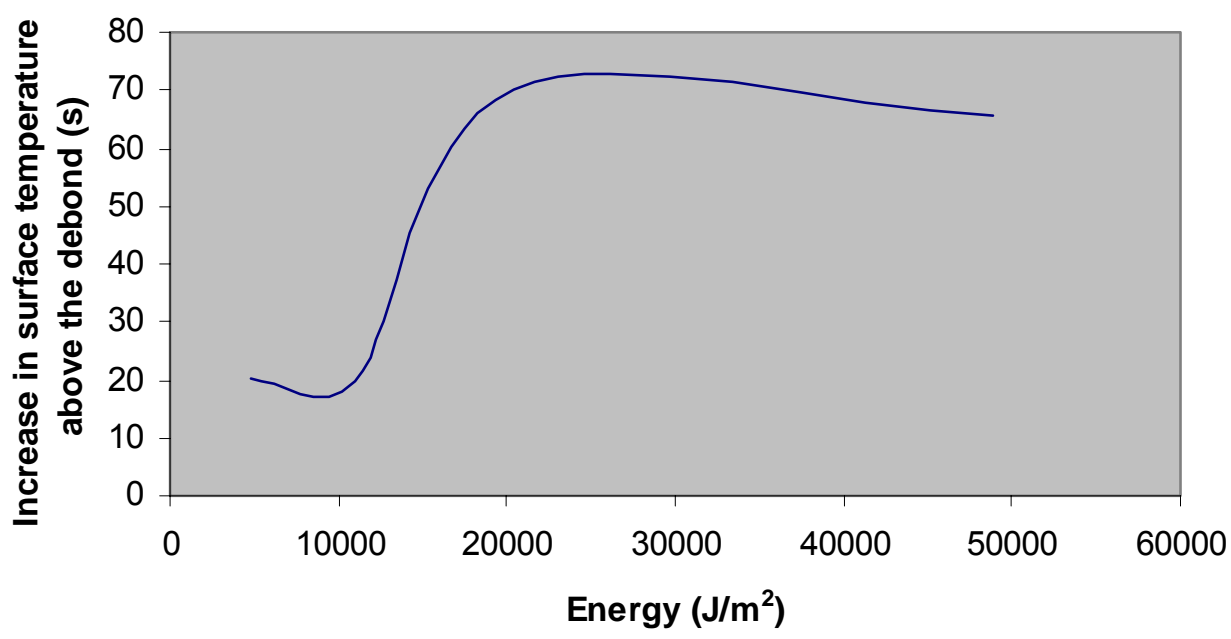

\section{Figure 5-48 Effect of energy input on increase in surface temperature above the debond for cylinders wrapped with CFRP composite}

Figure 5-47 and Figure 5-48 shows the increase in surface temperature above the debond with heat flux for cylinders wrapped with GFRP and CFRP composite respectively. It can be noted that instead of absolute maximum surface temperature, the increase in temperature is spoken because of the reason that initial temperature is always varying. So this gives an idea about the amount of heat flux to be used in the field in order to conduct the IRT experiment effectively without compromising the mechanical properties of FRP composite. In this case also, we can see that increase in surface temperature varies more sharply for cylinders wrapped with GFRP composite than the ones wrapped with CFRP composite. This is because of the higher thermal diffusivity value of CFRP composite

\subsubsection{Effect of Debond Width}

To have a better understanding of debond width on the transient heat transfer phenomenon, cylinders wrapped with three layers of GFRP and CFRP composite was chosen. The heating time for this parametric study was 70 seconds. Figure 5-49 and Figure 5-50 represents the variation of maximum thermal difference with debond width for cylinders wrapped with GFRP composite and CFRP composite respectively. It can be seen that for a given heating time for maximum thermal difference increases with the increase in width of the debond. As the lateral size of the debond increases, heat diffusion 
through the debond tends to be one dimensional. So for larger size defects, heat diffusion is predominantly in the direction perpendicular to the camera resulting in higher thermal difference. Figure 5-51 and 5-52 shows the effect of debond width on the time to achieve maximum thermal difference. As evident from the graphs, the time to achieve maximum thermal contrast increases as debond width increases. This is also because of the fact that heat diffusion changes from three dimensional to one dimensional mode as the lateral size of defect increases. However for smaller sizes, the heat diffuses through all the three sides of the debond making it a three dimensional heat diffusion phenomenon. Hence for smaller size debonds, heat dissipates faster than the larger sized debonds. Therefore, the time to achieve thermal difference also reduces for smaller sized debonds. As obvious from Figure 5-53, maximum surface temperature above the debond increases with an increase in debond width for cylinders wrapped with CFRP composite. For 3" x 3" airfilled debond, the maximum surface temperature is almost $100{ }^{\circ} \mathrm{C}$. For cylinders wrapped with GFRP composite, the maximum surface temperature decreases for 3" x 3 " air-filled debond. The reason of this phenomenon maybe uneven heating.

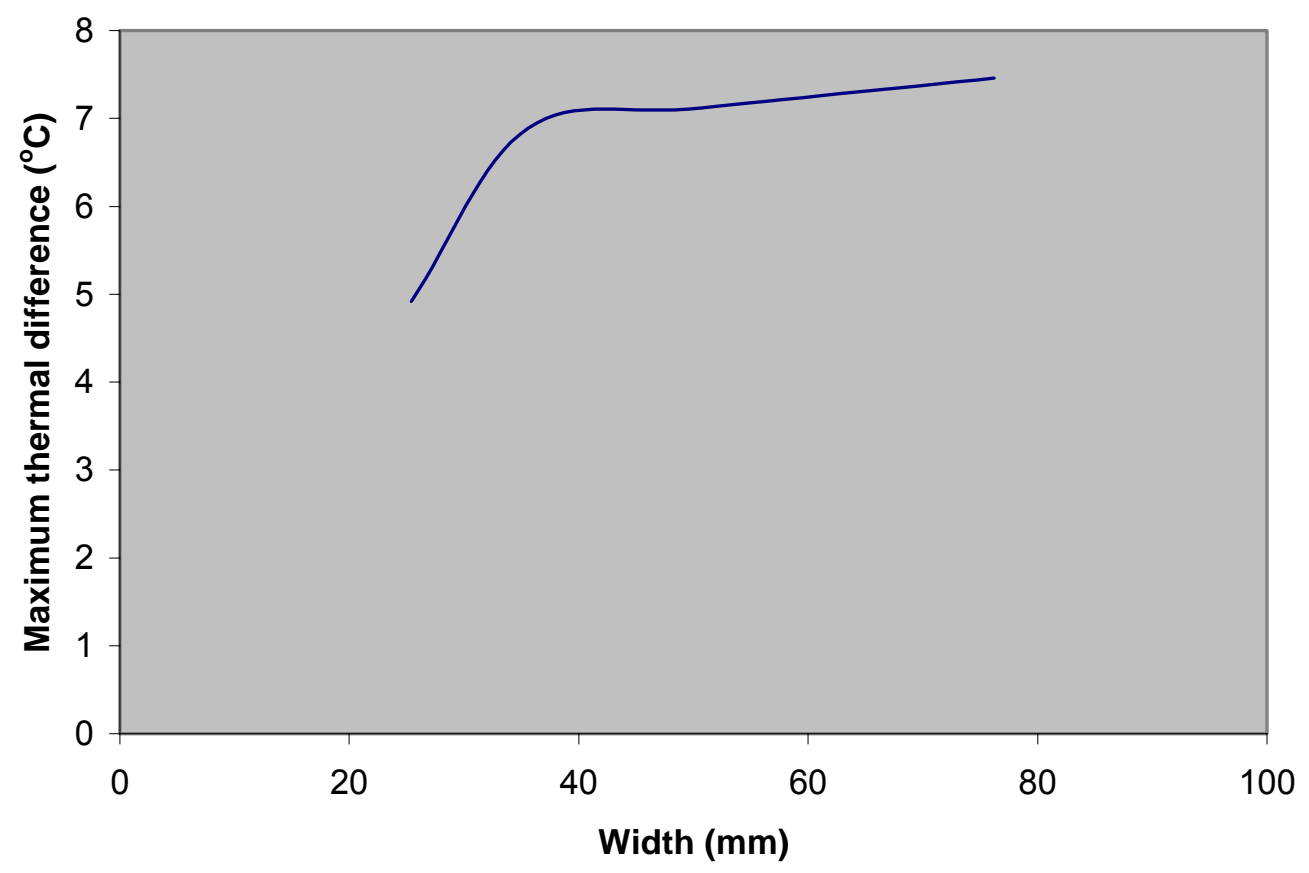

Figure 5-49 Effect of debond width on maximum thermal difference for cylinders wrapped with GFRP composite 


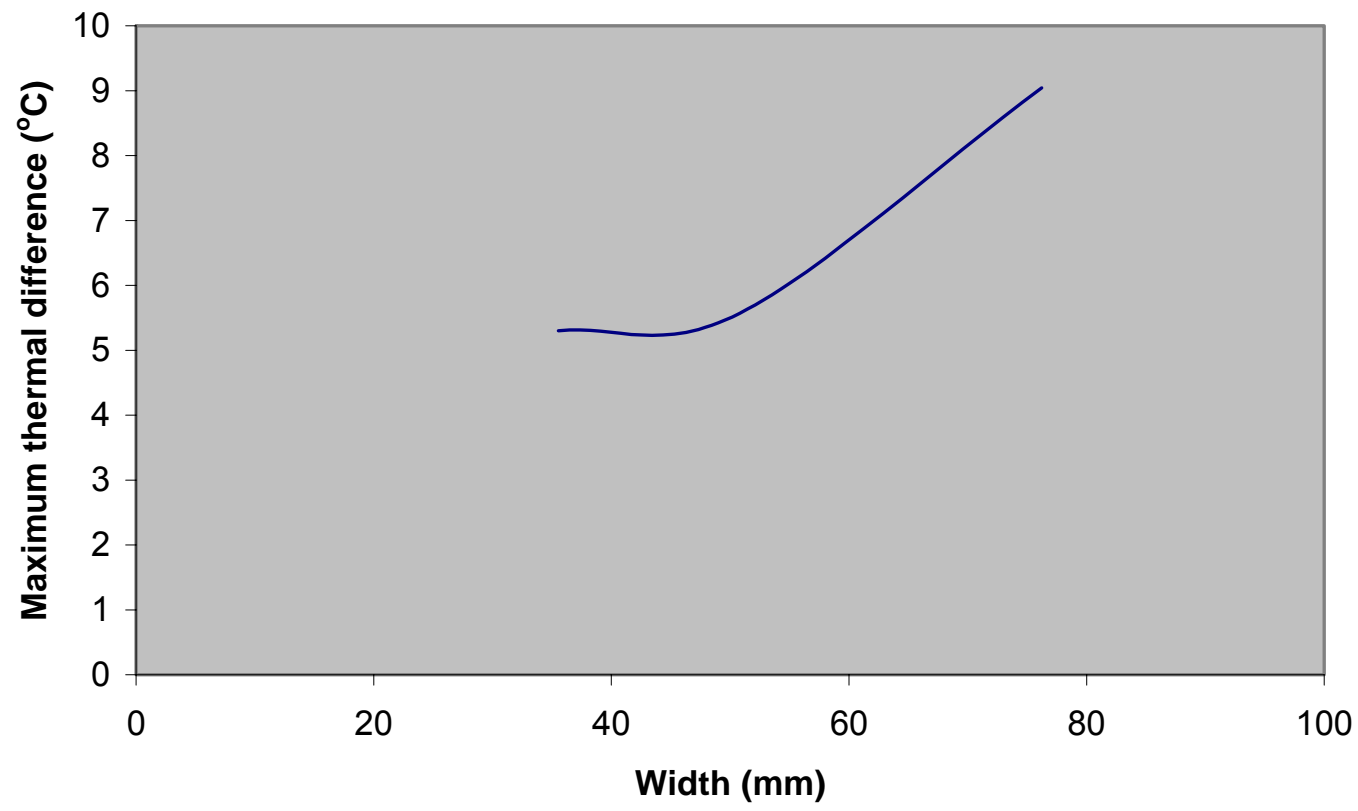

Figure 5-50 Effect of debond width on maximum thermal difference for cylinders wrapped with CFRP composite

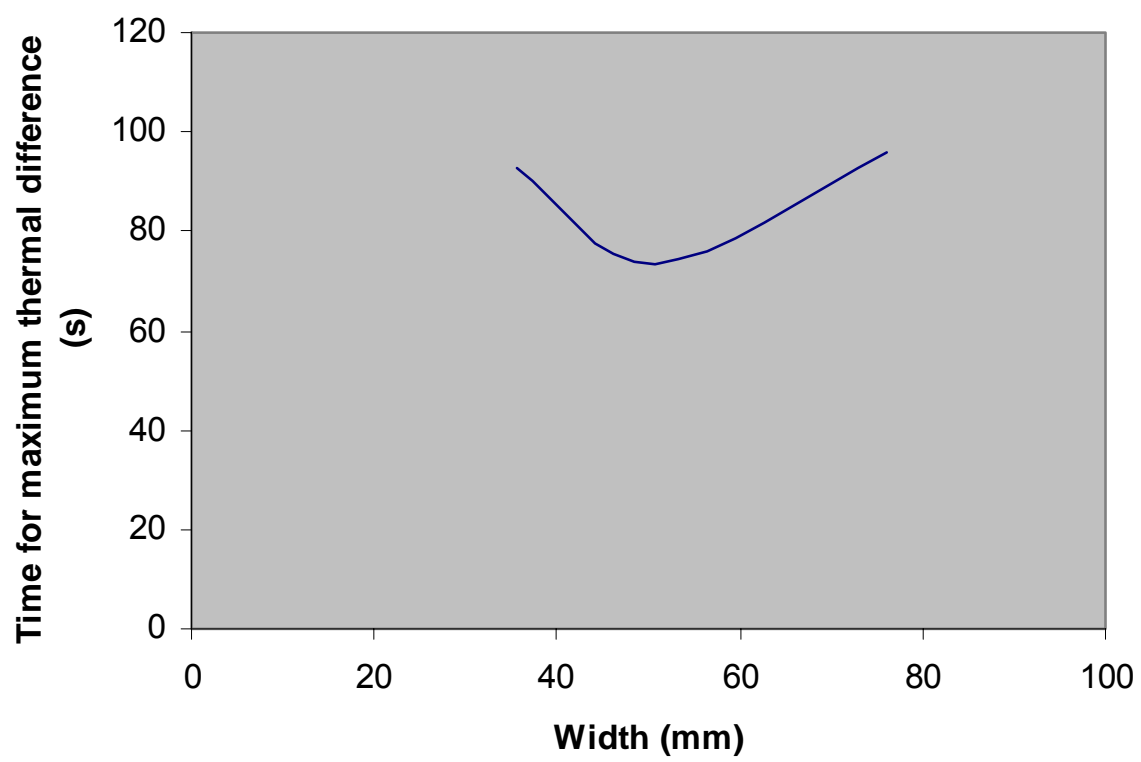

Figure 5-51 Effect of debond width on time to achieve maximum thermal difference for cylinders wrapped with CFRP composite 


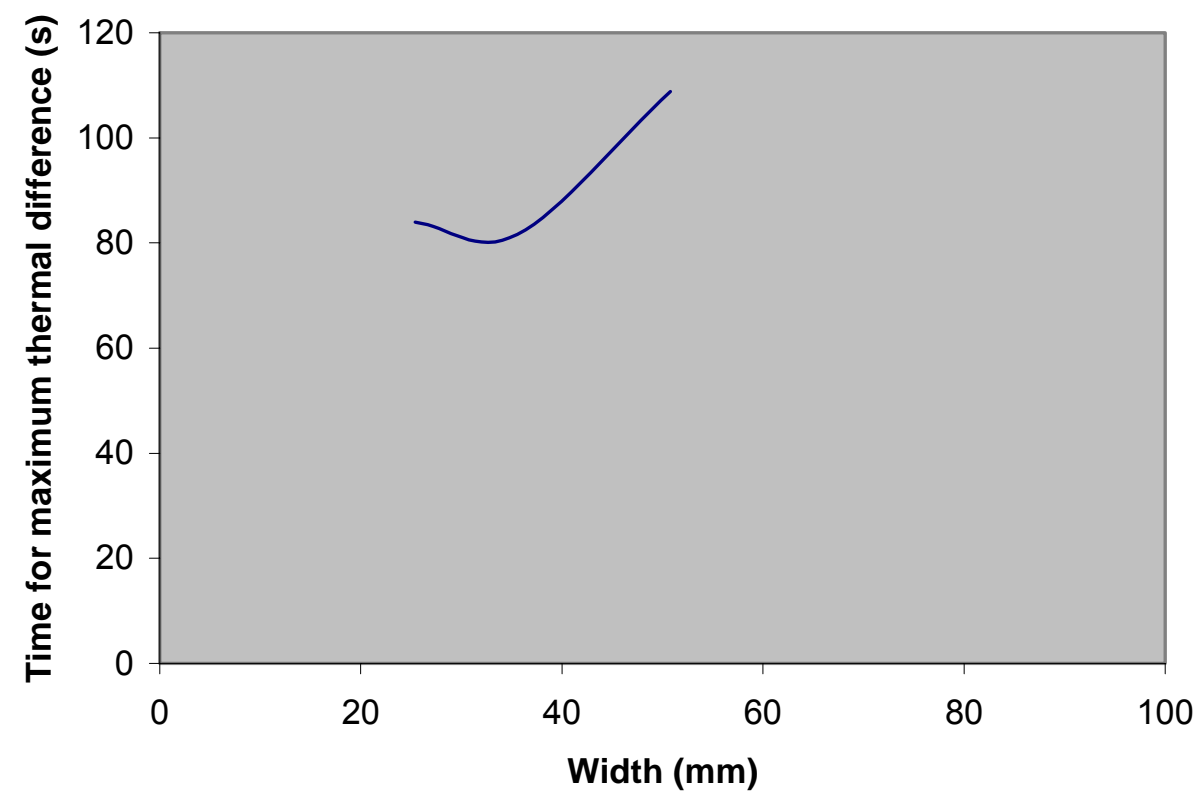

Figure 5-52 Effect of debond width on time to achieve maximum thermal difference for cylinders wrapped with GFRP composite

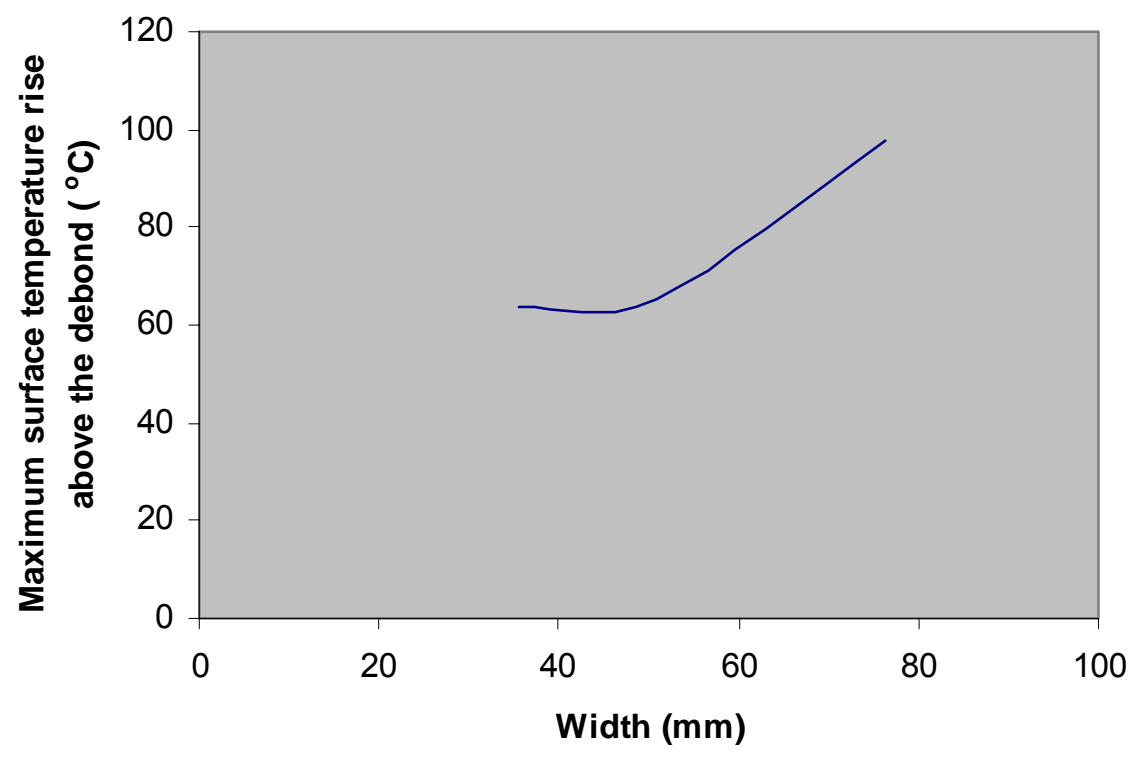

Figure 5-53 Effect of debond width on maximum surface temperature above the debond for cylinders wrapped with CFRP composite 


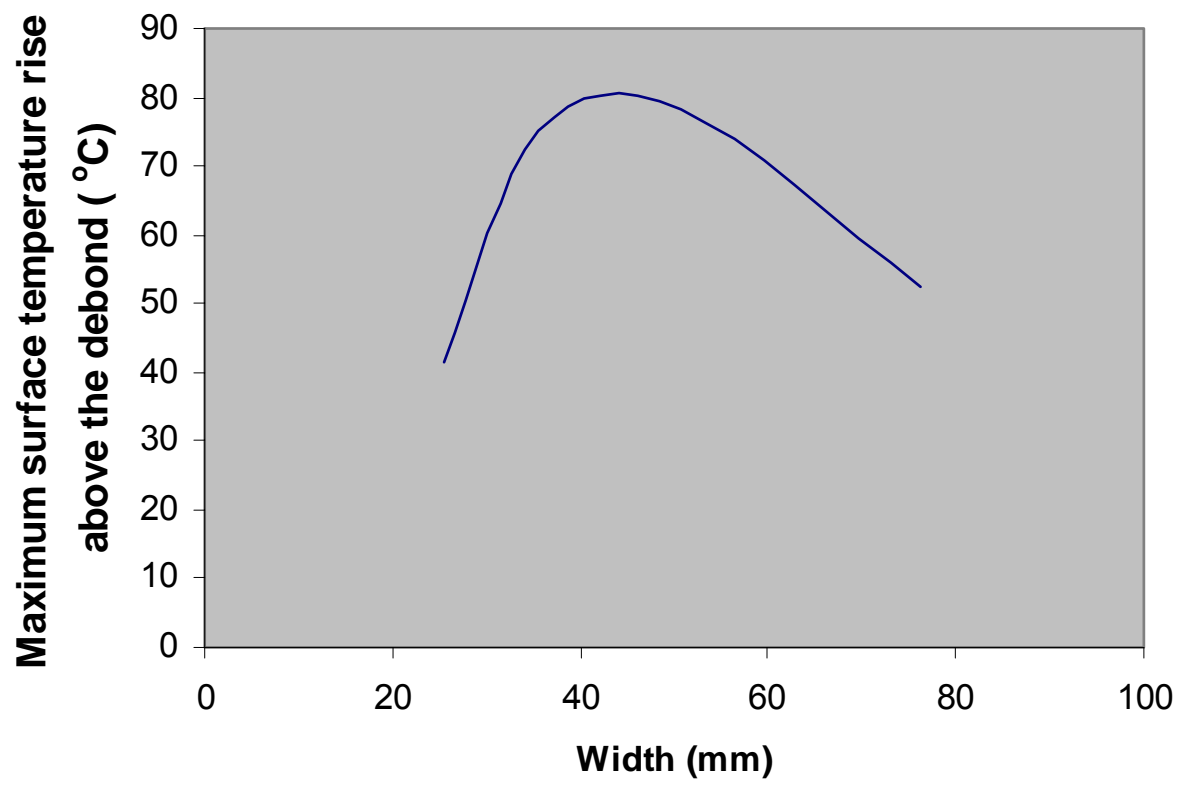

Figure 5-54 Effect of debond width on maximum surface temperature above the debond for cylinders wrapped with GFRP composite

\subsubsection{Effect of Debond Depth}

Experiments were also carried out to gain an insight to the influence of debond depth on the transient heat transfer phenomenon. Cylinders with a 2" x 2" air-filled debond and wrapped with GFRP composite were chosen. The number of composite layers varied from one layer to four layers. The heating time for this parametric study was also 70 seconds. 


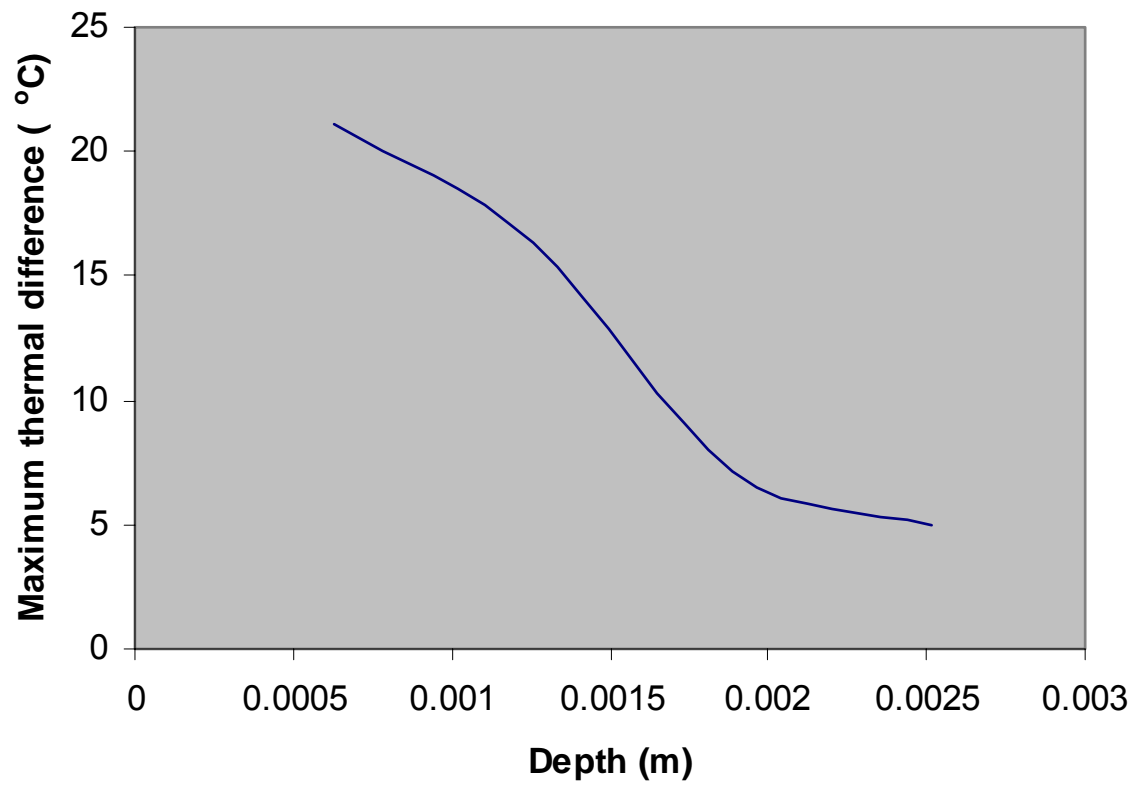

Figure 5-55 Effect of debond depth on maximum thermal difference for cylinders wrapped with GFRP composite

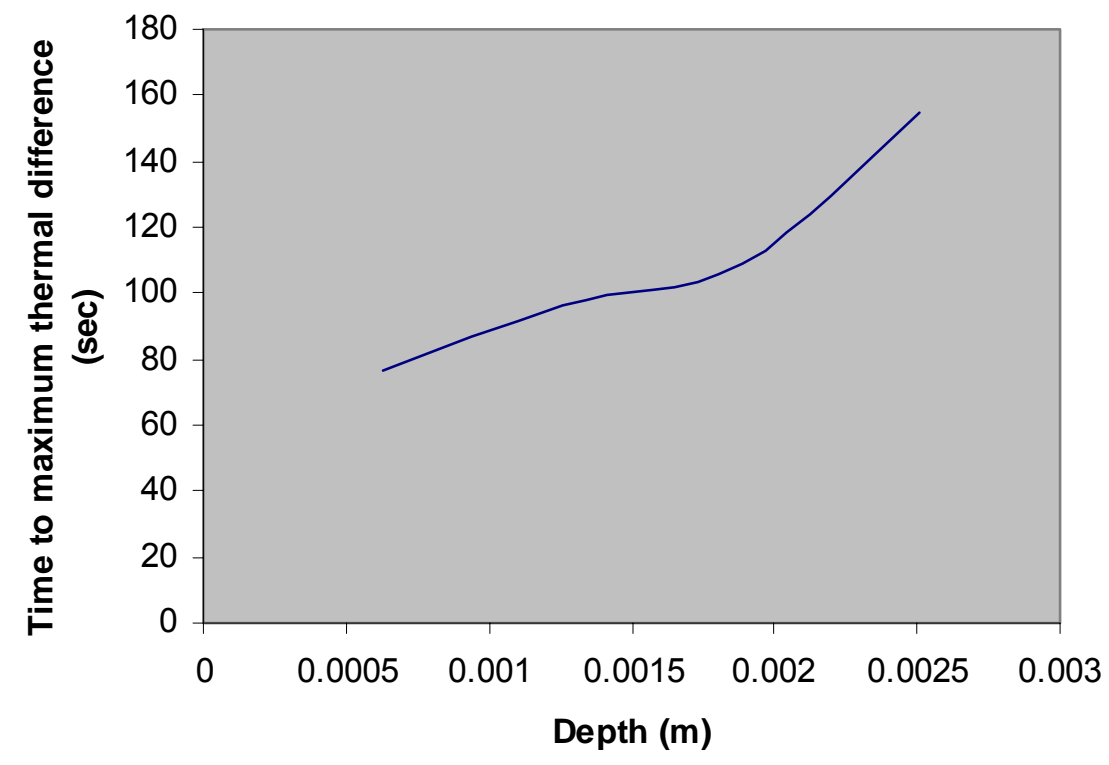

Figure 5-56 Effect of debond depth on time to achieve maximum thermal difference for cylinders wrapped with GFRP composite 


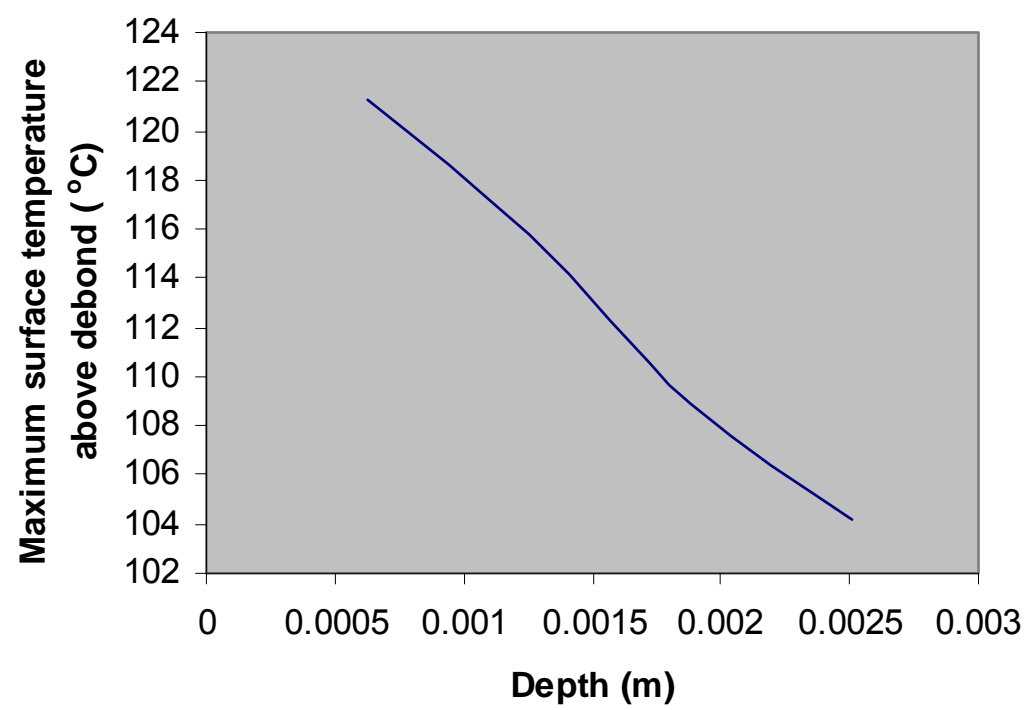

\section{Figure 5-57 Effect of debond depth on maximum surface temperature above the debond for cylinders wrapped with GFRP composite}

As we can see from Figure 5-55, maximum thermal difference decreases with an increase in debond depth. This is because for debonds located at greater depth, heat energy dissipates before it reaches the depth at which the debond is located.

In passive thermography, a surface temperature difference of $4^{\circ} \mathrm{C}$ confirms the presence of a discontinuity (Maldague 2000). Going in the same line, the following recommendations are made for field testing using active infrared thermography based on the above parametric study:

- For concrete cylinders wrapped with GFRP composite, 70 seconds of heat duration is adequate to detect debonds having widths from 1" up to 3 " $(76.2 \mathrm{~mm})$. For debond width of 3", maximum thermal difference for 70 seconds heating is about $7^{\circ} \mathrm{C}$ which is enough to mark it as debond. For width of 1 ", the maximum thermal difference is about $4{ }^{\circ} \mathrm{C}$ which is the lower limit for surface temperature difference to detect the presence of a debond. The maximum surface temperature difference for widths in between 1 " and 3 " falls between $4{ }^{\circ} \mathrm{C}$ and $7{ }^{\circ} \mathrm{C}$. Maximum surface temperature for 70 seconds heating for the widths ranging from 1" to 3 " does not increase more than $80{ }^{\circ} \mathrm{C}$ which is can be considered as a safe operating temperature. Although the parametric measurements for the effect of heat flux 
was done on a specimen having a 2" x 2" air-filled debond, 70 second heating on a cylindrical specimen having a 3" x 3" air-filled debond produced a thermal difference of $7.45852{ }^{\circ} \mathrm{C}$. Also, maximum surface temperature difference increases with an increase in debond width for 70 seconds. So it is safe to assume that 70 seconds of heat duration will detect debonds having widths starting from 1 " onwards.

- For CFRP composite wrapped concrete cylinders, 70 seconds of heat duration is adequate to detect debonds having widths from 1" up to 3" (76.2 mm). For debond width of 3", maximum thermal difference for 70 seconds heating is about $9^{\circ} \mathrm{C}$ which is enough to mark it as debond. For width of 1 ", the maximum thermal difference is about $5{ }^{\circ} \mathrm{C}$ which is the also good enough to detect the presence of a debond. The maximum surface temperature difference for widths in between 1" and 3" falls between $5{ }^{\circ} \mathrm{C}$ and $9{ }^{\circ} \mathrm{C}$. Maximum surface temperature for 70 seconds heating for the widths ranging from 1" to 3 " does not increase more than $100{ }^{\circ} \mathrm{C}$ which is can be considered as a safe operating temperature. Although the parametric measurements for the effect of heat flux was done on a specimen having a 2" x 2" air-filled debond, 70 seconds heating on a cylindrical specimen having a 3" x 3" air-filled debond produced a thermal difference of $9.04445{ }^{\circ} \mathrm{C}$. Also, maximum surface temperature difference increases with an increase in debond width for 70 seconds. So it is safe to assume that 70 seconds of heat duration will detect debonds having widths starting from 1" onwards.

\subsubsection{Conclusions}

The conclusions arrived from the above parametric study is as follows:

- Maximum thermal difference increases as the heat duration increases for both CFRP and GFRP composite wrapped concrete cylinders with embedded debonds.

- Maximum thermal contrast increases as the heat duration increases for GFRP composite wrapped concrete cylinders with embedded debonds. For CFRP composite wrapped concrete cylinders with debonds, the variation was erratic. 
- Time for maximum contrast increases with increase in energy input for for both CFRP and GFRP composite wrapped concrete cylinders with embedded debonds.

- Time for maximum thermal difference increases with increase in energy input for for both CFRP and GFRP composite wrapped concrete cylinders with embedded debonds.

- Increase in surface temperature above the debond increases with increase in energy input for both CFRP and GFRP composite wrapped concrete cylinders with embedded debonds.

- Maximum thermal difference increases with an increase in width of debond for both CFRP and GFRP composite wrapped concrete cylinders with embedded debonds.

- Time to achieve maximum thermal difference first decreases a little but then increases with an increase in width of debond for both CFRP and GFRP composite wrapped concrete cylinders with embedded debonds.

- Maximum thermal difference decreases with an increase in debond depth for GFRP composite wrapped concrete cylinders with embedded debonds.

- Time for maximum thermal difference increases with an increase in debond depth for GFRP composite wrapped concrete cylinders with embedded debonds.

- Maximum surface temperature above the debond decreases with an increase in debond depth for GFRP composite wrapped concrete cylinders with embedded debonds.

- For both GFRP and CFRP composite wrapped concrete cylinders the optimum heat duration for detection of debonds of air-filled debonds is 70 seconds.

\subsection{QUANTITATIVE CHARACTERIZATION RESULTS}

This section describes the results obtained of quantitative characterization of debond width and debond depth. The heating time for quantify the debond width and depth was 70 seconds as it was decided that 70 seconds heating time was optimum to detect air-filled debonds starting from 1" onwards in both CFRP and GFRP composite wrapped concrete cylinders. For debond depth, 2" x 2" air -filled debond was wrapped with 1,2,3 and 4 layers of GFRP composite. 


\subsubsection{Estimation of Debond Width}

First, it was necessary to determine the distance between adjacent pixels in the infrared image. For this purpose, an infrared image of a metal plate of size $76.2 \mathrm{~mm} \mathrm{x}$ $76.2 \mathrm{~mm}$ (3" x 3") was acquired keeping the camera at a distance of $0.9 \mathrm{~m} \mathrm{(3')} \mathrm{from} \mathrm{the}$ plate. From this image, it was determined that the region between adjacent pixels of the camera represented a distance of $1.34 \mathrm{~mm}$. Debond sizes were estimated at the best observation time which is the time when thermal difference between the debonded area and defect-free area is maximum (Starnes 2002). Two methods were used to estimate the debond sizes. The first method, Full Width at Half Maximum (FWHM), involved taking the width between the two half-maximum points on either side of the peak in the temperature profile across the debond. The second method consisted of estimating the debond width by calculating the inflection point locations on either side of the peak in the temperature profile. The distance between the two inflection points gives the estimated debond width. Table 5-1 gives the values of the actual width and the estimated width of the air-filled debonds at best observation time. It is evident that second method (Inflection Point Method) gives more accurate values than the first method, Full Width at Half Maximum (FWHM). Figure 5-58 gives the relation between estimated horizontal width as found out by finding the inflection points of the surface temperature profile and actual width in GFRP composite wrapped concrete cylinders. This relation is used to correlate the estimated widths found out by the same method to the actual widths. Table 5-2 gives the summary of results. It can be seen that barring one case this equation can be used to find the actual width in both CFRP and GFRP composite wrapped concrete columns. The equation relating the estimated width and the actual width is

$$
w_{\text {actual }}=18.915 \times e^{0.017 w_{\text {essimated }}}
$$

\subsubsection{Estimation of Debond Depth}

Three characteristic times were chosen to correlate debond depth to time. These times were time to peak contrast, time to half of peak contrast and time to peak slope of contrast. Debond depth was related to the characteristics times as well as the thermal diffusivity of the material. An equation was obtained by curve fitting from the data obtained from testing the cylinders wrapped with 1,2 and 3 layers of GFRP composite 
and then depth was evaluated for the cylinder wrapped with 4 layers of composite to validate the equation (Figure 5-59 to Figure 5-61). Two curves were fit into the data viz. linear fit two data point (fitting thermal response parameters of the cylinders wrapped with 2 and 3 layers of GFRP Composite) and linear fit with three data points (fitting thermal response parameters of the cylinders wrapped with 1, 2 and 3 layers of GFRP Composite) Table 5-3 gives the measured values of depth of the debond. Depths were also measured in accordance with equation (2.9). The parameters chosen were time to peak contrast, time to half of peak contrast and time to peak slope of contrast and the corresponding contrast values. Table 5-4 gives the values of depth of debond measured in accordance with equation (2.9). Constants $\mathrm{B}$ and $\mathrm{n}$ were found out by curve fitting from the data obtained from testing the cylinders wrapped with 1,2 and 3 layers of GFRP composite (Figure 5-62 to Figure 5-64). It can be seen that debond depth is always underestimated when evaluated with the help of equation (2.9). It is also evident that error is very high when debond depth is related to the thermal diffusivity and time to achieve peak slope of contrast. The reason is that calculating the slope includes finding derivative of the contrast curve which in turn introduces error in the computations.

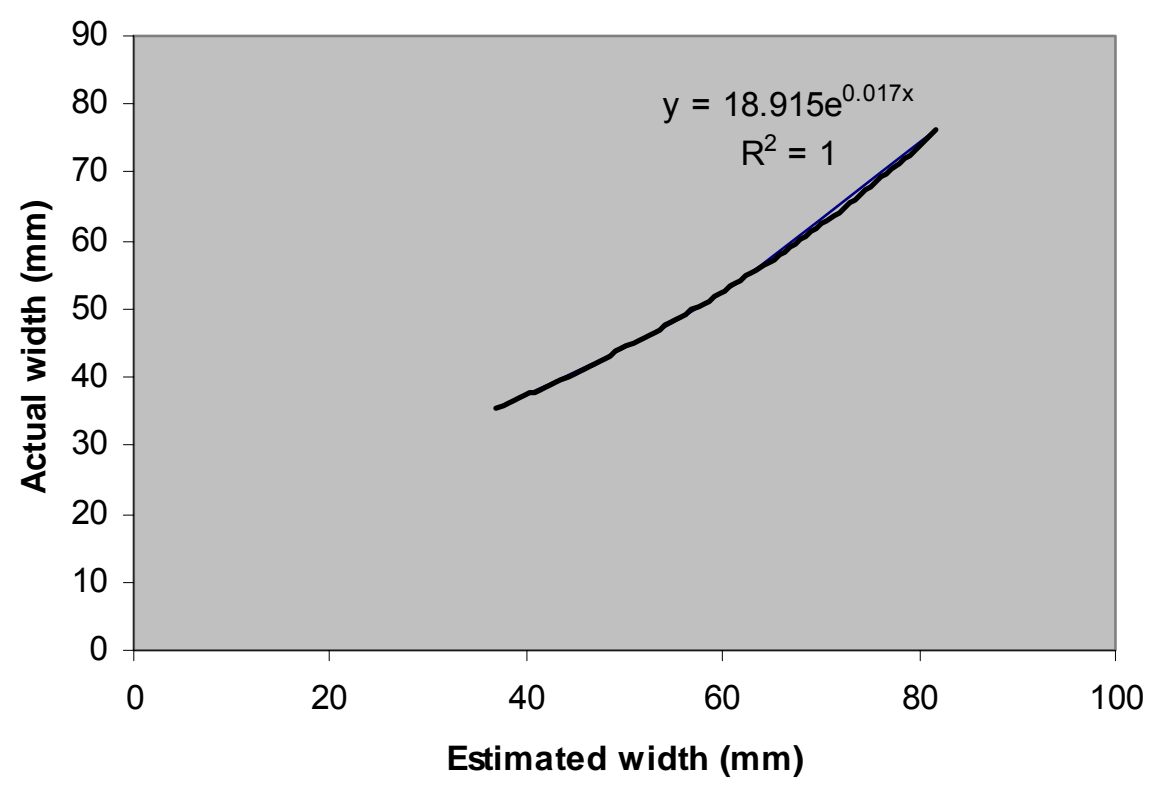

Figure 5-58 Correlation between actual horizontal width and estimated horizontal width when measured by finding the inflection points of the temperature profile above the debond for cylinders wrapped with GFRP composite 


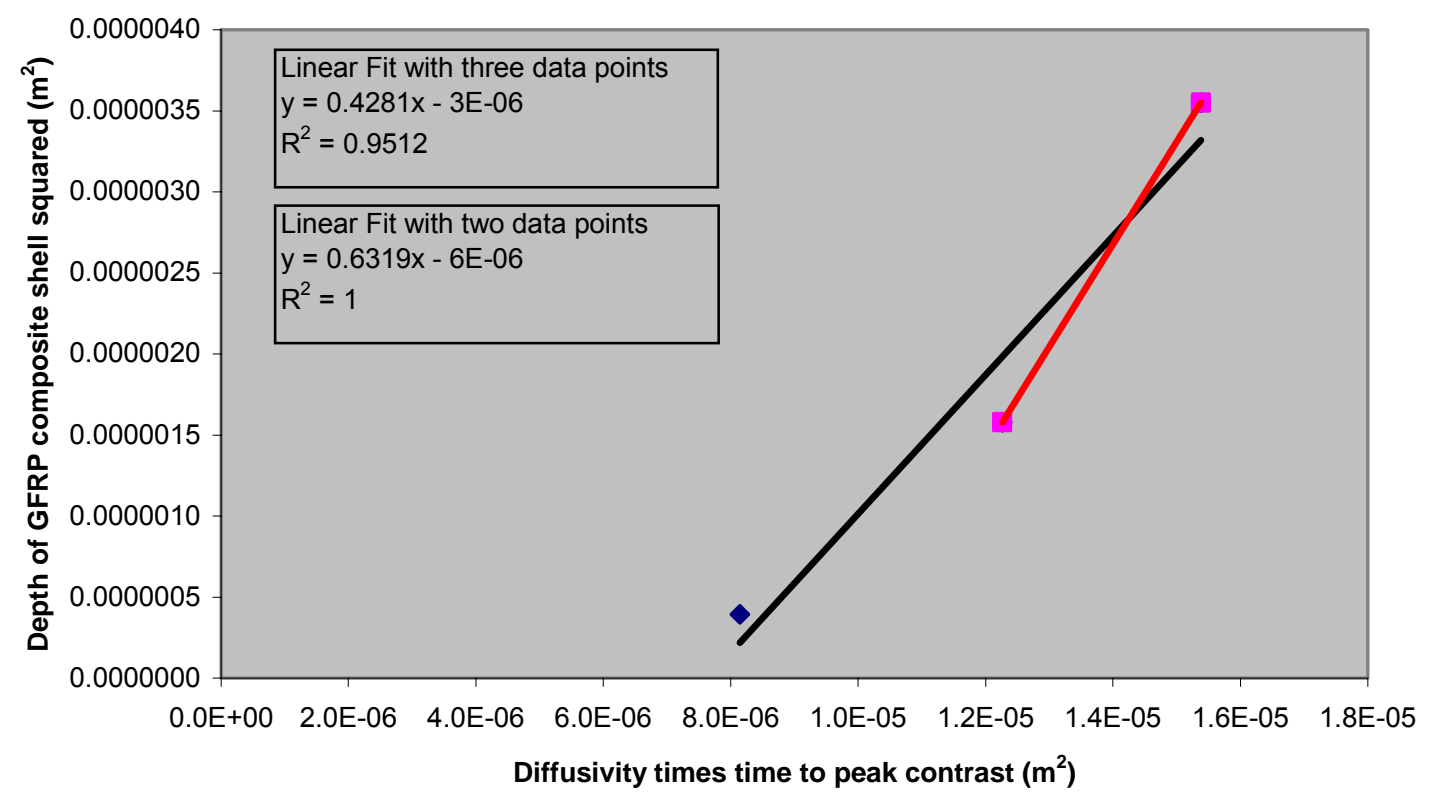

Figure 5-59 Plot of depth of GFRP composite shell squared versus time to peak contrast times diffusivity

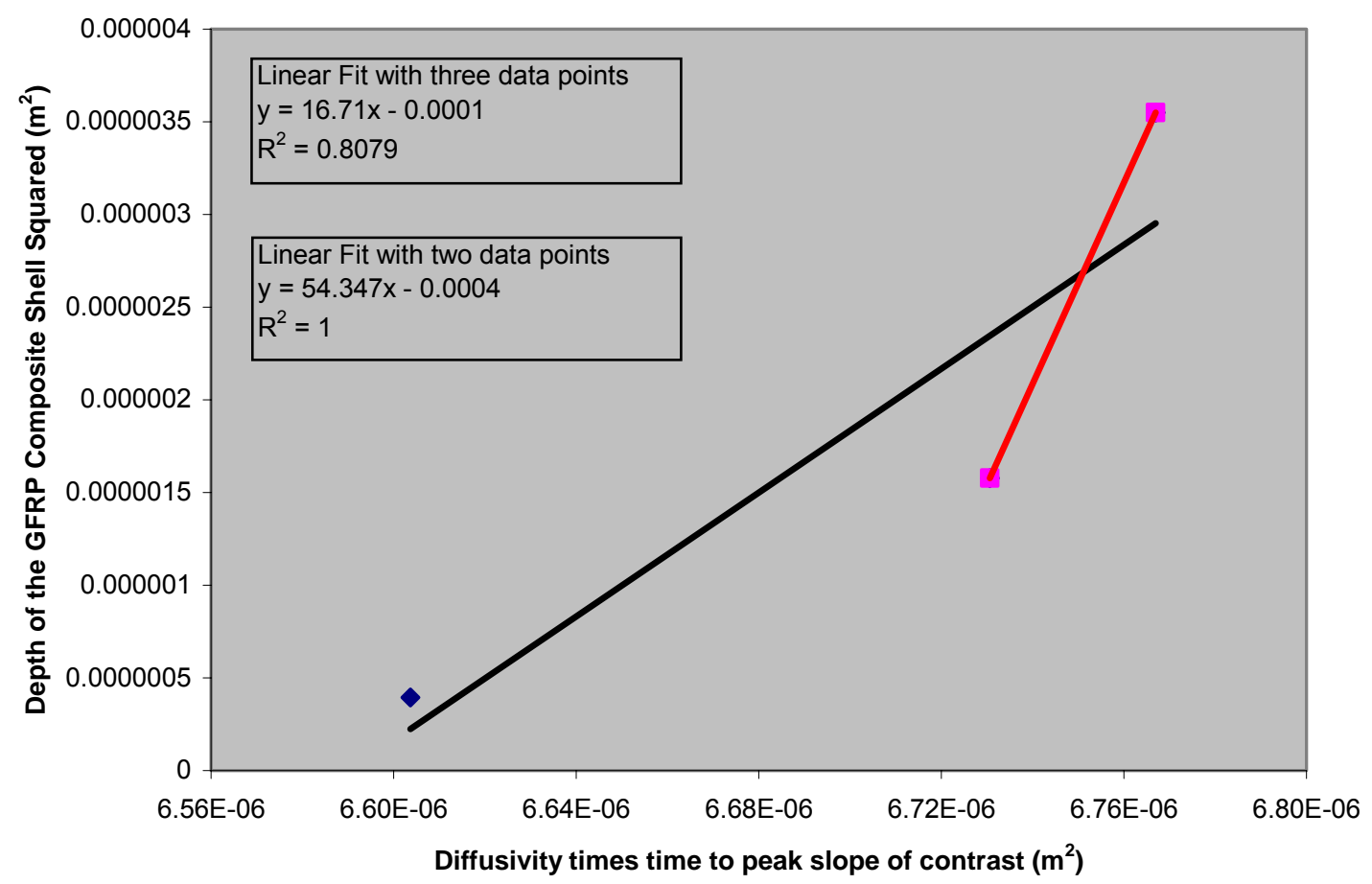

Figure 5-60 Plot of depth of GFRP composite shell squared versus time to peak slope of contrast times diffusivity 


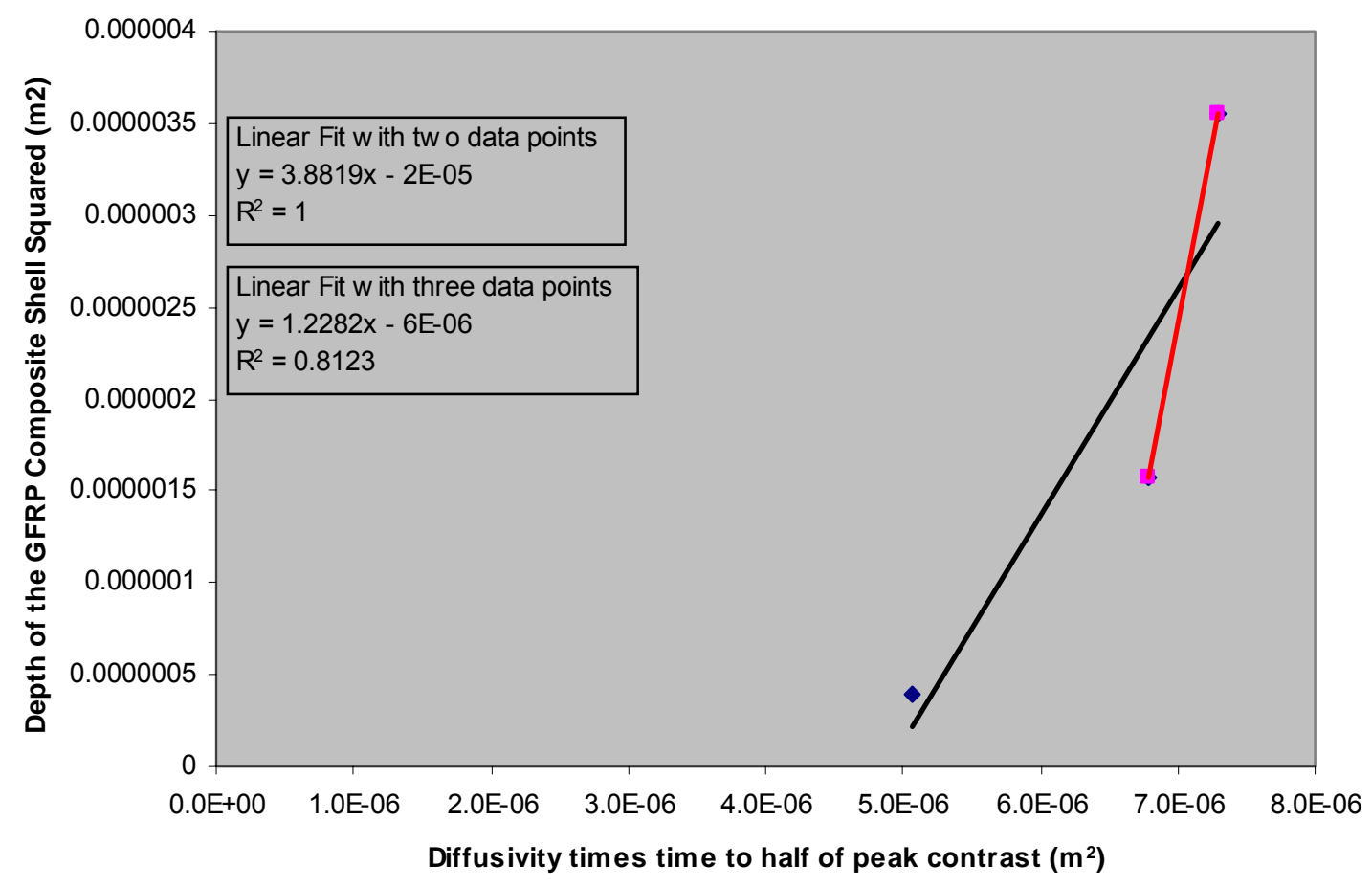

Figure 5-61 Plot of depth of GFRP composite shell squared versus time for half of peak contrast times diffusivity

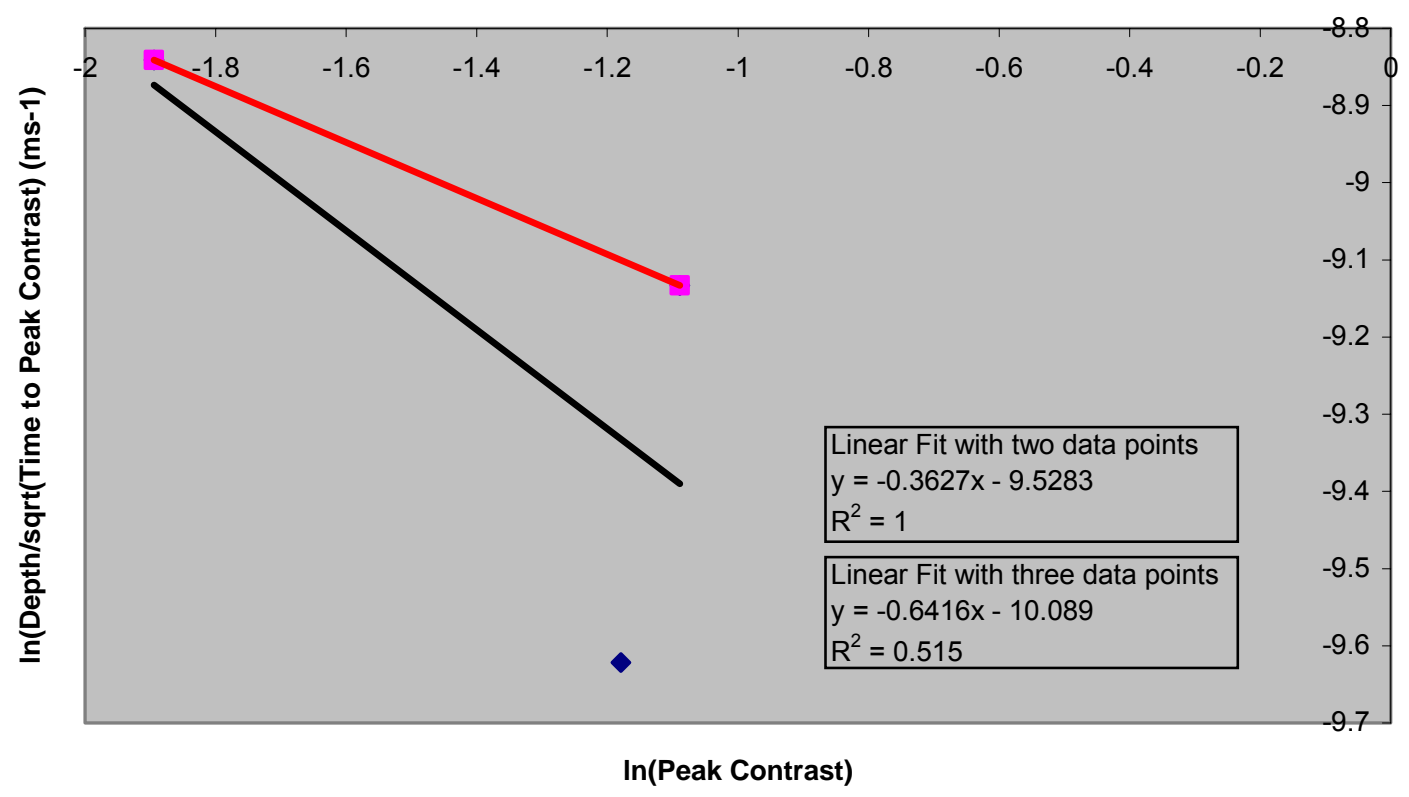

Figure 5-62 Curve fitting to find constants $B$ and $n$ in equation 2.9 with peak contrast and time to peak contrast as the characteristic parameters 


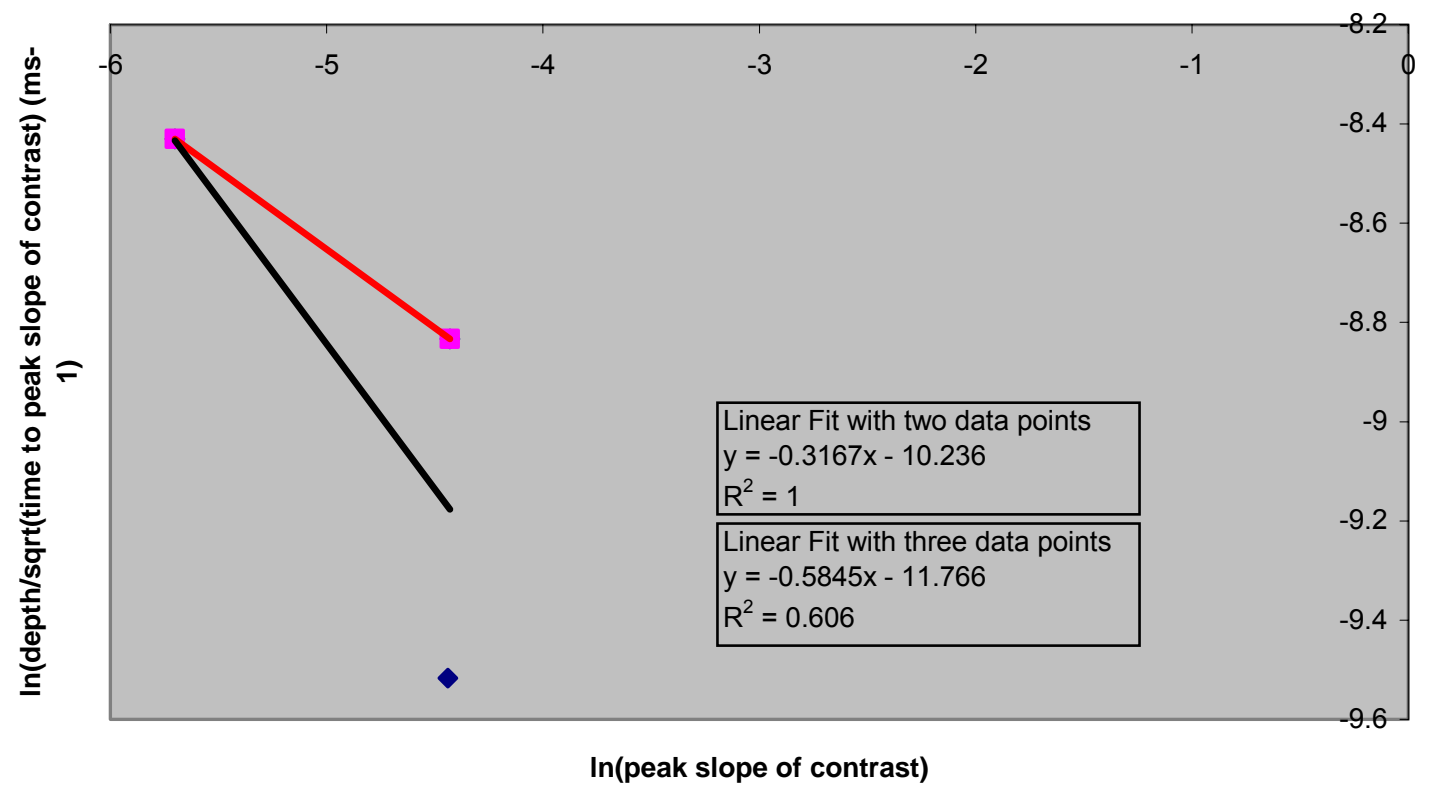

Figure 5-63 Curve fitting to find constants $B$ and $n$ in equation 2.9 with peak slope of contrast and time to peak slope of peak contrast as the characteristic parameters

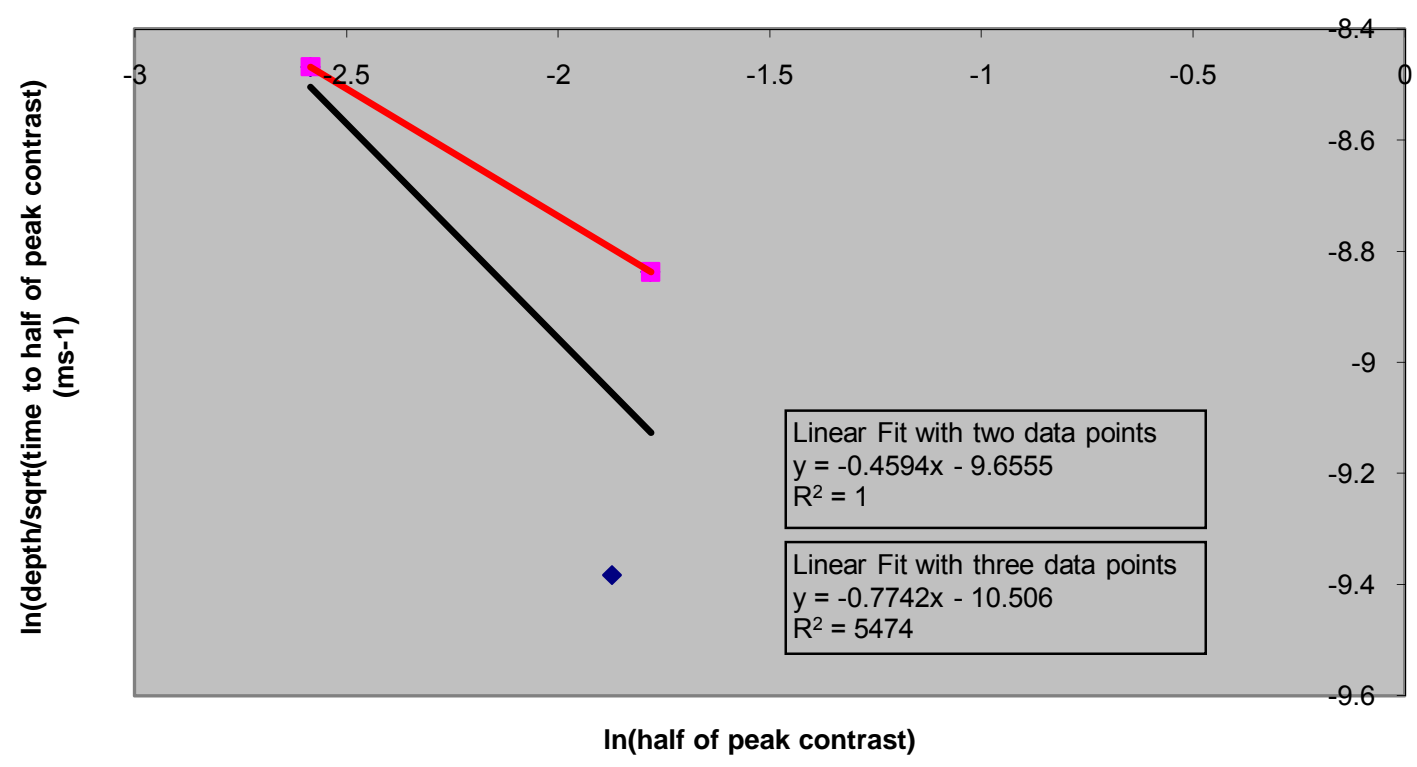

Figure 5-64 Curve fitting to find constants $B$ and $n$ in equation 2.9 with half of peak contrast and time to achieve half of peak contrast as the characteristic parameters 
Table 5-1 Estimated and actual widths at best observation time

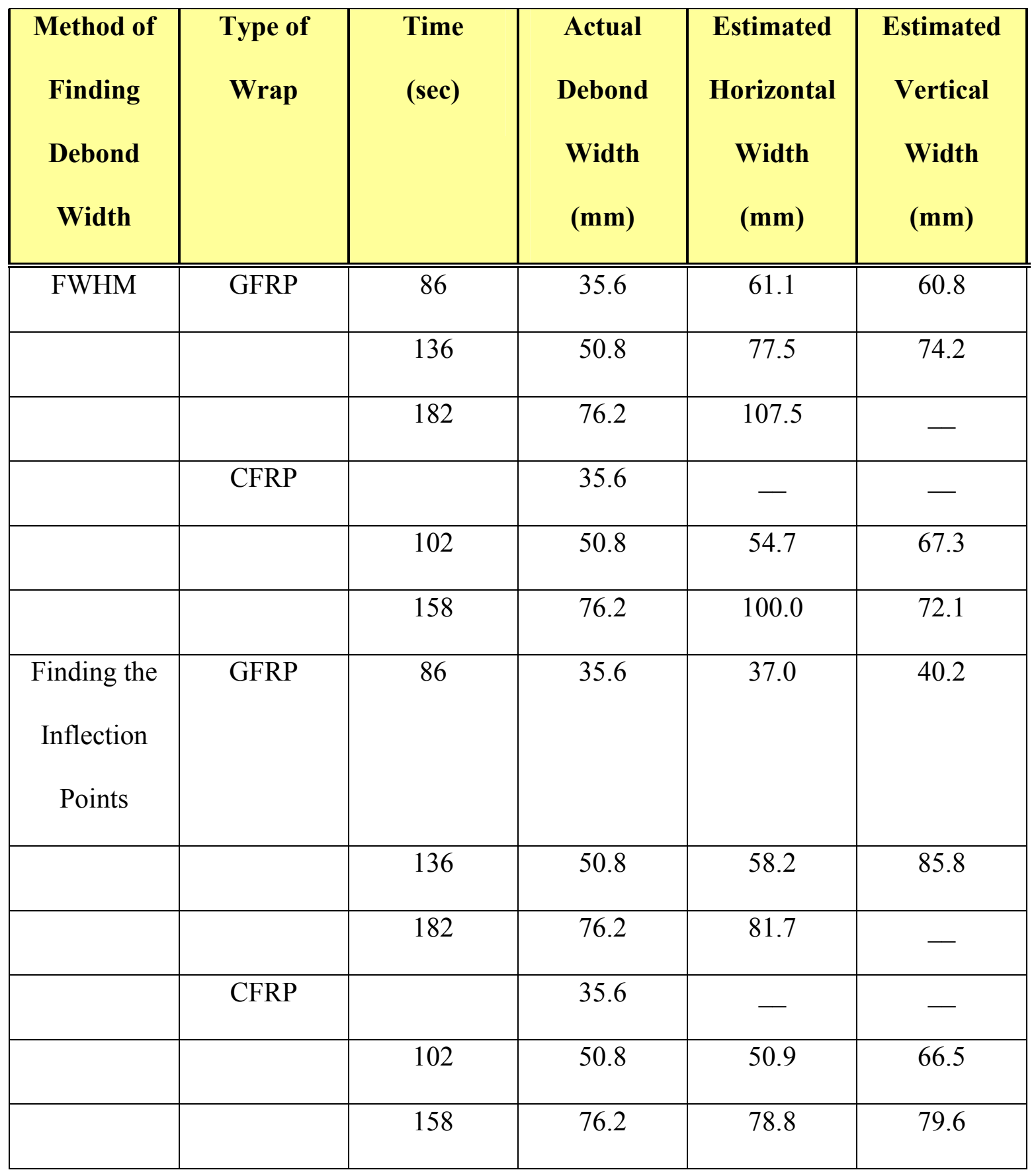


Table 5-2 Comparison between widths estimated by equation (5.3) with actual widths

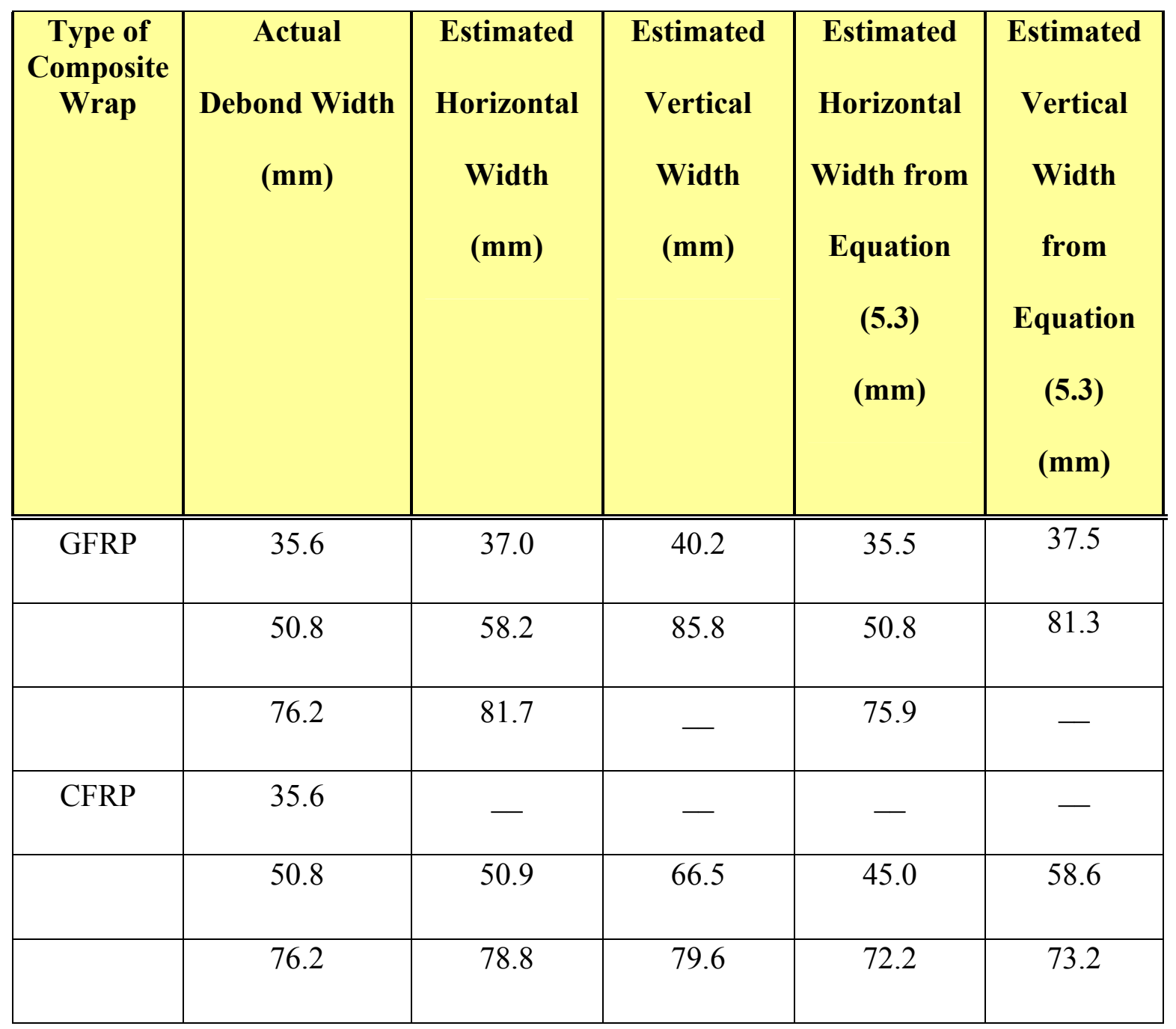


Table 5-3 Actual and estimated debond depths at different characteristic times

\begin{tabular}{|c|c|c|c|c|}
\hline Characteristic Time & $\begin{array}{c}\text { Characteristic Time } \\
\text { Value (s) }\end{array}$ & $\begin{array}{c}\text { Actual Depth } \\
\text { (m) }\end{array}$ & $\begin{array}{c}\text { Estimated Depth } \\
\text { (m) }\end{array}$ & $\begin{array}{c}\text { Error } \\
\text { (\%) }\end{array}$ \\
\hline \hline \multicolumn{5}{|c|}{ Linear fit with three data points } \\
\hline Time to Peak Contrast & 234.6 & 0.002512 & 0.002472 & $-1.6^{(1)}$ \\
\hline Time to Half of Peak Contrast & 104.2 & 0.002512 & 0.002368 & $-5.7^{(1)}$ \\
\hline Time to Peak Slope of Contrast & 77.6 & 0.002512 & 0.004198 & $67.1^{(2)}$ \\
\hline \multicolumn{7}{|c|}{ Linear fit with two data points } \\
\hline Time to Peak Contrast & 234.6 & 0.002512 & 0.002729 & $8.6^{(2)}$ \\
\hline Time to Half of Peak Contrast & 104.2 & 0.002512 & 0.004086 & $62.7^{(2)}$ \\
\hline Time to Peak Slope of Contrast & 77.6 & 0.002512 & $\mathrm{NA}^{(3)}$ & $\mathrm{NA}$ \\
\hline
\end{tabular}

1) Negative value of error indicates underestimation of the measured depth

2) Positive value of error indicates overestimation of the measured depth

3) Debond depth cannot be estimated because square root of a negative number is not a realistic debond depth value 
Table 5-4 Actual and estimated debond depths at different characteristic times in accordance with equation (2.9)

\begin{tabular}{|c|c|c|c|c|c|}
\hline $\begin{array}{c}\text { Characteristic } \\
\text { Time }\end{array}$ & $\begin{array}{c}\text { Value of } \\
\text { Characteristic } \\
\text { Time } \\
\text { (s) }\end{array}$ & $\begin{array}{c}\text { Value of } \\
\text { Characteristic } \\
\text { Contrast }\end{array}$ & $\begin{array}{l}\text { Actual } \\
\text { Depth } \\
\text { (m) }\end{array}$ & $\begin{array}{c}\text { Estimated } \\
\text { Depth } \\
\text { (m) }\end{array}$ & $\begin{array}{c}\text { Error } \\
(\%)\end{array}$ \\
\hline \multicolumn{6}{|c|}{ Linear fit with three data points } \\
\hline $\begin{array}{c}\text { Time to Peak } \\
\text { Contrast }\end{array}$ & 234.6 & 0.126046 & 0.002512 & 0.002403 & $-4.4^{(1)}$ \\
\hline $\begin{array}{l}\text { Time to Half of } \\
\text { Peak Contrast }\end{array}$ & 104.2 & 0.0631446 & 0.002512 & 0.002371 & $-5.6^{(1)}$ \\
\hline Time to Achieve & & & & & \\
\hline $\begin{array}{c}\text { Peak Slope of } \\
\text { Contrast }\end{array}$ & 77.6 & 0.002302 & 0.002512 & 0.002382 & $-5.2^{(1)}$ \\
\hline \multicolumn{6}{|c|}{ Linear fit with two data points } \\
\hline $\begin{array}{c}\text { Time to Peak } \\
\text { Contrast }\end{array}$ & 234.6 & 0.126046 & 0.002512 & 0.002362 & $-6.0^{(1)}$ \\
\hline $\begin{array}{l}\text { Time to Half of } \\
\text { Peak Contrast }\end{array}$ & 104.2 & 0.0631446 & 0.002512 & 0.002327 & $-7.4^{(1)}$ \\
\hline $\begin{array}{l}\text { Time to Achieve } \\
\text { Peak Slope of } \\
\text { Contrast }\end{array}$ & 77.6 & 0.002302 & 0.002512 & 0.002162 & $-13.9^{(1)}$ \\
\hline
\end{tabular}

1) Negative value of error indicates underestimation of the measured depth 


\subsubsection{Conclusions}

The method of finding the inflection points of the surface temperature profile gave more accurate results than FWHM method. Also, the equation found out by curve to correlate between estimated debond width and actual debond width works well for both CFRP and GFRP composite wrapped cylinders. The debond depth is always underestimated when estimated with the help of equation (2.9). Also, measurement error is very high when debond depth is related to the thermal diffusivity and time to achieve peak slope of contrast.

\subsection{SURFACE TEMPERATURE CURVES}

The main thermal response parameters that are of interest in nondestructive testing using infrared thermography technique are thermal difference and maximum surface temperature (Starnes et al. 2003). In this study, surface temperature above debonds and also above defect-free areas was recorded at every 2 seconds interval. Based on these measurements, two sets of thermal response curves are presented.

- Curves representing the variation of surface temperature of defective and defectfree areas with time.

- Curves representing the variation of thermal difference with time.

The plots for all the experimental cases are furnished in Appendix A. The heating duration was 70 seconds except for 3 layers of CFRP wrapped cylinder with 3" x 3" water-filled debond which was heated for 65 seconds. 


\section{CHAPTER 6}

\section{EXPERIMENTAL RESULTS FROM DESTRUCTIVE TESTING}

This chapter describes the stress versus strain behavior of CFRP and GFRP composite wrapped concrete cylinders with embedded flaws. Flaws were of three types: air-filled debond, water-filled debond and Teflon debond sheets. The sign convention adopted in this study was that axial compressive stress and axial compressive strain was positive and tensile circumferential strain (hoop strain) was negative. Concrete cylinders were wrapped with 3 layers of GFRP (Glass Fiber Reinforced Polymer) and CFRP (Carbon Fiber Reinforced Polymer) composite. Detailed graphs representing the stress strain behavior of the tested specimens are given in Appendix B.

\subsection{EFFECT OF DISCONTINUITY ON STRESS STRAIN BEHAVIOR}

In this section, the results that are obtained from the crushing test of the concrete cylinders (wrapped and plain) are presented.

\subsubsection{Tensile Strength of Coupon Specimens}

As described in section 3.3.1, ultimate tensile strength of FRP laminate is an important parameter as it is the maximum confinement pressure that the composite shell can impart to the underlying concrete core.

Coupon specimens were made in the laboratory to evaluate the tensile strength of the FRP Composite system (combination of fabric and resin) in the $0^{\circ}$ or circumferential direction. The details of the coupon specimens are given below:

- GFRP with epoxy resin

$>$ Number of Layers -6

Width of specimen $-0.98 \mathrm{in}(24.89 \mathrm{~mm})$

$>$ Thickness of specimen $-0.17 \mathrm{in}(4.32 \mathrm{~mm})$ 
- CFRP with epoxy resin

$>$ Number of Layers -4

Width of specimen -0.99 in $(25.15 \mathrm{~mm})$

$>$ Thickness of specimen $-0.16 \mathrm{in}(4.06 \mathrm{~mm})$

The Tensile testing of coupons was conducted in accordance with ASTM D 3039/D 3039M - 00. The tensile strength and modulus of elasticity of the composite wrap system was found to be as follows:

- $\quad$ GFRP with epoxy resin

Tensile strength $-44.5 \mathrm{ksi}$

$>$ Modulus of elasticity $-2092 \mathrm{ksi}$

- $\quad$ CFRP with epoxy resin

Tensile strength $-50.9 \mathrm{ksi}$

$>$ Modulus of elasticity $-3670 \mathrm{ksi}$

The GFRP fabric was $0^{\circ} / 90^{\circ}$ fabric with about $50 \%$ of the fibers in each of the two directions. On the other hand, the CFRP fabric was $0^{\circ} / 90^{\circ} / \pm 45^{\circ}$ fabric with $30 \%$ of the fabric in each of the $0^{\circ}$ and $90^{\circ}$ directions, and $20 \%$ of the fabric in each of the $+45^{\circ}$ and $-45^{\circ}$ directions. Although carbon fibers are stronger than glass fibers, since the GFRP fabric had a higher percentage of fibers in the $0^{\circ}$ direction, its tensile strength of $44.5 \mathrm{ksi}$ is not very different from the measured CFRP tensile strength of $50.9 \mathrm{ksi}$.

\subsubsection{Axial Compressive Strength of Unwrapped Specimens}

Two cylinders were tested in axial compression for determining the unwrapped compressive strength of the batch. Table 6-1 gives the ultimate strength for the control specimens (plain concrete cylinders without wrap). The average ultimate compressive load is $31.1 \mathrm{kips}$ and the corresponding ultimate compressive strength is $1.1 \mathrm{ksi}$. 
Table 6-1 Ultimate compressive strength of unwrapped cylinders

\begin{tabular}{|c|c|c|}
\hline $\begin{array}{c}\text { Cylinder } \\
\text { No }\end{array}$ & $\begin{array}{c}\text { Axial Strength } \\
\text { (kips) }\end{array}$ & $\begin{array}{c}\text { Average Axial Strength } \\
\text { (kips) }\end{array}$ \\
\hline \hline 1 & 33.9 & \multirow{2}{*}{31.1} \\
\hline 2 & 28.3 & \\
\hline
\end{tabular}

The above concrete strength of 1.1. ksi is significantly lower than the strength of typical new concrete and is actually representative of the strength of concrete that has been subjected to service loads and environmental degradation for a considerable time. Such lower strength concrete is typically encountered in old structures that are candidates for rehabilitation with the use of FRP wraps. The use of FRP wraps can significantly enhance the strength and ductility of concrete structures with such low strength (Mobasher and Raji 2007). Thus, the current study also serves to highlight the beneficial enhancements provided by the FRP wraps in terms of strength as well as ductility.

\subsubsection{Axial and Circumferential Strain of Unwrapped Specimens}

Table 6-2 gives the ultimate circumferential (hoop) and ultimate axial strain values for the control specimens (plain concrete cylinders without wrapping). Axial strain was measured with the help of LVDT and circumferential strain was measured with strain gage. The initial strain (correction factor, $\varepsilon_{0}$ ) was subtracted from all strains to report correct ultimate strains (see Figures B3 and B4 in Appendix B).

Table 6-2 Ultimate strain of unwrapped cylinders

\begin{tabular}{|c|c|c|c|c|}
\hline $\begin{array}{c}\text { Cylinder } \\
\text { No }\end{array}$ & Axial Strain & Hoop Strain & $\begin{array}{c}\text { Average } \\
\text { Axial Strain }\end{array}$ & $\begin{array}{c}\text { Average } \\
\text { Hoop Strain }\end{array}$ \\
\hline \hline 1 & 0.0048 & - & & \\
\hline 2 & 0.0042 & - & 0.0045 & - \\
\hline
\end{tabular}




\subsubsection{Axial Compressive Strength and Ultimate Strain of Wrapped Specimens}

The specimen wrapped with CFRP and GFRP composite were tested for evaluating the increase in axial strength and strains (circumferential and axial) due to wrapping. Stress was calculated by dividing the load obtained from the load cell by the original cross sectional area of the cylinders. The thickness of the composite was not taken into account while calculating the stress. The average maximum axial stress corresponding to axial strength of 166.6 kips and 250.0 kips were 5.9 ksi and 8.8 respectively. The higher value of axial compressive stress in the case of CFRP composite wrapped cylinders was attributed to the higher tensile strength of CFRP composite. Also, it should be noted that such high strength increase factors are obtained only in case of low strength concrete. At ultimate strain levels, the average axial strain is always higher than the average circumferential strain. The results are summarized in Table 6-3 and Table 64.

Table 6-3 Ultimate compressive strength of wrapped cylinders

\begin{tabular}{|c|c|c|c|}
\hline Cylinder No & $\begin{array}{c}\text { Axial Strength } \\
\text { (kips) }\end{array}$ & $\begin{array}{c}\text { Average Axial Strength } \\
\text { (kips) }\end{array}$ & $\begin{array}{c}\text { Strength } \\
\text { Increase } \\
\text { Factor } \\
\end{array}$ \\
\hline \multicolumn{4}{|c|}{ Wrapped with 3 layers of GFRP Composite } \\
\hline 1 & 168.0 & \multirow{3}{*}{166.6} & \multirow{3}{*}{5.4} \\
\hline 2 & 161.6 & & \\
\hline 3 & 170.2 & & \\
\hline \multicolumn{4}{|c|}{ Wrapped with 3 layers of CFRP Composite } \\
\hline 1 & 270.7 & \multirow{2}{*}{250.0} & \multirow{2}{*}{8.0} \\
\hline 2 & 229.1 & & \\
\hline
\end{tabular}


Table 6-4 Ultimate strain of wrapped cylinders

\begin{tabular}{|c|c|c|c|c|c|}
\hline $\begin{array}{c}\text { Cylinder } \\
\text { No }\end{array}$ & $\begin{array}{l}\text { Axial } \\
\text { Strain }\end{array}$ & $\begin{array}{l}\text { Hoop } \\
\text { Strain }\end{array}$ & $\begin{array}{c}\text { Average } \\
\text { Axial } \\
\text { Strain }\end{array}$ & $\begin{array}{c}\text { Average } \\
\text { Hoop } \\
\text { Strain }\end{array}$ & $\begin{array}{c}\text { Increase in } \\
\text { Axial } \\
\text { Strain } \\
\text { (Ratio) }\end{array}$ \\
\hline \multicolumn{6}{|c|}{ Wrapped with 3 layers of GFRP Composite } \\
\hline 1 & 0.0166 & 0.0111 & \multirow{3}{*}{0.0162} & \multirow{3}{*}{0.0124} & \multirow{3}{*}{3.6} \\
\hline 2 & 0.0151 & 0.0132 & & & \\
\hline 3 & 0.0170 & 0.0129 & & & \\
\hline \multicolumn{6}{|c|}{ Wrapped with 3 layers of CFRP Composite } \\
\hline 1 & 0.0265 & 0.0158 & \multirow{3}{*}{0.0197} & \multirow{3}{*}{0.0094} & \multirow{3}{*}{4.4} \\
\hline & & & & & \\
\hline 2 & 0.0129 & 0.0036 & & & \\
\hline
\end{tabular}

\subsubsection{Axial Compressive Strength of Wrapped Specimens with Simulated Debonds}

The setup of debonds that was adopted in this research and the corresponding debonded area are given in Table 6-5.

Table 6-5 Setup of debonds and corresponding area

\begin{tabular}{|c|c|c|c|}
\hline $\begin{array}{c}\text { Setup } \\
\text { No }\end{array}$ & Debond Type & $\begin{array}{c}\text { Area of Debonds } \\
\text { (in }^{2}\end{array}$ & $\begin{array}{c}\text { Percent Area of Debonds } \\
\text { (\%) }\end{array}$ \\
\hline \hline 1 & $\begin{array}{c}\text { One 1" x 1" air or water-filled debond } \\
\text { or Teflon on each side }\end{array}$ & 2 & 0.88 \\
\hline 2 & $\begin{array}{c}\text { One 1.4" x 1.4" air or water-filled } \\
\text { debond on each side }\end{array}$ & 4 & 3.73 \\
\hline 3 & $\begin{array}{c}\text { One 2" x 2" air or water-filled debond } \\
\text { or Teflon on each side }\end{array}$ & 8 & 7.95 \\
\hline 4 & $\begin{array}{c}\text { One 3" x 3" air or water-filled debond } \\
\text { or Teflon on each side }\end{array}$ & 18 & \multicolumn{2}{|c|}{} \\
\hline
\end{tabular}




\subsubsection{Compressive Strength of GFRP Composite Wrapped Cylinders with Air- filled Debonds}

The percent area of debond for the cylinders wrapped with GFRP composite with air-filled debonds and their corresponding compressive strengths are given in Table 6-6.

Table 6-6 Ultimate compressive strength of GFRP composite wrapped cylinders with air-filled debonds

\begin{tabular}{|c|c|c|}
\hline $\begin{array}{c}\text { Percent Area of } \\
\text { Debond } \\
(\%)\end{array}$ & $\begin{array}{c}\text { Compressive Strength } \\
\text { (kips) }\end{array}$ & $\begin{array}{c}\text { Percent Decrease in } \\
\text { Compressive Strength } \\
\text { (\%) }\end{array}$ \\
\hline \hline 0 & $166.6^{1}$ & 0 \\
\hline 0.88 & 158.7 & 5.0 \\
\hline 1.73 & 134.8 & 19.1 \\
\hline 3.53 & 109.2 & 34.5 \\
\hline 7.95 & 110.7 & 33.6 \\
\hline
\end{tabular}

1) Value in the table is the average of three wrapped specimens without debonds

As seen from the table maximum decrease in compressive strength is in the case where one 2" x 2" air-filled debond is inserted on both sides $(34.5 \%)$. The decrease in compressive strength in case of cylinder with 3"x 3" air-filled debond is $33.6 \%$.

\subsubsection{Compressive Strength of GFRP Composite Wrapped Cylinders with Water-filled Debonds}

Table 6-7 summarizes the percent area of debond of GFRP composite wrapped cylinders with simulated water-filled debonds and also the corresponding compressive strength values.

Table 6-7 Ultimate compressive strength of GFRP composite wrapped cylinders with water-filled debonds

\begin{tabular}{|c|c|c|}
\hline $\begin{array}{c}\text { Percent Area of } \\
\text { Debond } \\
(\%)\end{array}$ & $\begin{array}{c}\text { Compressive Strength } \\
\text { (kips) }\end{array}$ & $\begin{array}{c}\text { Percent Decrease in } \\
\text { Compressive Strength } \\
\text { (\%) }\end{array}$ \\
\hline \hline 0 & $166.6^{(1)}$ & 0 \\
\hline 0.88 & 127.9 & 23.2 \\
\hline 1.73 & 139.7 & 16.1 \\
\hline 3.53 & 146.2 & 12.2 \\
\hline 7.95 & 112.0 & 32.8 \\
\hline
\end{tabular}

1) Value in the table is the average of three wrapped specimens without debonds 
Here also, we see that except for two specimens, other specimens show larger decrease in compressive strength with an increase in area of discontinuity. The erratic behavior of compressive strength with area of debond can be attributed to several factor such uneven top surface of the cylinder, misalignment in placing the cylinder on the loading platen, inadvertent creation of gaps between the composite layers while wrapping, some confinement provided by water-filled debonds, etc.

\subsubsection{Compressive Strength of GFRP Composite Wrapped Cylinders with Teflon Sheets}

Table 6-8 summarizes the percent area of debond of GFRP composite wrapped cylinders with simulated Teflon sheets and also the corresponding compressive strength values.

Table 6-8 Ultimate compressive strength of GFRP composite wrapped cylinders with Teflon sheets

\begin{tabular}{|c|c|c|}
\hline $\begin{array}{c}\text { Percent Area of } \\
\text { Debond } \\
\text { (\%) }\end{array}$ & $\begin{array}{c}\text { Compressive Strength } \\
\text { (kips) }\end{array}$ & $\begin{array}{c}\text { Percent Decrease in } \\
\text { Compressive Strength } \\
\text { (\%) }\end{array}$ \\
\hline \hline 0 & $166.6^{(1)}$ & 0 \\
\hline 0.88 & 160.1 & 3.9 \\
\hline 1.73 & 150.2 & 9.8 \\
\hline 3.53 & 156.8 & 5.9 \\
\hline
\end{tabular}

1) Value in the table is the average of three wrapped specimens without debonds

As we can see decrease in compressive strength is less in case of cylinders thin Teflon sheets than the ones with air-filled and water-filled debonds. This is expected as more the thickness more concrete has to expand in order to get in contact with the FRP composite. The erratic behavior of compressive strength with area of debond can be attributed to several factor such uneven top surface of the cylinder, misalignment in placing the cylinder on the loading platen, inadvertent creation of gaps between the composite layers while wrapping etc. 


\subsubsection{Ultimate Strain of Cylinders GFRP Composite Wrapped Cylinders with Simulated Flaws}

Table 6-9 tabulates the ultimate strain (axial and hoop) experienced by the cylinders wrapped with GFRP composite with simulated flaws, i.e., air-filled debond, water-filled debond and Teflon sheets. It should be noted all the hoop strain values given in this table were measured above the defect-free area. Also, all the reported strain values have been computed by subtracting the initial strain (correction factor, $\varepsilon_{0}$ ) as shown in Figures B5 to B53 in Appendix B. As can be seen from Table 6-9, barring a few cylinders, all the other cylinders show a decrease in both axial as well as circumferential strain due to the insertion of the simulated flaws. The maximum decrease in axial strain and hoop strain is in case of the cylinder having two 3" x 3" air-filled debond on both sides. Also, Water-filled debond does withstand more pressure than air-filled debond (Dutta 2006). Also, Teflon sheets are very thin as compared to the air-filled debonds. Hence, in case of cylinders having Teflon sheets, concrete has to expand less to make the GFRP composite effective. This is the reason why the decrease in both axial and hoop strain is most significant in case of air-filled debonds. Also, the value of axial strain is found to be higher than circumferential strain in all the cases. Table 6-10 summarizes the circumferential strain values above debonds. As can be seen from the table, hoop strain above the debond is always less than the corresponding value above the defect-free area. This can be attributed to the fact that the debonded area is not directly in contact with the concrete surface. So, it does not get dilated as effectively as the area that is directly in contact with concrete surface. 
Table 6-9 Ultimate strain of GFRP composite wrapped cylinders with simulated flaws

\begin{tabular}{|l|c|c|c|c|}
\hline \multirow{2}{*}{\multicolumn{1}{|c}{ Type of Flaw }} & \multicolumn{2}{c|}{ Ultimate Strain } & \multicolumn{2}{c|}{$\begin{array}{c}\text { Percent Decrease in } \\
\text { Strain }\end{array}$} \\
\cline { 2 - 5 } & Axial & Hoop ${ }^{(2)}$ & Axial & Hoop \\
\hline Defect-free & $0.0162^{(1)}$ & $0.0124^{(1)}$ & 0 & 0 \\
\hline One 1" x 1" air-filled debond on both sides & 0.0094 & $-{ }^{(3)}$ & 41.9 & - \\
\hline One 1.4" x 1.4" air-filled debond on both sides & 0.0142 & 0.0087 & 12.3 & 29.8 \\
\hline One 2" x 2" air-filled debond on both sides & 0.0175 & 0.0075 & -8.0 & 39.5 \\
\hline One 3" x 3" air-filled debond on both sides & 0.0088 & $-(3)$ & 45.7 & - \\
\hline One 1" x 1" water-filled debond on both sides & 0.0094 & 0.0072 & 42.0 & 41.9 \\
\hline One 1.4" x 1.4" water-filled debond on both sides & 0.0170 & 0.0131 & -4.9 & -5.6 \\
\hline One 2" x 2" water-filled debond on both sides & - & 0.0092 & - & 25.8 \\
\hline One 3" x 3" water-filled debond on both sides & 0.0125 & $-(3)$ & 22.8 & - \\
\hline One 1" x 1" Teflon on both sides & 0.0163 & 0.0125 & -0.6 & -0.8 \\
\hline One 1.4" x 1.4" Teflon on both sides & 0.0119 & - & 26.5 & - \\
\hline One 2" x 2" Teflon on both sides & 0.0144 & 0.0106 & 11.1 & 14.5 \\
\hline
\end{tabular}

1) Value in the table is the average of three wrapped specimens without debonds

2) Strain gauges are located above defect-free area

3) Premature tearing of strain gage 
Table 6-10 Hoop strain values above debonds of GFRP composite wrapped cylinders with simulated flaws

\begin{tabular}{|l|c|}
\hline \multicolumn{1}{|c|}{ Type of Flaw } & Ultimate Hoop Strain \\
\hline One 1" x 1" air-filled debond on both sides & $-(2)$ \\
\hline One 1.4" x 1.4" air-filled debond on both sides & 0.0029 \\
\hline One 3" x 3" air-filled debond on both sides & $-^{(2)}$ \\
\hline One 1.4" x 1.4" water-filled debond on both sides & 0.0044 \\
\hline One 2" x 2" water-filled debond on both sides & (2) $^{(2)}$ \\
\hline
\end{tabular}

1) Strain gauges are located above debonds

2) Premature tearing of strain gage

\subsubsection{Volumetric strain and Axial Strain Relationship for GFRP composite wrapped cylinders with simulated flaws}

Volumetric strain is defined by Saenz et al. 2007 as:

$\varepsilon_{\mathrm{v}}=\varepsilon_{\mathrm{c}}+2 \varepsilon_{\theta}$

where $\varepsilon_{\mathrm{v}}$ is the volumetric strain, $\varepsilon_{\mathrm{c}}$ is the axial compressive strain and $\varepsilon_{\theta}$ is the radial strain. In this equation, axial strain is taken as positive and radial strain is taken as negative. At the initial stage of axial compressive loading, concrete exhibits volumetric contraction. As the axial compressive strength increases, radial strain increases at a higher rate than the axial strain. As a result, volumetric strain starts reducing as the material gradually enters the expansion zone. This essentially means that volumetric strain at some point of loading may become zero. This point of zero volumetric strain is of particular interest because it marks the onset of dilation response of FRP confined concrete meaning FRP composite wrap begins to resist the stiffness degradation of the confined concrete (Saenz et al. 2007). Since FRP composite wrap reduces the dilation of concrete, the axial strain at which volumetric strain becomes zero is an important parameter. Table 6-11 gives the axial strain values at which volumetric strain becomes zero for cylinders wrapped with GFRP composite. 
Table 6-11 Axial strain values at zero volumetric strain of GFRP composite wrapped cylinders

\begin{tabular}{|c|c|}
\hline Type of Flaw & $\begin{array}{c}\text { Axial Strain at Zero } \\
\text { Volumetric Strain }\end{array}$ \\
\hline Defect free cylinder number 1 & 0.0114 \\
\hline Defect free cylinder number 2 & 0.0122 \\
\hline Defect free cylinder number 3 & 0.0136 \\
\hline One 1" x 1" air-filled debond on both sides & --- \\
\hline One 1.4" x 1.4" air-filled debond on both sides & 0.0085 \\
\hline One $2 "$ x 2" air-filled debond on both sides & --- \\
\hline One $3 "$ x 3" air-filled debond on both sides & --- \\
\hline One $1 " \mathrm{x} 1$ " water-filled debond on both sides & 0.0075 \\
\hline One $1.4 " \mathrm{"} \mathrm{x} 1.4$ " water-filled debond on both sides & 0.0125 \\
\hline One $2 "$ x 2" water-filled debond on both sides & -- \\
\hline One 3" x 3" water-filled debond on both sides & --- \\
\hline One 1" x 1" Teflon sheet on both sides & 0.0127 \\
\hline One 1.4" x 1.4" Teflon sheet on both sides & --- \\
\hline One $2 "$ x 2" Teflon sheet on both sides & 0.0112 \\
\hline
\end{tabular}

As we can see from the above table, for majority of the cylinders tested, the volumetric strain never reached zero meaning FRP composite casing was effective in arresting the dilation of concrete. For these cases, the axial strain value at zero volumetric strain is not reported. 


\subsubsection{Compressive Strength of CFRP Composite Wrapped Cylinders with Air- filled Debonds}

The percent area of debond for the cylinders wrapped with CFRP composite with air-filled debonds and their corresponding compressive strengths are given in Table 6-12.

Table 6-12 Ultimate compressive strength of CFRP composite wrapped cylinders with air-filled debonds

\begin{tabular}{|c|c|c|}
\hline $\begin{array}{c}\text { Percent Area of } \\
\text { Debond } \\
\text { (\%) }\end{array}$ & $\begin{array}{c}\text { Compressive Strength } \\
\text { (kips) }\end{array}$ & $\begin{array}{c}\text { Percent Decrease in } \\
\text { Compressive Strength } \\
(\%)\end{array}$ \\
\hline \hline 0 & $250.0^{(1)}$ & 0 \\
\hline 0.88 & 172.3 & 31.1 \\
\hline 1.73 & 229.8 & 8.1 \\
\hline 3.53 & 187.2 & 25.1 \\
\hline 7.95 & 201.5 & 19.4 \\
\hline
\end{tabular}

1) Value in the table is the average of two wrapped specimens without debonds

As seen from the Table 6-12, barring the data for one cylinder with 1" $\mathrm{x}$ 1" airfilled debond is inserted on both sides, maximum decrease in compressive strength shows the usual trend of decrease in compressive strength although the compressive strength with 3.53 percent debonded area is slightly lower than the corresponding value with 7.95 percent debonded area. This can be attributed to many factors such as unevenness in top surface of the cylinder, extra air gap created during wrapping etc.

\subsubsection{Compressive Strength of CFRP Composite Wrapped Cylinders with Water-filled Debonds}

Table 6-13 summarizes the percent area of debond of CFRP composite wrapped cylinders with simulated water-filled debonds and also the corresponding compressive strength values. Here also, we see that except for two specimens, other specimens show larger decrease in compressive strength with an increase in area of discontinuity. The erratic behavior can again be attributed to factors such as surface unevenness, air gap between the wrap and underlying concrete surface etc. 
Table 6-13 Ultimate compressive strength of CFRP composite wrapped cylinders with water-filled debonds

\begin{tabular}{|c|c|c|}
\hline $\begin{array}{c}\text { Percent Area of } \\
\text { Debond } \\
(\%)\end{array}$ & $\begin{array}{c}\text { Compressive Strength } \\
\text { (kips) }\end{array}$ & $\begin{array}{c}\text { Percent Decrease in } \\
\text { Compressive Strength } \\
\text { (\%) }\end{array}$ \\
\hline \hline 0 & $250.0^{(1)}$ & 0 \\
\hline 0.88 & 156.0 & 37.6 \\
\hline 1.73 & 187.3 & 25.1 \\
\hline 3.53 & 143.5 & 42.6 \\
\hline
\end{tabular}

1) Value in the table is the average of two wrapped specimens without debonds

Here also, we see that except for two specimens, other specimens show larger decrease in compressive strength with an increase in area of discontinuity. The erratic behavior can again be attributed to factors such as surface unevenness, air gap between the wrap and underlying concrete surface etc.

\subsubsection{Compressive Strength of CFRP Composite Wrapped Cylinders with Teflon Sheets}

Table 6-14 summarizes the percent area of debond of GFRP composite wrapped cylinders with simulated Teflon sheets and also the corresponding compressive strength values.

Table 6-14 Ultimate compressive strength of CFRP composite wrapped cylinders with Teflon sheets

\begin{tabular}{|c|c|c|}
\hline $\begin{array}{c}\text { Percent Area of } \\
\text { Debond } \\
\text { (\%) }\end{array}$ & $\begin{array}{c}\text { Compressive Strength } \\
\text { (kips) }\end{array}$ & $\begin{array}{c}\text { Percent Decrease in } \\
\text { Compressive Strength } \\
\text { (\%) }\end{array}$ \\
\hline \hline 0 & $250.0^{(1)}$ & 0 \\
\hline 0.88 & 199.8 & 20.1 \\
\hline 1.73 & 201.5 & 19.4 \\
\hline 3.53 & 196.0 & 21.6 \\
\hline 7.95 & 187.7 & 24.9 \\
\hline
\end{tabular}

1) Value in the table is the average of two wrapped specimens without debonds

As we can see, barring the case of the cylinder with 1.73 percent of debonds, decrease in compressive strength follows the usual trend of decrease in compressive strength with increase in non contact.area. 


\subsubsection{Ultimate Strain of Cylinders CFRP Composite Wrapped Cylinders with Simulated Flaws}

Table 6-15 tabulates the ultimate axial and hoop strain experienced by the cylinders wrapped with CFRP composite with simulated flaws i.e. air-filled debond, water-filled debond and Teflon sheets. It should be noted all the hoop strain values given in this table were measured above the defect-free area.. The maximum decrease in hoop strain is in case of the cylinder having two 3" x 3" air-filled debond on both sides. The maximum decrease in axial strain is in case of the cylinder having two 1.4" x 1.4" waterfilled debond on both sides. Also, the value of axial strain is found to be higher than circumferential strain in all the cases.

In most of the cases, volumetric strain does not go to zero which indicates effective confinement. 
Table 6-15 Ultimate strain of CFRP composite wrapped cylinders with simulated flaws

\begin{tabular}{|c|c|c|c|c|}
\hline \multirow[t]{2}{*}{ Type of Flaw } & \multicolumn{2}{|c|}{ Ultimate Strain } & \multicolumn{2}{|c|}{$\begin{array}{l}\text { Percent Decrease } \\
\text { in Strain }\end{array}$} \\
\hline & Axial & Hoop $^{(1)}$ & Axial & Hoop \\
\hline Defect-free & 0.0197 & 0.0094 & 0 & 0 \\
\hline $\begin{array}{l}\text { One 1" x 1" air-filled debond on both } \\
\text { sides }\end{array}$ & - & 0.0053 & - & 43.6 \\
\hline $\begin{array}{l}\text { One } 1.4 " \text { x } 1.4 \text { " air-filled debond on } \\
\text { both sides }\end{array}$ & 0.0208 & 0.0091 & -5.6 & 3.2 \\
\hline $\begin{array}{l}\text { One } 2 " \text { x 2" air-filled debond on both } \\
\text { sides }\end{array}$ & 0.0139 & 0.0039 & 29.4 & 58.5 \\
\hline $\begin{array}{l}\text { One } 3 " \text { x } 3 " \text { air-filled debond on both } \\
\text { sides }\end{array}$ & 0.0111 & 0.0018 & 43.7 & 80.9 \\
\hline $\begin{array}{l}\text { One } 1 " \text { x } 1 \text { " water-filled debond on } \\
\text { both sides }\end{array}$ & 0.0134 & 0.0018 & 32.0 & 80.9 \\
\hline $\begin{array}{l}\text { One } 1.4 " \text { x } 1.4 " \text { water-filled debond } \\
\text { on both sides }\end{array}$ & 0.0082 & 0.0014 & 58.4 & 85.1 \\
\hline $\begin{array}{l}\text { One } 2 " \text { × } 2 " \text { water-filled debond on } \\
\text { both sides }\end{array}$ & - & - & - & - \\
\hline $\begin{array}{l}\text { One } 3 " \text { x 3" water-filled debond on } \\
\text { both sides }\end{array}$ & 0.0099 & 0.0071 & 49.7 & 24.5 \\
\hline One $1 " \mathrm{x} 1$ " Teflon on both sides & 0.0102 & 0.0021 & 48.2 & 77.7 \\
\hline One $1.4 " \mathrm{x} 1.4 "$ Teflon on both sides & 0.0166 & 0.0073 & 15.7 & 22.3 \\
\hline One 2" x 2" Teflon on both sides & 0.0092 & 0.0038 & 53.3 & 59.6 \\
\hline One $3 "$ x 3" Teflon on both sides & 0.0115 & 0.0047 & 41.6 & 50.0 \\
\hline
\end{tabular}

1) Strain gauges are located above defect-free area 


\subsubsection{Volumetric strain and Axial Strain Relationship for CFRP composite wrapped cylinders with simulated flaws}

Table 6-16 gives the axial strain values at which volumetric strain becomes zero for cylinders wrapped with CFRP composite. Several values in the table are blank which indicates that effective confinement was provided by the wrap and the volumetric strain did not go to the zero value.

Table 6-16 Axial strain values at zero volumetric strain of CFRP composite wrapped cylinders

\begin{tabular}{|c|c|}
\hline Type of Flaw & Axial Strain at Zero Volumetric Strain \\
\hline Defect free cylinder number 1 & 0.0121 \\
\hline Defect free cylinder number 2 & - \\
\hline One 1" x 1" air-filled debond on both sides & - \\
\hline $\begin{array}{l}\text { One } 1.4 " \text { x } 1.4 \text { " air-filled debond on both } \\
\text { sides }\end{array}$ & - \\
\hline One 2" x 2" air-filled debond on both sides & - \\
\hline One $3 "$ x 3" air-filled debond on both sides & - \\
\hline $\begin{array}{l}\text { One 1" } 1 " \text { N } 1 \text { " water-filled debond on both } \\
\text { sides }\end{array}$ & -- \\
\hline $\begin{array}{l}\text { One } 1.4 " \text { x } 1.4 \text { " water-filled debond on both } \\
\text { sides }\end{array}$ & -- \\
\hline $\begin{array}{l}\text { One } 2 " \text { × 2" water-filled debond on both } \\
\text { sides }\end{array}$ & 0.0529 \\
\hline $\begin{array}{l}\text { One 3" x 3" water-filled debond on both } \\
\text { sides }\end{array}$ & -- \\
\hline One 1" x 1" Teflon sheet on both sides & - \\
\hline One $1.4^{\prime \prime}$ x 1.4" Teflon sheet on both sides & - \\
\hline One $2 "$ x 2" Teflon sheet on both sides & --- \\
\hline One 3" x 3" Teflon sheet on both sides & - \\
\hline
\end{tabular}




\subsubsection{Conclusion}

Barring few exceptions, it can be seen from the Table 6-6 to Table 6-8 and Table 6-12 to table 6-14 that axial compressive strength of columns decreases with an increase in the percentage area of debonds between the FRP composite (CFRP and GFRP) and the underlying concrete surface. Decrease in compressive strength in case of GFRP composite wrapped cylinders with Teflon sheets was less than the corresponding airfilled and water-filled debond cases. The decrease in both axial and hoop strain is most significant in case of air-filled debonds for GFRP composite wrapped cylinders. Also, the value of axial strain is found to be higher than circumferential strain in all the cylinders wrapped with GFRP composite. Also, for GFRP composite wrapped cylinders, hoop strain above the debond is always less than the corresponding value above the defect-free area. Also, for GFRP composite wrapped specimens, barring a few exceptions, axial strain at which volumetric strain becomes zero reduces as the debond size increases. In some cases the volumetric strain never reached zero meaning FRP composite casing was effective in arresting the dilation of concrete. In case of CFRP composite wrapped specimens, FRP composite was effective in arresting the radial expansion of underlying concrete in most of the cases.

\subsection{DUCTILITY ENHANCEMENT}

Ductility enhancement is very much desirable in structural components because of the stress redistribution that it facilitates. The ductility enhancement factor is given by the ratio of ultimate axial strain of the wrapped member to the ultimate axial strain at of plain concrete specimen. Table 6-17 and Table 6-18 summarizes the ductility enhancement for various concrete specimens wrapped with GFRP composite and CFRP composite, respectively. 
Table 6-17 Ductility enhancement of GFRP composite wrapped cylinders

\begin{tabular}{|l|c|}
\hline \multicolumn{1}{|c|}{ Type of Flaw } & Ductility Enhancement Factor \\
\hline \hline Defect free cylinder number 1 & 3.7 \\
\hline Defect free cylinder number 2 & 3.4 \\
\hline Defect free cylinder number 3 & 2.1 \\
\hline One 1" x 1" air-filled debond on both sides & 3.2 \\
\hline One 1.4" x 1.4" air-filled debond on both sides & 3.9 \\
\hline One 2" x 2" air-filled debond on both sides & 2.0 \\
\hline One 3" x 3" air-filled debond on both sides & 2.1 \\
\hline One 1" x 1" water-filled debond on both sides & 3.8 \\
\hline One 1.4" x 1.4" water-filled debond on both sides & --- \\
\hline One 2" x 2" water-filled debond on both sides & 2.8 \\
\hline One 3" x 3" water-filled debond on both sides & 3.6 \\
\hline One 1" x 1" Teflon sheet on both sides & 2.6 \\
\hline One 1.4" x 1.4" Teflon sheet on both sides & 3.2 \\
\hline One 2" x 2" Teflon sheet on both sides & \\
\hline
\end{tabular}

As seen from the table, 3" x 3" air-filled debond resulted in the least ductility enhancement. As evident from the table ductility of the defective cylinders is less than the defect free specimens excepting the case of the cylinder with 1.4" x 1.4" water-filled debond. Also it is evident that ductility was increased due to wrapping as the ductility enhancement ratio is greater than one in all the cases. 
Table 6-18 Ductility enhancement of CFRP composite wrapped cylinders

\begin{tabular}{|l|c|}
\hline \multicolumn{1}{|c|}{ Type of Flaw } & Ductility Enhancement Factor \\
\hline \hline Defect free cylinder number 1 & 5.9 \\
\hline Defect free cylinder number 2 & 5.9 \\
\hline One 1" x 1" air-filled debond on both sides & 4.6 \\
\hline One 1.4" x 1.4" air-filled debond on both sides & 3.1 \\
\hline One 2" x 2" air-filled debond on both sides & 2.5 \\
\hline One 3" x 3" air-filled debond on both sides & 3.0 \\
\hline One 1" x 1" water-filled debond on both sides & 1.8 \\
\hline One 1.4" x 1.4" water-filled debond on both sides & 13.5 \\
\hline One 2" x 2" water-filled debond on both sides & 2.2 \\
\hline One 3" x 3" water-filled debond on both sides & 2.3 \\
\hline One 1" x 1" Teflon sheet on both sides & 3.7 \\
\hline One 1.4" x 1.4" Teflon sheet on both sides & 2.0 \\
\hline One 2" x 2" Teflon sheet on both sides & 2.6 \\
\hline One 3" x 3" Teflon sheet on both sides & \\
\hline
\end{tabular}

As seen from the table, 1.4" $\mathrm{x} 1.4$ " water-filled debond resulted in the least ductility enhancement. Except for the cylinder with 2" x 2" water-filled debond, ductility of defective cylinders is less than the average ductility of defect free specimens. Apart from two specimens, ductility was increased due to wrapping. Barring a few cylinders, wrapping with carbon increases the ductility as seen from Table 6-17 and Table 6-18. This is because of presence of angular fabric $\left( \pm 45^{\circ}\right)$ that helps in fiber reorientation mechanism. 


\subsection{COMPARISON BETWEEN ANALYTICAL MODELS AND EXPERIMENTAL RESULTS}

The maximum confinement pressure $\mathrm{p}_{\mathrm{u}}$ that can be exerted by the confining device can be found by equating circumferential strain to ultimate strain $\varepsilon_{f u}$ of FRP fabric and is given by:

$\mathrm{p}_{\mathrm{u}}=\mathrm{E}_{\mathrm{l}} \varepsilon_{\mathrm{fu}}=\left(2 \mathrm{f}_{\mathrm{fu}} \mathrm{nt}\right) / \mathrm{D}$

where $f_{f u}$ is the ultimate tensile strength of FRP composite, $n$ is the number of layers in the FRP laminate, $t$ is the thickness of each layer of FRP composite and $\mathrm{D}$ is the diameter of the concrete cylinder.

The experimental results of the study (results of concrete cylinders wrapped with CFRP composite and GFRP composite without any debonds) were compared with analytical calculation as furnished below.

All of the following models are listed in the research study by De Lorenzis et al. (2003).

\subsubsection{GFRP Composite Wrapped Cylinders}

\section{Model 1}

This model is proposed by Miyauchi et al. (1997) and confined compressive strength of concrete is given by

$$
\frac{f^{\prime}{ }_{c c}}{f^{\prime}{ }_{c o}}=1+3.485\left(\frac{p_{u}}{f^{\prime}{ }_{c o}}\right)
$$

Where $p_{u}$ is the theoretical maximum confinement pressure that can be exerted by the confinement device, $\mathrm{f}^{\prime}{ }_{c o}$ is the unconfined compressive strength and $\mathrm{f}^{\prime}{ }_{\mathrm{cc}}$ is the confined compressive strength of concrete.

$\mathrm{p}_{\mathrm{u}}=\left(2 \mathrm{f}_{\mathrm{fu}} \mathrm{nt}\right) / \mathrm{D}$

Where $\mathrm{D}$ is diameter of the cylinder, $\mathrm{n}$ is the number of FRP layers, $\mathrm{t}$ is the thickness of each layer of FRP composite and $\mathrm{f}_{\mathrm{fu}}$ is the ultimate tensile stress of FRP composite. 
In our case,

$\mathrm{D}=6$ in

$\mathrm{n}=3$

$\mathrm{f}_{\mathrm{fu}}=44.5 \mathrm{ksi}$

$\mathrm{t}=0.0289 \mathrm{in}$

$\frac{f^{\prime}{ }_{c c}}{f^{\prime}{ }_{c o}}=5.1$

Experimental increase in compressive strength $=5.4$

Experimental increase in confined compressive strength/ Analytical increase confined compressive strength

$=5.4 / 5.1=1.06$

\section{Model 2}

This model is proposed by Toutanji (1999) and confined compressive strength of

concrete is given by

$\frac{f_{c c}^{\prime}}{f_{c o}^{\prime}}=1+3.5\left(\frac{p_{u}}{f_{c o}^{\prime}}\right)^{0.85}$

where the terms in the equation are already explained above

$$
\frac{f^{\prime}{ }_{c c}}{f^{\prime}{ }_{c o}}=5.0
$$

Experimental increase in compressive strength $=5.4$

Experimental increase in confined compressive strength/ Analytical increase confined compressive strength

$=5.4 / 5.0=1.08$

\section{Model 3}

This model is proposed by Saaman et al. (1998) and confined compressive strength of concrete is given by

$$
\frac{f_{c c}^{\prime}}{f^{\prime}{ }_{c o}}=1+6.0\left(\frac{p_{u}^{0.7}}{f^{\prime}{ }_{c o}}\right)
$$

where the terms in the equation are already explained above

$$
\frac{f^{\prime}{ }_{c c}}{f^{\prime}{ }_{c o}}=7.5
$$


Experimental increase in compressive strength $=5.4$

Experimental increase in confined compressive strength/ Analytical increase confined compressive strength

$=5.4 / 7.5=0.72$

\section{Model 4}

This model is proposed by Saafi et al. (1999) and confined compressive strength of concrete is given by

$$
\frac{f_{c c}^{\prime}}{f_{c o}^{\prime}}=1+2.2\left(\frac{p_{u}}{f_{c o}^{\prime}}\right)^{0.84}
$$

where the terms in the equation are already explained above

$$
\frac{f^{\prime}{ }_{c c}}{f^{\prime}{ }_{c o}}=3.5
$$

Experimental increase in compressive strength $=5.4$

Experimental increase in confined compressive strength/ Analytical increase confined compressive strength

$=5.4 / 3.5=1.54$

\section{Model 5}

This model is proposed by Spoelstra and Monti (1998) ("approximate") and confined compressive strength of concrete is given by

$$
\frac{f^{\prime}{ }_{c c}}{f^{\prime}{ }_{c o}}=0.2+3\left(\frac{p_{u}}{f_{c o}^{\prime}}\right)^{0.5}
$$

where the terms in the equation are already explained above

$$
\frac{f^{\prime}{ }_{c c}}{f^{\prime}{ }_{c o}}=3.4
$$

Experimental increase in compressive strength $=5.4$

Experimental increase in confined compressive strength/ Analytical increase confined compressive strength

$=5.4 / 3.4=1.59$ 


\section{Model 6}

This model is proposed by Kono et al. (1998) and confined compressive strength of concrete is given by

$$
\frac{f^{\prime}{ }_{c c}}{f^{\prime}{ }_{c o}}=1+0.0572 \times p_{u}
$$

where the terms in the equation are already explained above

$$
\frac{f^{\prime}{ }_{c c}}{f^{\prime}{ }_{c o}}=1.1
$$

Experimental increase in compressive strength $=5.4$

Experimental increase in confined compressive strength/ Analytical increase confined compressive strength

$=5.4 / 1.1=4.91$

\section{Model 7}

This model is proposed by Mander et al. (1988) and is used in ACI 440.2R-02 to predict the confined compressive strength of concrete. The equation is given by

$$
\frac{f^{\prime}{ }_{c c}}{f^{\prime}{ }_{c o}}=2.25 \times \sqrt{1+7.9 \frac{p_{u}}{f^{\prime}{ }_{c o}}}-2 \times \frac{p_{u}}{f^{\prime}{ }_{c o}}-1.25
$$

where the terms in the equation are already explained above

$$
\frac{f^{\prime}{ }_{c c}}{f^{\prime}{ }_{c o}}=3.6
$$

Experimental increase in compressive strength $=5.4$

Experimental increase in confined compressive strength/ Analytical increase confined compressive strength

$=5.4 / 3.6=1.50$

The experimental values were compared with the analytical models (Table 6-19) and the model by Miyauchi et al. (1997) provided the best correlation with the experimental results, with Toutanji (1999) as the close second. All the models except Saaman et al. (1998) under predicted the value of confined concrete strength. 
Table 6-19 Comparison between experimental and analytical compressive strength of concrete cylinders wrapped with GFRP composite

\begin{tabular}{|c|c|c|c|c|c|c|}
\hline \multicolumn{7}{|c|}{ Experimental Increase in Strength / Analytical Increase in Strength } \\
\hline \hline $\begin{array}{c}\text { Kono } \\
\text { et al. }\end{array}$ & $\begin{array}{c}\text { Miyauchi } \\
\text { et al. } \\
(1997)\end{array}$ & $\begin{array}{c}\text { Toutanji } \\
(1999)\end{array}$ & $\begin{array}{c}\text { Saaman } \\
\text { et al. }\end{array}$ & $\begin{array}{c}\text { Saafi } \\
\text { et al. }\end{array}$ & $\begin{array}{c}\text { Spoelstra and Monti } \\
(1998)\end{array}$ & $\begin{array}{c}\text { Mander } \\
\text { et al. }\end{array}$ \\
\hline 4.91 & 1.06 & 1.08 & 0.72 & 1.54 & (“approximate”) & $(1988)$ \\
\hline
\end{tabular}

\subsubsection{CFRP Composite Wrapped Cylinders}

\section{Model 1}

This model is proposed by Miyauchi et al. (1997) and confined compressive strength of concrete is given by

$$
\frac{f_{c c}^{\prime}}{f_{c o}^{\prime}}=1+3.485\left(\frac{p_{u}}{f^{\prime}{ }_{c o}}\right)
$$

Where $p_{u}$ is the theoretical maximum confinement pressure that can be exerted by the confinement device, $\mathrm{f}^{\prime}{ }_{\text {co }}$ is the unconfined compressive strength and $\mathrm{f}^{\prime}{ }_{\mathrm{cc}}$ is the confined compressive strength of concrete.

$\mathrm{p}_{\mathrm{u}}=\left(2 \mathrm{f}_{\mathrm{fu}} \mathrm{nt}\right) / \mathrm{D}$

Where $\mathrm{D}$ is diameter of the cylinder, $\mathrm{n}$ is the number of FRP layers, $\mathrm{t}$ is the thickness of each layer of FRP composite and $\mathrm{f}_{\mathrm{fu}}$ is the ultimate tensile strength of FRP composite.

In our case,

$\mathrm{D}=6$ in

$\mathrm{n}=3$

$\mathrm{f}_{\mathrm{fu}}=50.9 \mathrm{ksi}$

$\mathrm{t}=0.0394$ in

$\frac{f^{\prime}{ }_{c c}}{f^{\prime}{ }_{c o}}=7.4$

Experimental increase in compressive strength $=8.0$

Experimental increase in confined compressive strength/ Analytical increase confined compressive strength

$=8.0 / 7.4=1.08$ 


\section{Model 2}

This model is proposed by Toutanji (1999) and confined compressive strength of concrete is given by

$\frac{f_{c c}^{\prime}}{f_{c o}^{\prime}}=1+3.5\left(\frac{p_{u}}{f_{c o}^{\prime}}\right)^{0.85}$

where the terms in the equation are already explained above

$\frac{f^{\prime}{ }_{c c}}{f^{\prime}{ }_{c o}}=6.8$

Experimental increase in compressive strength $=8.0$

Experimental increase in confined compressive strength/ Analytical increase confined compressive strength

$=8.0 / 6.8=1.17$

\section{Model 3}

This model is proposed by Saaman et al. (1998) and confined compressive strength of concrete is given by

$$
\frac{f_{c c}^{\prime}}{f_{c o}^{\prime}}=1+6.0\left(\frac{p_{u}^{0.7}}{f_{c o}^{\prime}}\right)
$$

where the terms in the equation are already explained above

$$
\frac{f^{\prime}{ }_{c c}}{f^{\prime}{ }_{c o}}=9.9
$$

Experimental increase in compressive strength $=8.0$

Experimental increase in confined compressive strength/ Analytical increase confined compressive strength

$=8.0 / 9.9=0.81$

\section{Model 4}

This model is proposed by Saafi et al. (1999) and confined compressive strength of concrete is given by

$$
\frac{f_{c c}^{\prime}}{f_{c o}^{\prime}}=1+2.2\left(\frac{p_{u}}{f_{c o}^{\prime}}\right)^{0.84}
$$

where the terms in the equation are already explained above 


$$
\frac{f^{\prime}{ }_{c c}}{f^{\prime}{ }_{c o}}=4.6
$$

Experimental increase in compressive strength $=8.0$

Experimental increase in confined compressive strength/ Analytical increase confined compressive strength

$=8.0 / 4.6=1.74$

\section{Model 5}

This model is proposed by Spoelstra and Monti (1998) ("approximate") and confined compressive strength of concrete is given by

$\frac{f^{\prime}{ }_{c c}}{f^{\prime}{ }_{c o}}=0.2+3\left(\frac{p_{u}}{f^{\prime}{ }_{c o}}\right)^{0.5}$

where the terms in the equation are already explained above

$\frac{f^{\prime}{ }_{c c}}{f^{\prime}{ }_{c o}}=4.3$

Experimental increase in compressive strength $=8.0$

Experimental increase in confined compressive strength/ Analytical increase confined compressive strength

$=8.0 / 4.3=1.86$

\section{Model 6}

This model is proposed by Kono et al. (1998) and confined compressive strength of concrete is given by

$\frac{f^{\prime}{ }_{c c}}{f^{\prime}{ }_{c o}}=1+0.0572 \times p_{u}$

where the terms in the equation are already explained above

$\frac{f^{\prime}{ }_{c c}}{f^{\prime}{ }_{c o}}=1.1$

Experimental increase in compressive strength $=8.0$

Experimental increase in confined compressive strength/ Analytical increase confined compressive strength

$=8.0 / 1.1=7.27$ 


\section{Model 7}

This model is proposed by Mander et al. (1988) and is used in ACI 440.2R-02 to predict the confined compressive strength of concrete. The equation is given by

$$
\frac{f_{c c}^{\prime}}{f_{c o}^{\prime}}=2.25 \times \sqrt{1+7.9 \frac{p_{u}}{f_{c o}^{\prime}}}-2 \times \frac{p_{u}}{f_{c o}^{\prime}}-1.25
$$

where the terms in the equation are already explained above

$$
\frac{f^{\prime}{ }_{c c}}{f^{\prime}{ }_{c o}}=3.9
$$

Experimental increase in compressive strength $=8.0$

Experimental increase in confined compressive strength/ Analytical increase confined compressive strength

$=8.0 / 3.9=2.05$

The experimental values were compared with the analytical models (Table 6-20) and model by Miyauchi et al. (1997) provided the best correlation with the experimental results. Models by Toutanji (1999), Saafi et el. (1999), Mander et al. (1988), Spoelstra and Monti (1998) (“approximate") and Kono et al. (1998) under predicted the value of confined concrete strength.

Table 6-20 Comparison between experimental and analytical compressive strength of concrete cylinders wrapped with CFRP composite

\begin{tabular}{|c|c|c|c|c|c|c|}
\hline \multicolumn{7}{|c|}{ Experimental Increase in Strength / Analytical Increase in Strength } \\
\hline \hline $\begin{array}{c}\text { Kono } \\
\text { et al. }\end{array}$ & $\begin{array}{c}\text { Miyauchi } \\
\text { et al. } \\
(1998)\end{array}$ & $\begin{array}{c}\text { Toutanji } \\
(1997)\end{array}$ & $\begin{array}{c}\text { Saaman } \\
\text { et al. }\end{array}$ & $\begin{array}{c}\text { Saafi } \\
\text { et al. }\end{array}$ & $\begin{array}{c}\text { Spoelstra and Monti } \\
(1999)\end{array}$ & $\begin{array}{c}\text { Mander } \\
\text { et al. } \\
(1998)\end{array}$ \\
\hline 7.27 & 1.08 & 1.17 & 0.81 & 1.74 & ("approximate") & $(1988)$ \\
\hline
\end{tabular}

\subsubsection{Relation between Debonded Area and Confined Compressive Strength}

Based on the model that showed the best fit with the experimental data (Miyauchi et al. 1997), an attempt was made to correlate the debonded area (air-filled debond) with the confined compressive strength. Equation by Mander et al (1988) that is used by ACI 440.2R-02 was also considered for this correlation. Separate multiplying factors for the two models were derived for cylinders that had air-filled debonds glued to the concrete surface. These factors when multiplied to the existing expressions for the models gave the 
confined compressive strength of the cylinders that had air-filled debonds within acceptable accuracy. The equation was derived for GFRP composite wrapped cylinders with air-filled debonds and for CFRP composite wrapped cylinders with Teflon sheets.

\subsubsection{GFRP Composite Wrapped Cylinders}

As seen from the previous section, model by Miyauchi et al. (1997) provided the best approximation with the experimental results for GFRP composite wrapped cylinders. The increase in confined compressive strengths for the various debonded area is divided by increase in confined compressive strength from the model (equation 6.3) to get the multiplying factor. These multiplying factors were plotted against the debonded area and a regression equation was obtained. This equation is the factor that has to be multiplied to the equation of the model to get the confined compressive strengths for various debonded areas. The multiplying factors and equations relating various areas of defects as based on the model by Miyauchi et al. (1997) are as follows:

- Multiplying factor : $-0.1437 \times \ln (a)+0.9441$

- Equation : $f^{\prime}{ }_{c c}=f^{\prime}{ }_{c o} \times(-0.1437 \times \ln (a)+0.9441) \times\left(1+3.485\left(\frac{p_{u}}{f^{\prime}{ }_{c o}}\right)\right)$

Following the same procedure, multiplying factor based on the model by Mander et al. (1988) as per equation (6.9), is also derived. For this model:

- $\quad$ Multiplying factor : $-0.2035 \times \ln (a)+1.3374$

- Equation:

$$
f^{\prime}{ }_{c c}=f^{\prime}{ }_{c o} \times(-0.2035 \times \ln (a)+1.3374) \times\left(2.25 \times \sqrt{1+7.9 \frac{p_{u}}{f_{c o}^{\prime}}}-2 \times \frac{p_{u}}{f_{c o}^{\prime}}-1.25\right)
$$

Where $p_{u}$ is the theoretical maximum confinement pressure that can be exerted by the confinement device, $\mathrm{f}^{\prime}$ co is the unconfined compressive strength, $a$ is the percent area of debond and $\mathrm{f}_{\mathrm{cc}}$ is the confined compressive strength of concrete.

Table 6-21 and Table 6-22 summarize the predicted values of the compressive strengths based on equation 6.17 and equation 6.18 along with the percentage error. 
Table 6-21 Comparison between predicted compressive strength and experimental compressive strength for GFRP composite wrapped cylinders with air-filled debonds based on equation 6.17

\begin{tabular}{|c|c|c|c|}
\hline $\begin{array}{c}\text { Percent Area of } \\
\text { Debond } \\
\text { (\%) }\end{array}$ & $\begin{array}{c}\text { Experimental Compressive } \\
\text { Strength } \\
\text { (kips) }\end{array}$ & $\begin{array}{c}\text { Predicted Compressive } \\
\text { Strength } \\
\text { (kips) }\end{array}$ & $\begin{array}{c}\text { Error } \\
\text { (\%) }\end{array}$ \\
\hline 0.88 & 158.7 & 152.7 & 3.8 \\
\hline 1.73 & 134.8 & 137.3 & -1.8 \\
\hline 3.53 & 109.2 & 121.0 & -10.8 \\
\hline 7.95 & 110.7 & 102.5 & 7.4 \\
\hline
\end{tabular}

Table 6-22 Comparison between predicted compressive strength and experimental compressive strength for GFRP composite wrapped cylinders with air-filled debonds based on equation 6.18

\begin{tabular}{|c|c|c|c|}
\hline $\begin{array}{c}\text { Percent Area of } \\
\text { Debond } \\
\text { (\%) }\end{array}$ & $\begin{array}{c}\text { Experimental Compressive } \\
\text { Strength } \\
\text { (kips) }\end{array}$ & $\begin{array}{c}\text { Predicted Compressive } \\
\text { Strength } \\
\text { (kips) }\end{array}$ & $\begin{array}{c}\text { Error } \\
\text { (\%) }\end{array}$ \\
\hline 0.88 & 158.7 & 152.6 & 3.8 \\
\hline 1.73 & 134.8 & 137.2 & -1.8 \\
\hline 3.53 & 109.2 & 121.0 & -10.8 \\
\hline 7.95 & 110.7 & 102.5 & 7.4 \\
\hline
\end{tabular}


As we can see, in terms of percentage error, both the equations are quite identical. However, model by Miyauchi et al. (1997) has a better predictability with the experimental results for wrapped specimens without debonds. Hence, equation 6.17 should be used to predict the compressive strength of GFRP composite wrapped concrete cylinders for different area of debonds.

Figure 6-1 and 6-2 show the predicted compressive strength value and the experimental compressive strength values of all the cylindrical tested specimens in accordance with equation 6.17 and equation 6.18 respectively. Figure 6-3 and 6-4 show the predicted compressive stress value and the experimental compressive stress values of all the cylindrical tested specimens in accordance with equation 6.17 and equation 6.18 respectively. As can be seen from the plots, the predicted values are less than the actual compressive strength values for most of the specimens. 


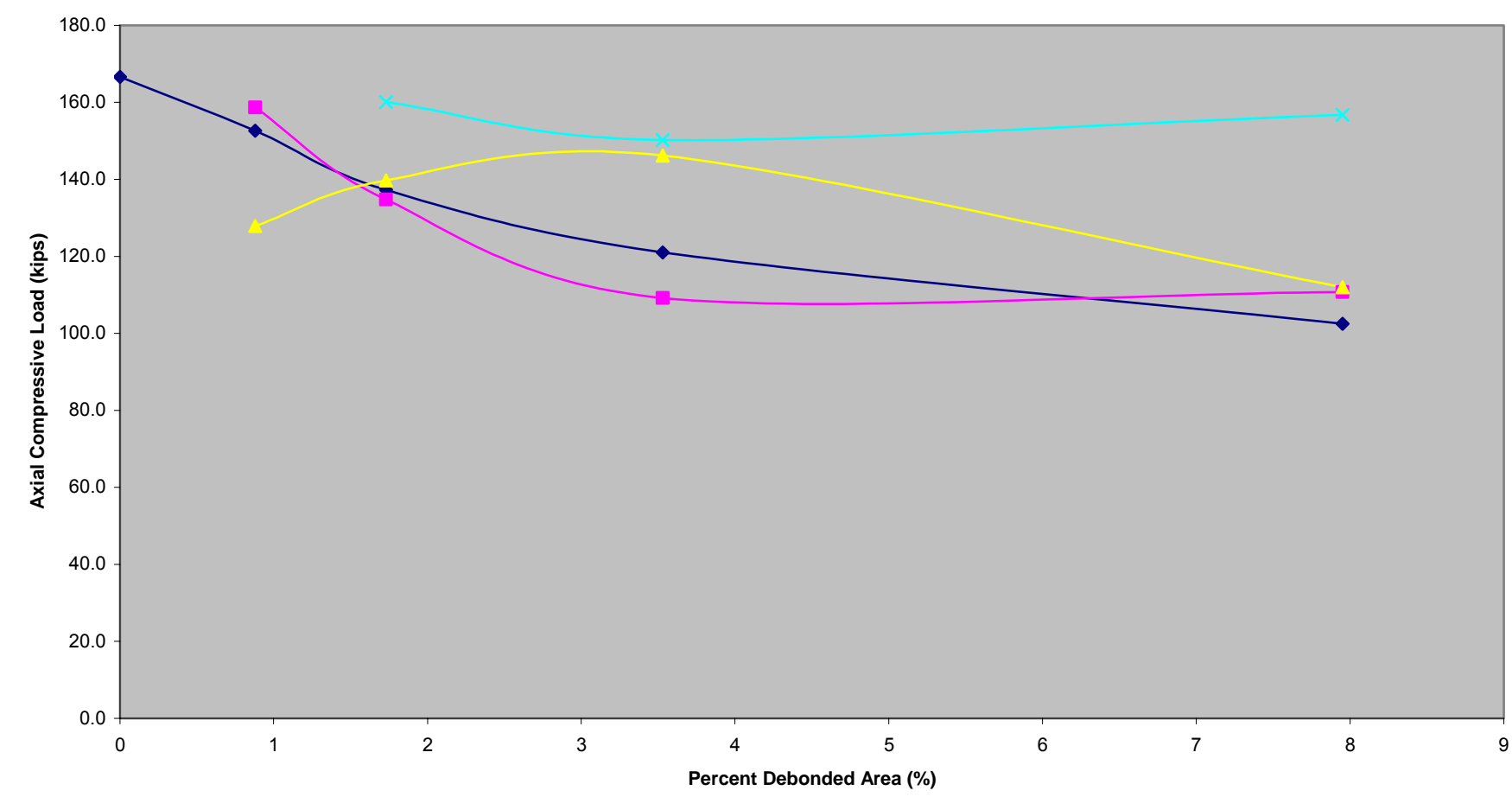

$\longrightarrow$ Predicted Value According to Equation 6.17

$\rightarrow$ - Experimental Value (GFRP wrapped cylinders with air-filled debonds)

Experimental Value (GFRP wrapped cylinders with water-filled debonds)

$\rightarrow$ Experimental Value (GFRP wrapped cylinders with Teflon sheet)

Figure 6-1 Comparison between predicted compressive strength according to equation 6.17 and experimental compressive strengths 


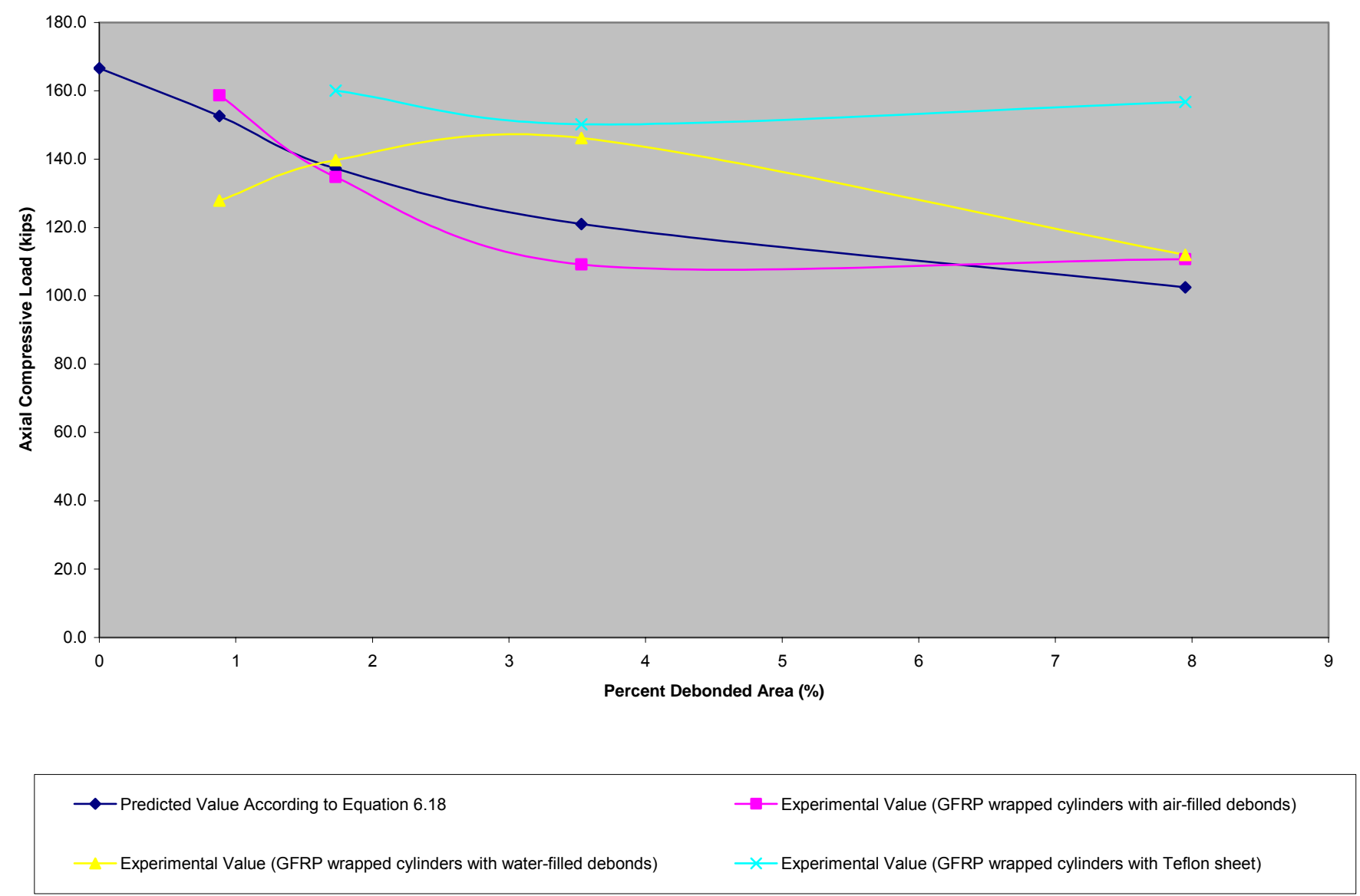

Figure 6-2 Comparison between predicted compressive strengths according to equation 6.18 and experimental compressive strengths 


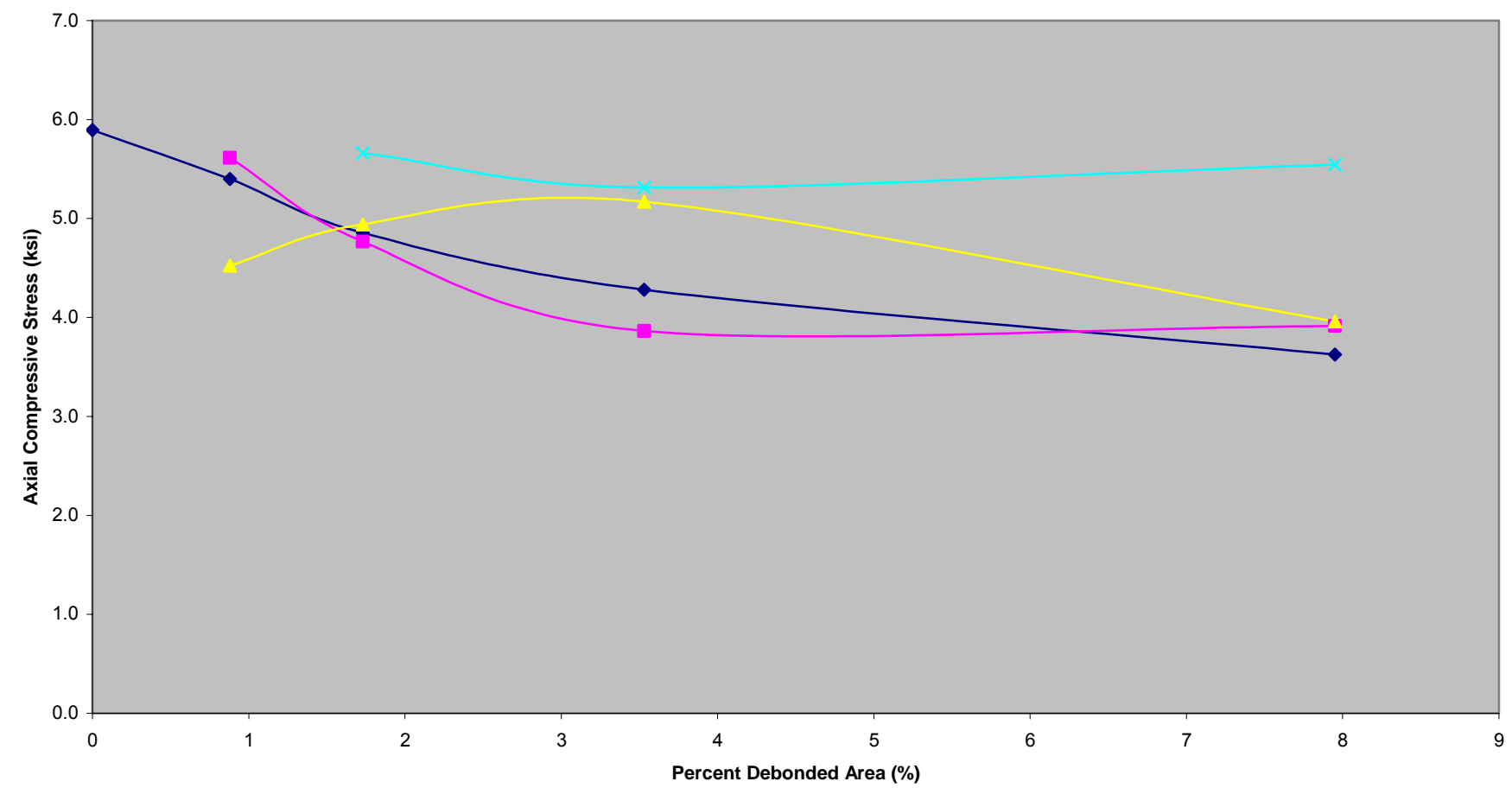

$\begin{array}{ll}\longrightarrow \text { Predicted Value According to Equation } 6.17 & - \text { Experimental Value (GFRP wrapped cylinders with air-filled debonds) } \\ \longrightarrow \text { Experimental Value (GFRP wrapped cylinders with water-filled debonds) } & -x \text { Experimental Value (GFRP wrapped cylinders with Teflon sheet) }\end{array}$

Figure 6-3 Comparison between predicted compressive stress according to equation 6.17 and experimental compressive stress 

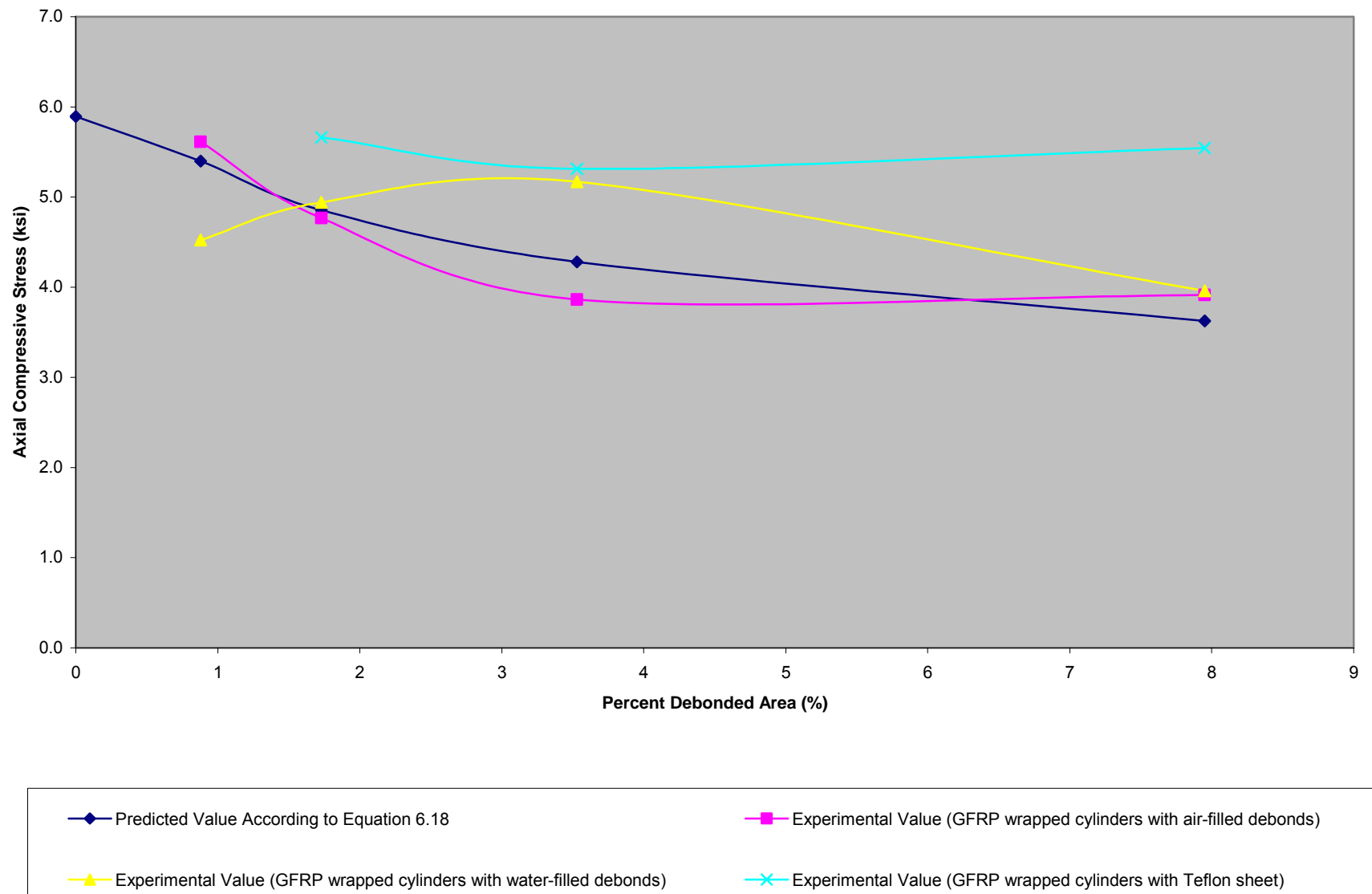

Figure 6-4 Comparison between predicted compressive stress according to equation 6.18 and experimental compressive stress 


\subsubsection{CFRP Composite Wrapped Cylinders}

As seen from the previous section (Section 6.2, Table 6.20), model by Miyauchi et al. (1997) provided the best approximation with the experimental results for CFRP composite wrapped cylinders as well. The increase in confined compressive strengths for the various debonded area is divided by increase in confined compressive strength from the model in equation 6.10 to get the multiplying factor. These multiplying factors are plotted against the debonded area and a regression equation is obtained. This equation is the factor that has to be multiplied to the equation of the model to get the confined compressive strengths for various debonded area. The multiplying factors and equations relating various areas of defects as based on the model by Miyauchi et al. (1997) are as follows:

- Multiplying factor : $-0.0394 \times \ln (a)+0.8986$

- Equation : $f_{c c}^{\prime}=f^{\prime}{ }_{c o} \times(-0.0394 \times \ln (a)+0.8986) \times\left(1+3.485\left(\frac{p_{u}}{f_{c o}^{\prime}}\right)\right)$

Following the same procedure, multiplying factor based on the model by Mander et al. (1988), as stated in ACI 440.2R-02, is also derived. For this model:

- Multiplying factor : $-0.0748 \times \ln (a)+1.7051$

- Equation:

$$
f^{\prime}{ }_{c c}=f^{\prime}{ }_{c o} \times(-0.0748 \times \ln (a)+1.7051) \times\left(2.25 \times \sqrt{1+7.9 \frac{p_{u}}{f_{c o}^{\prime}}}-2 \times \frac{p_{u}}{f_{c o}^{\prime}}-1.25\right)
$$

Where $p_{u}$ is the theoretical maximum confinement pressure that can be exerted by the confinement device, $\mathrm{f}^{\prime}{ }_{\mathrm{co}}$ is the unconfined compressive strength, $a$ is the percent area of debond and $\mathrm{f}^{\prime}{ }_{\mathrm{cc}}$ is the confined compressive strength of concrete.

Table 6-21 and Table 6-22 summarize the predicted values of the compressive strengths based on equation 6.19 and equation 6.20 along with the percentage error. 
Table 6-23 Comparison between predicted compressive strength and experimental compressive strength for CFRP composite wrapped cylinders with Teflon sheets based on equation 6.19

\begin{tabular}{|c|c|c|c|}
\hline $\begin{array}{c}\text { Percent Area of } \\
\text { Debond } \\
\text { (\%) }\end{array}$ & $\begin{array}{c}\text { Experimental Compressive } \\
\text { Strength } \\
\text { (kips) }\end{array}$ & $\begin{array}{c}\text { Predicted Compressive } \\
\text { Strength } \\
\text { (kips) }\end{array}$ & $\begin{array}{c}\text { Error } \\
\mathbf{( \% )}\end{array}$ \\
\hline 1.73 & 201.5 & 201.8 & -0.17 \\
\hline 3.53 & 196.0 & 195.4 & 0.32 \\
\hline 7.95 & 187.7 & 188.0 & 0.16 \\
\hline
\end{tabular}

Table 6-24 Comparison between predicted compressive strength and experimental compressive strength for CFRP composite wrapped cylinders with Teflon sheets based on equation 6.20

\begin{tabular}{|c|c|c|c|}
\hline $\begin{array}{c}\text { Percent Area of } \\
\text { Debond } \\
\text { (\%) }\end{array}$ & $\begin{array}{c}\text { Experimental Compressive } \\
\text { Strength } \\
\text { (kips) }\end{array}$ & $\begin{array}{c}\text { Predicted Compressive } \\
\text { Strength } \\
\text { (kips) }\end{array}$ & $\begin{array}{c}\text { Error } \\
\text { (\%) }\end{array}$ \\
\hline 1.73 & 201.5 & 201.8 & -0.17 \\
\hline 3.53 & 196.0 & 195.4 & 0.32 \\
\hline 7.95 & 187.7 & 188.0 & 0.16 \\
\hline
\end{tabular}

As we can see, in terms of percentage error, both the equations are identical. However, model by Miyauchi et al. (1997) has a better predictability with respect to the experimental results for wrapped specimens without debonds. Hence, equation 6.19 should be used to predict the compressive strength of CFRP composite wrapped concrete cylinders for different area of debonds. 
Figure 6-5 and 6-6 show the predicted compressive strength value and the experimental compressive strength values of all the cylindrical tested specimens in accordance with equation 6.19 and equation 6.20 respectively. Figure 6-7 and 6-8 show the predicted compressive stress value and the experimental compressive stress values of all the cylindrical tested specimens in accordance with equation 6.19 and equation 6.20 respectively As can be seen from the plots, the predicted values are less than the actual compressive strength values for most of the specimens.

\subsubsection{Conclusions}

Model by Miyauchi et al. (1997) correlated well with the experimental results of both CFRP composite and GFRP composite wrapped cylinders. Therefore, in order to correlate the compressive strength to area of debonds, multiplying factors and equations derived based on the model by Miyauchi et al. (1997) should be used. It is important to note that as per Tables 6.19 and 6.20, the model by Mander et al. (1988) that has been adopted by ACI 440.2R-02 (2002) predicts the strength level which is $67 \%$ (or $1 / 1.5$ ) of the experimental value for GFRP and $50 \%$ (or $1 / 2$ ) for the CFRP wrapped cylinders. On the other hand, the model by Miyauchi et al. (1997) results in excellent match with the experimental values. The multiplying factor equations based on percentage area of debond show coefficients which are in the same proportion (67\% for GFRP and $50 \%$ for CFRP) for the model by Miyauchi et al (1997) as compared to the model by Mander et al. (1988) as evident from Equations 6.17 and 6.18 for GFRP and Equations 6.19 and 6.20 for CFRP, respectively. 


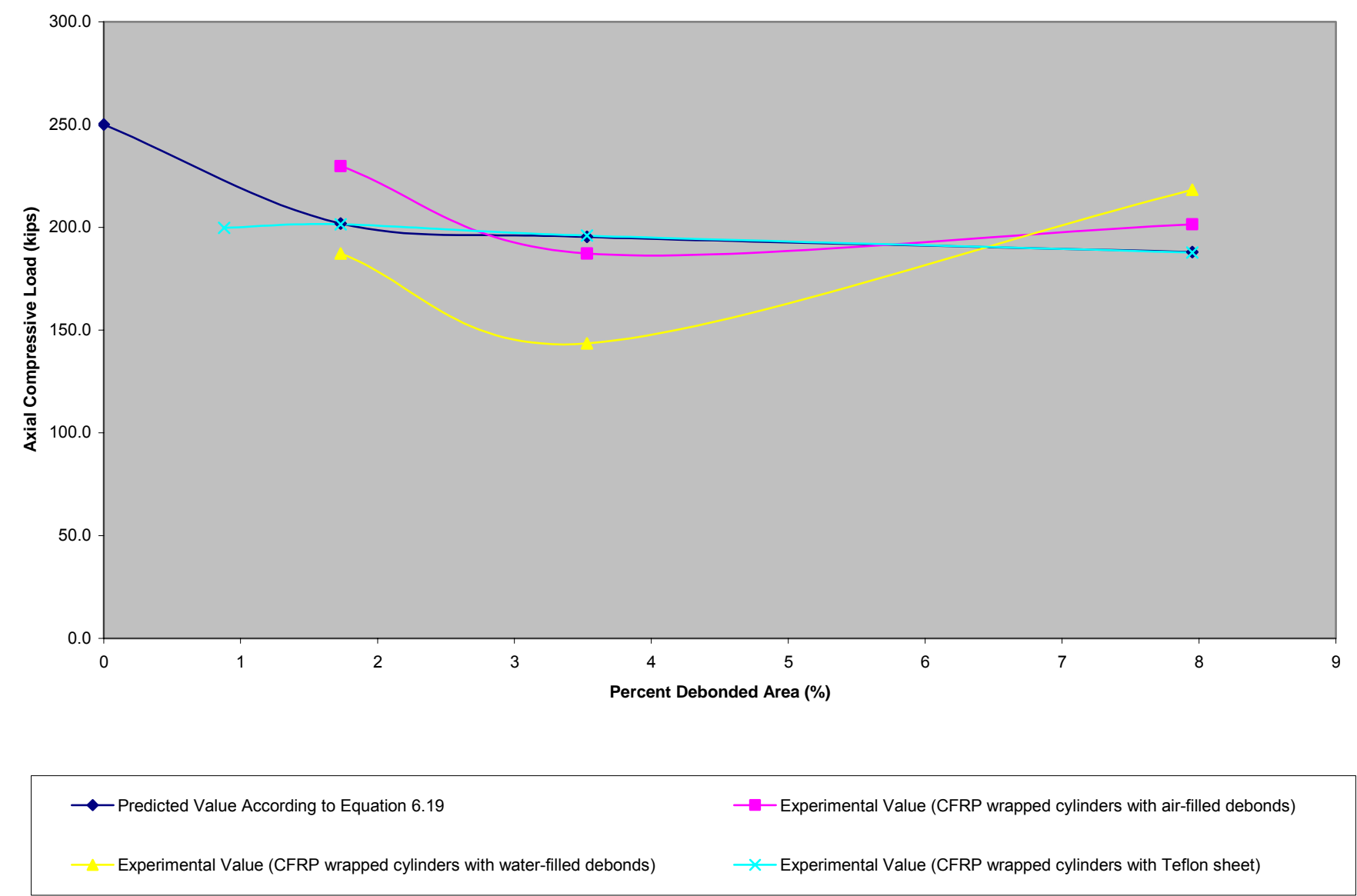

Figure 6-5 Comparison between predicted compressive strengths according to equation 6.19 and experimental compressive strengths 


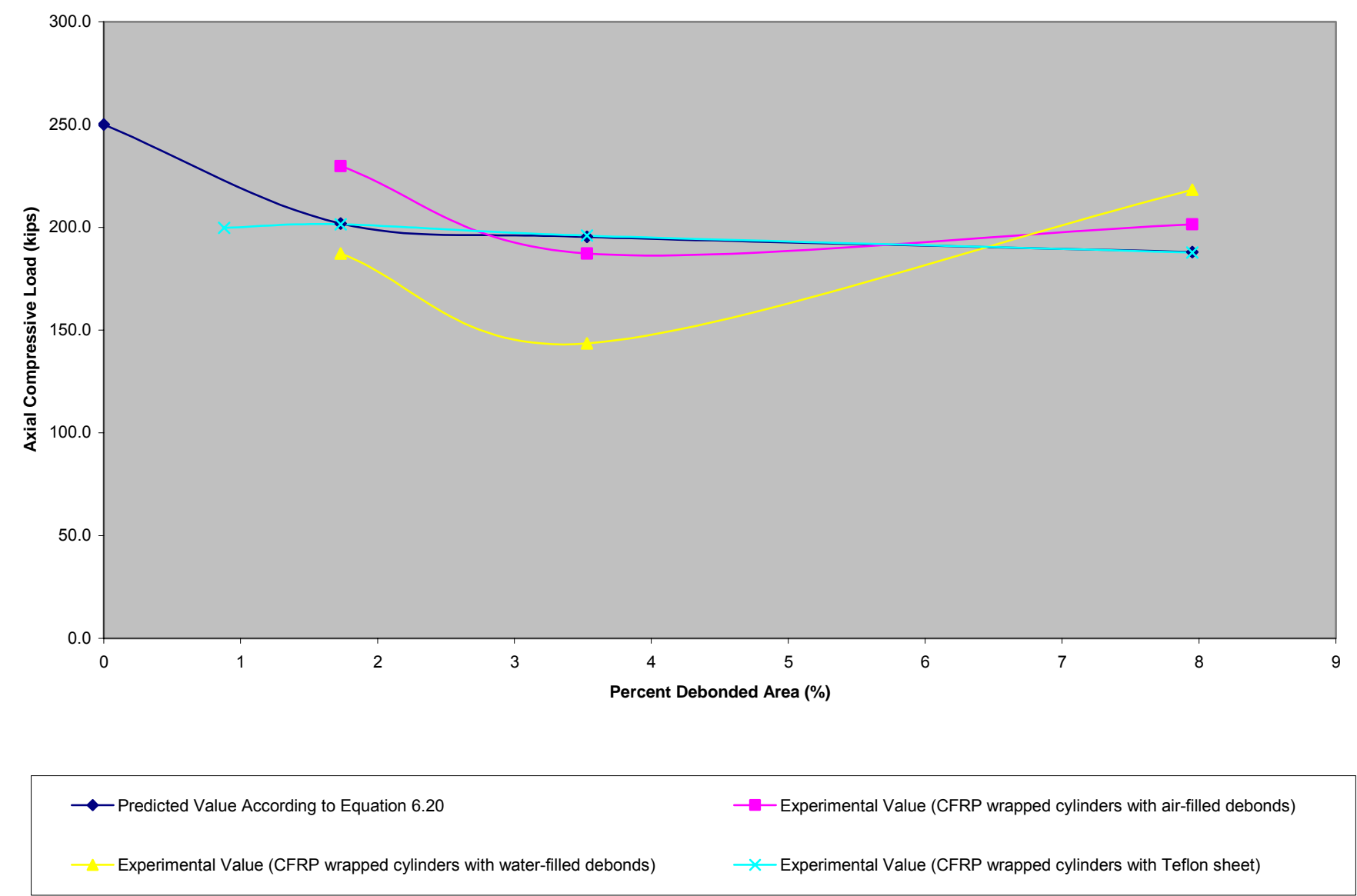

Figure 6-6 Comparison between predicted compressive strengths according to equation 6.20 and experimental compressive strengths 


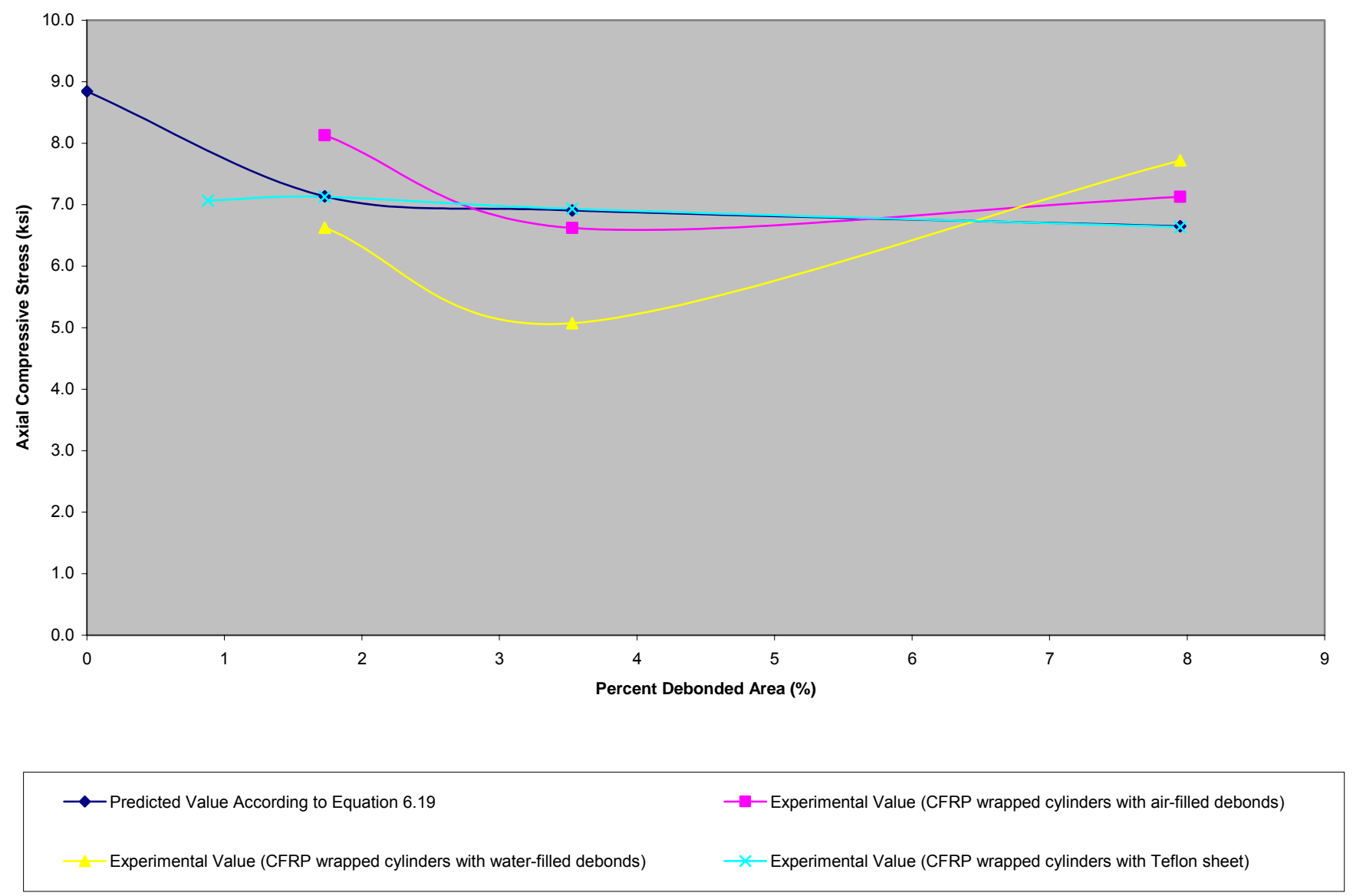

Figure 6-7 Comparison between predicted compressive stress according to equation 6.19 and experimental compressive stress 


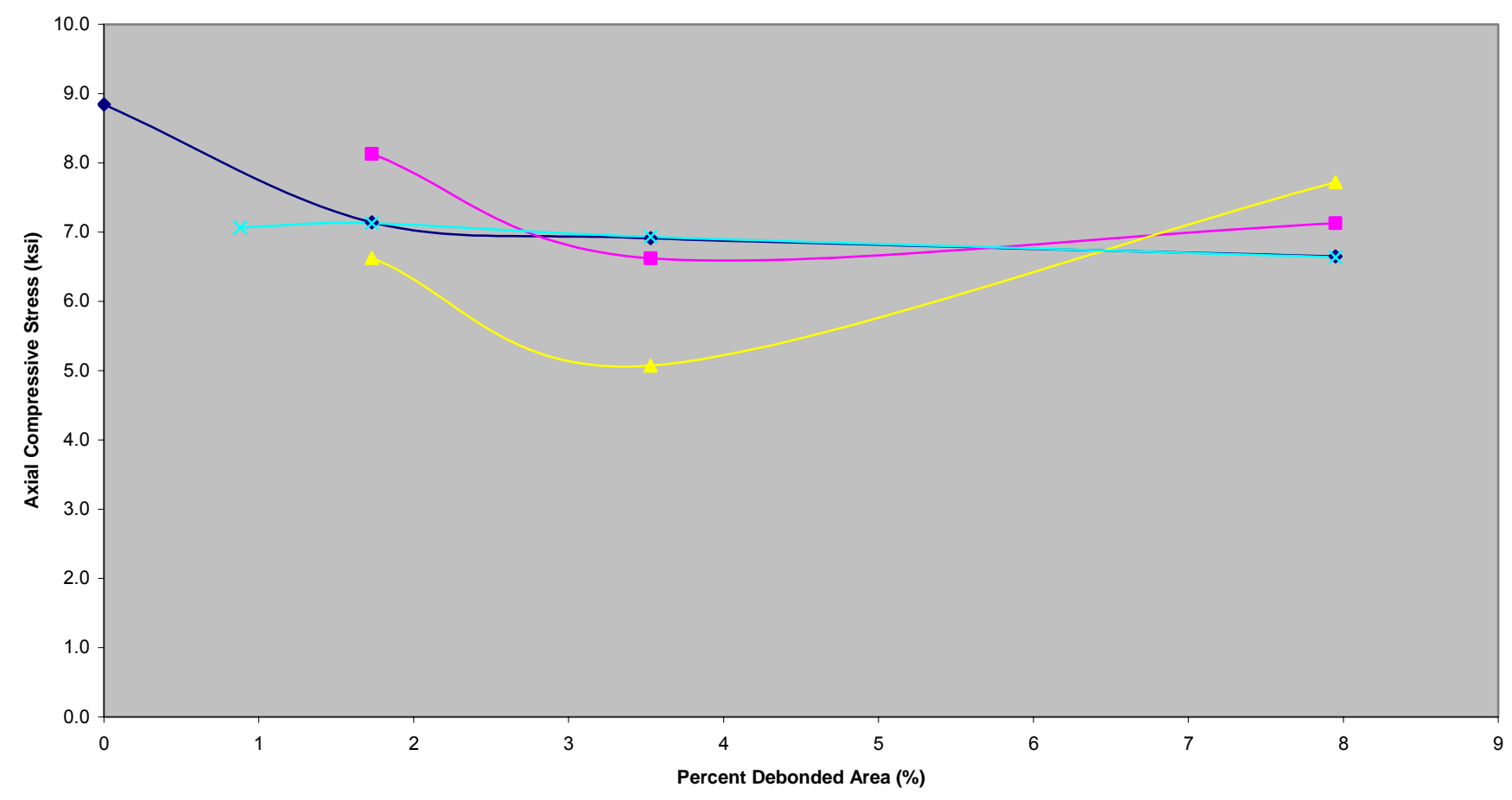

$\longrightarrow$ Predicted Value According to Equation 6.20

- Experimental Value (CFRP wrapped cylinders with air-filled debonds)

Experimental Value (CFRP wrapped cylinders with water-filled debonds)

$\rightarrow$ Experimental Value (CFRP wrapped cylinders with Teflon sheet)

Figure 6-8 Comparison between predicted compressive stress according to equation 6.20 and experimental compressive stress 


\subsection{REDUCTION FACTOR}

Table 6-25 and Table 6-26 summarize the reduction factors for percentage debonded area for GFRP and CFRP wrapped cylinders respectively. These factors for GFRP and CFRP wrapped cylinders are based on curve fit equations 6.17 and 6.19, respectively. The reduction factors for GFRP composite wrapped cylinders are for columns with embedded air-filled debonds which also take into account other debond (teflon and water-filled) as shown in Figures 6-1 to 6-4. For the CFRP composite wrapped cylinders, columns with embedded Teflon sheets was used to develop the theoretical equation, and this accounted for all other defects (air-filled and all but one data point in the water-filled category) as shown in Figures 6-5 to 6-8. The factors indicate the reduction in axial compressive strength due to presence of debonded area expressed as a fraction of the total surface area of the column.

Since the ACI 440.2R-02 (2002) document specifies that the debonded areas in externally bonded FRP components be limited to $5 \%$ of the total area, based on Tables 625 and 6-26, reduction factors of 0.7 and 0.8 are proposed for the design of GFRP and CFRP composite wrapped concrete, respectively.

Table 6-25 Reduction Factors for GFRP Composite wrapped Cylinders based on Equation 6.17

\begin{tabular}{|c|c|}
\hline $\begin{array}{c}\text { Percent Area of } \\
\text { Debond } \\
(\%)\end{array}$ & Reduction Factor \\
\hline 0.88 & 0.96 \\
\hline 1.73 & 0.87 \\
\hline 3.53 & 0.76 \\
\hline 5.00 & $\mathbf{0 . 7 1}$ \\
\hline 7.95 & 0.65 \\
\hline
\end{tabular}


Table 6-26 Reduction Factors for CFRP Composite wrapped Cylinders based on Equation 6.19

\begin{tabular}{|c|c|}
\hline $\begin{array}{c}\text { Percent Area of } \\
\text { Debond } \\
\text { (\%) }\end{array}$ & Reduction Factor \\
\hline 0.88 & 0.90 \\
\hline 1.73 & 0.88 \\
\hline 3.53 & 0.85 \\
\hline $\mathbf{5 . 0 0}$ & $\mathbf{0 . 8 4}$ \\
\hline 7.95 & 0.82 \\
\hline
\end{tabular}

\subsection{FAILURE MODE}

This section presents sample pictures showing the failure modes of FRP composite (GFRP composite and CFRP composite) wrapped concrete cylinders that were tested using Universal Compression Testing Machine as a part of this research.

\subsubsection{Concrete Cylinders Wrapped with GFRP Composite}

Failure of the concrete cylinders wrapped with GFRP composite wrap occurred due to the rupture of the FRP composite jacket and was brittle in nature. The failure was sudden accompanied by large sound. Fiber rupture occurred rapidly and with the fiber jacket opening up, crushed concrete core spalled off. Typical failure pattern of concrete cylinder wrapped with GFRP composite without any debond and with simulated 2" x 2" air-filled debond is shown in Figure 6-9 and Figure 6-10 respectively. 


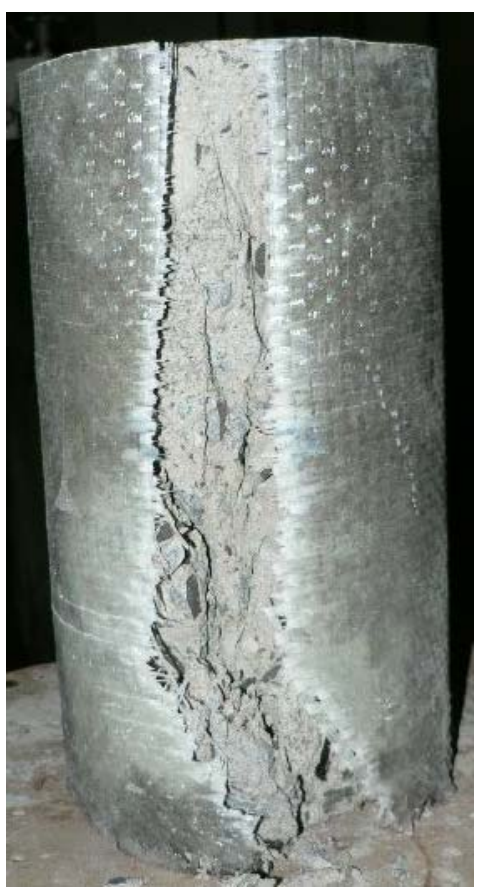

Figure 6-9 Failure mode of GFRP composite $\left(0^{\circ} / 90^{\circ}\right)$ wrapped concrete cylinder without any simulated debond

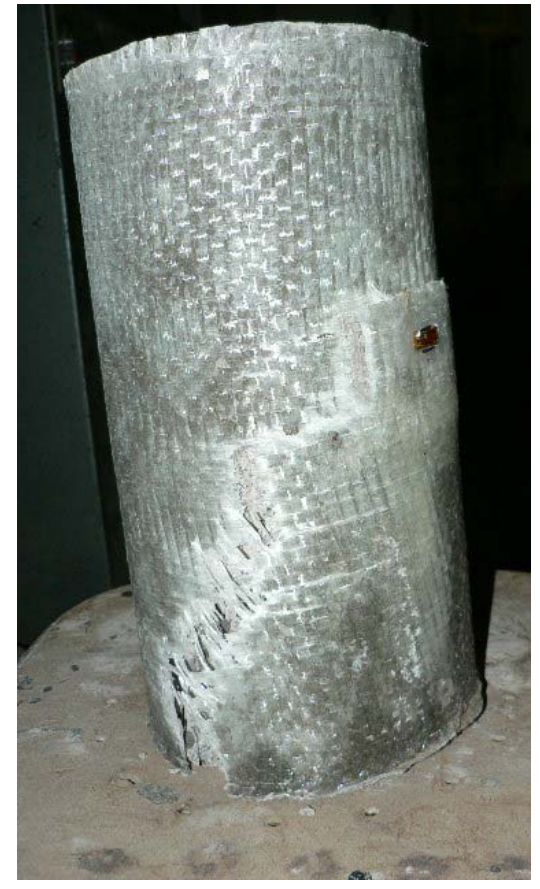

(a) 1" 1 1"

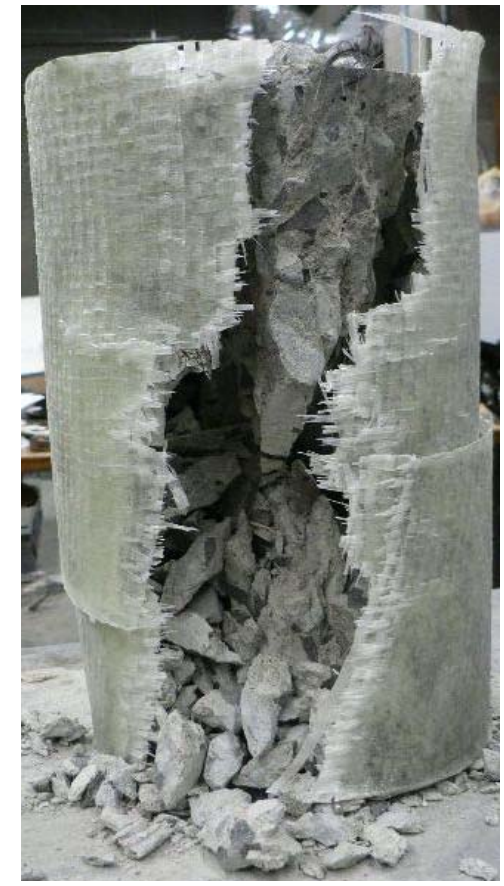

(b) 2" $\mathrm{x} 2 \%$

Figure 6-10 Failure mode of GFRP composite $\left(0^{\circ} / 90^{\circ}\right)$ wrapped concrete cylinder with 1" $x$ 1" and $2 " x 2$ " air-filled debonds 


\subsubsection{Concrete Cylinders Wrapped with CFRP Composite}

Failure mode of concrete specimens wrapped with CFRP composite was ductile. No significant fiber breakage was observed at failure which indicated an effective confining action by the carbon fiber. This is attributed to the fiber orientation mechanism that allows a large circumferential strain of the composite jacket. Figure 6-11 shows a representative failure pattern of CFRP composite wrapped concrete cylinder that has a 2 " x 2" air-filled debond on both sides.

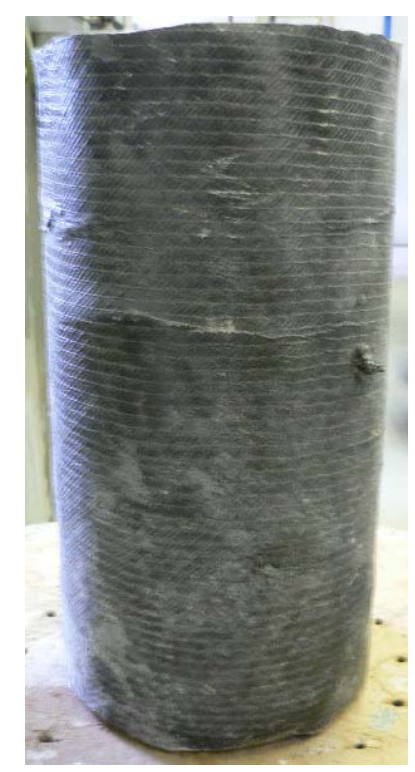

Figure 6-11 Failure mode of CFRP composite $\left(0^{\circ} / \pm 45^{\circ} / 90^{\circ}\right)$ wrapped concrete cylinder with 2 " 2 " air-filled debond 


\section{CHAPTER 7}

\section{CONCLUSIONS AND RECOMMENDATIONS}

\subsection{CONCLUSIONS}

The following conclusions are drawn from this study:

- Digital Infrared Thermography (IRT) proved to be very effective in detecting airfilled debond of sizes 1" x 1", 1.4" x 1.4", 2"x 2" and 3" x 3" in concrete cylinders wrapped around with Glass Fiber Reinforced Polymer (GFRP) composite and Carbon Fiber Reinforced Polymer (CFRP) composite. Also, waterfilled debonds of sizes 1.4"x 1.4", 2" x 2" and 3" x 3" actually showed up as airfilled debonds ("hot spots") in the infrared images because of the relatively small thickness of the FRP wraps.

- Maximum thermal contrast increases as the heat duration increases for GFRP composite wrapped concrete cylinders with embedded debonds. For CFRP composite wrapped concrete cylinders with debonds, the variation was erratic. This is because carbon is a conductive material, leading to heat transfer in both the circumferential direction and through the thickness of the wrap.

- Time for maximum contrast increases with increase in energy input for both CFRP and GFRP composite wrapped concrete cylinders with embedded debonds.

- Increase in surface temperature above the debond increases with increase in energy input for both CFRP and GFRP composite wrapped concrete cylinders with embedded debonds.

- Maximum thermal difference increases with an increase in width of the debond for both CFRP and GFRP composite wrapped concrete cylinders with embedded debonds. This is because the lateral (circumferential) heat transfer is more prominent for smaller defects and less prominent for larger defect widths.

- Time to achieve maximum thermal difference first decreases a little but then increases with an increase in width of debond for both CFRP and GFRP composite wrapped concrete cylinders with embedded debonds.

- Maximum thermal difference decreases with an increase in debond depth for GFRP composite wrapped concrete cylinders with embedded debonds. 
- Time for maximum thermal difference increases with an increase in debond depth for GFRP composite wrapped concrete cylinders with embedded debonds.

- Maximum surface temperature above the debond decreases with an increase in debond depth for GFRP composite wrapped concrete cylinders with debonds.

- For both GFRP and CFRP composite wrapped concrete cylinders the optimum heat duration for detection of air-filled debonds is 70 seconds for the specific heat source used in this study.

- The method of finding the inflection points of the surface temperature profile gave more accurate results than Full Width at Half Maximum (FWHM) method. Also, the equation obtained by curve fitting to correlate between estimated and actual debond widths works well for both CFRP and GFRP composite wrapped cylinders. Also, dedond depth is always underestimated when estimated with the help of equation (2.9). Also, measurement error is very high when debond depth is related to the thermal diffusivity and time to achieve ultimate slope of contrast.

- For cylinder compressive strength, the model by Miyauchi et al. (1997) correlated very well with the experimental results of CFRP composite and GFRP composite wrapped cylinders. Also, the correlation between various other models including the ACI 440.2R-02 (2002) equation and the experimental results have been discussed in detail.

- Barring few exceptions, it is seen that the axial compressive strength of columns decreases with an increase in the percentage area of debonds between the GFRP composite and the underlying concrete surface. Decrease in compressive strength in case of GFRP composite wrapped cylinders with Teflon sheets was less than the corresponding air-filled and water-filled debond cases. The decrease in both axial and hoop strain is most significant in case of air-filled debonds for GFRP composite wrapped cylinders. Also, the value of axial strain is found to be higher than circumferential strain in all the cylinders wrapped with GFRP composite. Also, for GFRP composite wrapped cylinders, hoop strain above the debond is always less than the corresponding value above the defect-free area. Also, for GFRP composite wrapped specimens, barring a few exceptions, axial strain at which the volumetric strain becomes zero reduces as the debond size increases. In 
some cases the volumetric strain never reached zero meaning FRP composite wrap was effective in arresting the dilation of concrete. In case of CFRP composite wrapped specimens, the composite wrap was effective in arresting the radial expansion of underlying concrete in most of the cases. Axial strain values were found to be higher than hoop strain values in all the tested specimens.

- CFRP composite $\left(0^{\circ} / \pm 45^{\circ} / 90^{\circ}\right)$ wrapped cylinders exhibited higher ductility than the GFRP composite $\left(0^{\circ} / 90^{\circ}\right)$ wrapped cylinders due to fiber reorientation mechanism available in the CFRP fabric which had angular $\left( \pm 45^{\circ}\right)$ fibers as well.

- Failure mode for cylinders wrapped with GFRP composite $\left(0^{\circ} / 90^{\circ}\right)$ was brittle and those wrapped with CFRP composite $\left(0^{\circ} / \pm 45^{\circ} / 90^{\circ}\right)$ was ductile. The same failure modes were observed in the research study carried out by Au et al. (2005).

- Since ACI 440.2R-02 (2002) document specifies that the debonded areas in externally bonded FRP components be limited to $5 \%$ of the total area, and based on the experimental results, reduction factors of 0.7 and 0.8 are proposed for the design of GFRP and CFRP composite wrapped concrete, respectively.

\subsection{RECOMMENDATIONS FOR FUTURE RESEARCH}

A number of recommendations can be put forward for future study on detection of air-filled and water-filled debonds with the help of IRT and on stress strain behavior of composite wrapped cylinders with simulated debonds. Future study can concentrate on quantitative techniques like thermal tomography which will enable better understanding of debond depth related issues. This kind of information, if extracted, can herald a new phase in the field of nondestructive testing because a precise knowledge of the width or depth of the debond will help immensely to characterize its severity and carry out the rehabilitation process in a more efficient manner. Heat transfer finite element modeling for cylindrical members should be used to better describe the heat transfer process between the debond and the surrounding and also to determine the effect of applied heat transfer rate on surface temperature differences. Also, finite element modeling of FRP composite wrapped cylinders with simulated debonds subjected to axial compressive loading can be performed in order to achieve a better theoretical understanding of the stress strain behavior of specimens with debonds. 


\section{REFERENCES}

ACI 440.2R-02 (2002). Guide for the Design and Construction of Externally Bonded FRP Systems for Strengthening Concrete Structures, American Concrete Institute, Farmington Hills, MI.

ASTM D 3039/D 3039M - 00 (2000). "Standard Test Method for Tensile Properties of Polymer Matrix Composite Materials.” Annual Book of ASTM Standards, American Society for Testing and Materials, West Conshohocken, PA, 106-117.

ASTM E 1933-99a (2000). "Standard Test Methods for Measuring and Compensating for Emissivity Using Infrared Radiometers.” Annual Book of ASTM Standards, American Society for Testing and Materials, West Conshohocken, PA, 1005-1007.

Au, C. and Buyukozturk, O. (2005)."Effect of Fiber Orientation and Ply Mix on Fiber Reinforced Polymer-Confined Concrete." Journal of Composites for Construction, ASCE, 9(5), 397-407.

Brown, J. R., and Hamilton, H. R. (2007). "Heating Methods and Detection Limits for Infrared Thermography Inspection of Fiber-Reinforced Polymer Composites." ACI Materials Journal, 104(5), 481-490.

Dutta, S. S., (2006). "Nondestructive Evaluation of FRP Wrapped Concrete Cylinders Using Infrared Thermography and Ground Penetrating Radar.” MS Thesis, Department of Civil and Environmental Engineering, West Virginia University, Morgantown, West Virginia.

Favro, L.D., Han, X., Kuo, P.K., and Thomas, R.L. (1995). “ Imaging the early Time Behavior of Reflected Thermal-Wave Pulses.” Thermosense XVII. Proceedings of SPIE, Vol. 2473, 163-166.

FLIR SYSTEMS (2002a). ThermaCAM ${ }^{T M}$ S60 Operator's Manual, Revision A, 14 June. 
FLIR SYSTEMS (2002b). ThermaCAM ${ }^{T M}$ Researcher Operating Manual, Version A.

Fyfe Co. LLC (2000). http://www.fyfeco.com/products/epoxies/pdf/s.pdf

Ghosh, K.K., and Karbhari, V.M. (2006). "A Critical Review of Infrared Thermography As a Method for Non-Destructive Evaluation of FRP Rehabilitated Structures." Int. J. Materials and Product Technology, 25(4),241-266.

Giorleo, G., and Meola, C. (2002). "Comparison Between Pulsed and Modulated Thermography in Glass-Epoxy Laminates." NDT \& E International, 35, 287-292.

Godinez-Azcuaga, V. F., Gostautas, R. S., Finlayson, R. D., and Miller, M. (2004). "Nondestructive Evaluation of FRP Wrapped Concrete Columns and Bridges." Proceedings of Structural Materials VI- An NDT Conference, Buffalo, New York, September 14-17, 139-146.

Harries, K. A., and Carey, S.A. (2003). "Shape and "gap" Effects on the Behavior of Variably Confined Concrete." Cement and Concrete Research, check vol no, 881-890.

Hing, C. L., (2006). "Nondestructive Evaluation of Fiber Reinforced Polymer Bridge Decks Using Ground Penetrating Radar and Infrared Thermography.” Ph.D. Dissertation, Department of Civil and Environmental Engineering, West Virginia University, Morgantown, West Virginia.

Kaplan, H. (1999). Practical Applications of Infrared Thermal Sensors and Imaging Equipment, SPIE - The International Society for Optical Engineering, Bellingham, Washington, USA.

Kono, S., Inazumi, M., and Kaku, T. (1998). “ Evaluation of Confining Effects of CFRP Sheets on Reinforced Concrete Members." Proc., ICCI’ 1998, Tucson, AZ, 343-355.

Kreith, F., and Bohn, M. S. (1993). Principles of Heat Transfer, 5th Edition, International Thomson Publishing / PWS Publishing Company, Boston, MA, 558 - 560. 
Lorenzis, L. D., and Tepfers, R. (2003). "Comparative Study of Models on Confinement of Concrete Cylinders with Fiber-Reinforced Polymer Composites." Journal of Composites for Construction, ASCE, 7(3), 219-237.

Maldague, X. (1993). Nondestructive Evaluation of Materials by Infrared Thermography, Springer-Verlag, London.

Maldague, X. (2000). "Applications of Infrared Thermography in Nondestructive Evaluation." Trends in Optical Nondestructive Testing (invited chapter), Pramod Rastogi ed., 591-609. (paper also available at http://www.ndt.net/v06n04.htm).

Mander, J. B., Priestley, M. J. N., and Park, R. (1988). “ Theoretical Stress-Strain Model for Confined Concrete." Journal of Structural Engineering, ASCE, 114(8), 1804-1826.

Martin, R. E., Gyekenyesi, A. L., and Shepard, S. M. (2003). "Interpreting the Results of Pulsed Thermography Data." Materials Evaluation, 61(5), 611-616.

Mehta, P. K. (1986). CONCRETE Structure, Properties, and Materials, Prentice-Hall, Inc., Englewood Cliffs, New Jersey 07632.

Mindess, S., Young, J. F., and Darwin, D. (2003). Concrete, Second Edition, PrenticeHall, Inc., Englewood Cliffs, New Jersey 07632.

Mirmiran, A., and Shahawy, M. (1997). "Behavior of Concrete Columns Confined by Fiber Composites." Journal of Structural Engineering, ASCE, 123(5), 583-590.

Miyauchi, K., Nishibayashi, S., and Inoue, S. (1997). "Estimation of Strengthing Effects with Carbon Fiber Sheet for Concrete Column." Proc., FRPRCS-3, Sapporo, Japan, Vol.1, 217-224

Mobasher, B., and Raji, B. (2007). "Rehabilitation of Concrete Structures," Structure magazine, April, 17-18. 
Parker, W.J., Jenkins, R.J., Butler, C.P., and Abbott, G.L. (1961). "Flash Method of Determining Thermal Diffusivity, Heat Capacity and Thermal Conductivity.” Journal of Applied Physics, 32, 1679-1684.

Plotnikov, Y. A. (1999). "Modeling of the Multiparameter Inverse Task of Transient Thermography. Review of Progress in Quantitative Nondestructive Evaluation, 18, 873880.

Rajappa, R.R. (2004). "Behaviour of FRP Wrapped Concrete Cylinders.” MS Thesis, Department of Civil and Environmental Engineering, West Virginia University, Morgantown, West Virginia.

Saafi, M., Toutanji, H. A., and Li, Z. (1999). "Behavior of Concrete Columns Confined with Fiber Reinforced Polymer Tubes.” ACI Materials Journal, 96(4), 500-509.

Saenz, N., and Pantelides, C.P. (2007). "Strain-Based Confinement Model for FRPConfined Concrete.” Journal of Structural Engineering, ASCE, 133(6), 825-833.

Samaan, M., Mirmiran, A., and Shahawy, M. (1998). "Model of Concrete Confined by Fiber Composites.” Journal of Structural Engineering, ASCE, 124(9), 1025-1031.

Shepard, S. M., Rubadeux, B. A., and Ahmed, T. (1999). "Automated Thermographic Defect Recognition and Measurement." Nondestructive Characterization of Materials IX, AIP Conference Proceedings 497, Sydney, Australia, 373-378.

Shepard, S. M., Lhota, J. R., Rubadeux, B. A., Wang, D., and Ahmed, T. (2003). "Reconstruction and Enhancement of Active Thermographic Image Sequences." Opt. Eng., 42, 1337-1342.

Shepard, S.M. (2006). "Understanding Flash Thermography.” Materials Evaluation, 64 (5), 460-464.

Shepard, S.M. (2007). "Thermography of Composites.” Materials Evaluation, 65(7), 690-696. 
Spoelstra, M.R., and Monti, G. (1999). "FRP-Confined Concrete Model." Journal of Composites for Construction, ASCE, 3(3), 143-150.

Starnes, M. A. (2002). "Development of Technical Bases for Using Infrared Thermography for Nondestructive Evaluation of Fiber Reinforced Polymer Composites Bonded to Concrete." Ph.D. Dissertation, Department of Civil and Environmental Engineering, Massachusetts Institute of Technology, Cambridge, Massachusetts.

Starnes, M. A., Carino, N. J., and Kausel, E. A.(2003). "Preliminary Thermography Studies for Quality Control of Concrete Structures Strengthened with Fiber-reinforced Polymer Composites." Journal of Materials in Civil Engineering, ASCE, 15(3), 266273.

Steele III, W. E. (2001). "Detection of Subsurface Anomalies in Fiber Reinforced Polymer (FRP) Wrapped Timber Bridge Components using Infrared Thermography. MS Thesis, Department of Civil and Environmental Engineering, West Virginia University, Morgantown, WV.

Sun, J. G. (2006). “Analysis of Pulsed Thermography Methods for Defect Depth Prediction." ASME Journal of Heat Transfer. 128(4), 329-338.

Toutanji, H. A. (1999). "Stress Strain Characteristics of Concrete Columns Externally Confined with Advanced Fiber Composite Sheets.” ACI Materials Journal, 96(3), 397404.

Vasudevan, A. (2004) "Application of Digital Infrared Thermography for Nondestructive Evaluation of Composite Bridge Components." MS Thesis, Department of Civil and Environmental Engineering, West Virginia University, Morgantown, WV. 


\section{APPENDIX A}

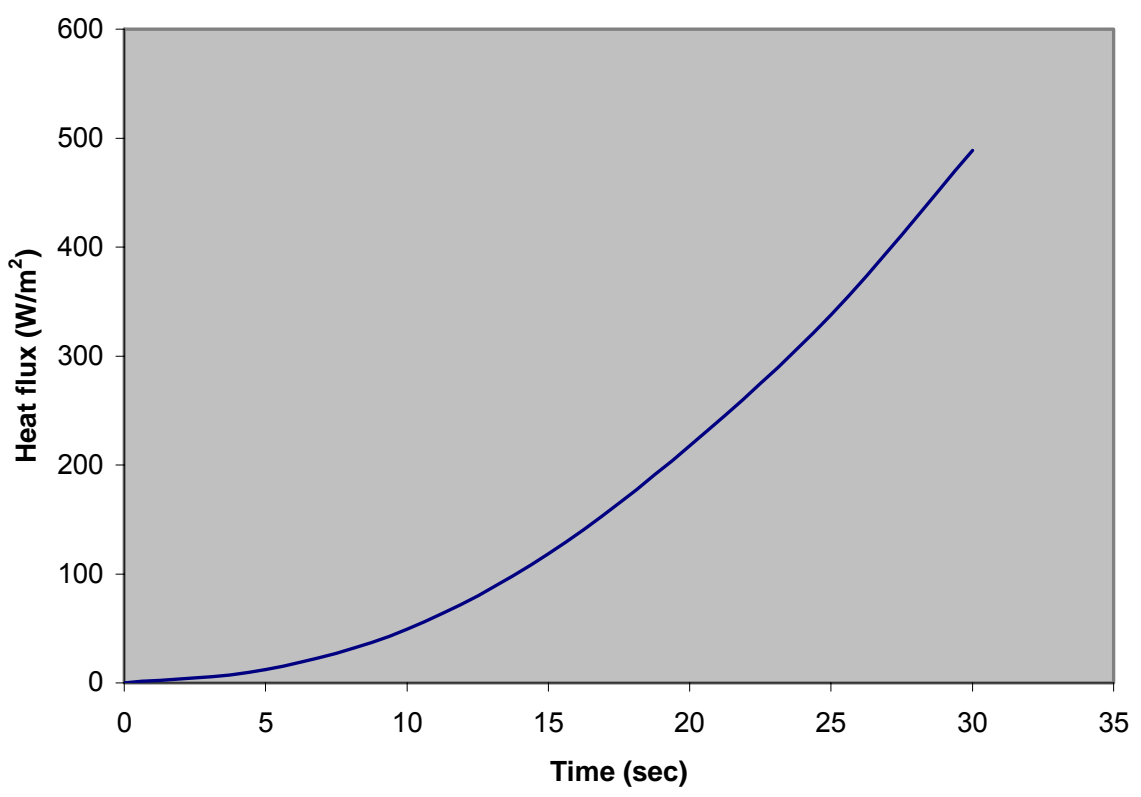

Figure A1 Heat Flux vs. time plot for 30 seconds heat duration

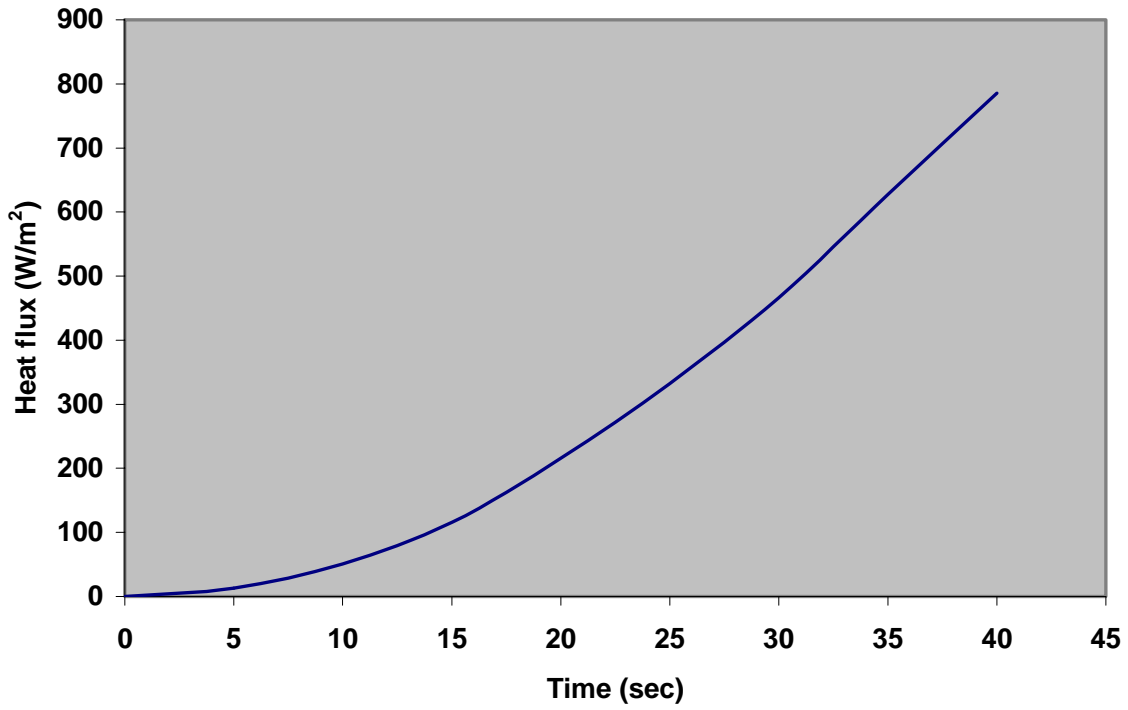

Figure A2 Heat Flux vs. time plot for 40 seconds heat duration 


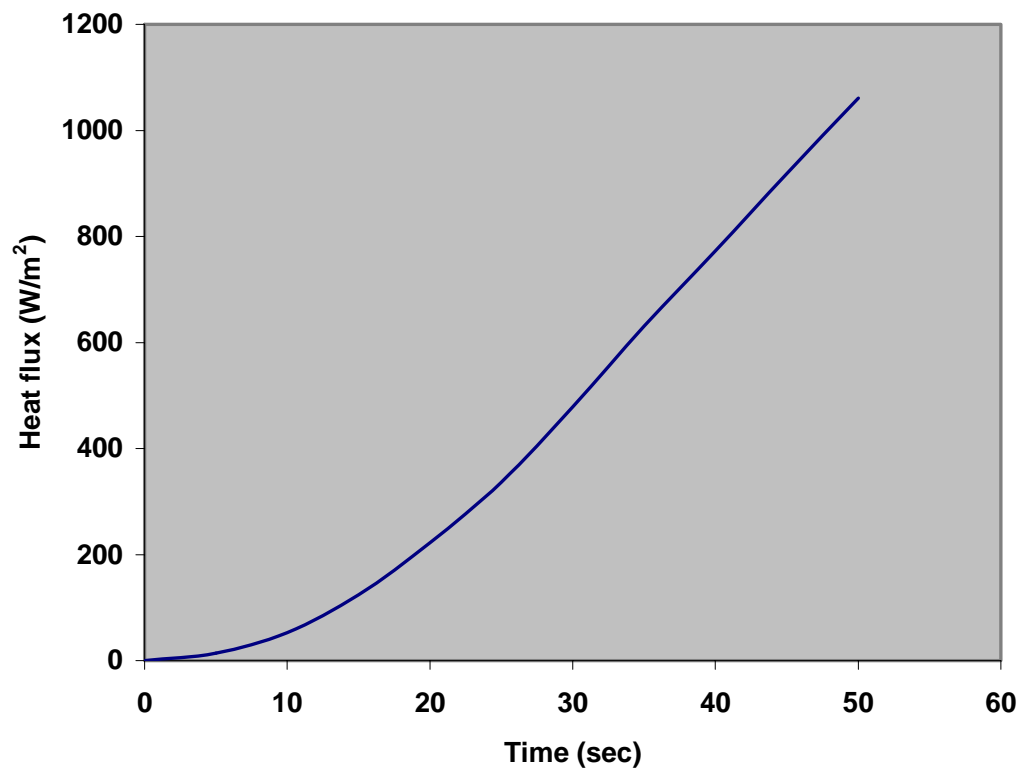

Figure A3 Heat Flux vs. time plot for 50 seconds heat duration

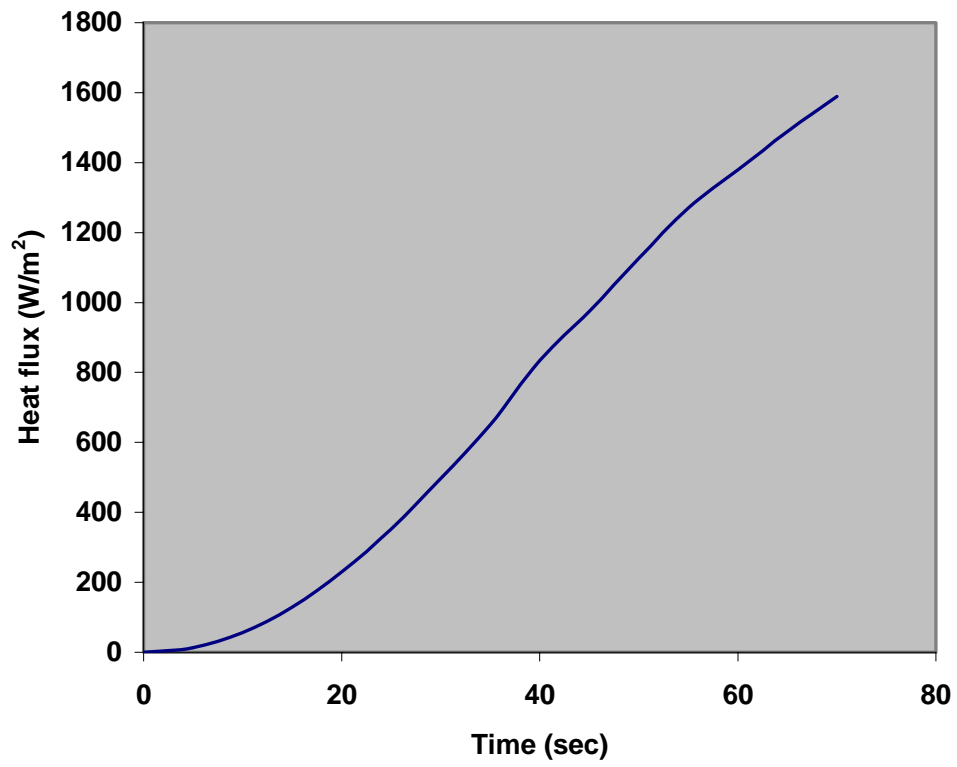

Figure A4 Heat Flux vs. time plot for 70 seconds heat duration 


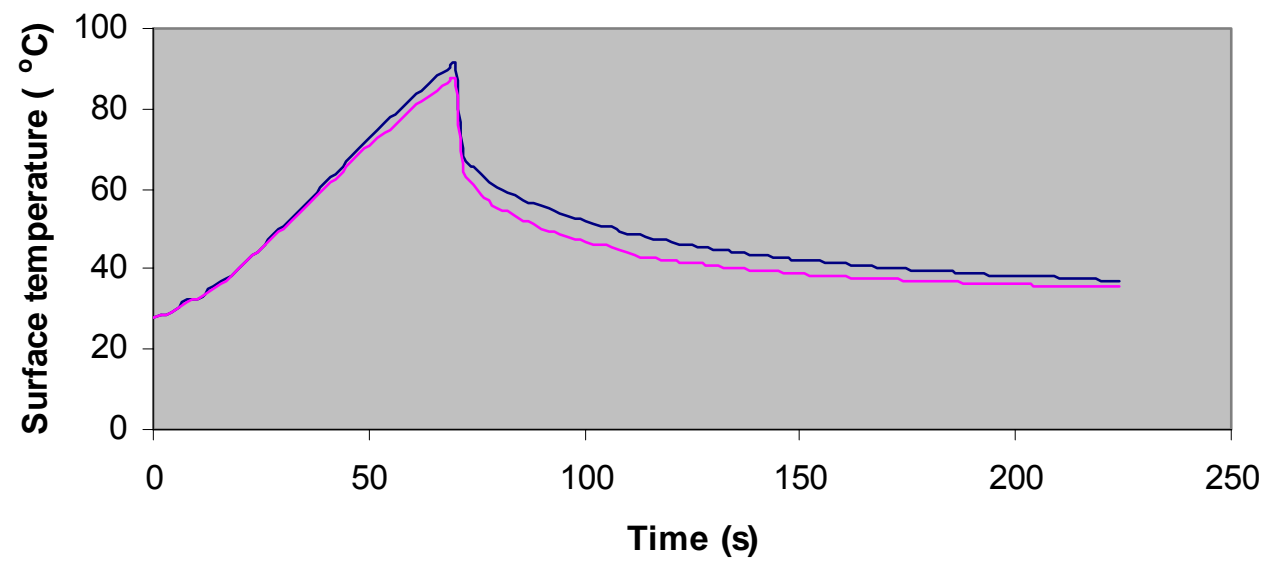

- above the debond __ above defect-free area

Figure A5 Surface temperature versus time curve for 3 layers of CFRP composite wrapped cylinder with 1.4" x 1.4" air-filled debond

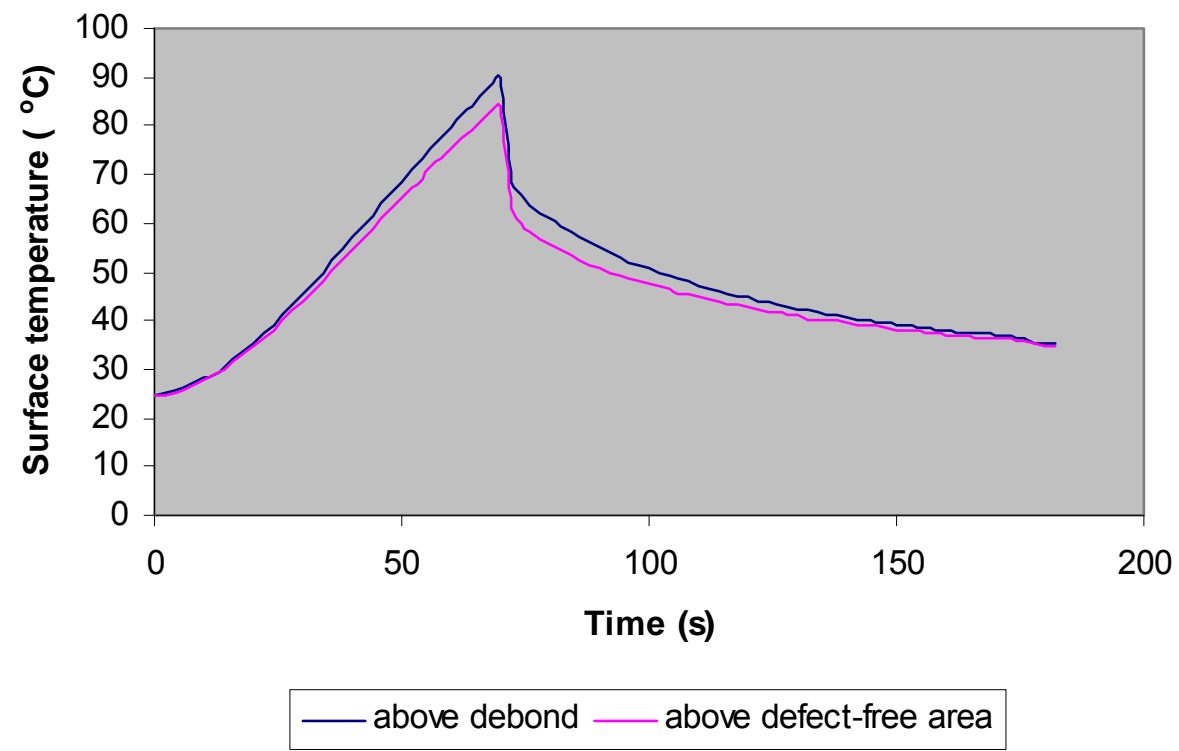

Figure A6 Surface temperature versus time curve for 3 layers of CFRP composite wrapped cylinder with 2" x 2" air-filled debond 


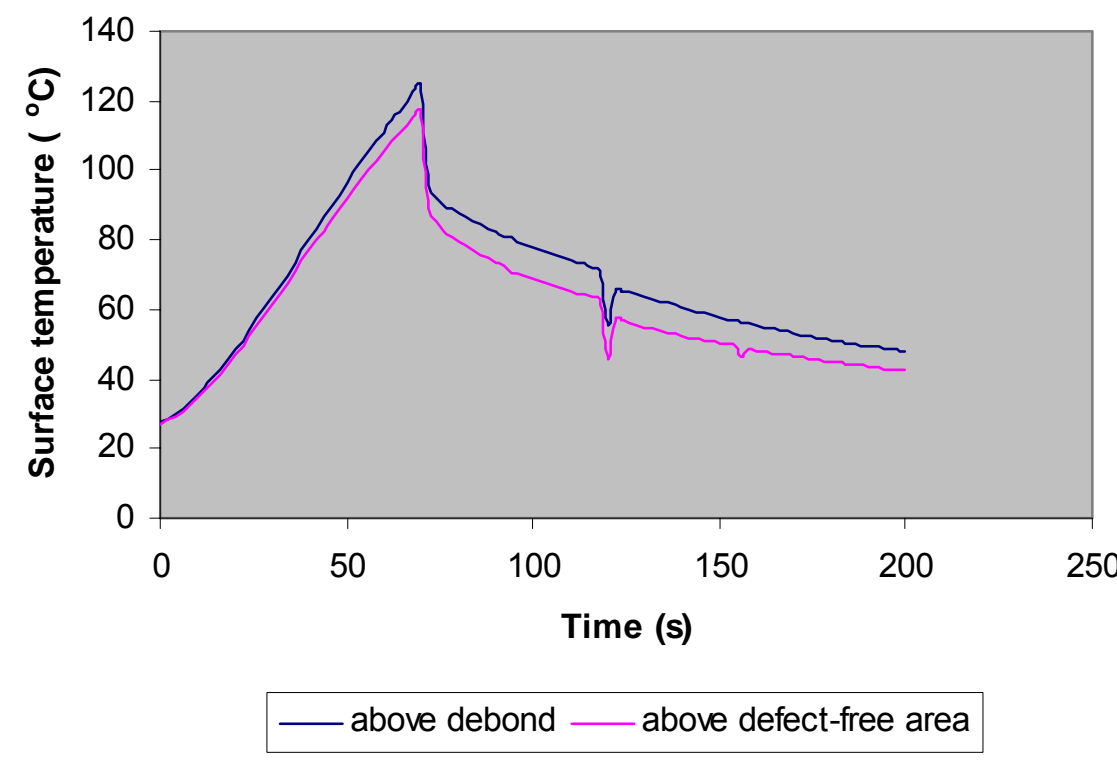

Figure A7 Surface temperature versus time curve for 3 layers of CFRP composite wrapped cylinder with 3" x 3" air-filled debond

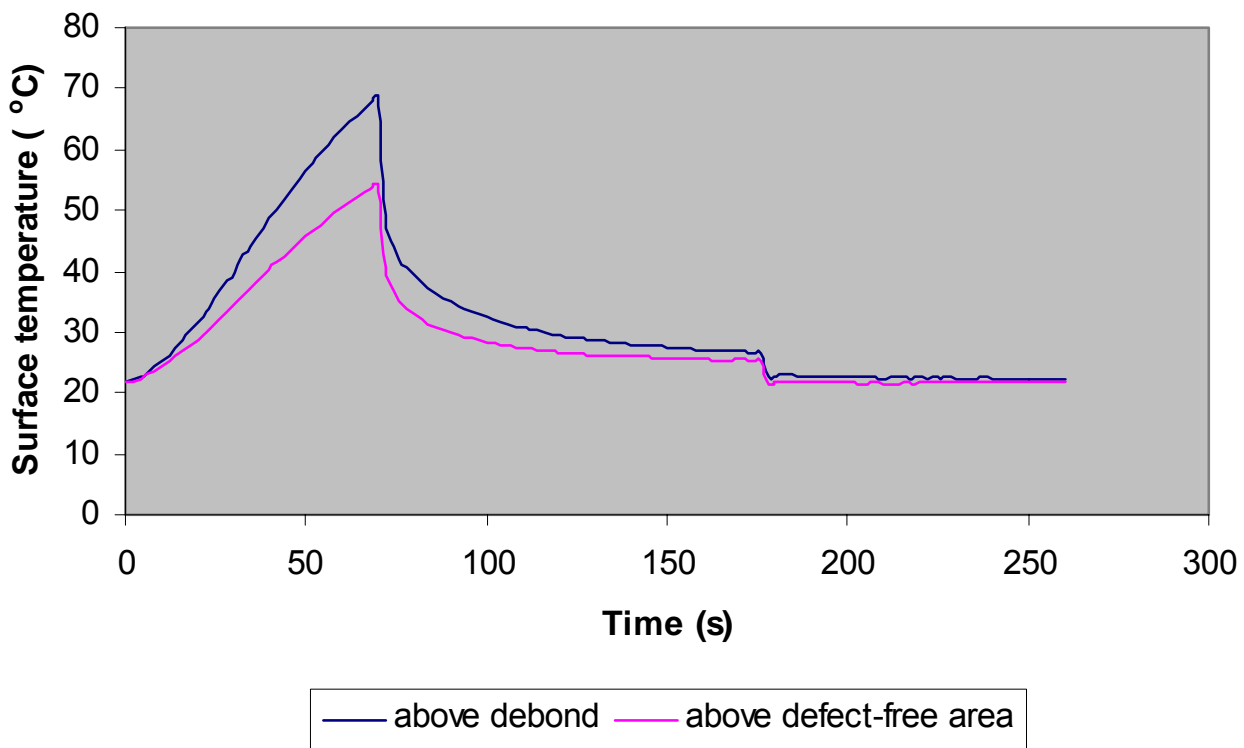

Figure A8 Surface temperature versus time curve for 3 layers of CFRP composite wrapped cylinder with 1.4 " $x$ 1.4" water-filled debond 


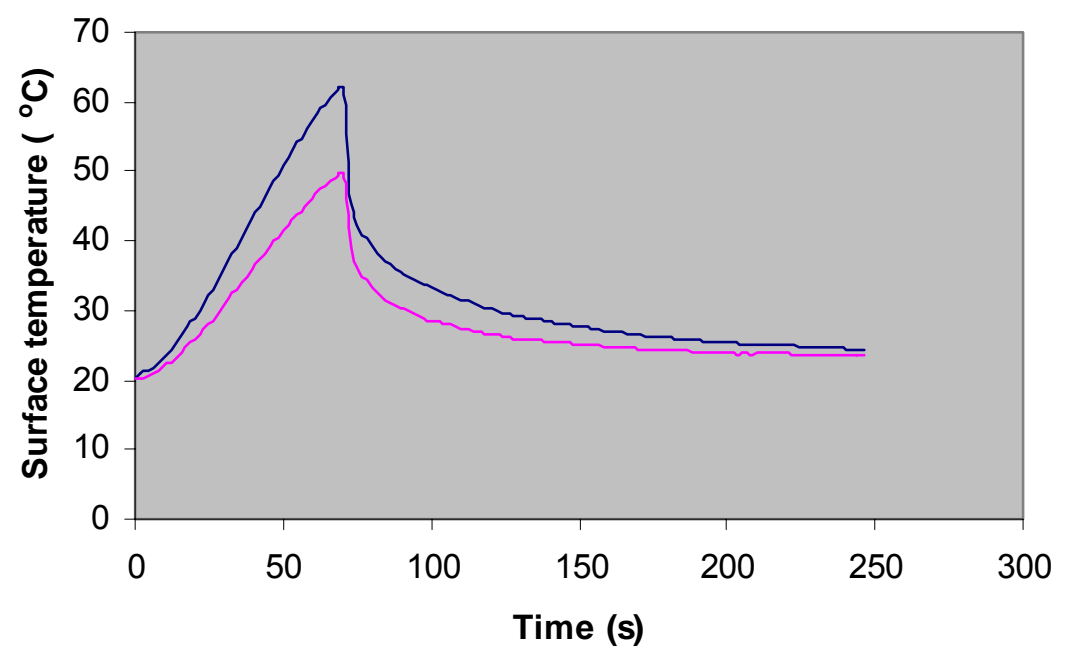

_above debond __ above defect-free area

Figure A9 Surface temperature versus time curve for 3 layers of CFRP composite wrapped cylinder with 2 " $x$ " water-filled debond

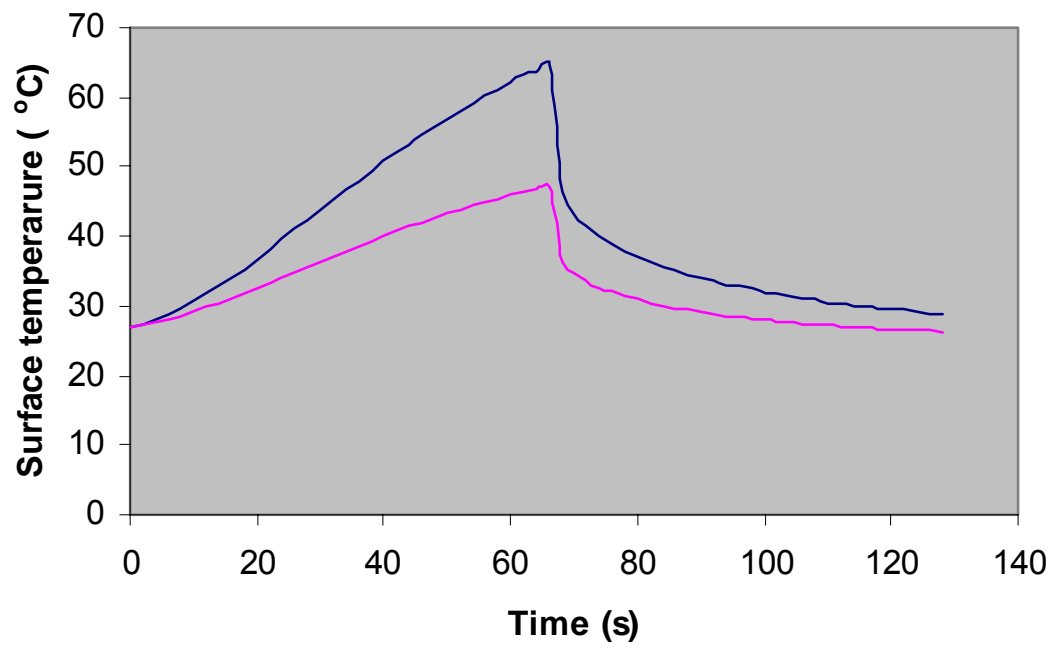

above debond _ above defect-free area

Figure A10 Surface temperature versus time curve for 3 layers of CFRP composite wrapped cylinder with 3" x 3" water-filled debond 


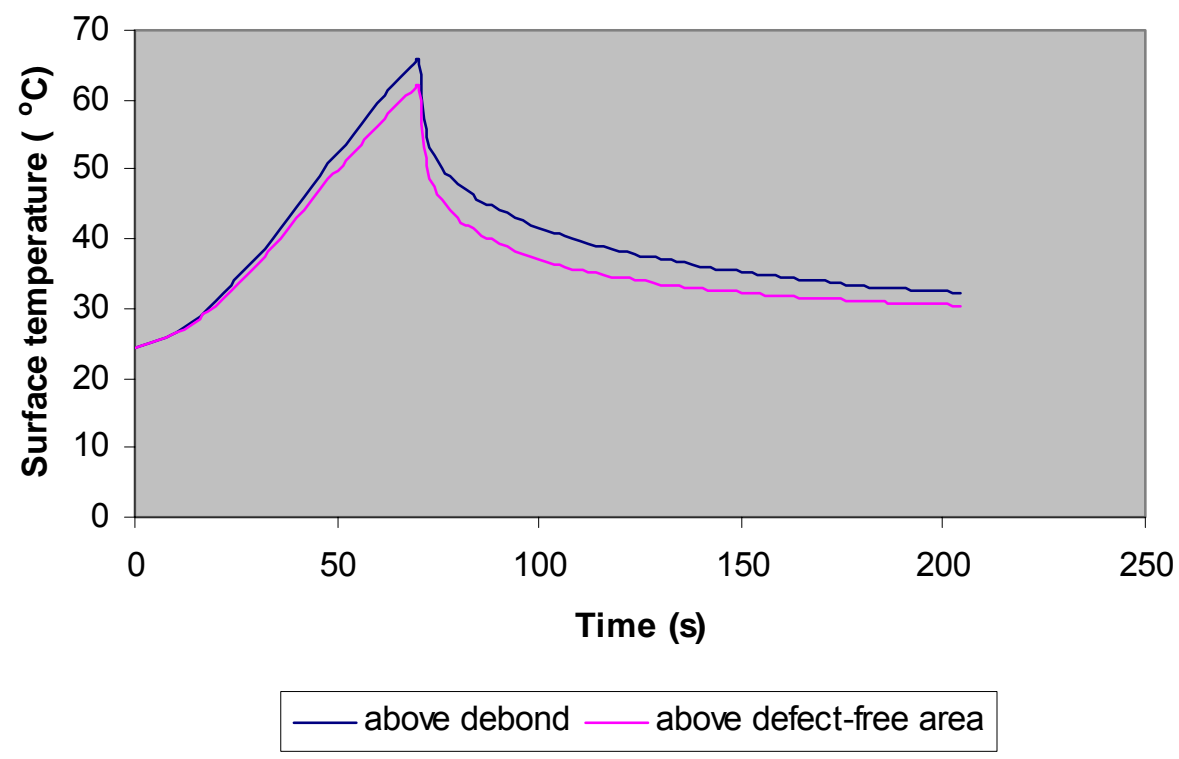

Figure A11 Surface temperature versus time curve for 3 layers of GFRP composite wrapped cylinder with 1 " $x 1$ " air-filled debond

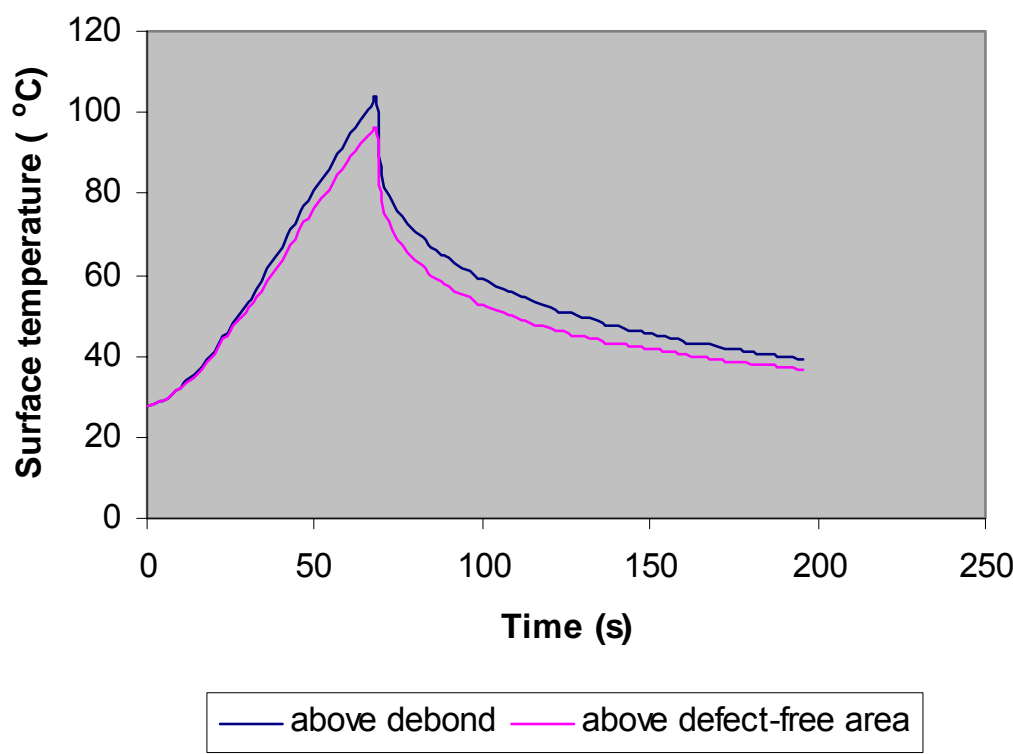

Figure A12 Surface temperature versus time curve for 3 layers of GFRP composite wrapped cylinder with 1.4" x 1.4" air-filled debond 


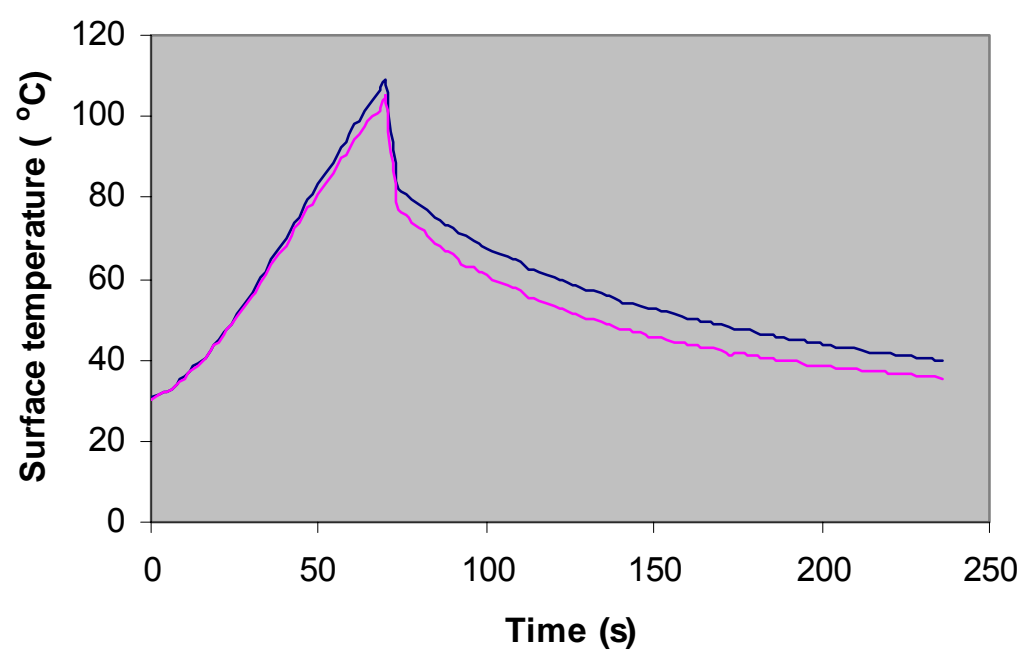

above debond _-above defect-free area

Figure A13 Surface temperature versus time curve for 3 layers of GFRP composite wrapped cylinder with 2 " $x$ 2" air-filled debond

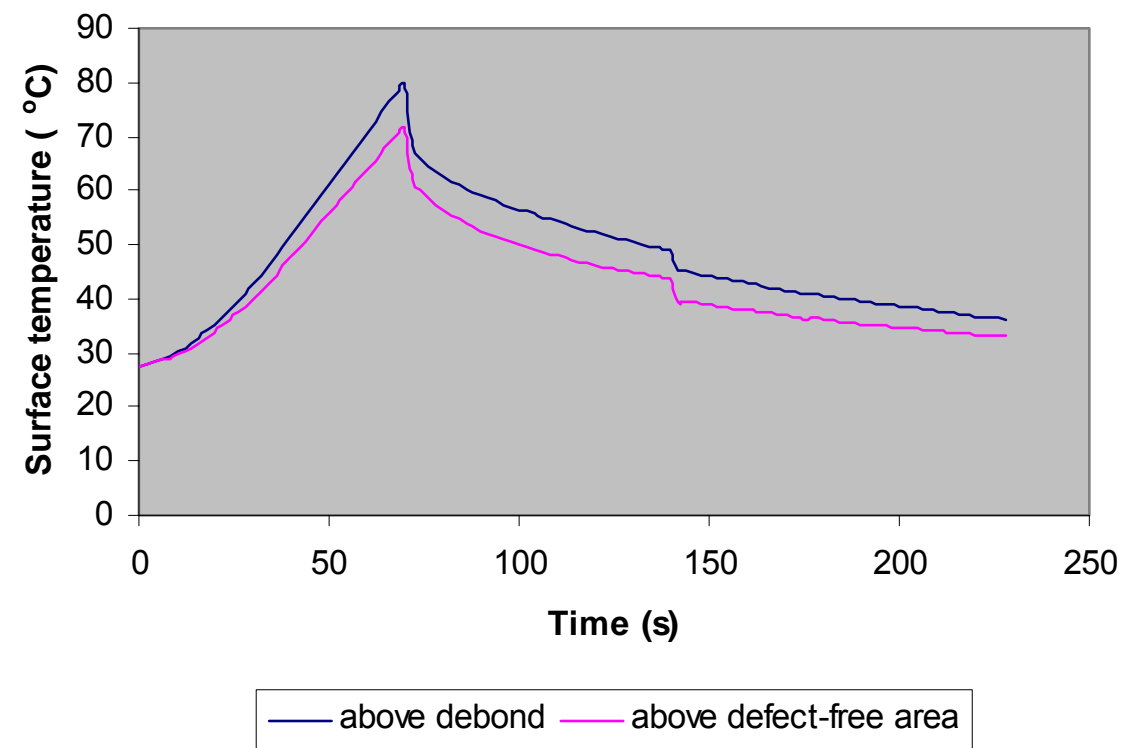

Figure A14 Surface temperature versus time curve for 3 layers of GFRP composite wrapped cylinder with 3" $\mathbf{3}$ " air-filled debond 


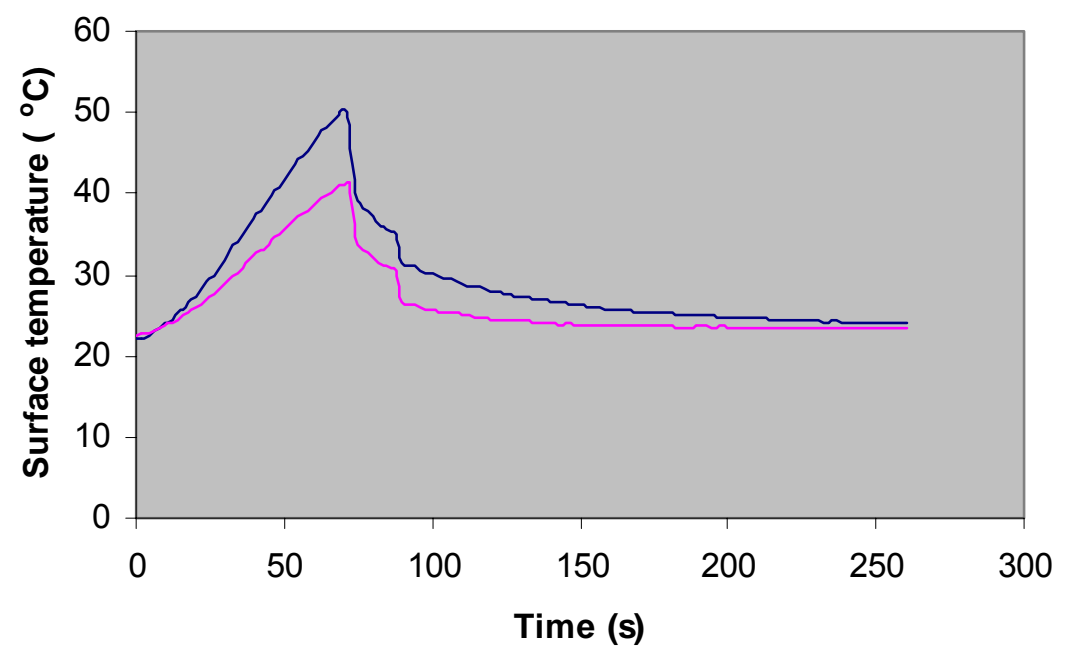

_ above debond __ above defect-free area

Figure A15 Surface temperature versus time curve for 3 layers of GFRP composite wrapped cylinder with 2 " $x 2$ " water-filled debond

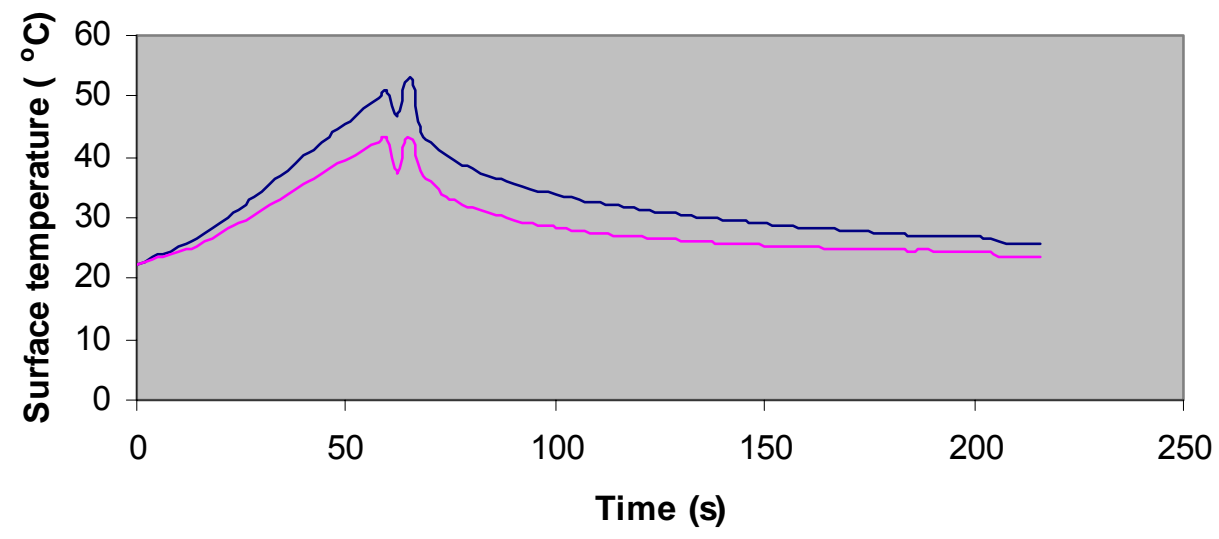

_ above debond __above defect-free area

Figure A16 Surface temperature versus time curve for 3 layers of GFRP composite wrapped cylinder with 3 ” $x$ 3" water-filled debond 


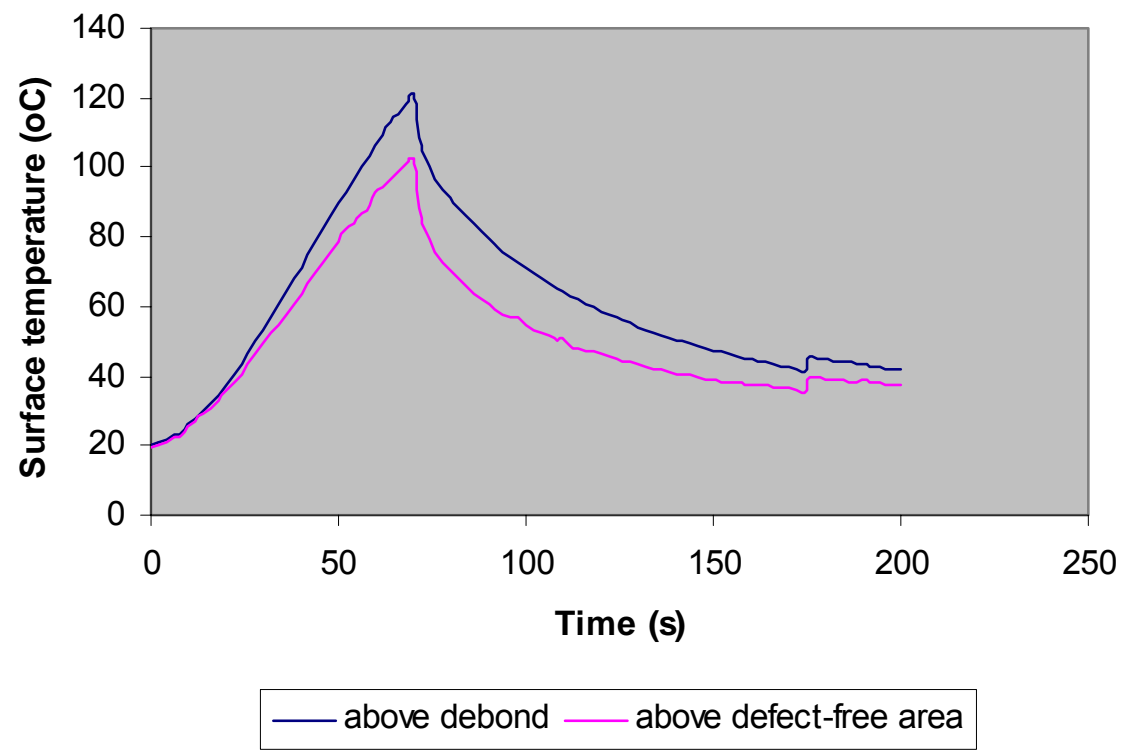

Figure A17 Surface temperature versus time curve for 1 layer GFRP composite wrapped cylinder with 2 " 2 " air-filled debond

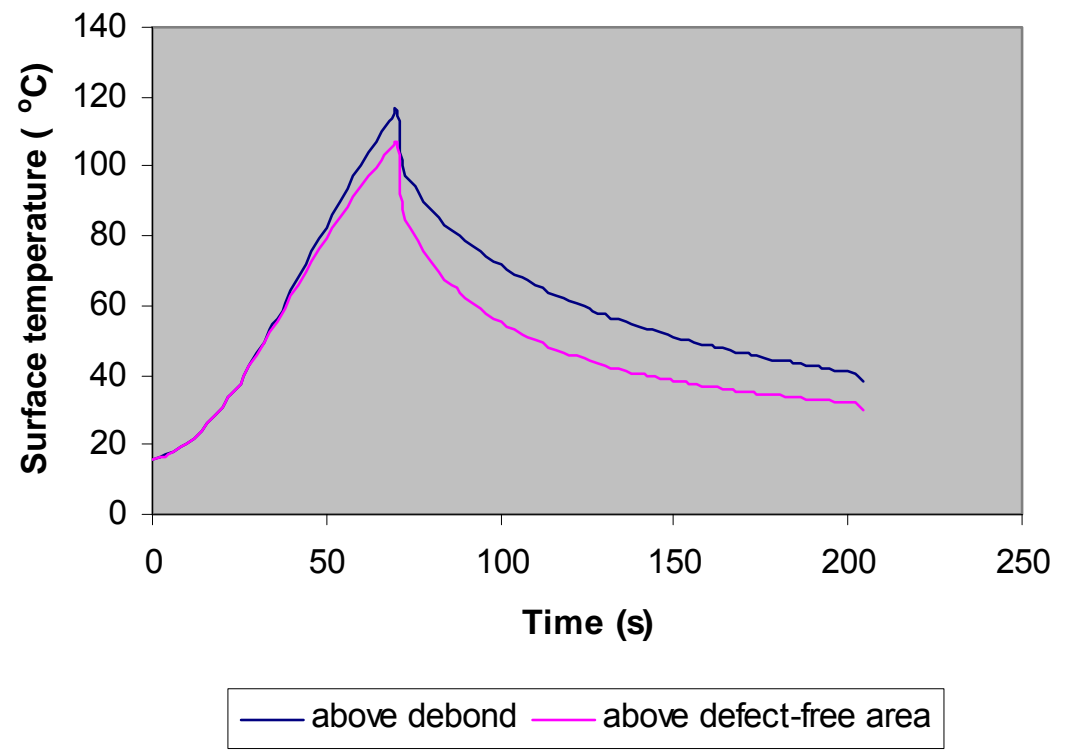

Figure A18 Surface temperature versus time curve for 2 layers GFRP composite wrapped cylinder with 2 " 12 " air-filled debond 


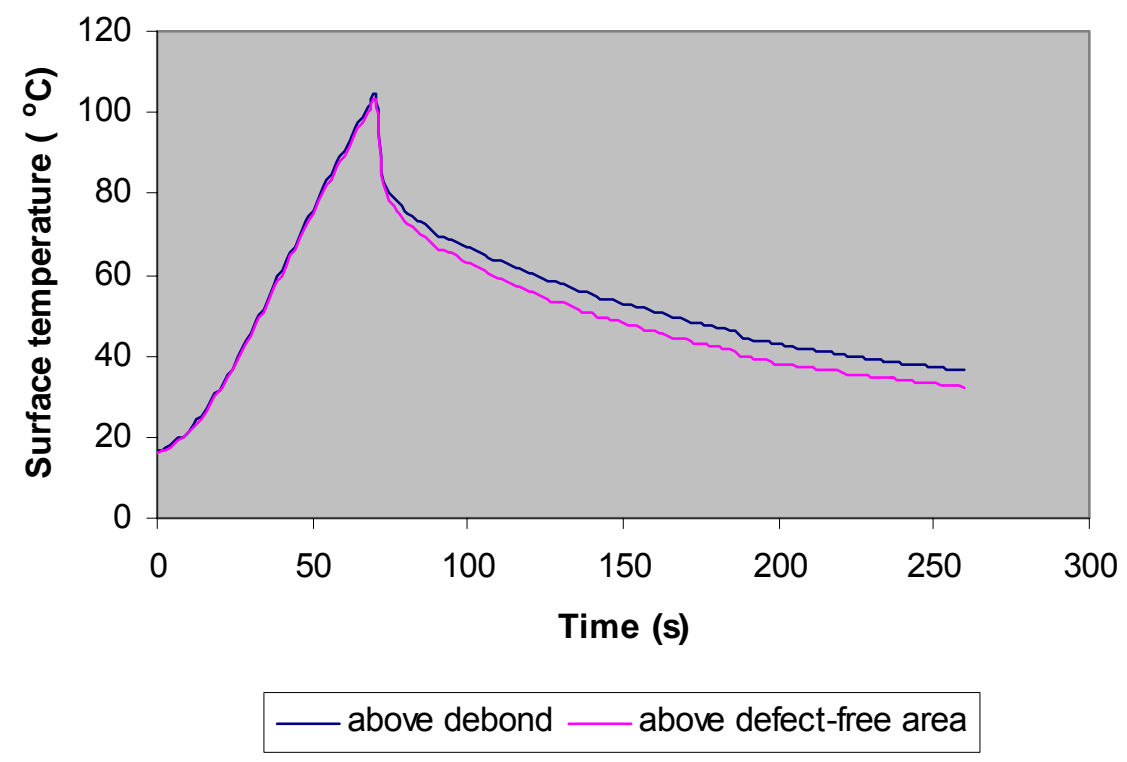

Figure A19 Surface temperature versus time curve for 4 layers GFRP composite wrapped cylinder with 2 " 2 " air-filled debond

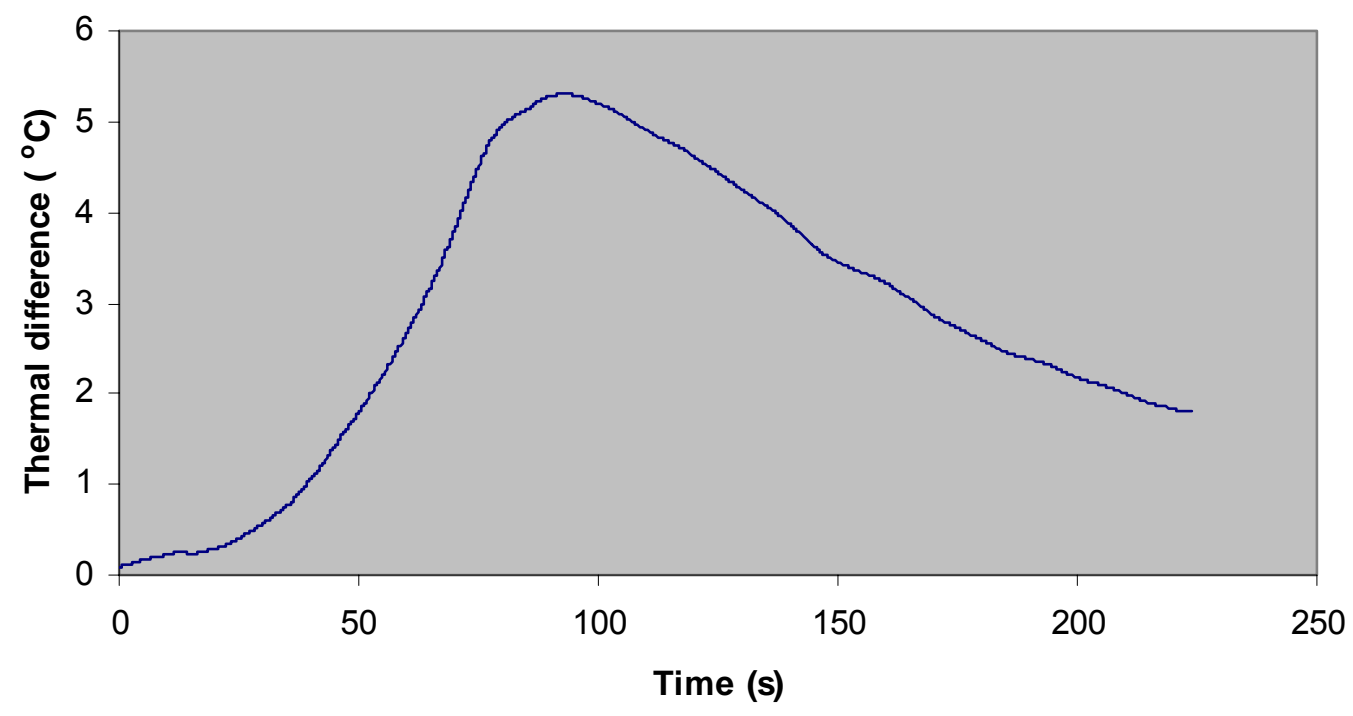

Figure A20 Thermal difference versus time curve for 3 layers of CFRP composite wrapped cylinder with 1.4" $x$ 1.4" air-filled debond 


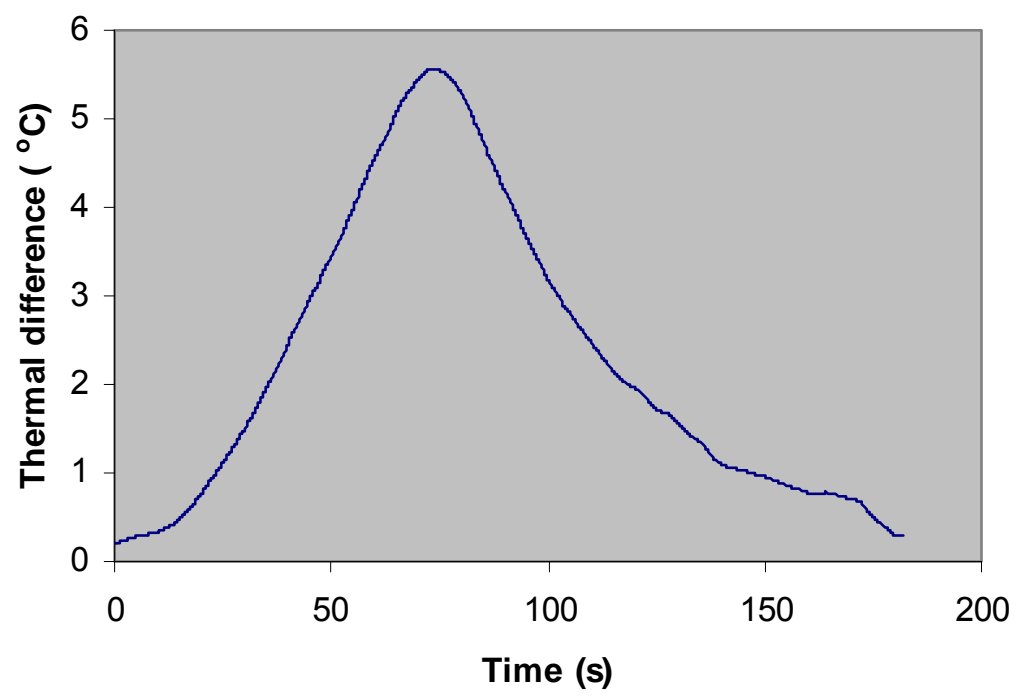

Figure A21 Thermal difference versus time curve for 3 layers of CFRP composite wrapped cylinder with 2 " $x 2$ " air-filled debond

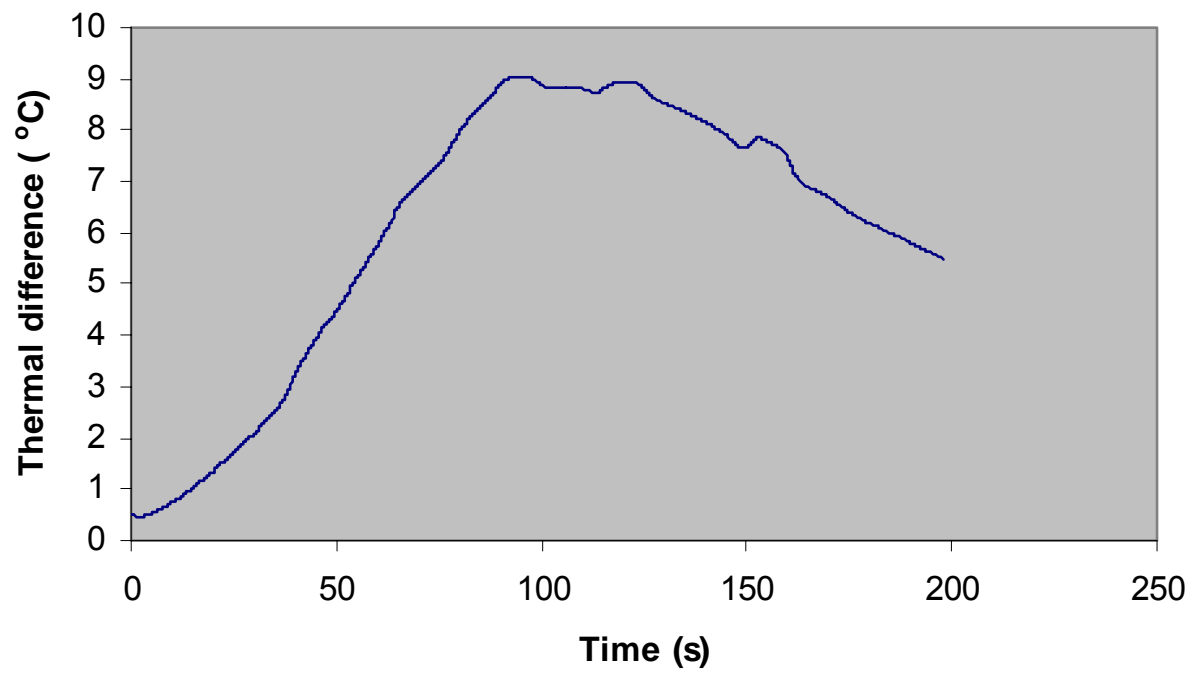

Figure A22 Thermal difference versus time curve for 3 layers of CFRP composite wrapped cylinder with 3 " $x$ 3" air-filled debond 


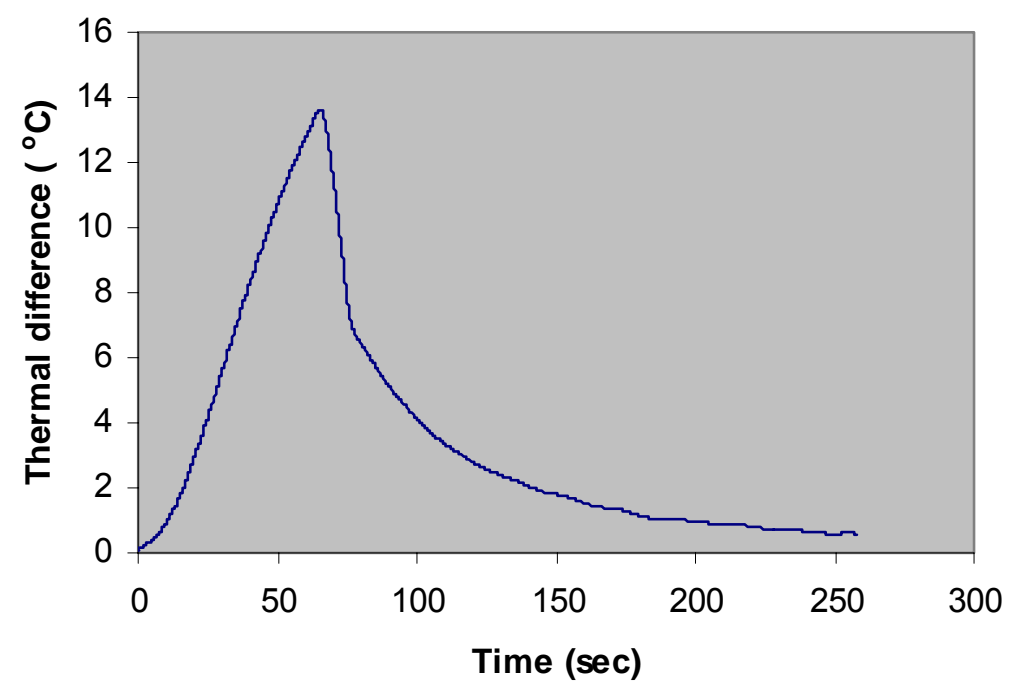

Figure A23 Thermal difference versus time curve for 3 layers of CFRP composite wrapped cylinder with 1.4" $x$ 1.4" water-filled debond

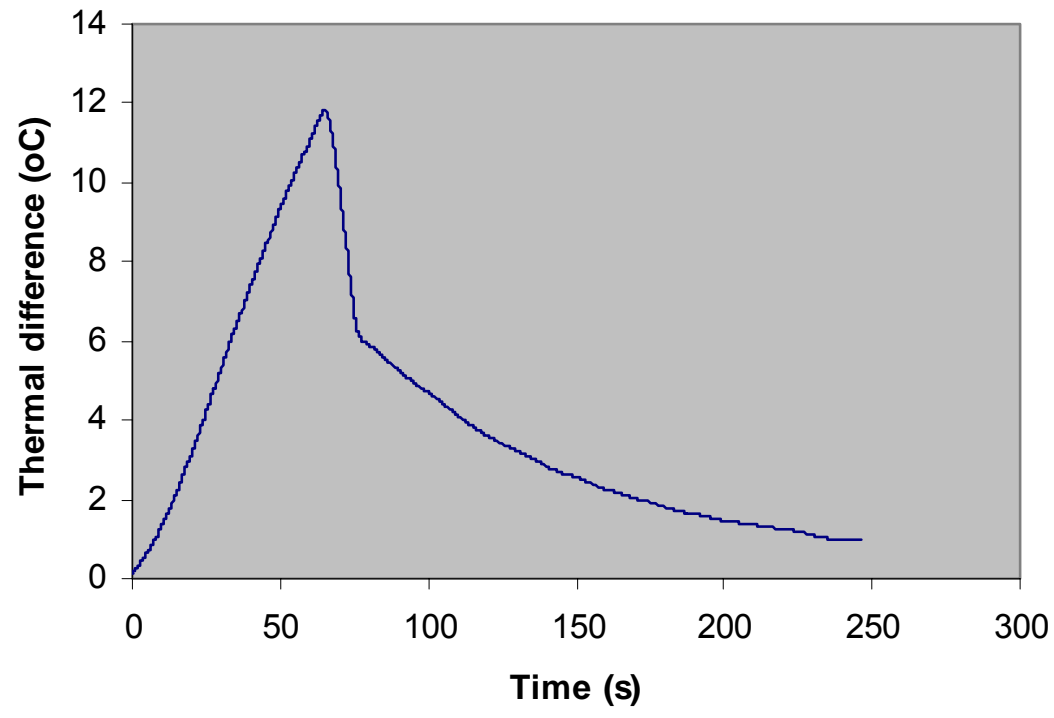

Figure A24 Thermal difference versus time curve for 3 layers of CFRP composite wrapped cylinder with $2 "$ x 2 " water-filled debond 


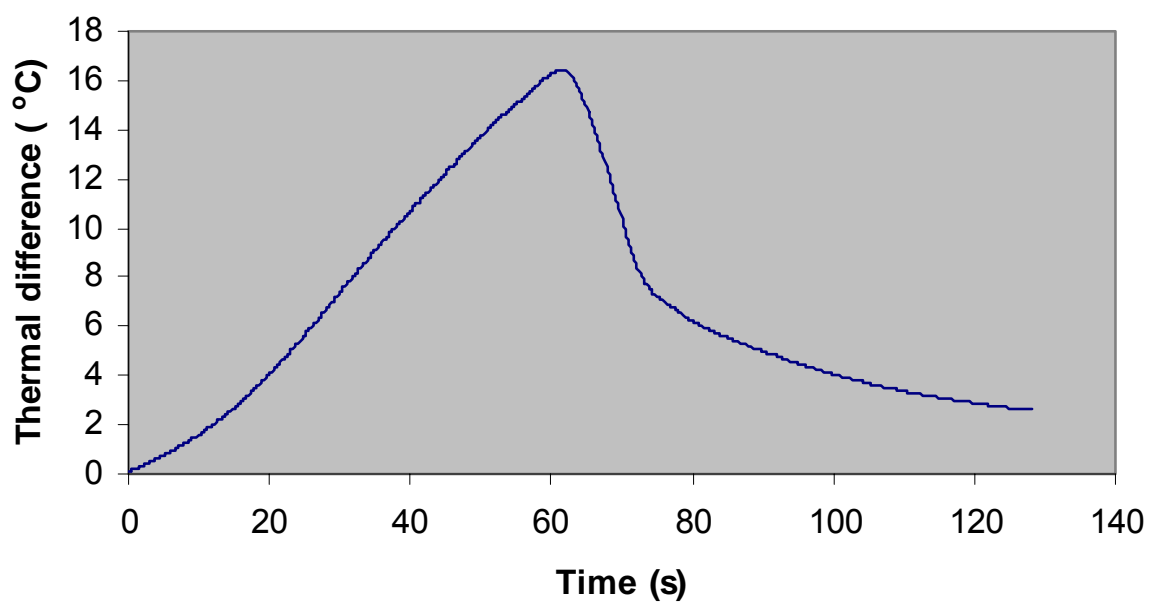

Figure A25 Thermal difference versus time curve for 3 layers of CFRP composite wrapped cylinder with 3" $x$ 3" water-filled debond

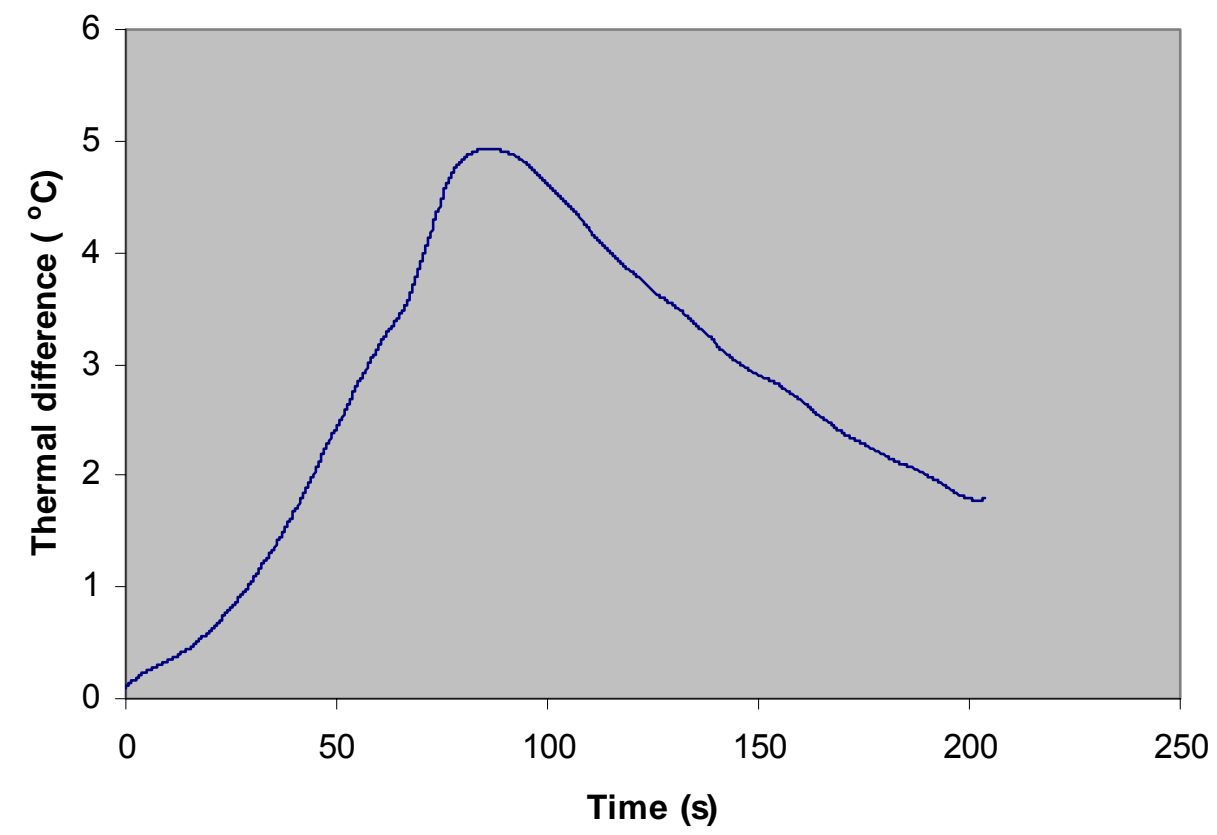

Figure A26 Thermal difference versus time curve for 3 layers of GFRP composite wrapped cylinder with 1 " $x$ 1" air-filled debond 


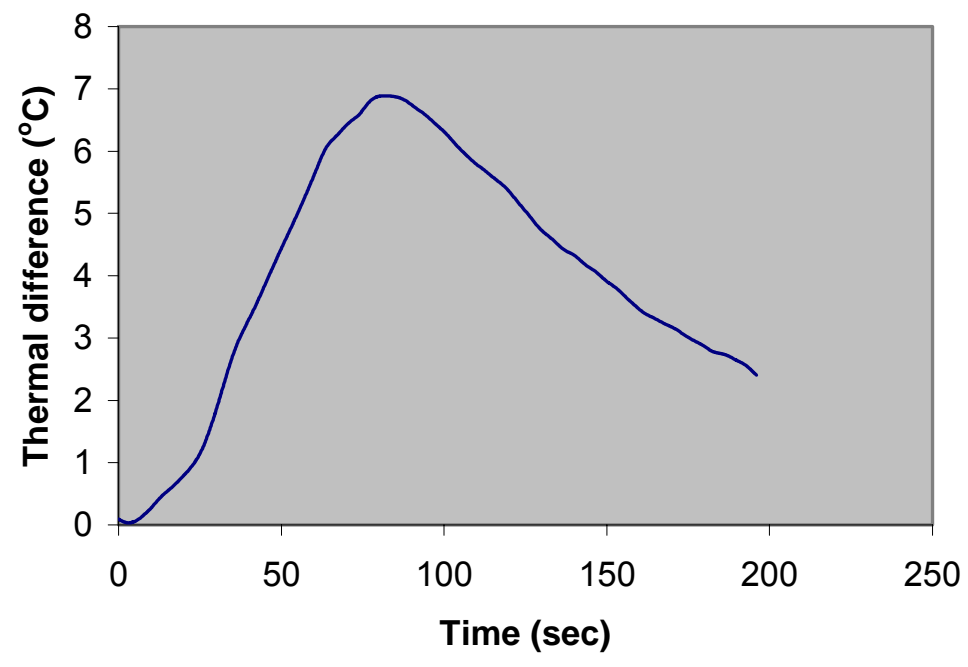

Figure A27 Thermal difference versus time curve for 3 layers of GFRP composite wrapped cylinder with 1.4" $x$ 1.4" air-filled debond

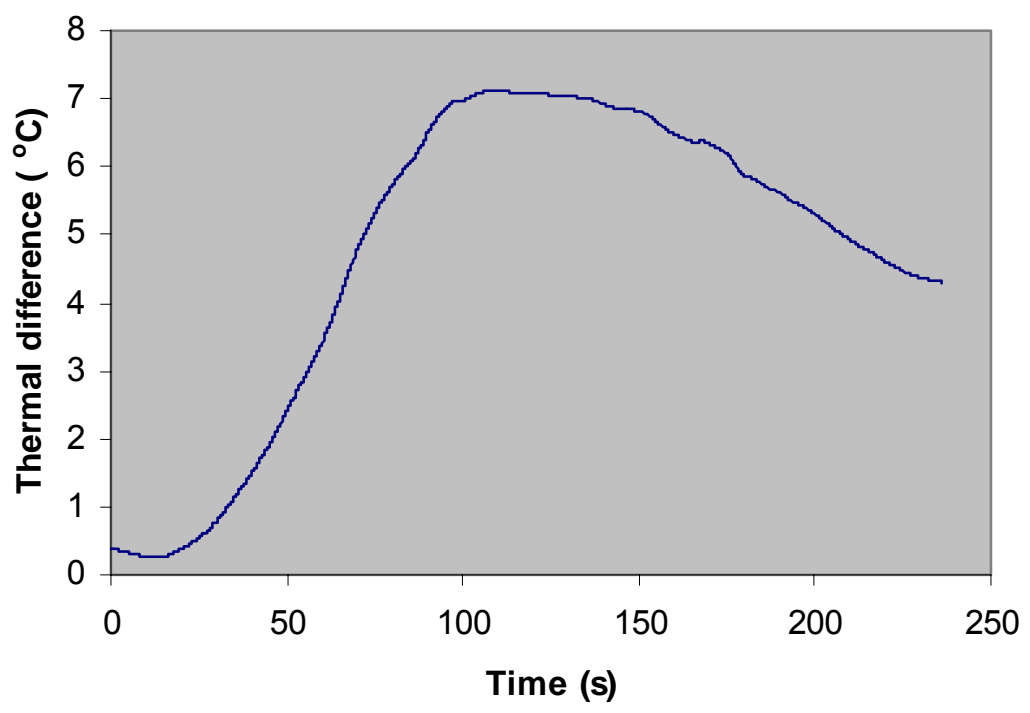

Figure A28 Thermal difference versus time curve for 3 layers of GFRP composite wrapped cylinder with 2 " $\mathrm{x}$ 2" air-filled debond 


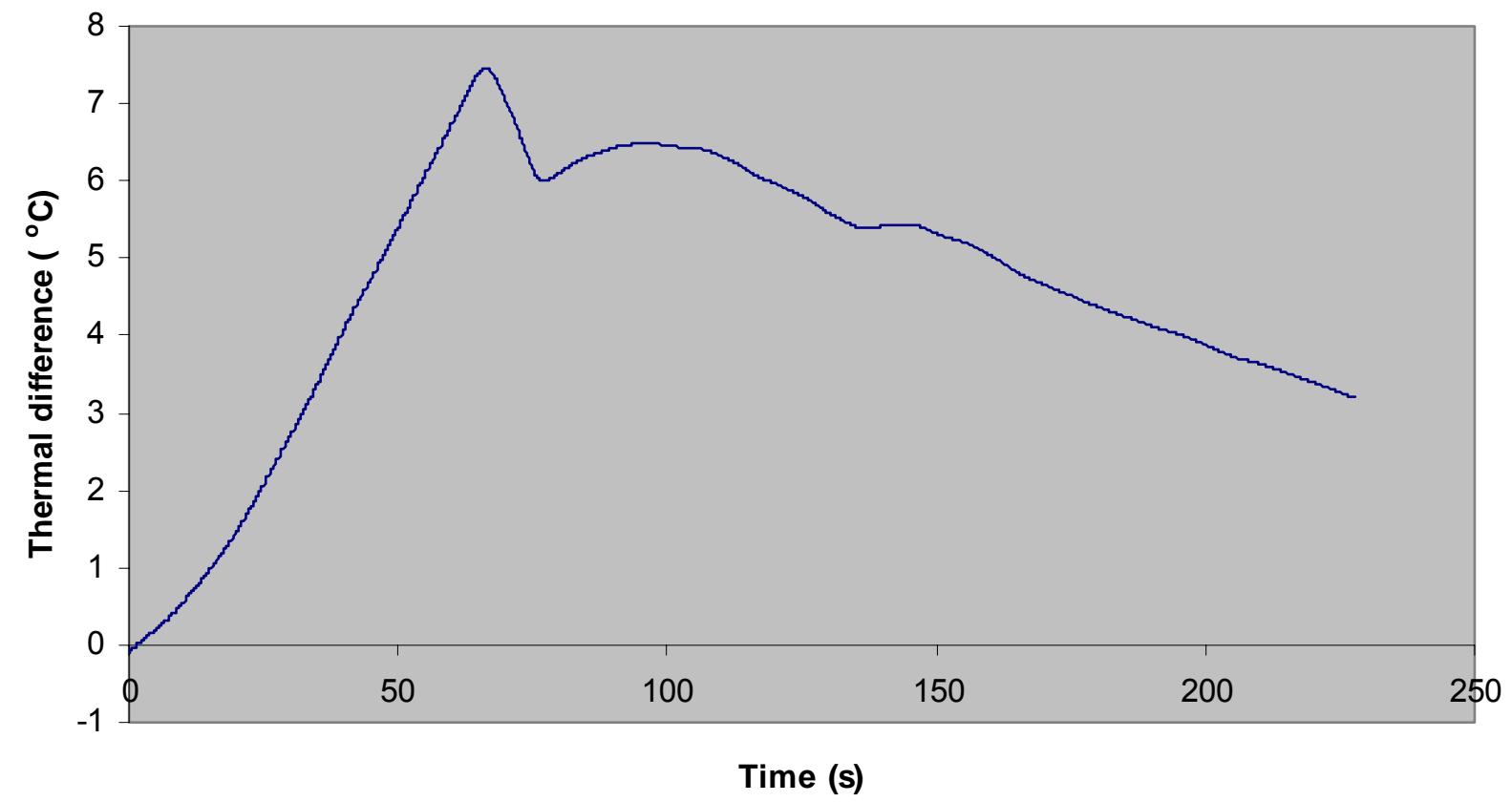

Figure A29 Thermal difference versus time curve for 3 layers of GFRP composite wrapped cylinder with 3 " $x$ 3" air-filled debond

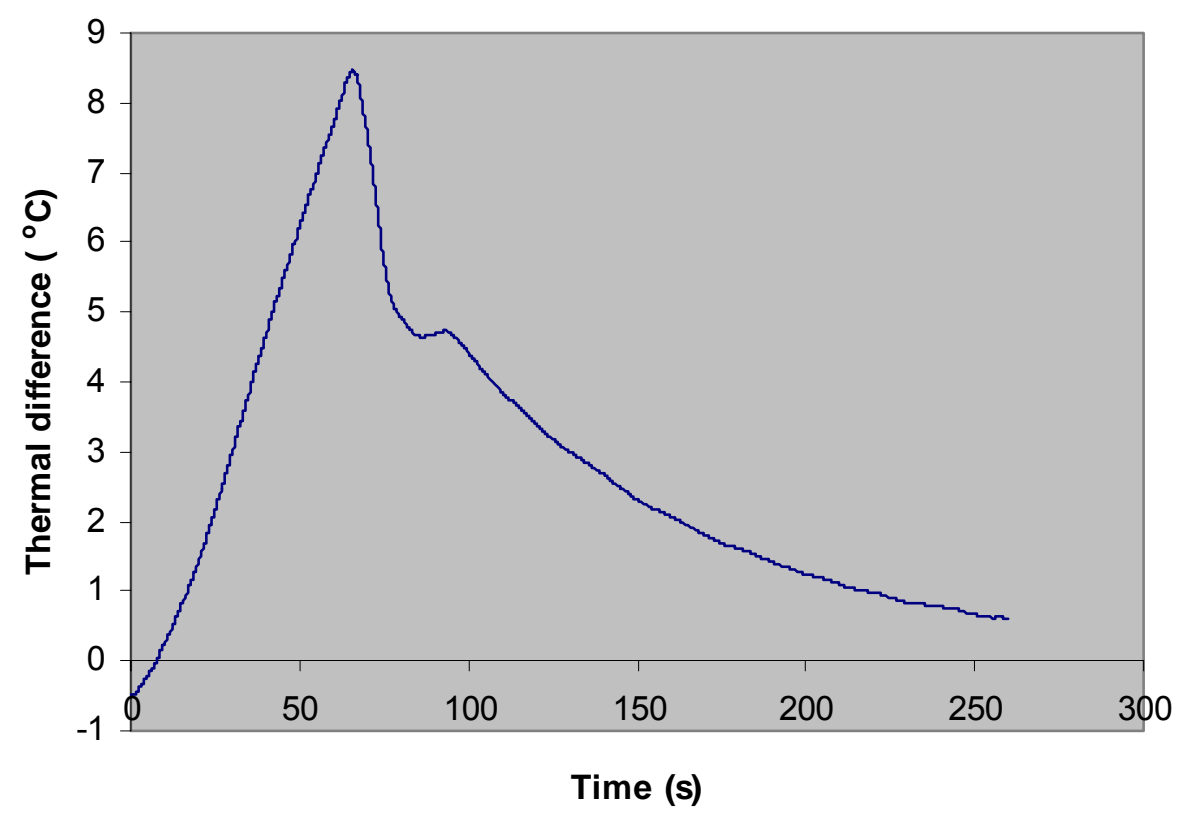

Figure A30 Thermal difference versus time curve for 3 layers of GFRP composite wrapped cylinder with 2" $\mathrm{x} 2$ " water-filled debond 


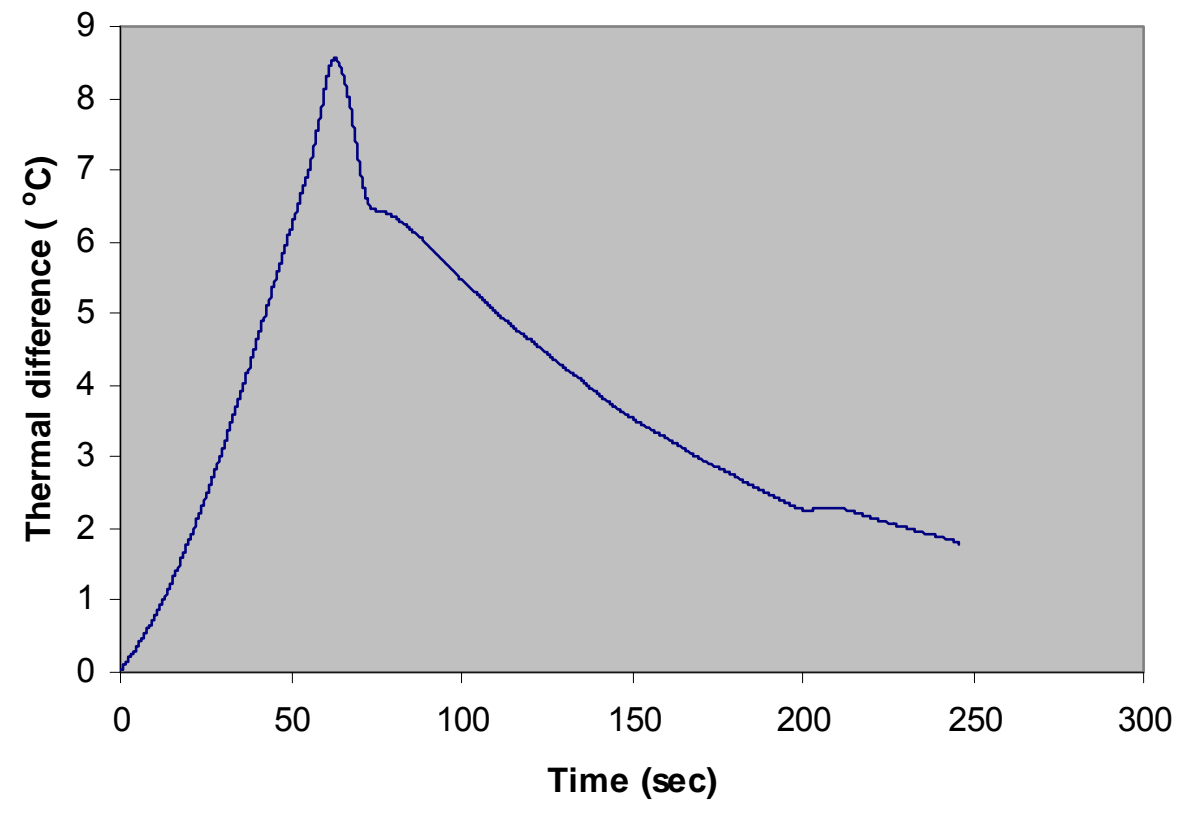

Figure A31 Thermal difference versus time curve for 3 layers of GFRP composite wrapped cylinder with 3 ” $x 3$ ” water-filled debond

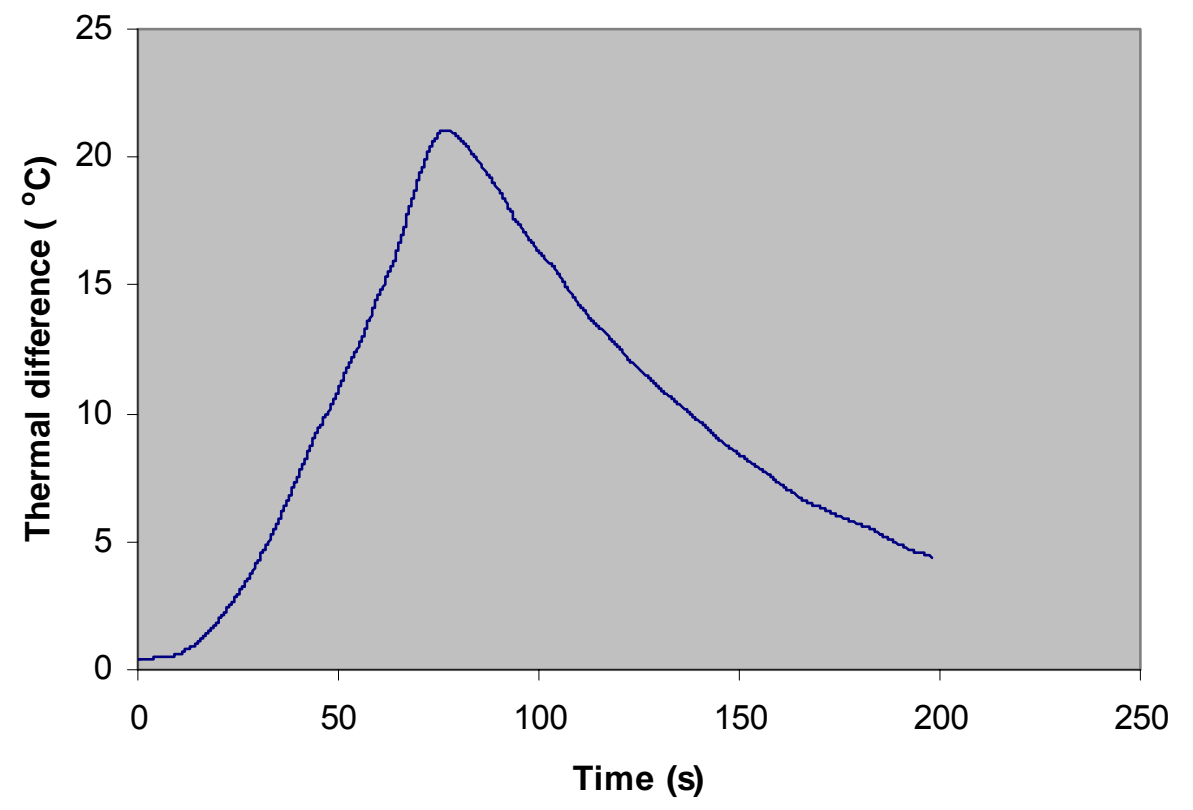

Figure A32 Thermal difference versus time curve for 1 layer of GFRP composite wrapped cylinder with 2 " 2 2" air-filled debond 


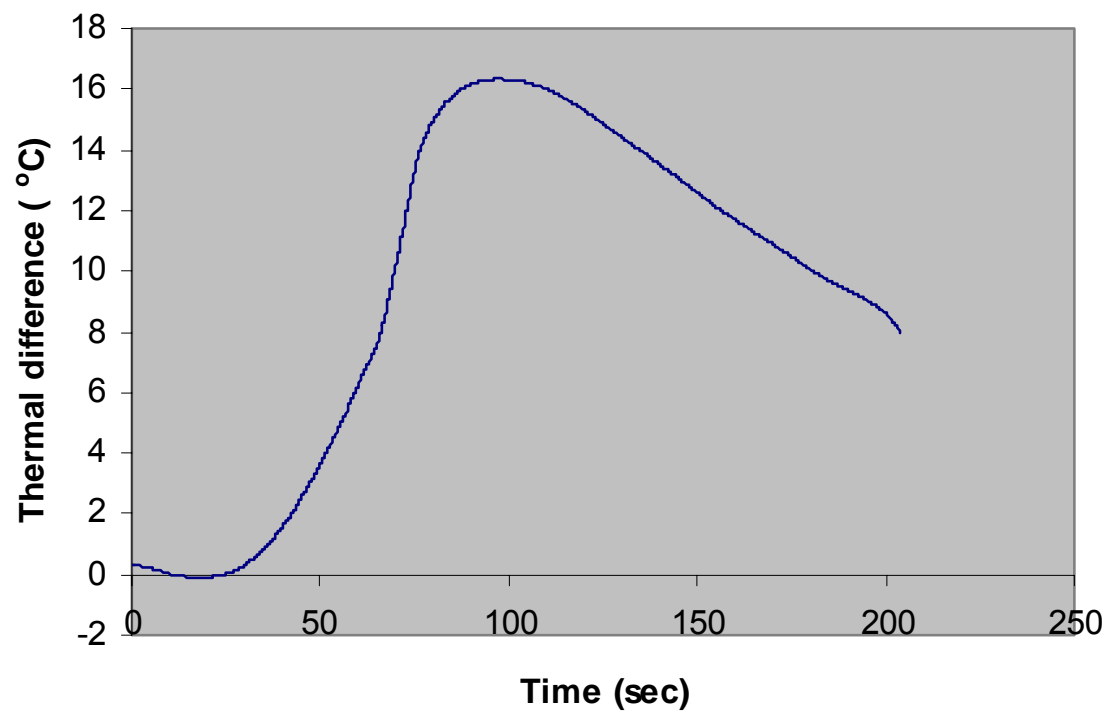

Figure A33 Thermal difference versus time curve for 2 layers of GFRP composite wrapped cylinder with 2 " $x$ 2" air-filled debond

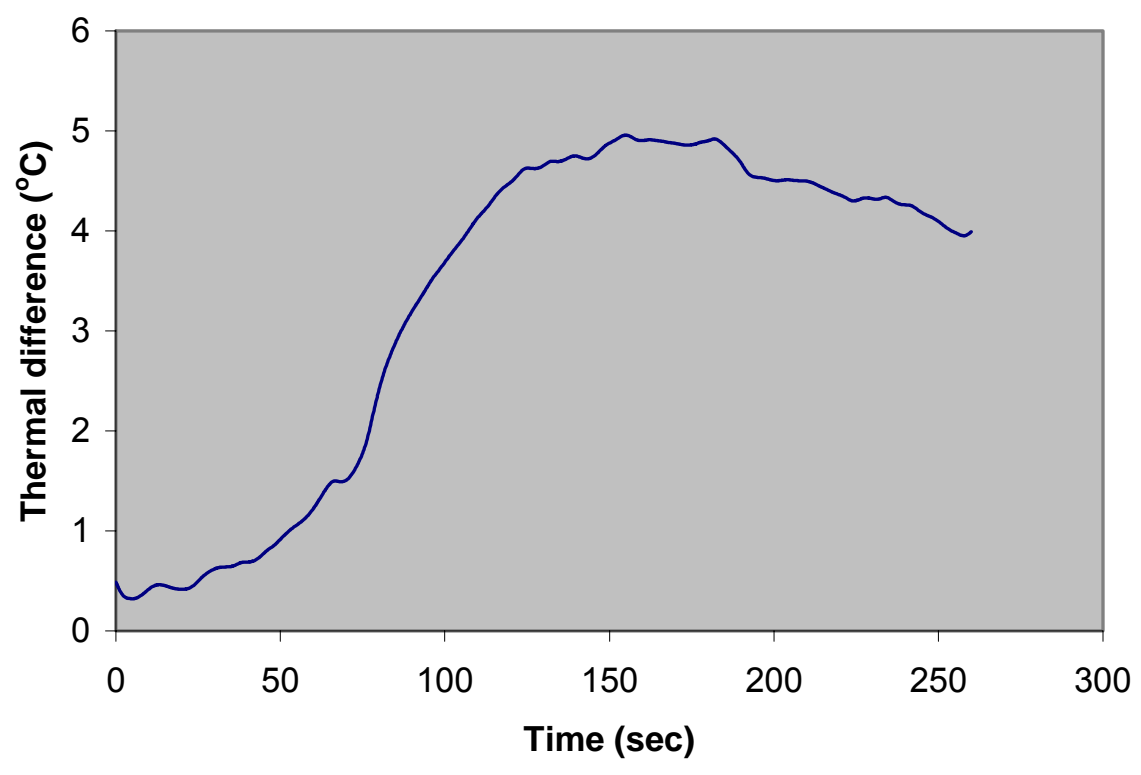

Figure A34 Thermal difference versus time curve for 4 layers of GFRP composite wrapped cylinder with 2" $x$ 2" air-filled debond 


\section{APPENDIX B}

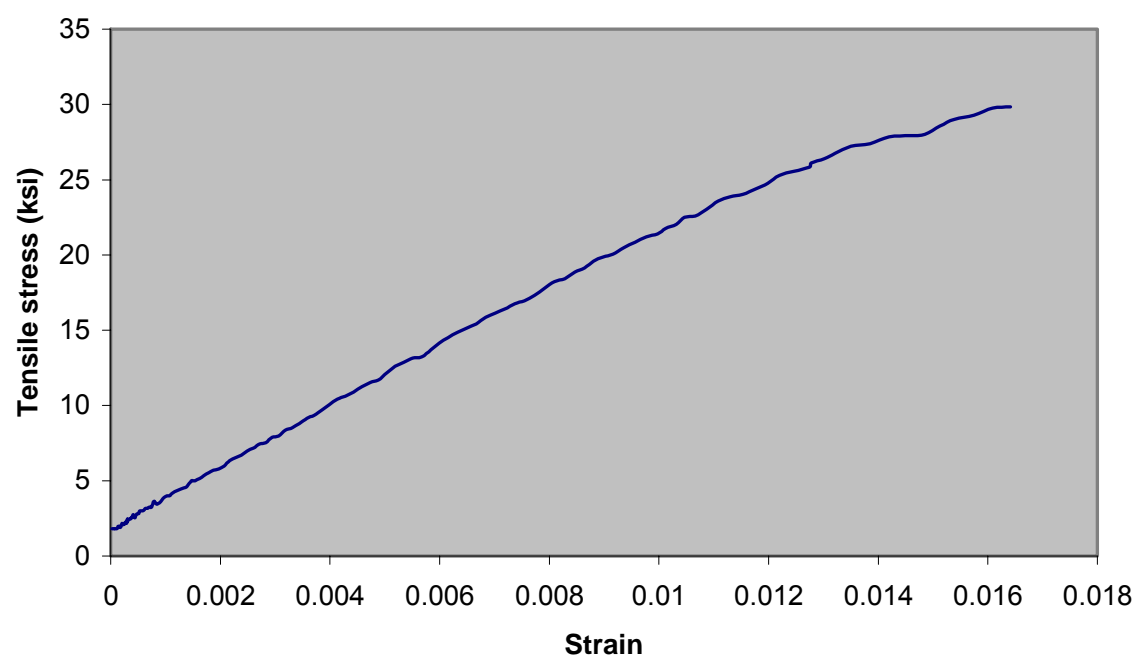

Figure B1 Tensile stress vs. tensile strain for GFRP $\left(0^{\circ} / 90^{\circ}\right)$ coupon specimen

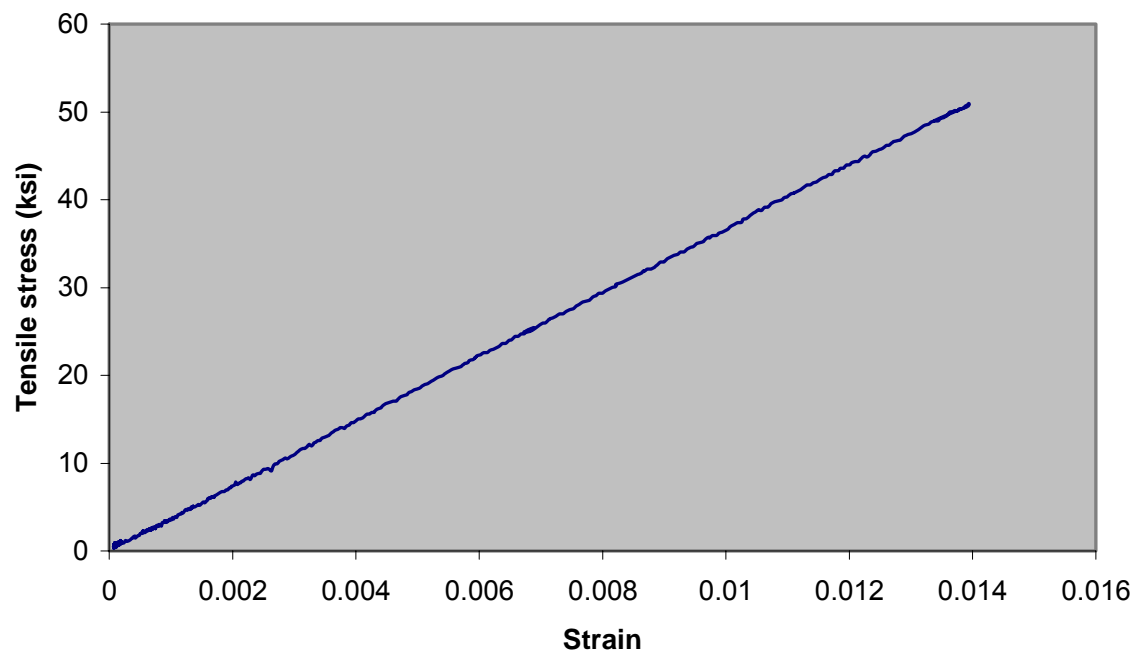

Figure B2 Tensile stress vs. tensile strain for CFRP $\left(0^{\circ} / \pm 45^{\circ} / 90^{\circ}\right)$ coupon specimen 


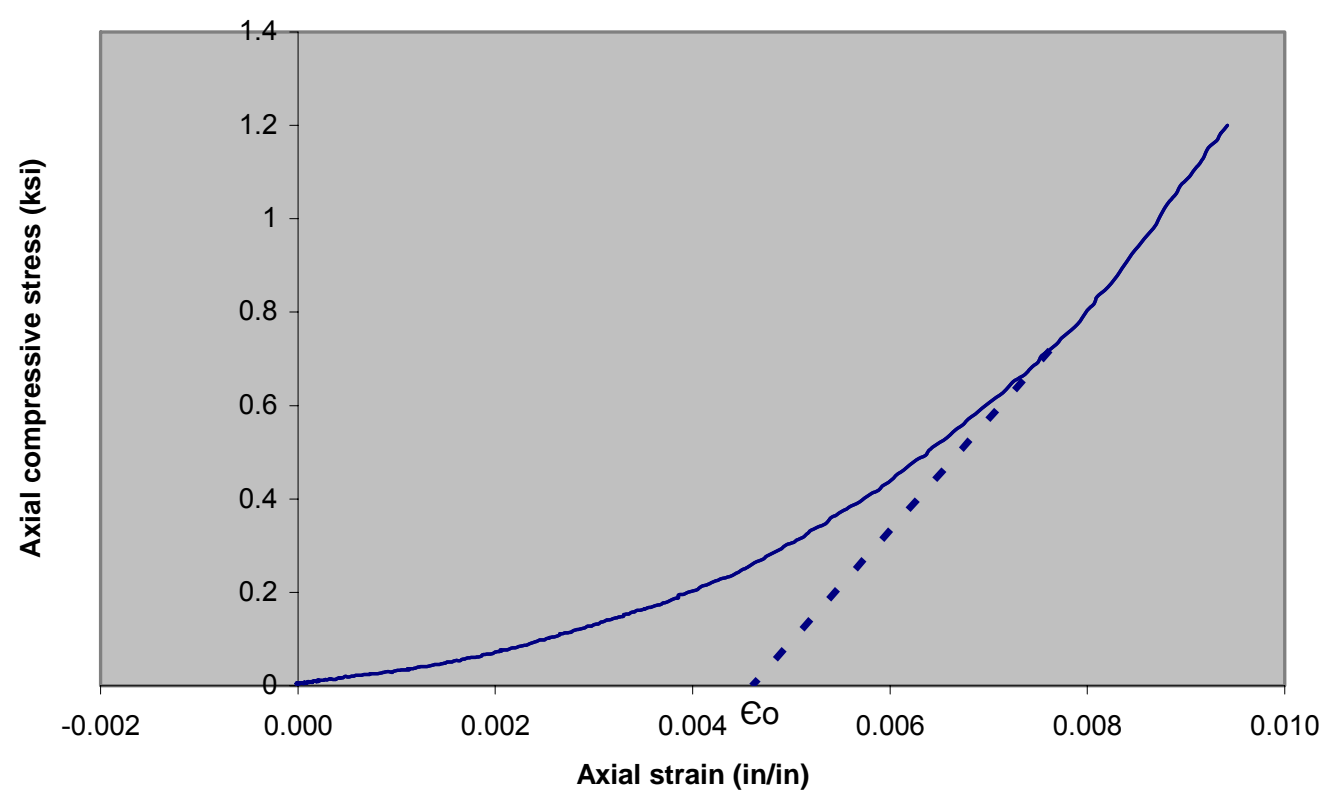

Figure B3 Axial compressive stress vs. axial compressive strain for plain concrete cylinder number 1

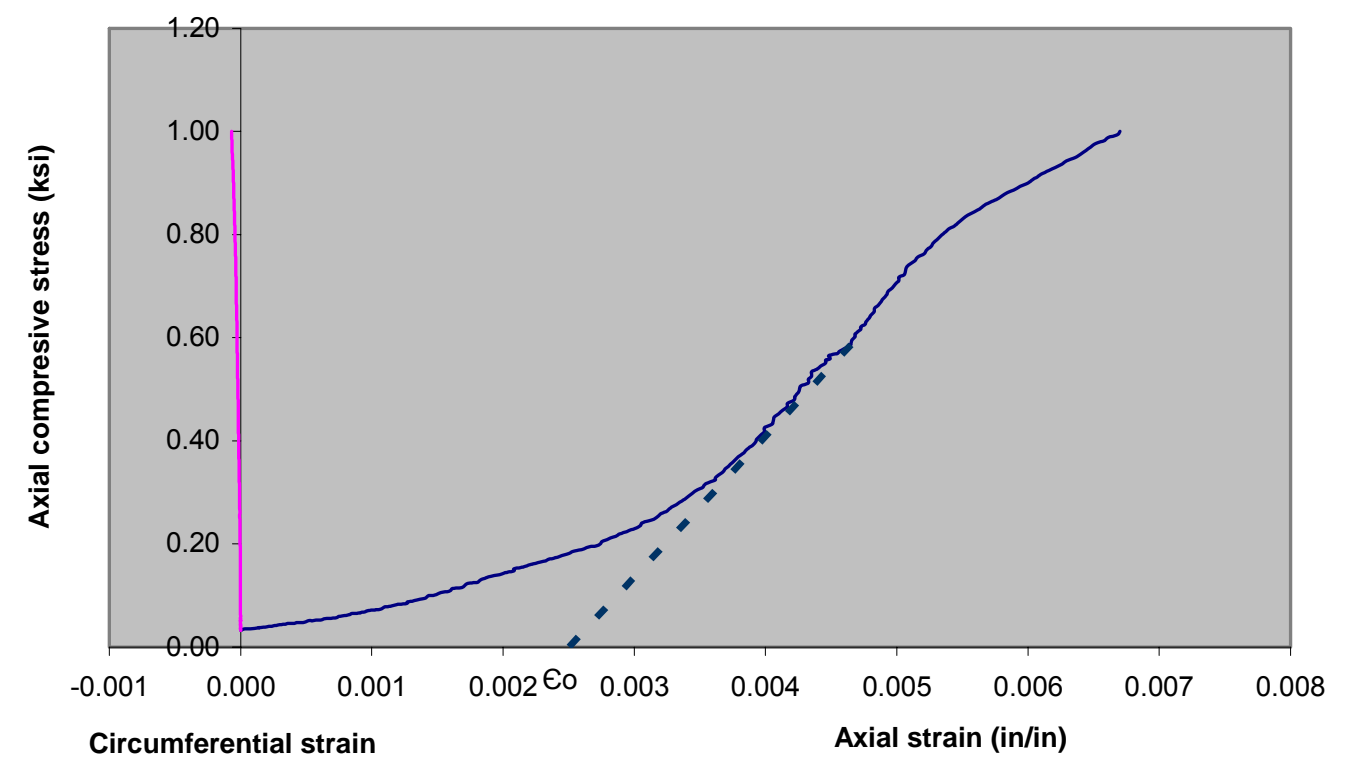

Figure B4 Axial compressive stress vs. strain for plain concrete cylinder number 2 


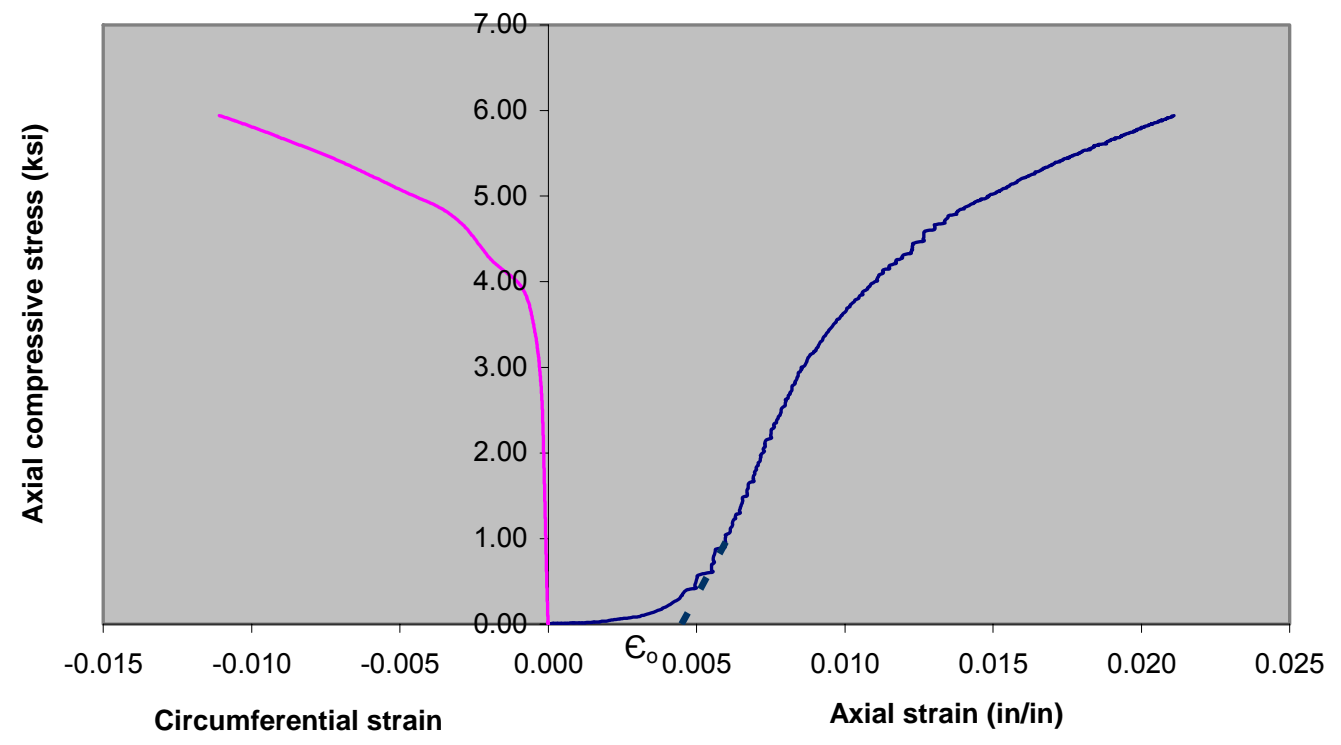

Figure B5 Axial compressive stress vs. strain for defect free cylinder number 1 wrapped with GFRP composite $\left(0^{\circ} / 90^{\circ}\right)$

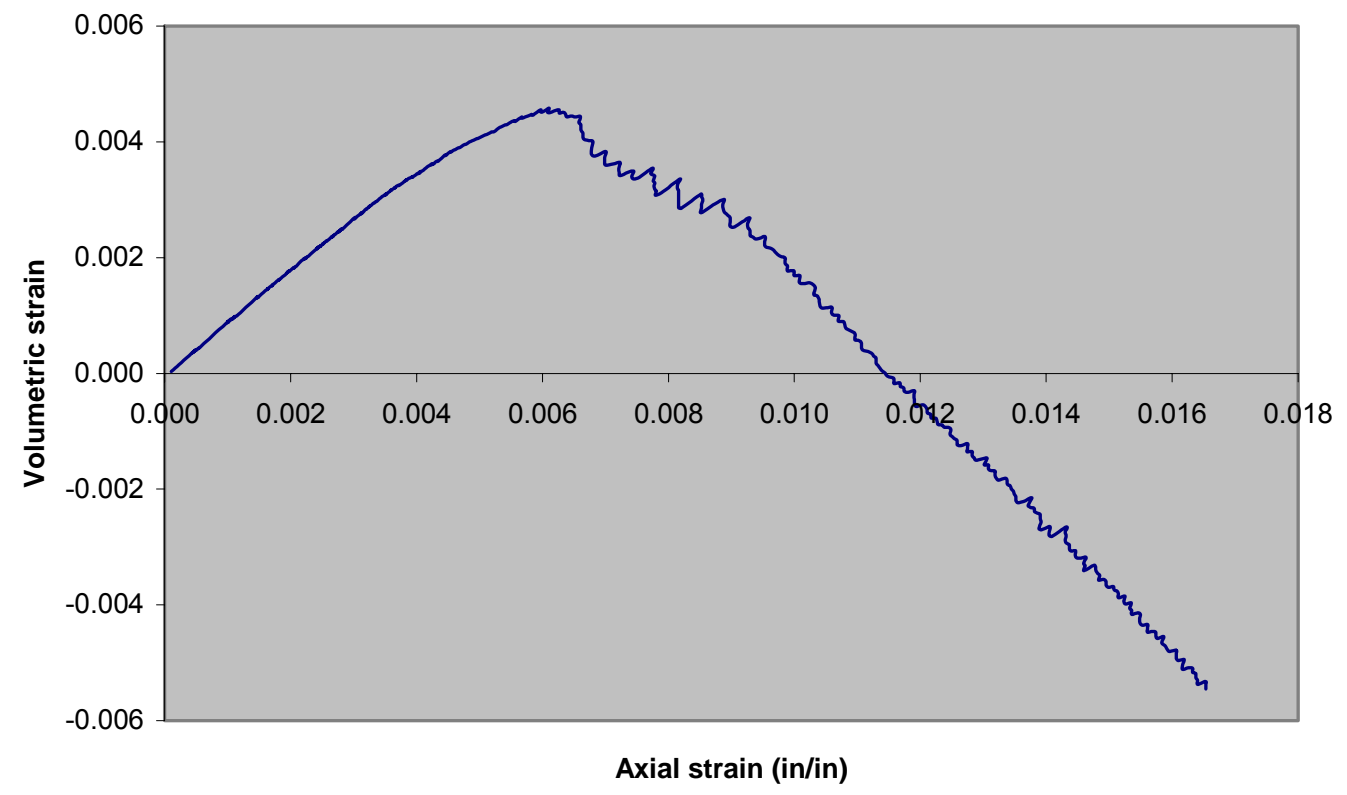

Figure B6 Volumetric strain vs. axial strain for defect free cylinder number 1 wrapped with GFRP composite $\left(0^{\circ} / 90^{\circ}\right)$ 


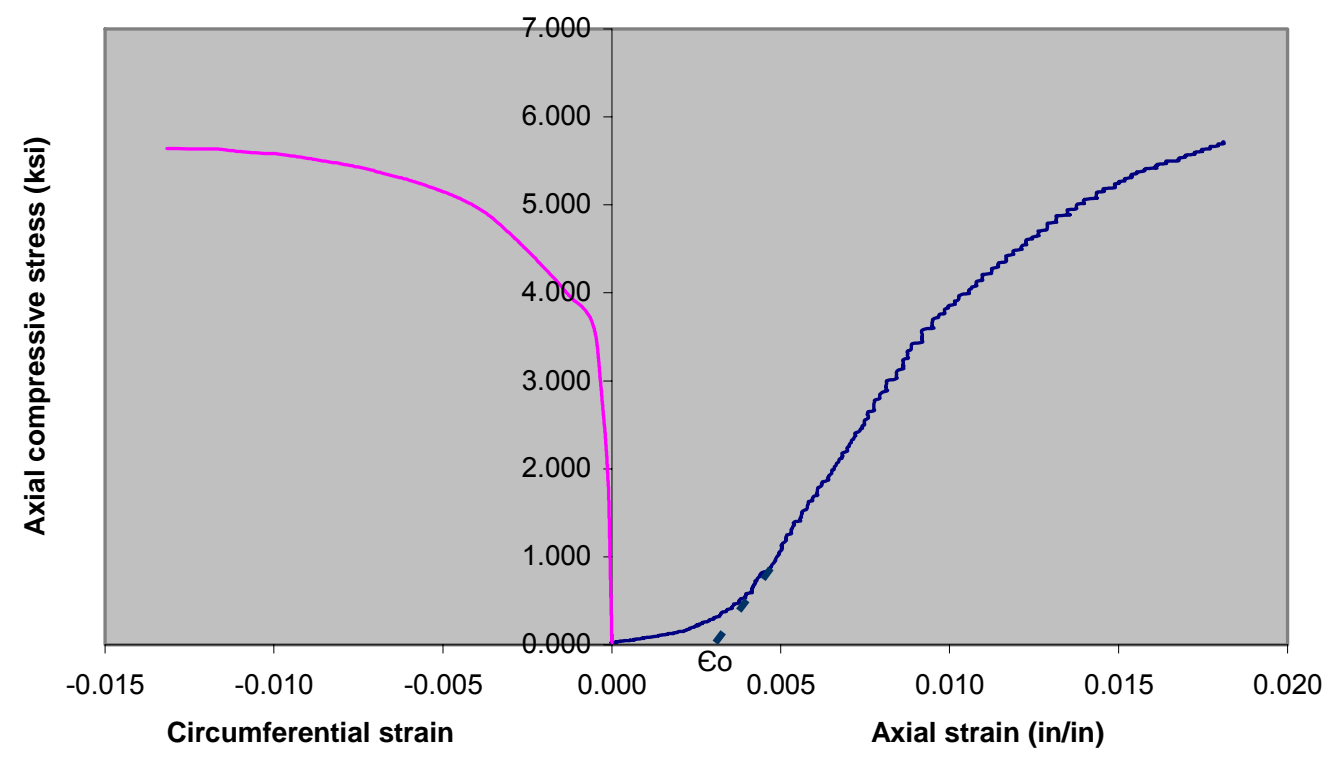

Figure B7 Axial compressive stress vs. strain for defect free cylinder number 2 wrapped with GFRP composite $\left(0^{\circ} / 90^{\circ}\right)$

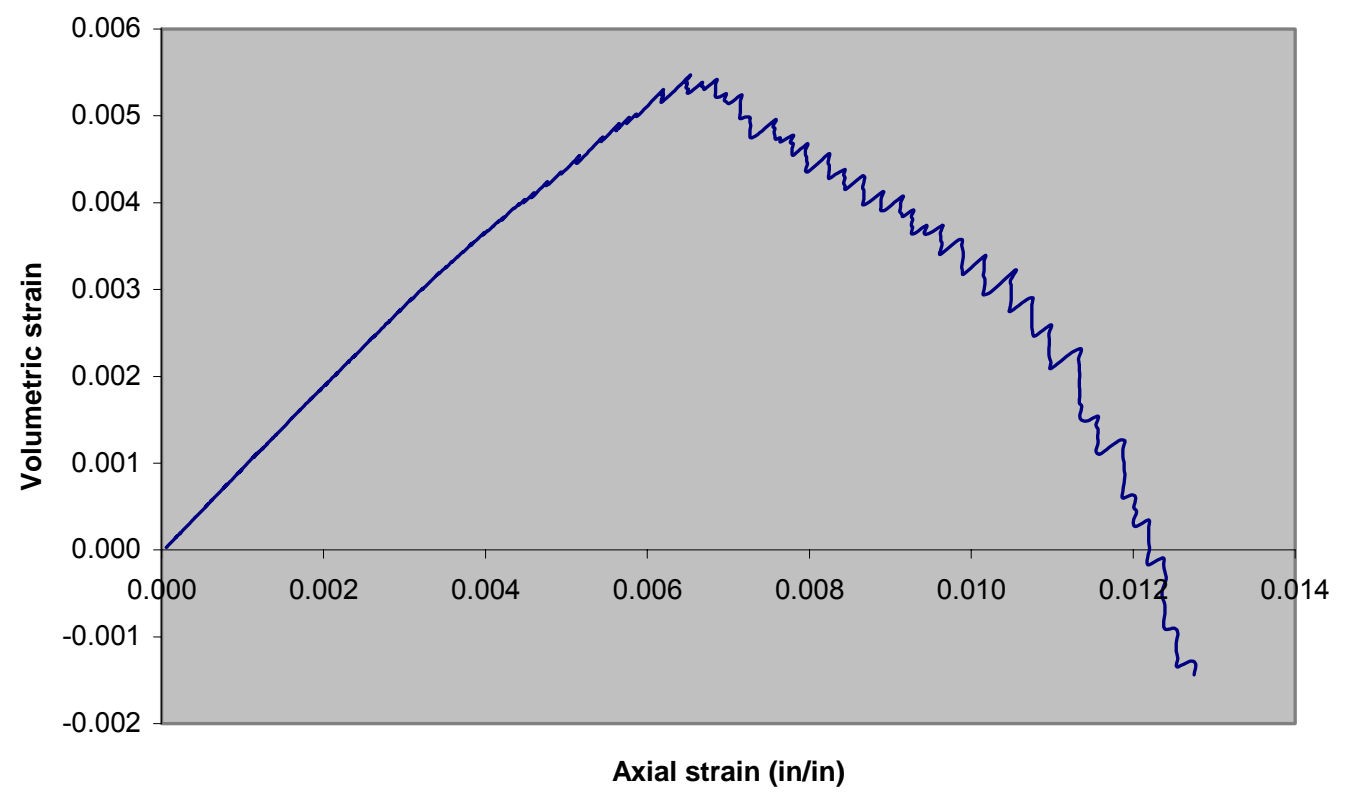

Figure B8 Volumetric strain vs. axial strain for defect free cylinder number 2 wrapped with GFRP composite $\left(0^{\circ} / 90^{\circ}\right)$ 


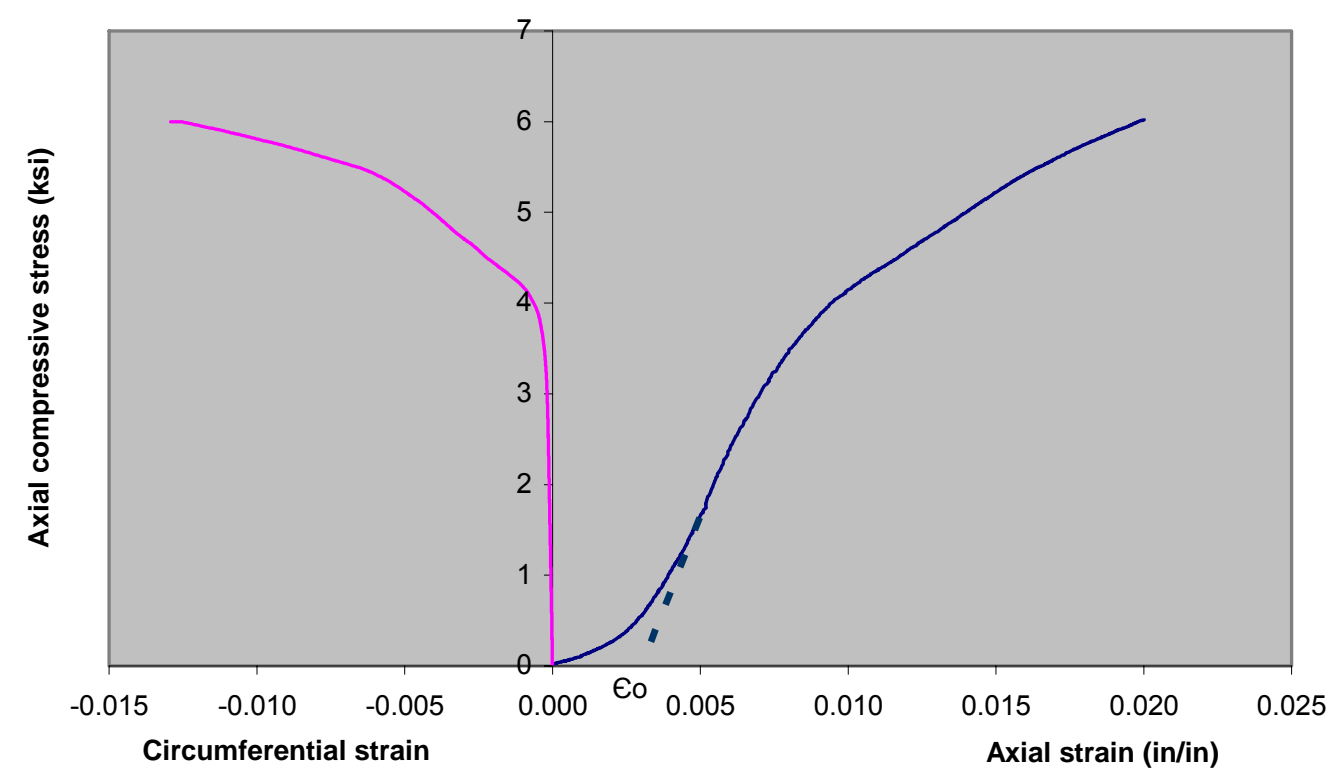

Figure B9 Axial compressive stress vs. strain for defect free cylinder number 3 wrapped with GFRP composite $\left(0^{\circ} / 90^{\circ}\right)$

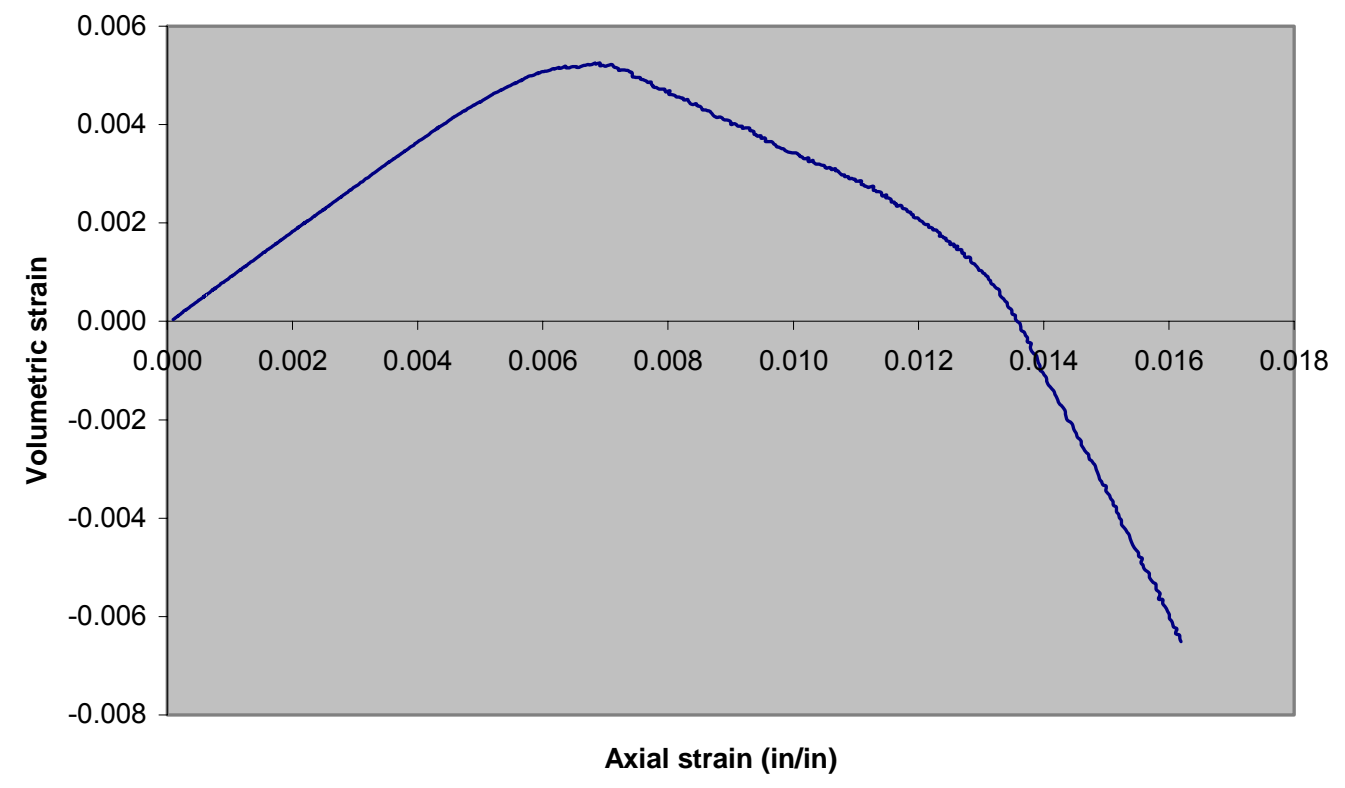

Figure B10 Volumetric strain vs. axial strain for defect free cylinder number 3 wrapped with GFRP composite $\left(0^{\circ} / 90^{\circ}\right)$ 


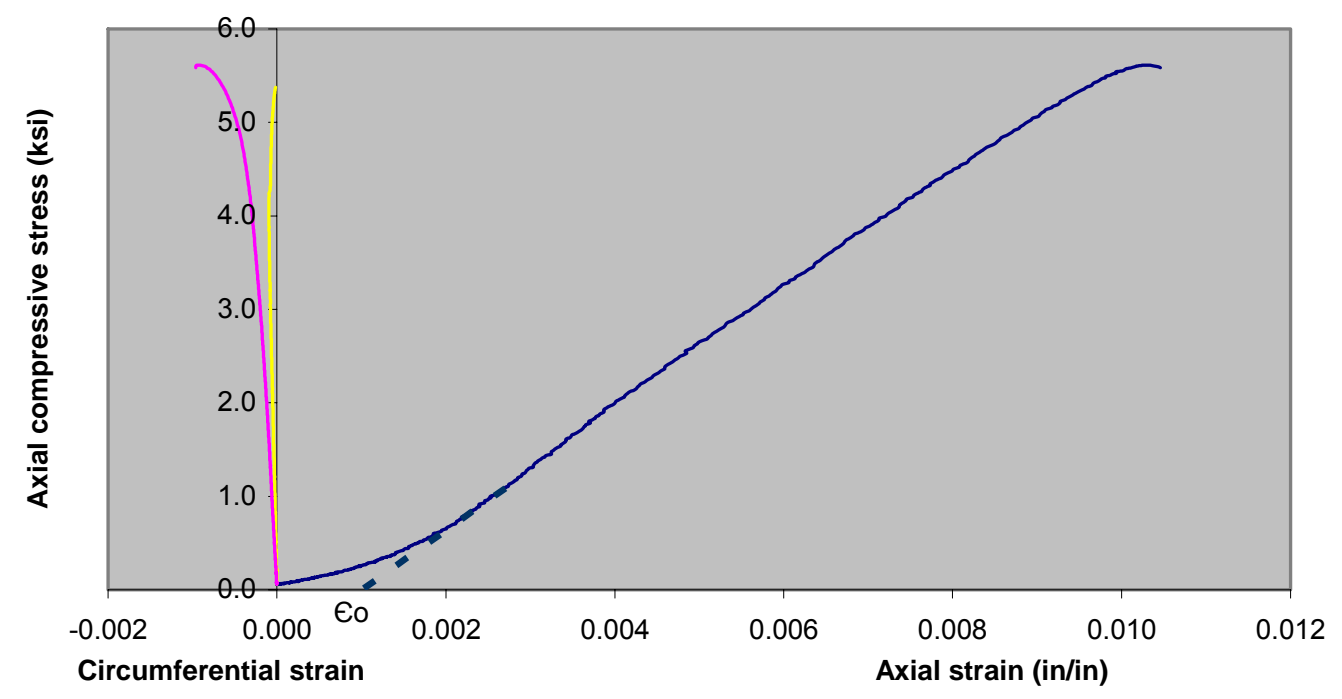

above debond

above defect-free area

Figure B11 Axial compressive stress vs. strain for cylinder with 1" x 1" air-filled debond wrapped with GFRP composite $\left(0^{\circ} / 90^{\circ}\right)$

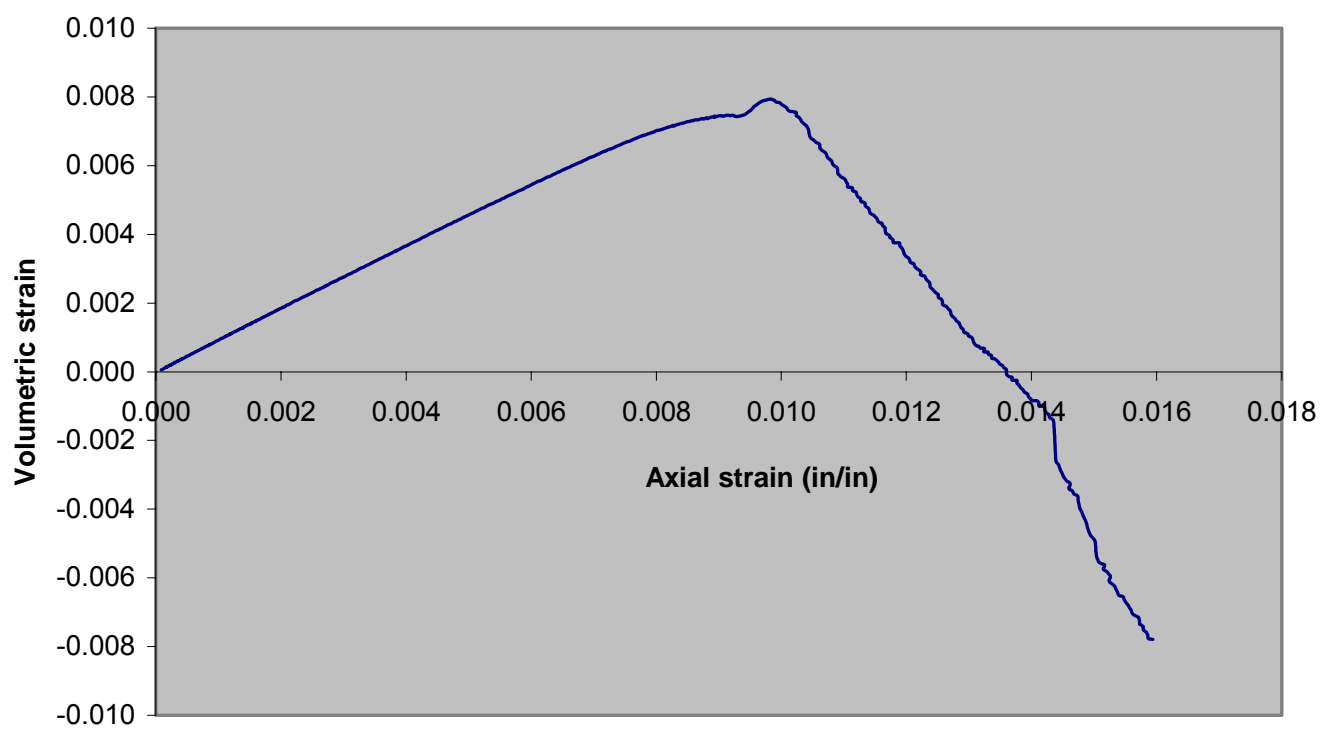

Figure B12 Volumetric strain vs. axial strain for cylinder with 1" x 1 " air-filled debond wrapped with GFRP composite $\left(0^{\circ} / 90^{\circ}\right)$ 


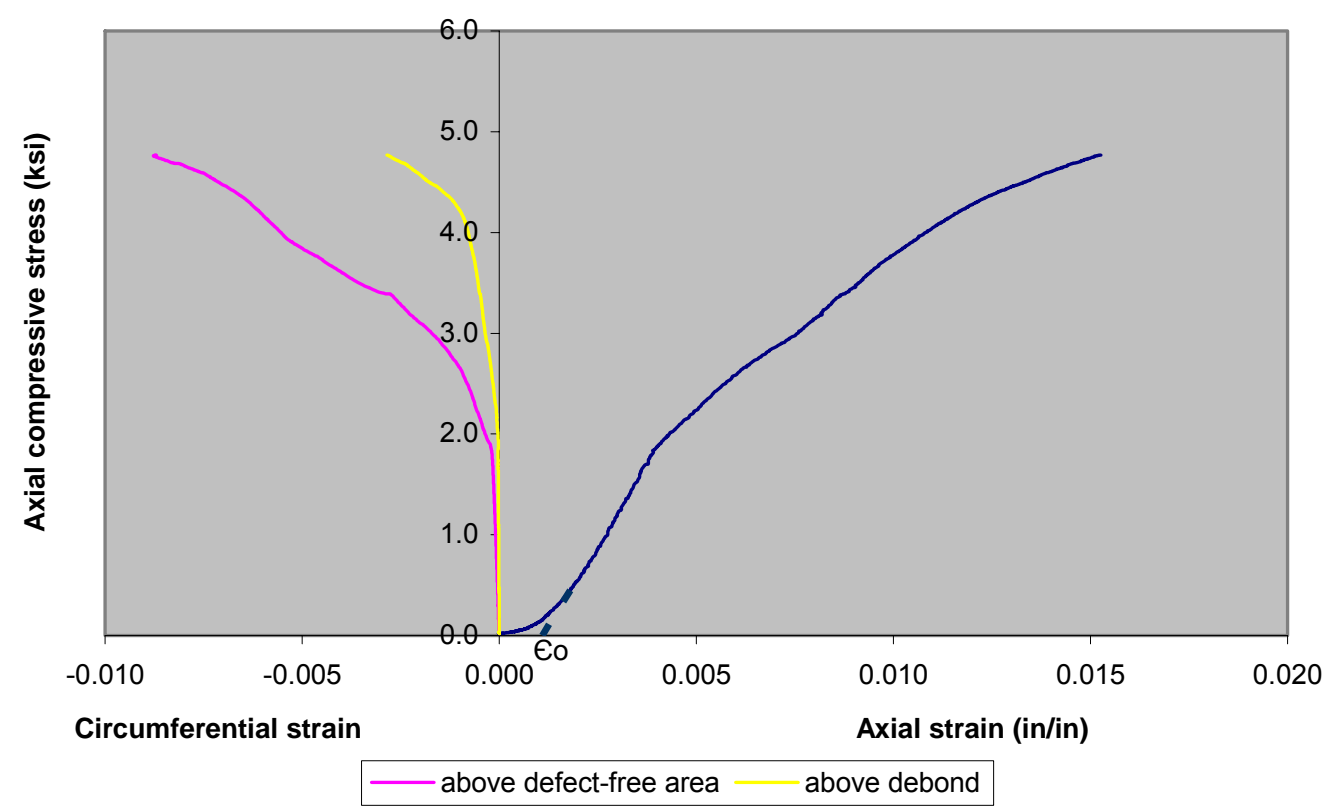

Figure B13 Axial compressive stress vs. strain for cylinder with 1.4" x 1.4" air-filled debond wrapped with GFRP composite $\left(0^{\circ} / 90^{\circ}\right)$

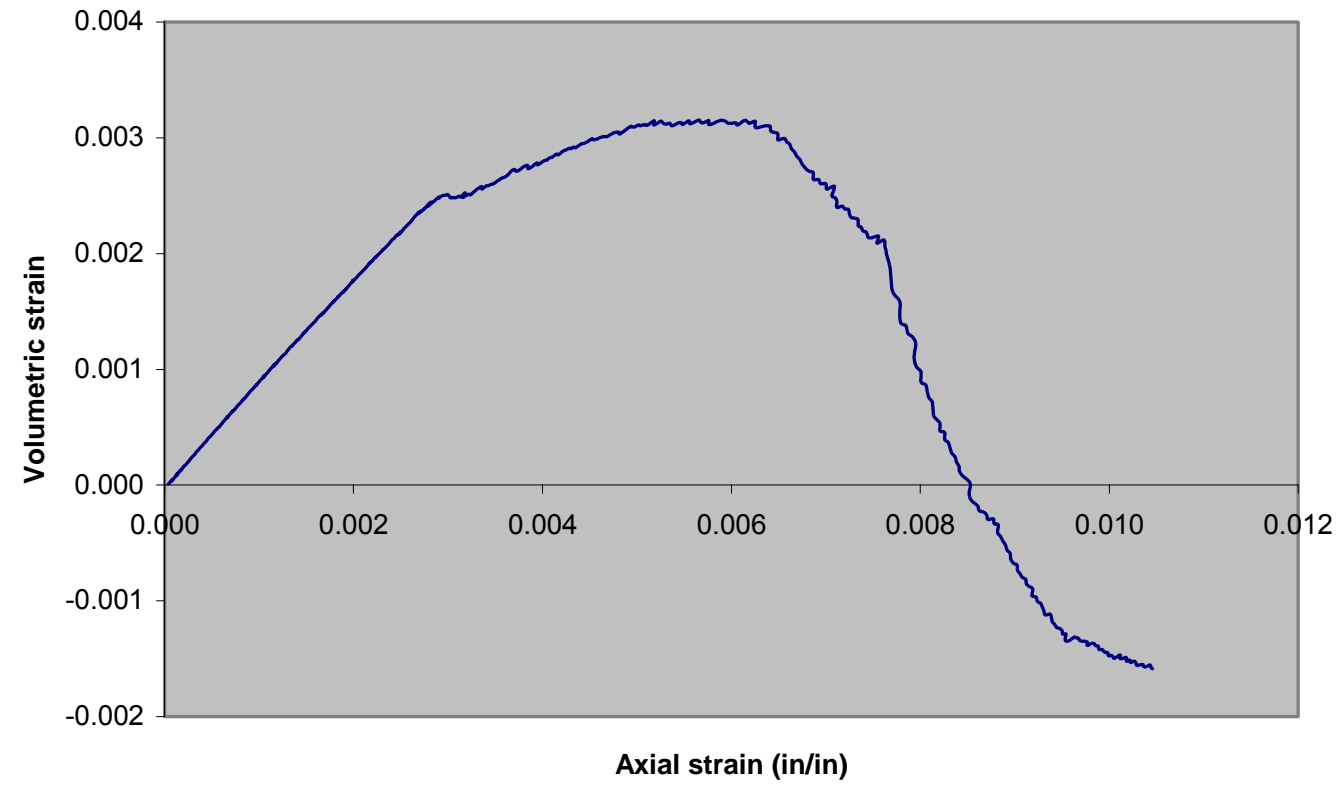

Figure B14 Volumetric strain vs. axial strain for cylinder with 1.4" x 1.4" air-filled debond wrapped with GFRP composite $\left(0^{\circ} / 90^{\circ}\right)$ 


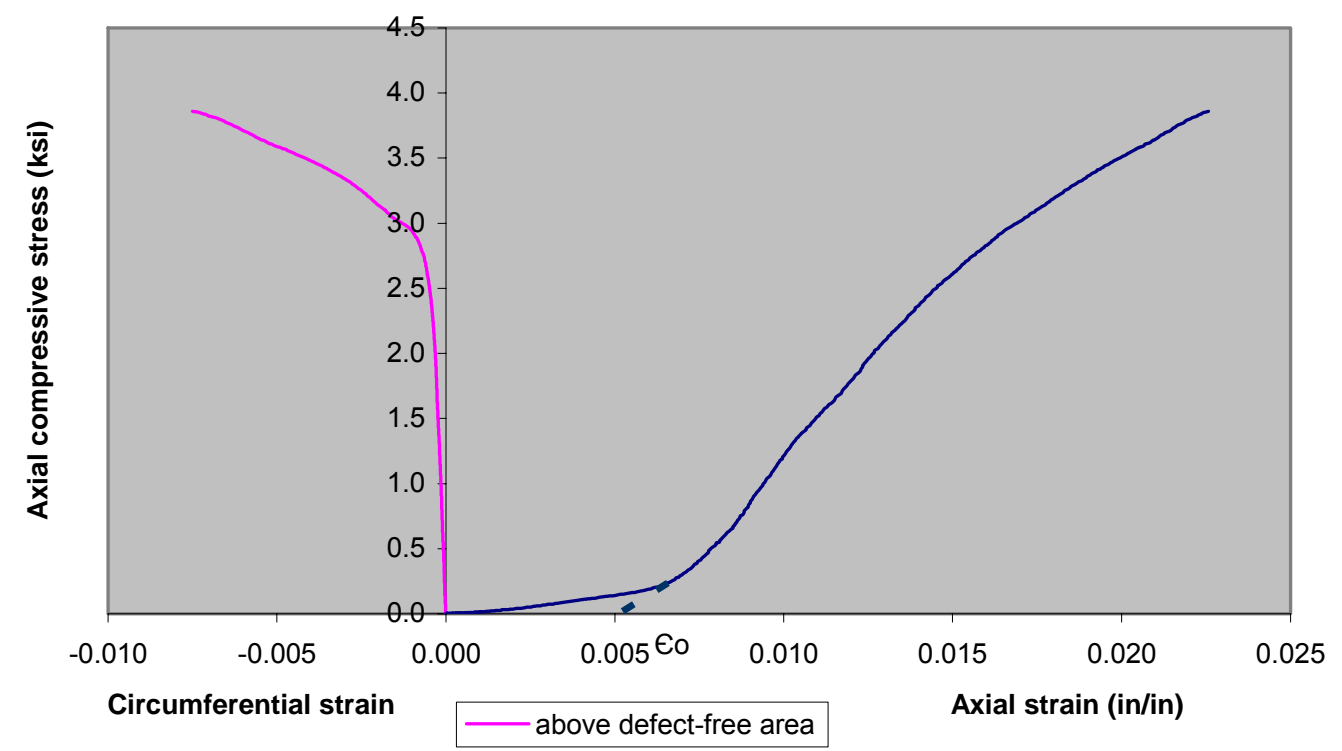

Figure B15 Axial compressive stress vs. strain for cylinder with 2" x 2" air-filled debond wrapped with GFRP composite $\left(0^{\circ} / 90^{\circ}\right)$

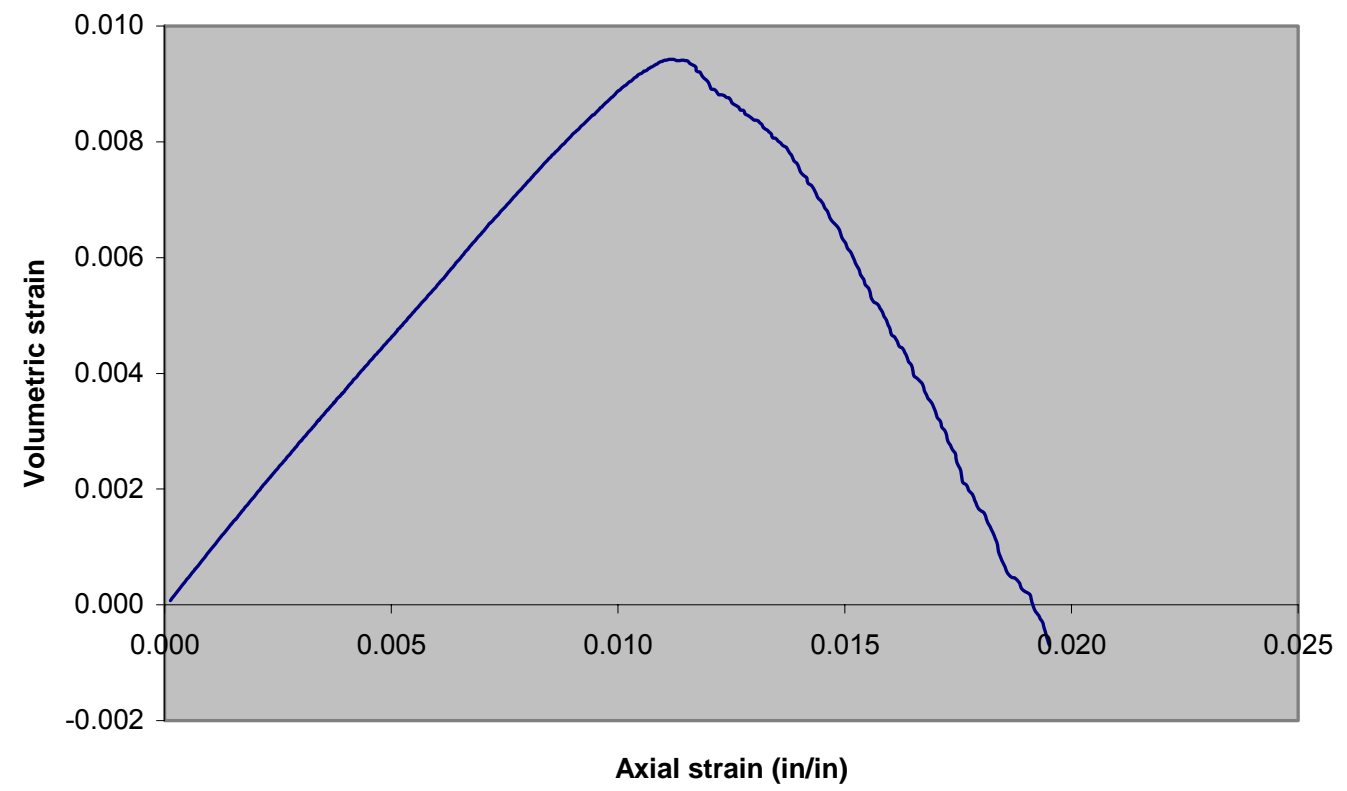

Figure B16 Volumetric strain vs. axial strain for cylinder with 2" x 2" air-filled debond wrapped with GFRP composite $\left(0^{\circ} / 90^{\circ}\right)$ 


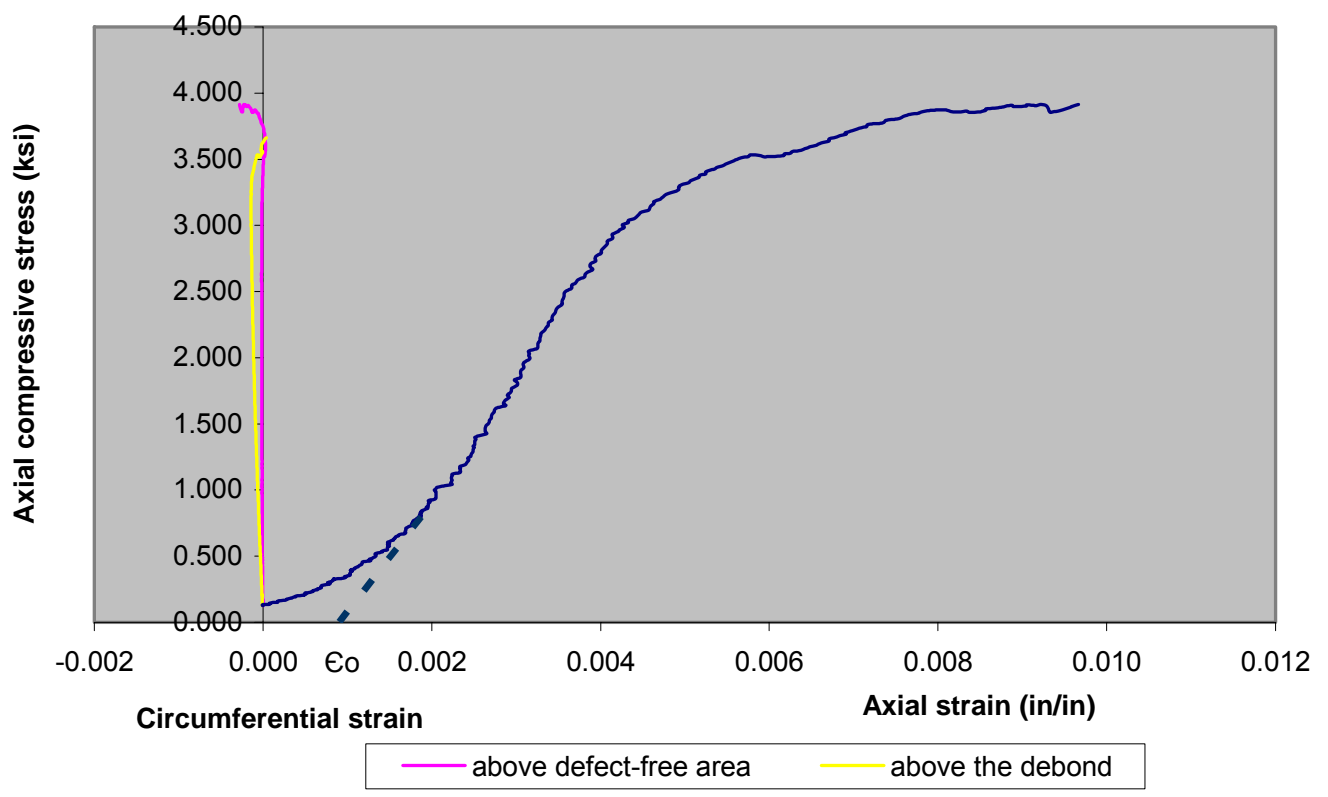

Figure B17 Axial compressive stress vs. strain for cylinder with 3" x 3" air-filled debond wrapped with GFRP composite

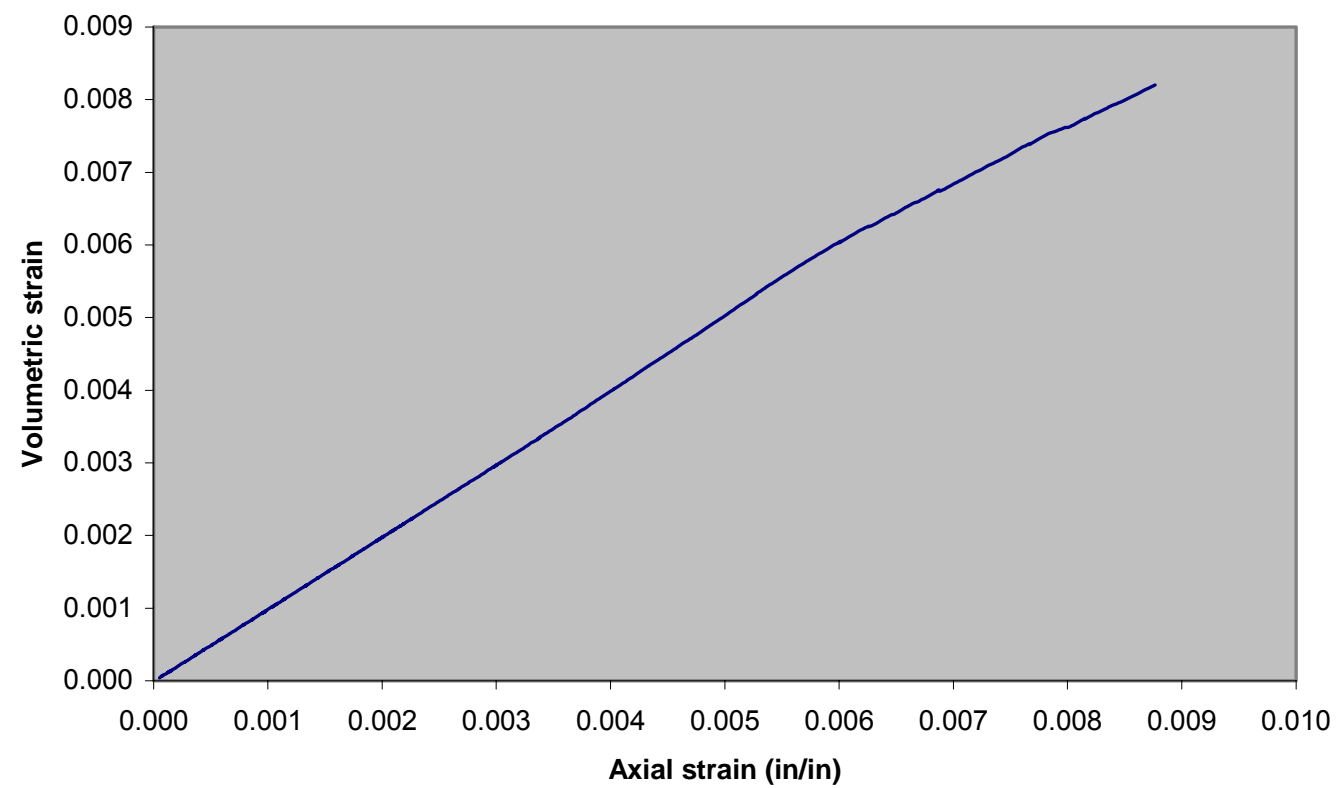

Figure B18 Volumetric strain vs. axial strain for cylinder with 3" x 3" air-filled debond wrapped with GFRP composite $\left(0^{\circ} / 90^{\circ}\right)$ 


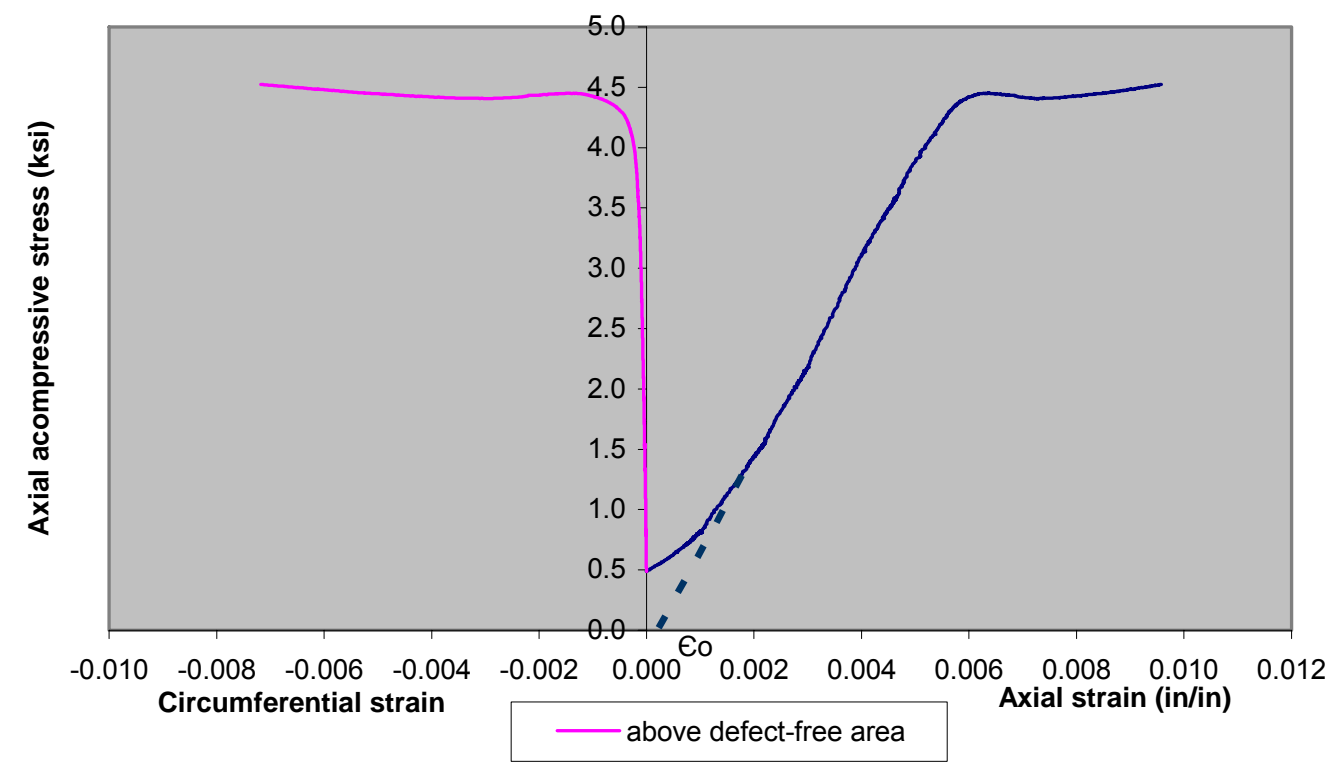

Figure B19 Axial compressive stress vs. strain for cylinder with 1" x 1" water-filled debond wrapped with GFRP composite $\left(0^{\circ} / 90^{\circ}\right)$

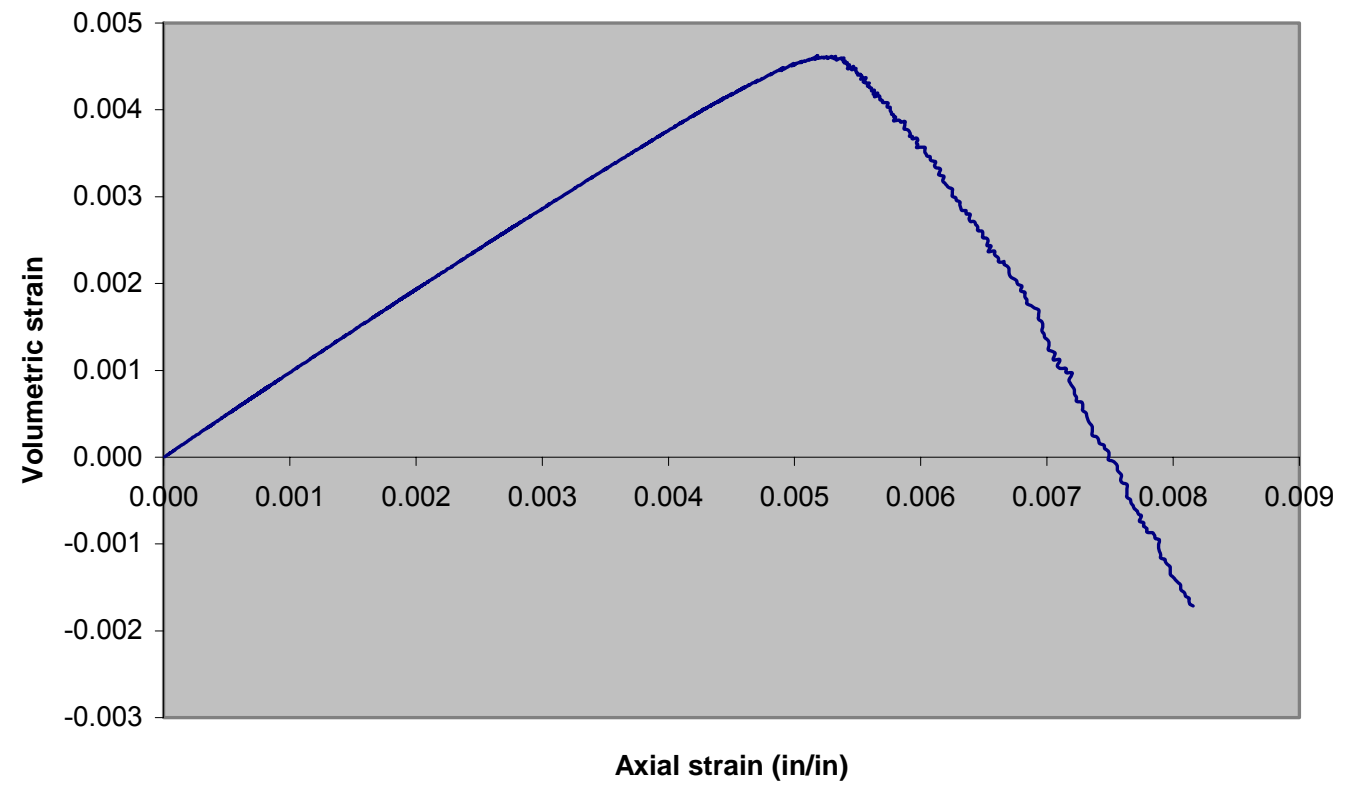

Figure B20 Volumetric strain vs. axial strain for cylinder with 1" x 1" water-filled debond wrapped with GFRP composite $\left(0^{\circ} / 90^{\circ}\right)$ 


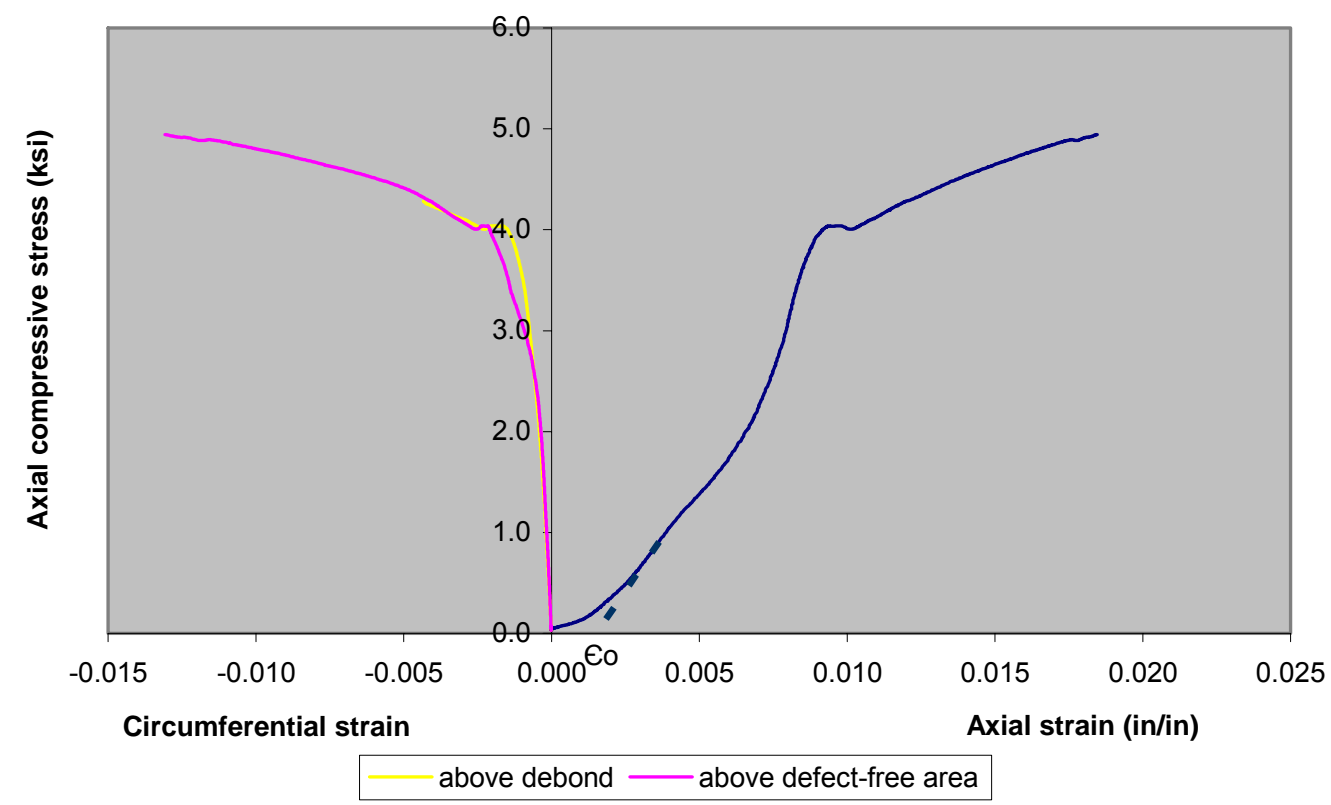

Figure B21 Axial compressive stress vs. strain for cylinder with 1.4" x 1.4" waterfilled debond wrapped with GFRP composite $\left(0^{\circ} / 90^{\circ}\right)$

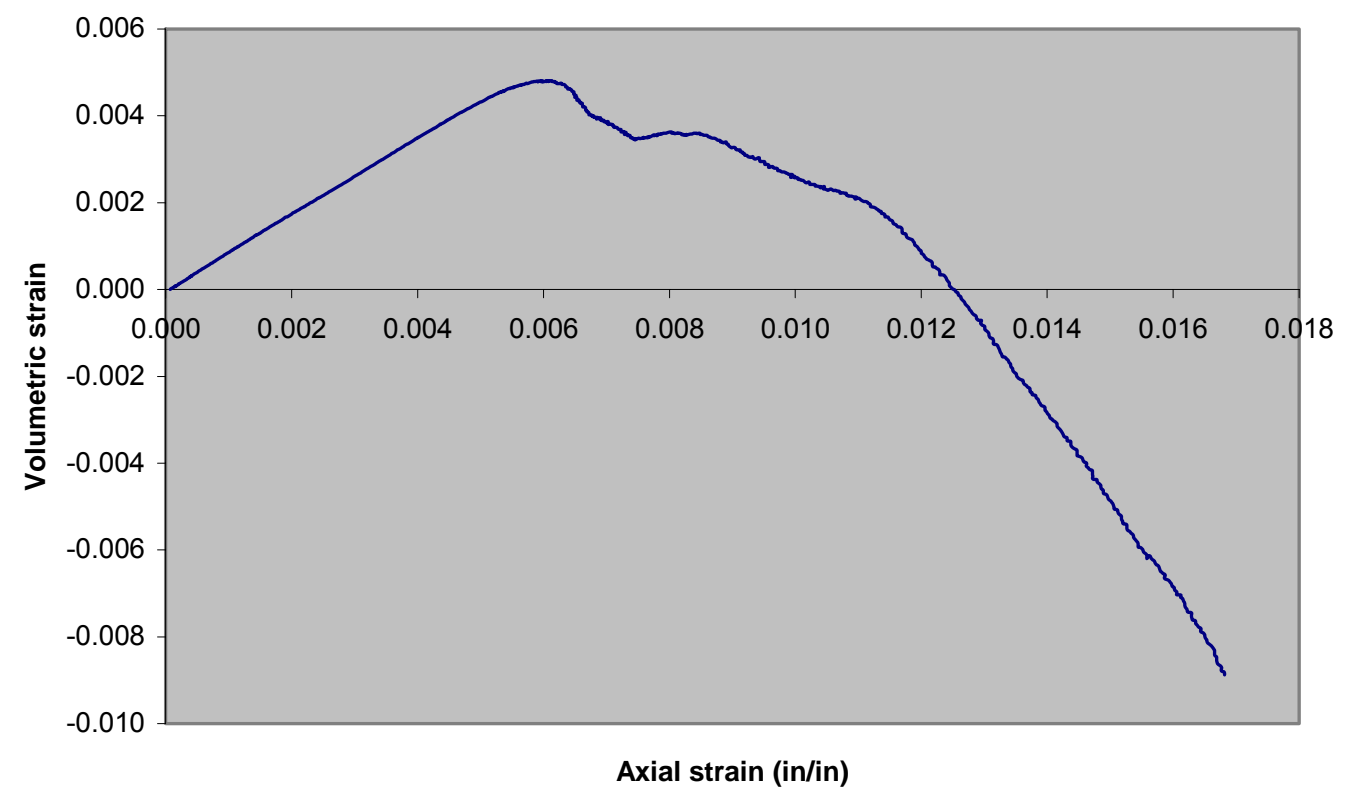

Figure B22 Volumetric strain vs. axial strain for cylinder with 1.4" $x$ 1.4" waterfilled debond wrapped with GFRP composite $\left(0^{\circ} / 90^{\circ}\right)$ 


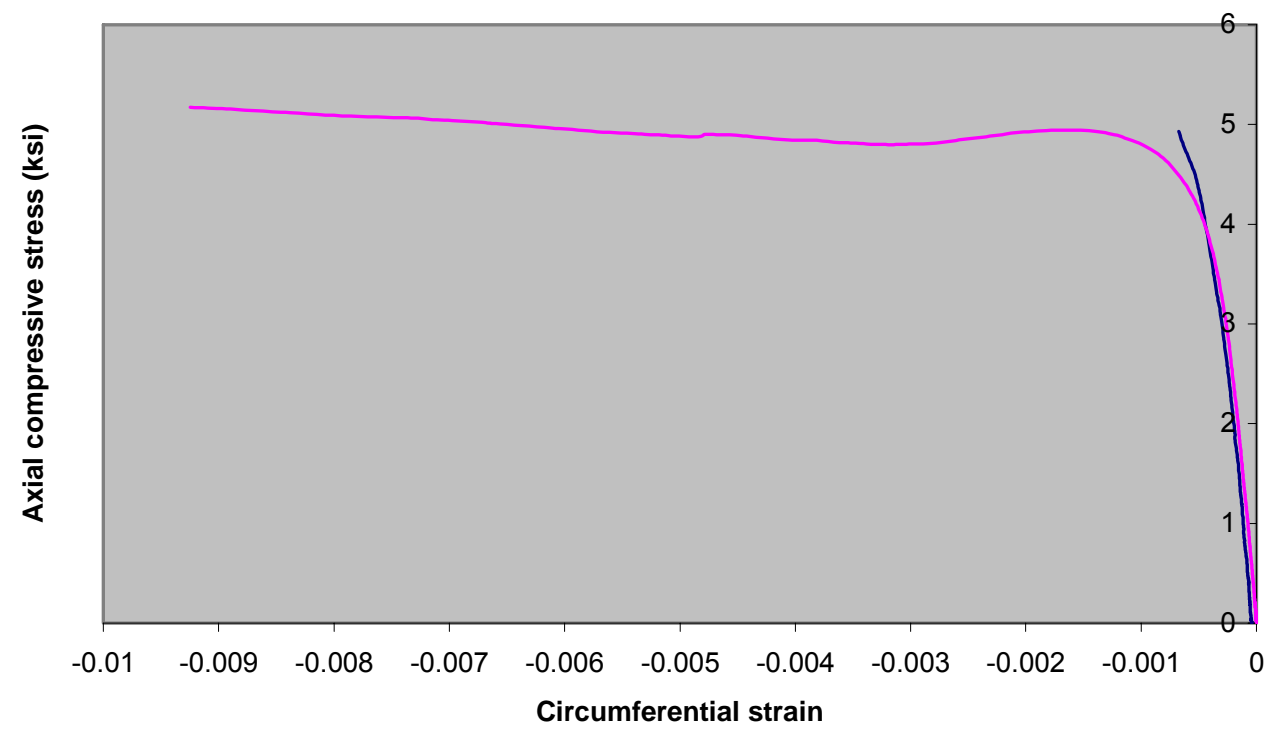

above debond $\longrightarrow$ above defect-free area

Figure B23 Axial compressive stress vs. strain for cylinder with 2" x 2" water-filled debond wrapped with GFRP composite $\left(0^{\circ} / 9^{\circ}\right)$

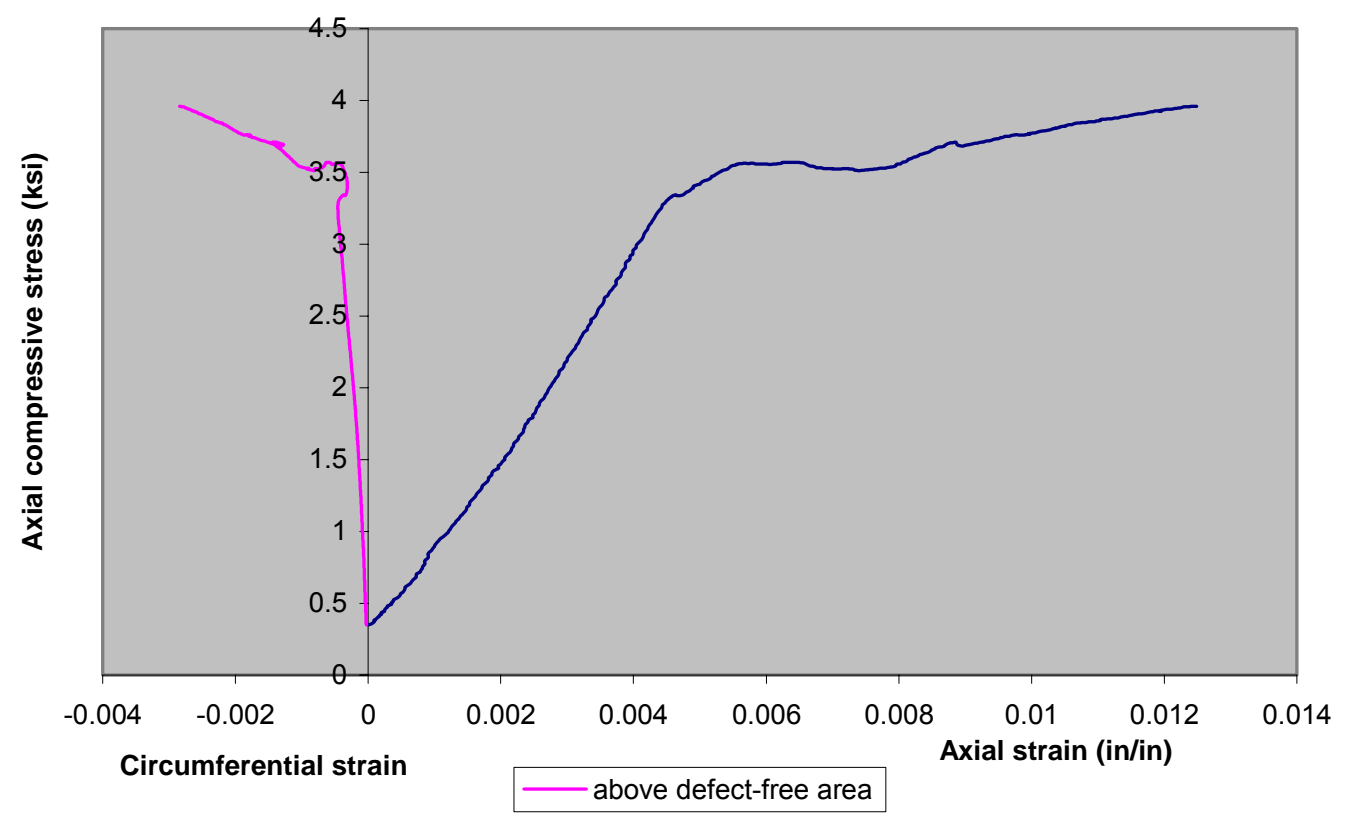

Figure B24 Axial compressive stress vs. strain for cylinder with 3" x 3" water-filled debond wrapped with GFRP composite $\left(0^{\circ} / 90^{\circ}\right)$ 


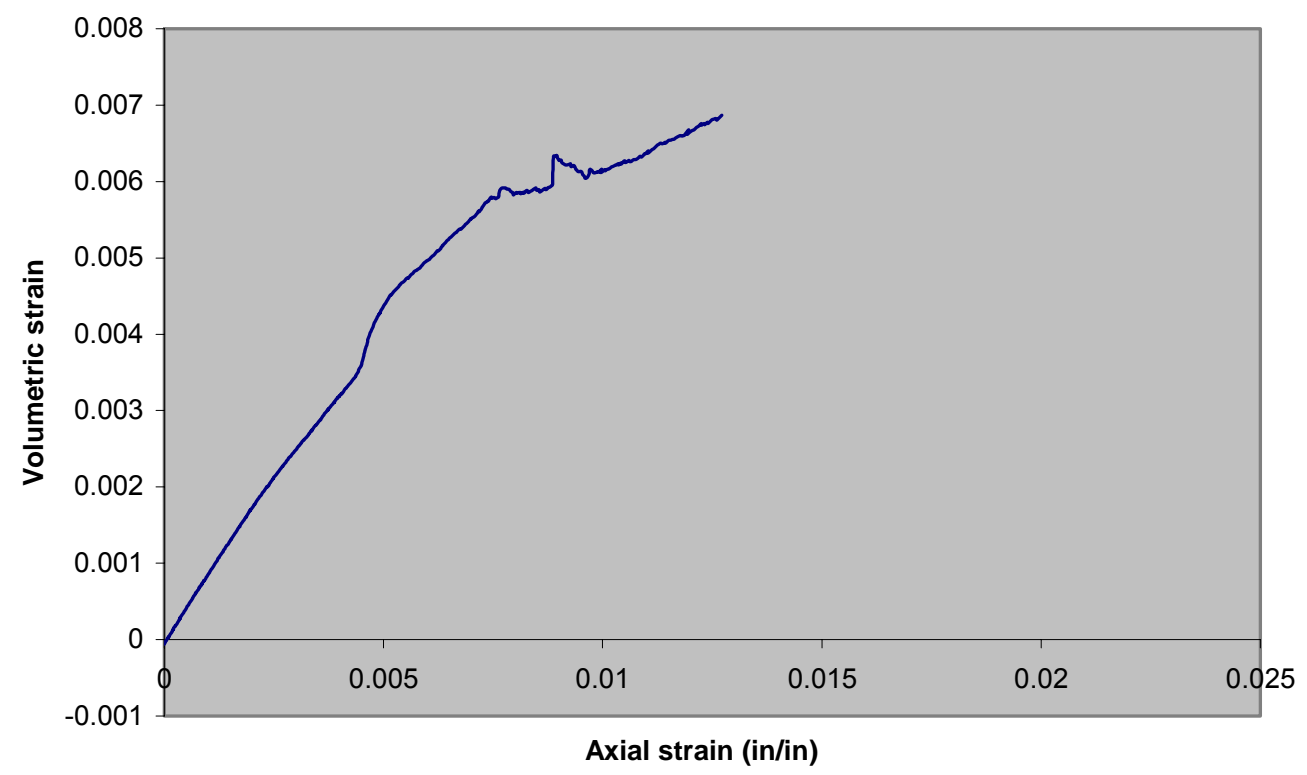

Figure B25 Volumetric strain vs. axial strain for cylinder with 3" x 3" water-filled debond wrapped with GFRP composite $\left(0^{\circ} / 90^{\circ}\right)$

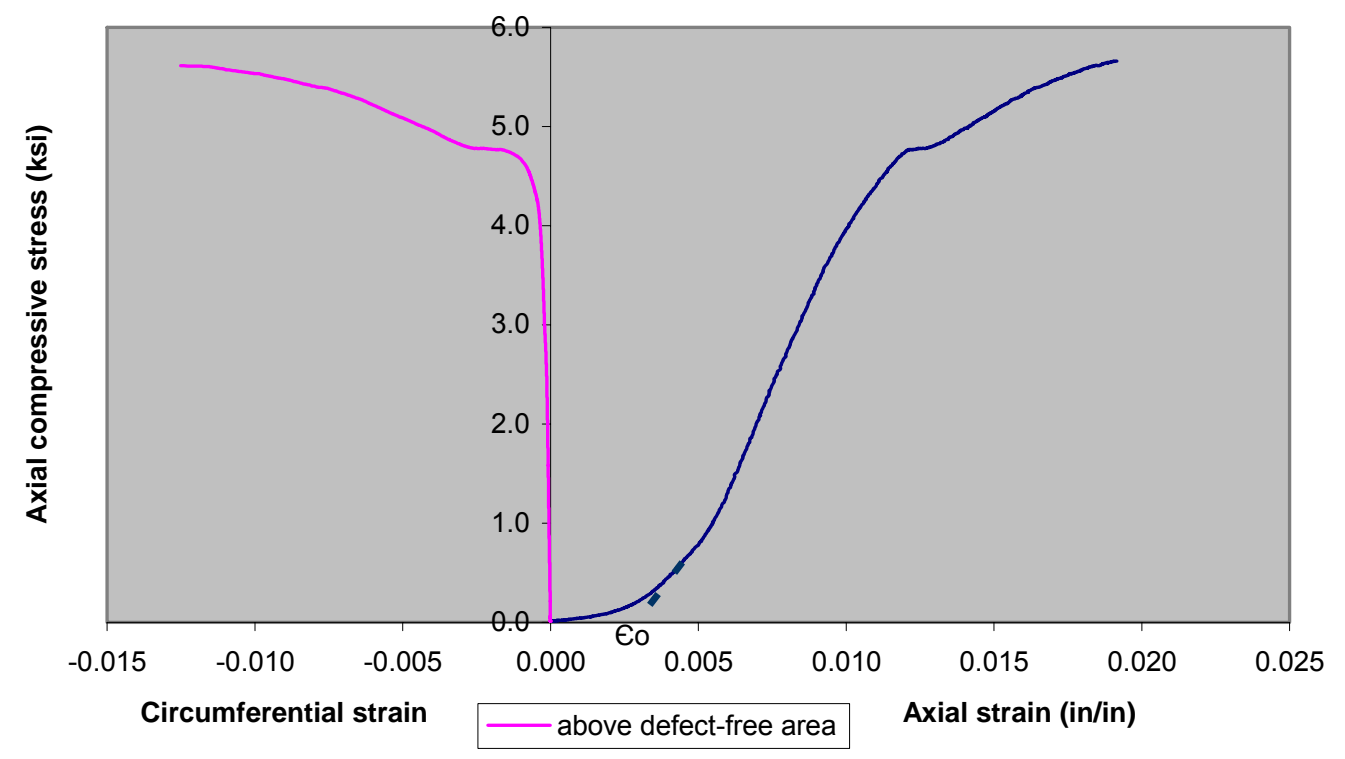

Figure B26 Axial compressive stress vs. strain for cylinder with 1" x 1" Teflon sheet wrapped with GFRP composite $\left(0^{\circ} / 9^{\circ}\right)$ 


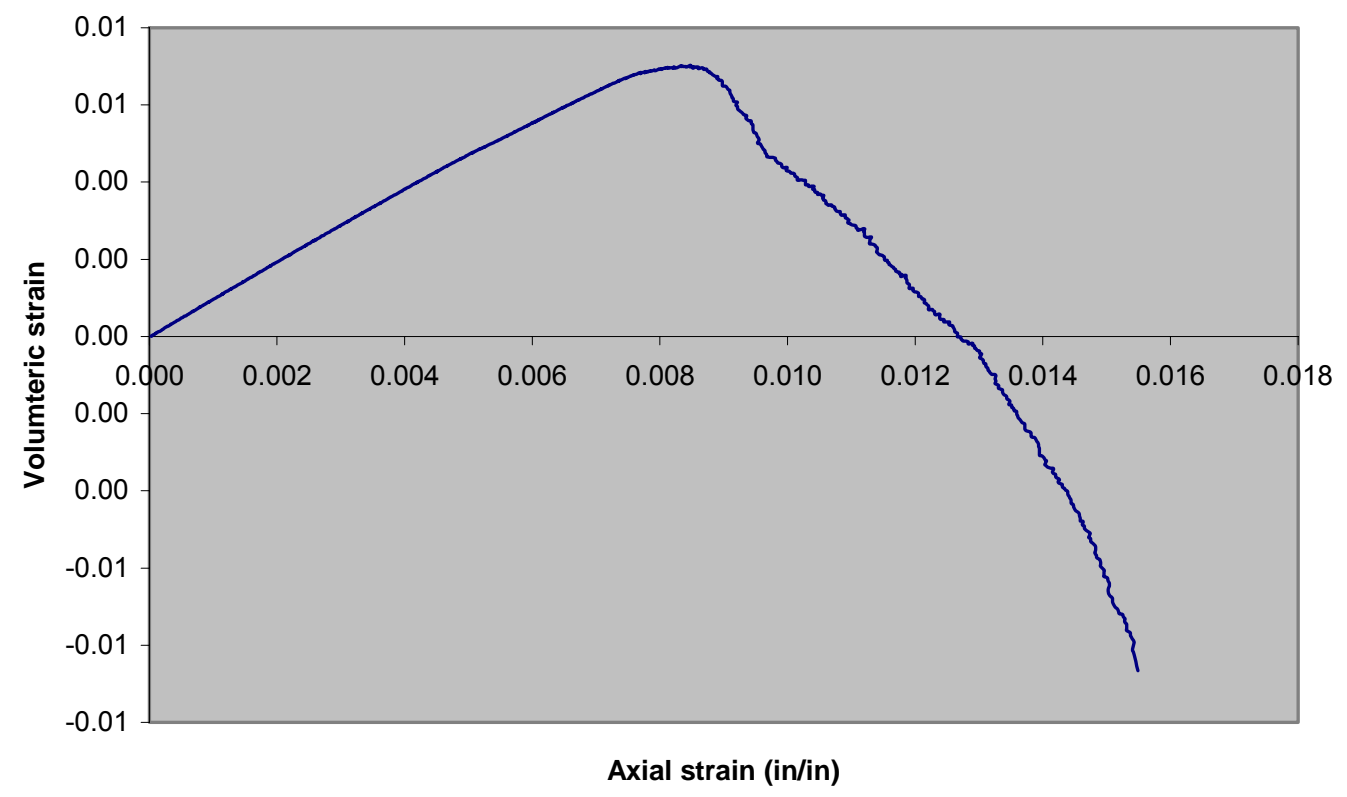

Figure B27 Volumetric strain vs. axial strain for cylinder with 1" x 1" Teflon sheet wrapped with GFRP composite $\left(0^{\circ} / 90^{\circ}\right)$

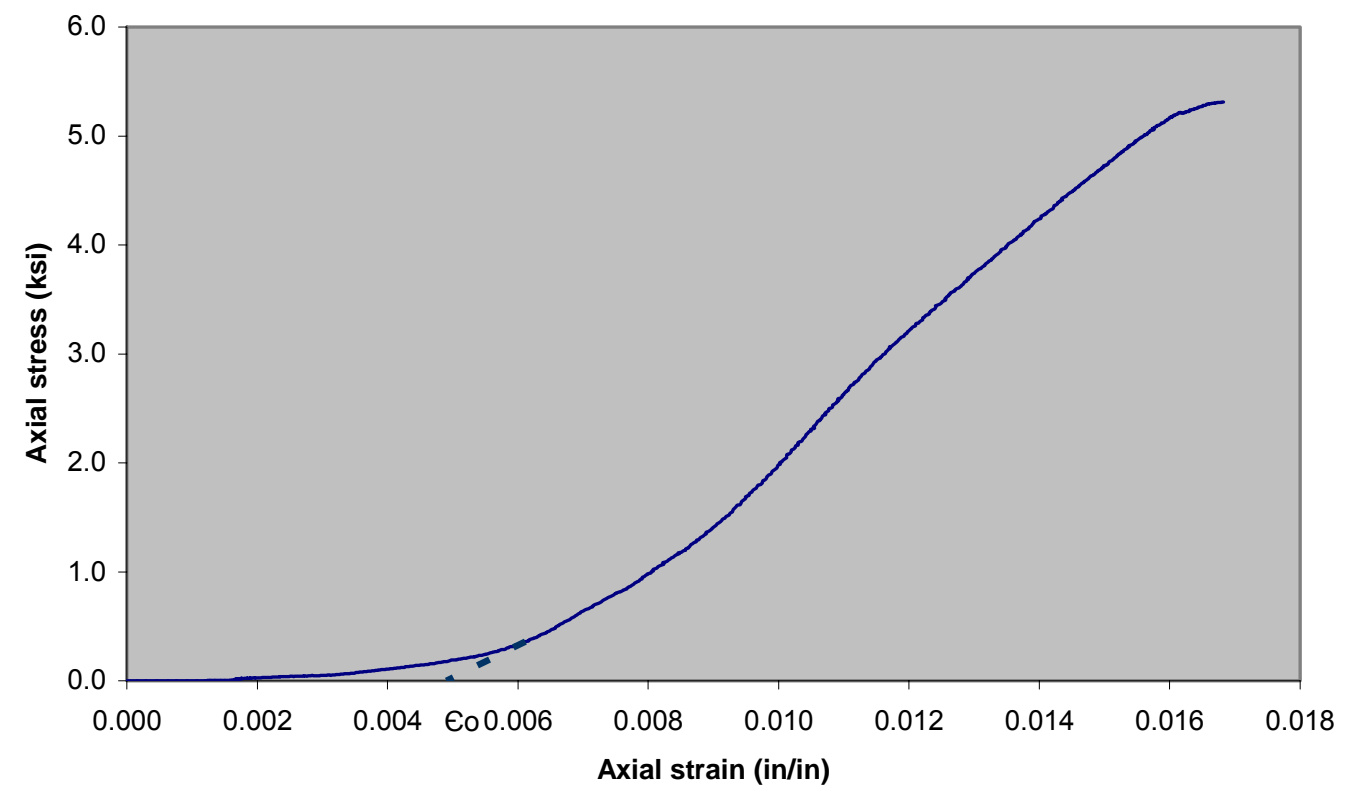

Figure B28 Axial compressive stress vs. axial strain for cylinder with 1.4" x 1.4" Teflon sheet wrapped with GFRP composite $\left(0^{\circ} / 9^{\circ}\right)$ 


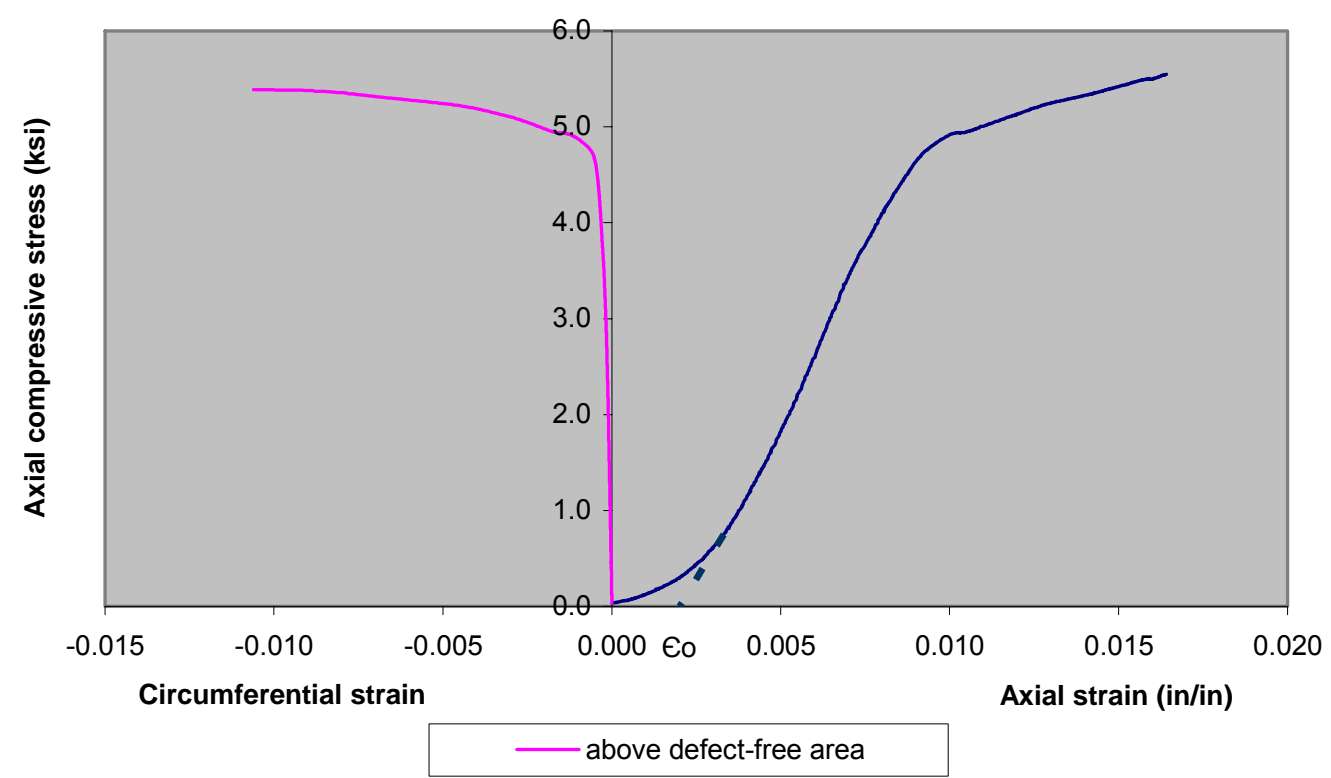

Figure B29 Axial compressive stress vs. strain for cylinder with 2" x 2" Teflon sheet wrapped with GFRP composite $\left(0^{\circ} / 90^{\circ}\right)$

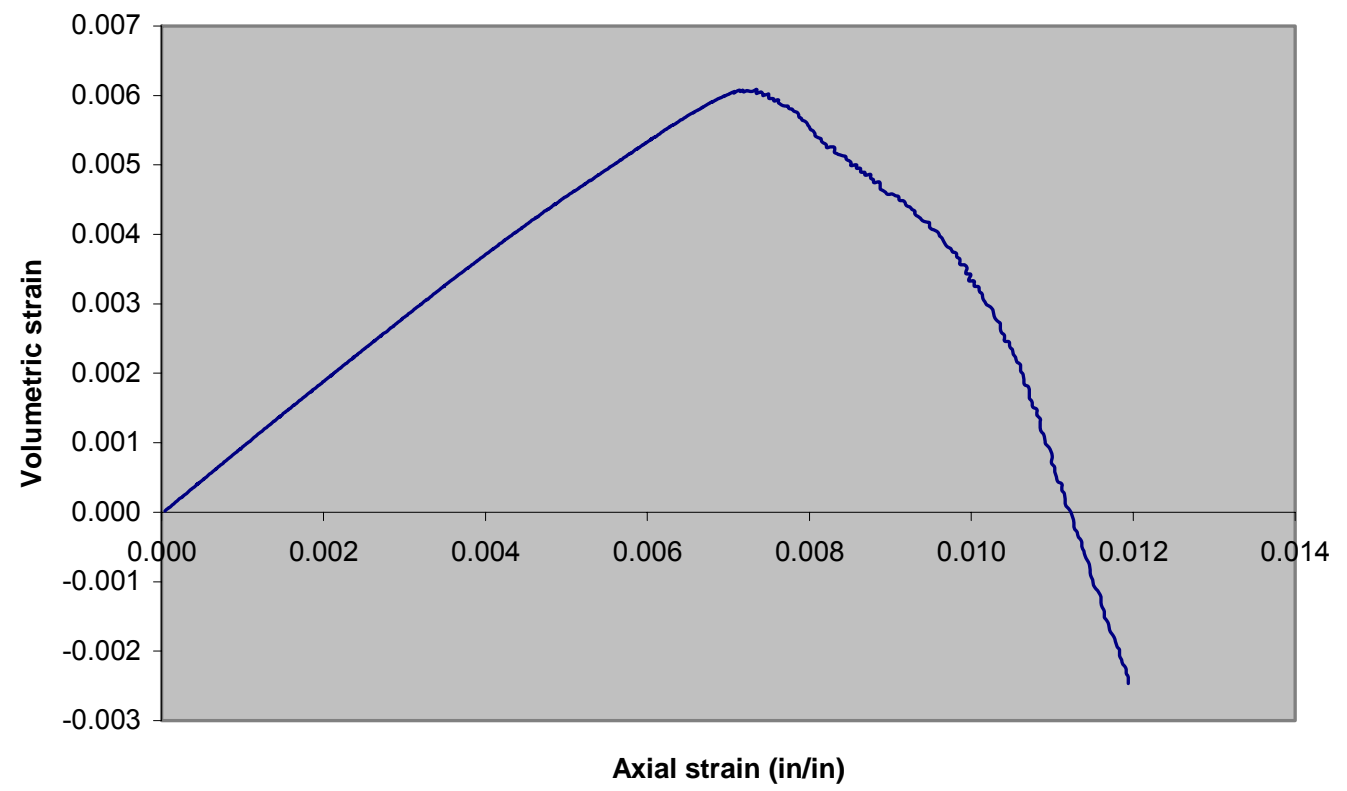

Figure B30 Volumetric strain vs. axial strain for cylinder with 2" x 2" Teflon sheet wrapped with GFRP composite $\left(0^{\circ} / 90^{\circ}\right)$ 


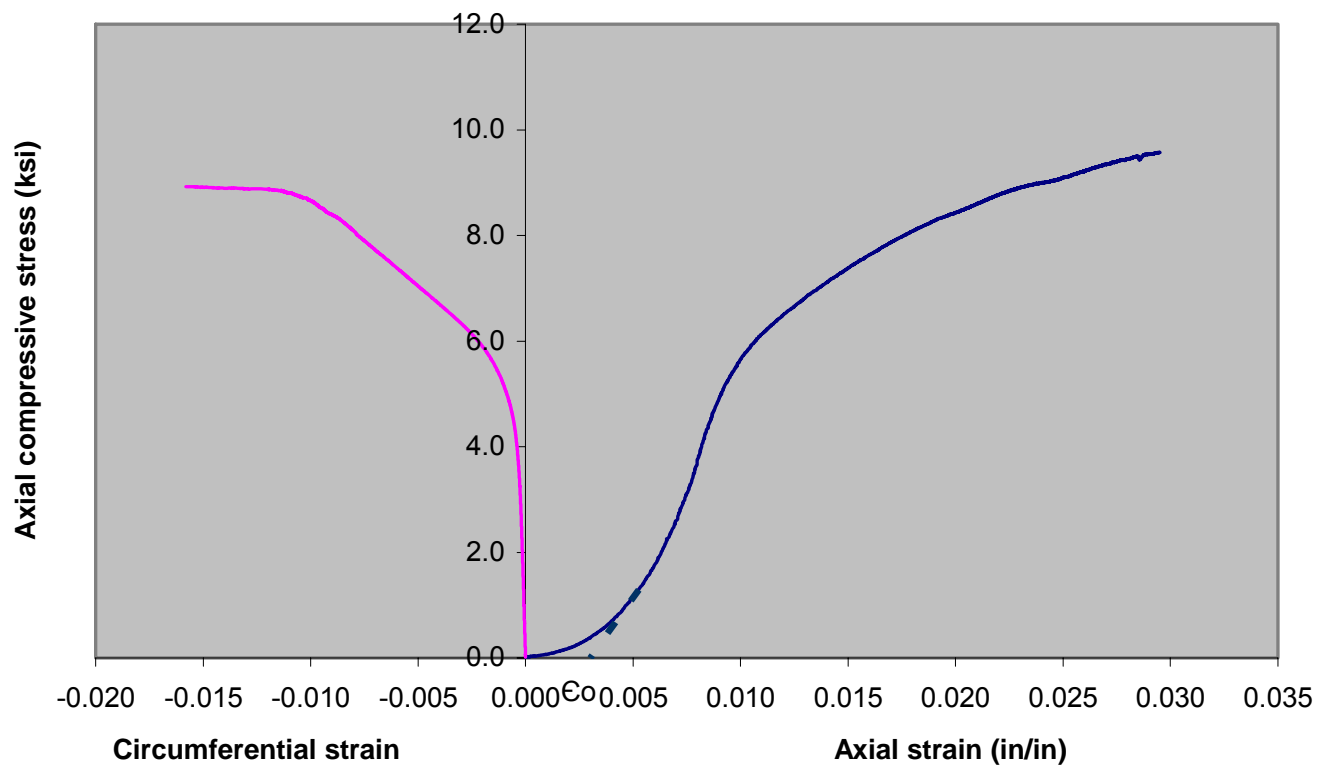

Figure B31 Axial compressive stress vs. strain for defect free cylinder number 1 wrapped with CFRP composite $\left(0^{\circ} / \pm 45^{\circ} / 9^{\circ}\right)$

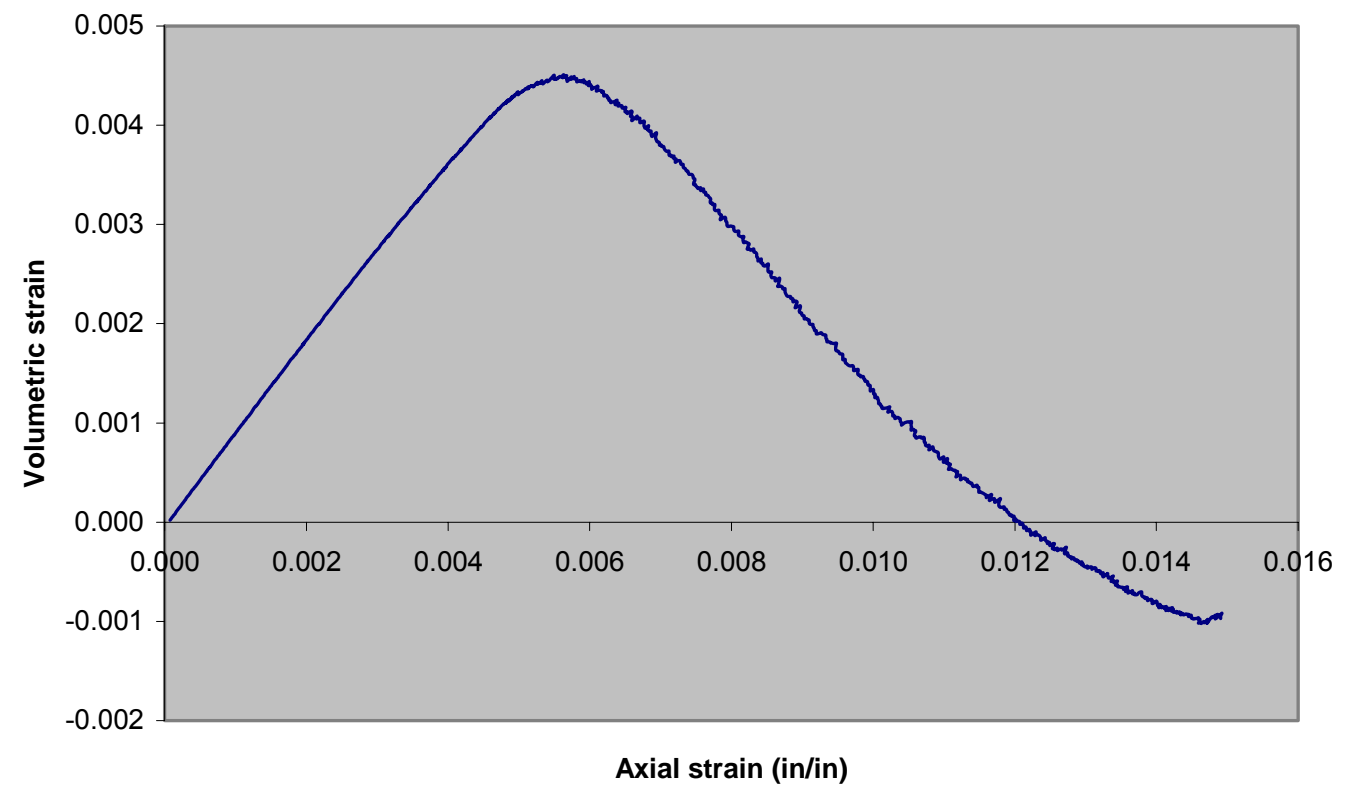

Figure B32 Volumetric strain vs. axial strain for defect free cylinder number 1 wrapped with CFRP composite $\left(0^{\circ} / \pm 45^{\circ} / 90^{\circ}\right)$ 


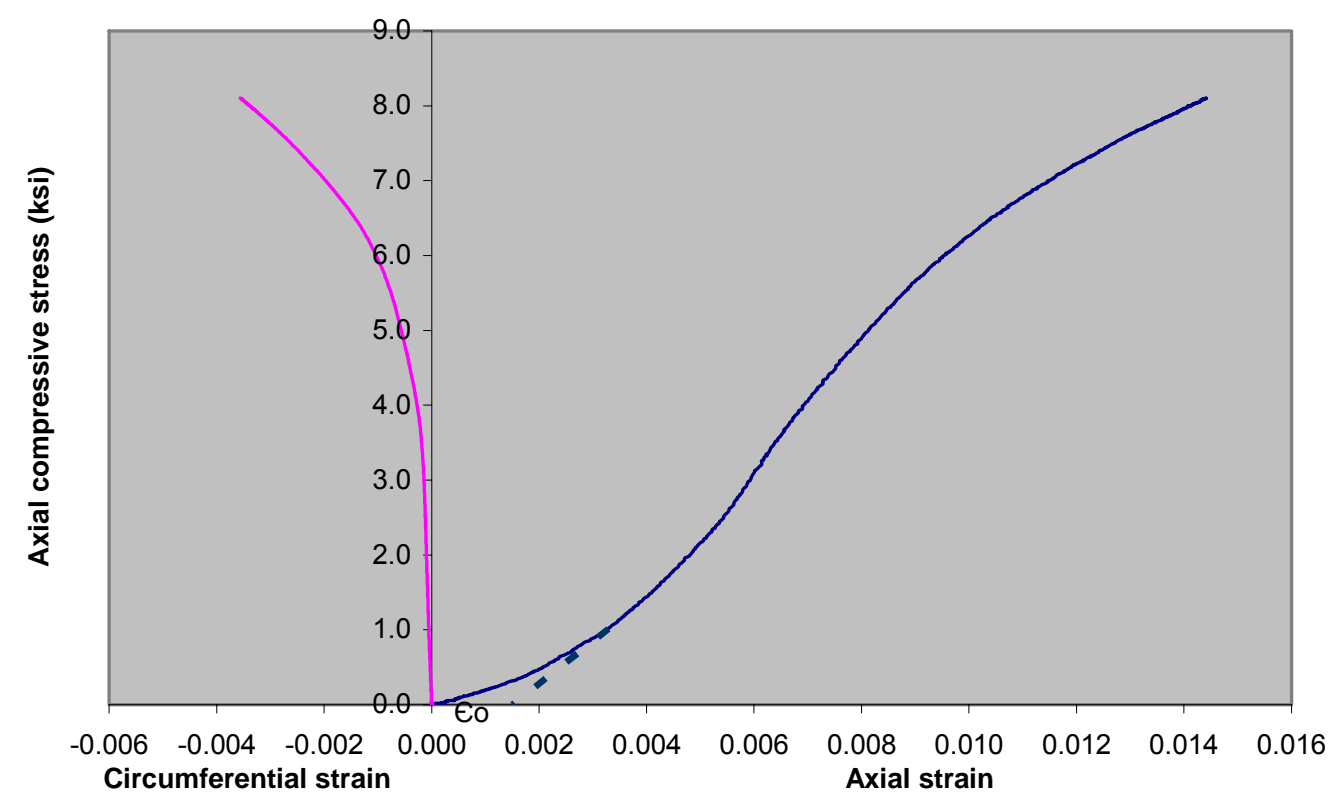

Figure B33 Axial compressive stress vs. strain for defect free cylinder number 2 wrapped with CFRP composite $\left(0^{\circ} / \pm 45^{\circ} / 9^{\circ}\right)$

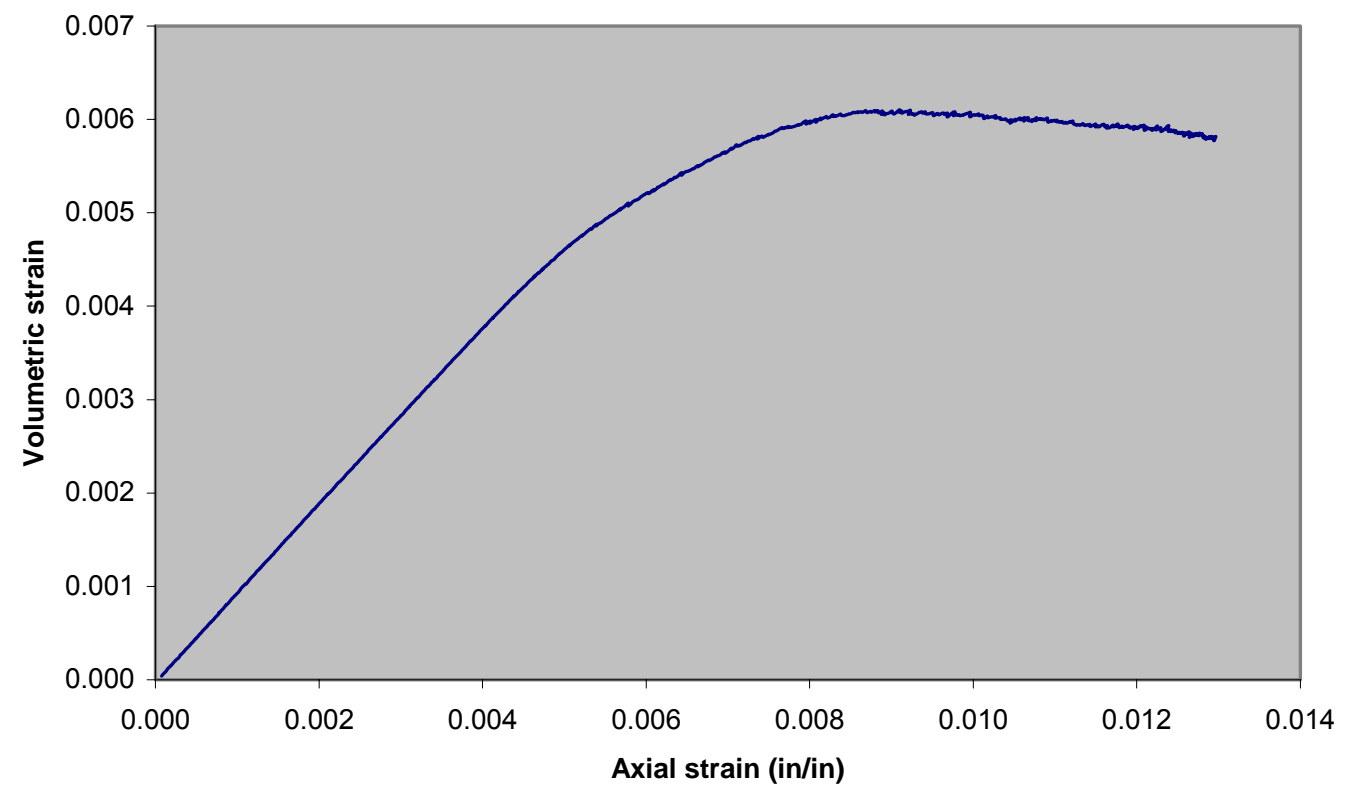

Figure B34 Volumetric strain vs. axial strain for defect free cylinder number 2 wrapped with CFRP composite $\left(0^{\circ} / \pm 45^{\circ} / 90^{\circ}\right)$ 


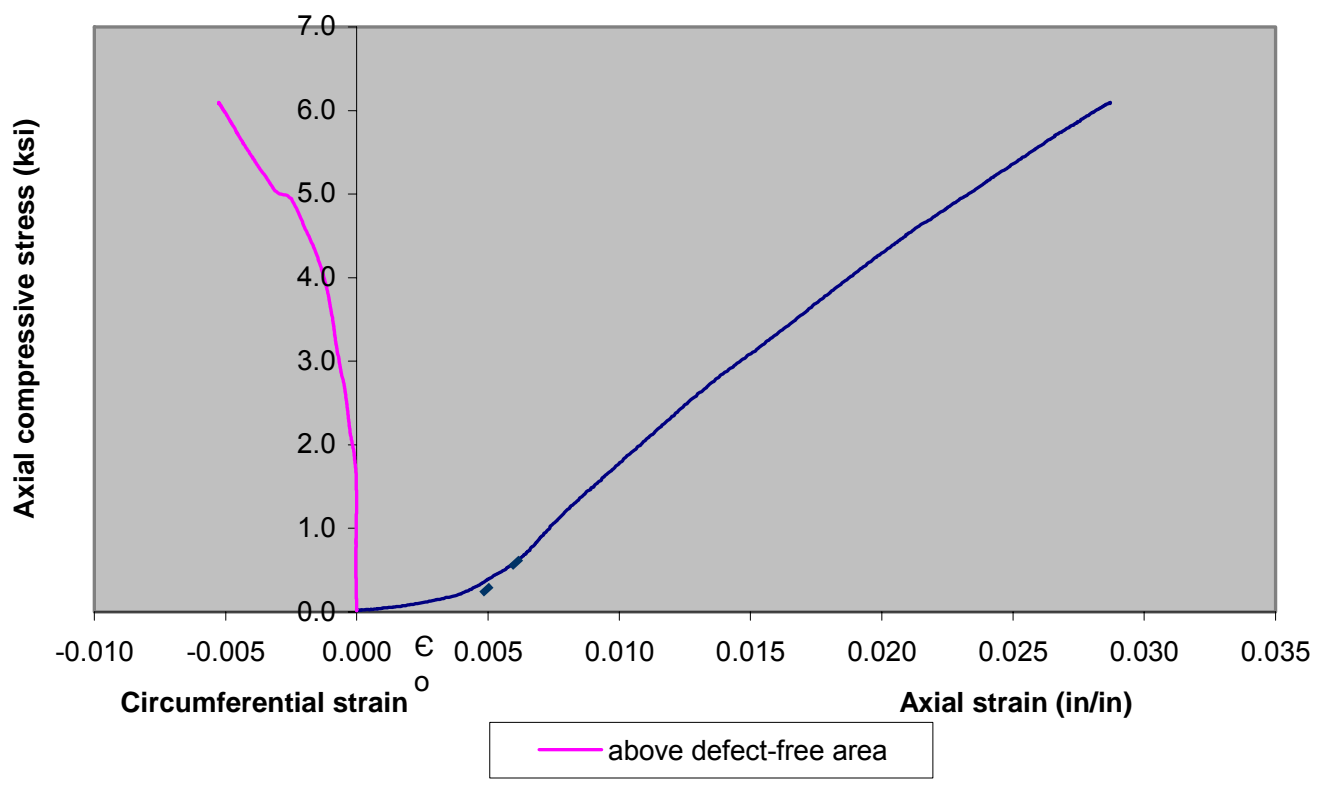

Figure B35 Axial compressive stress vs. strain for cylinder with 1" x 1" air-filled debond wrapped with CFRP composite $\left(0^{\circ} / \pm 4^{\circ} / 90^{\circ}\right)$

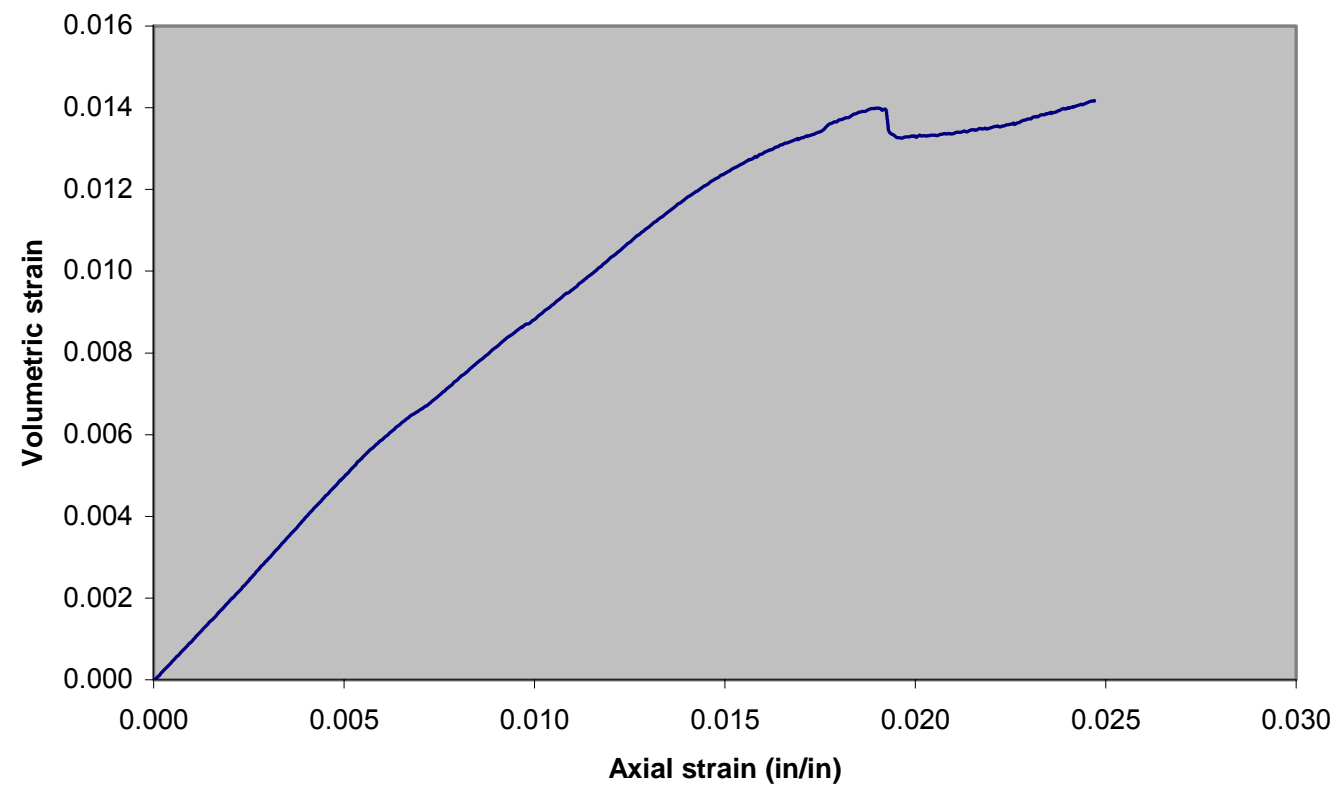

Figure B36 Volumetric strain vs. axial strain for cylinder with 1" x 1" air-filled debond wrapped with CFRP composite $\left(0^{\circ} / \pm 45^{\circ} / 90^{\circ}\right)$ 


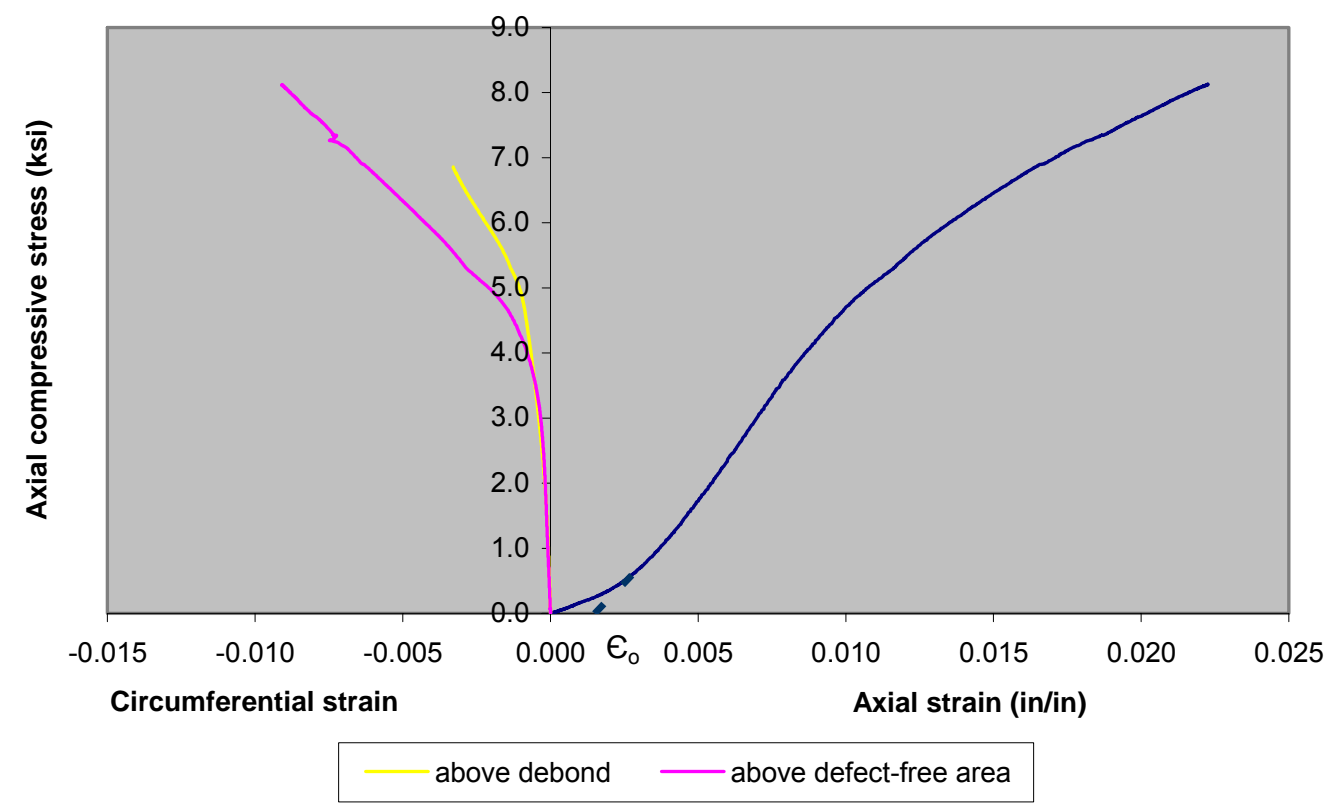

Figure B37 Axial compressive stress vs. strain for cylinder with 1.4" x 1.4" air-filled debond wrapped with CFRP composite $\left(0^{\circ} / \pm 45^{\circ} / 90^{\circ}\right)$

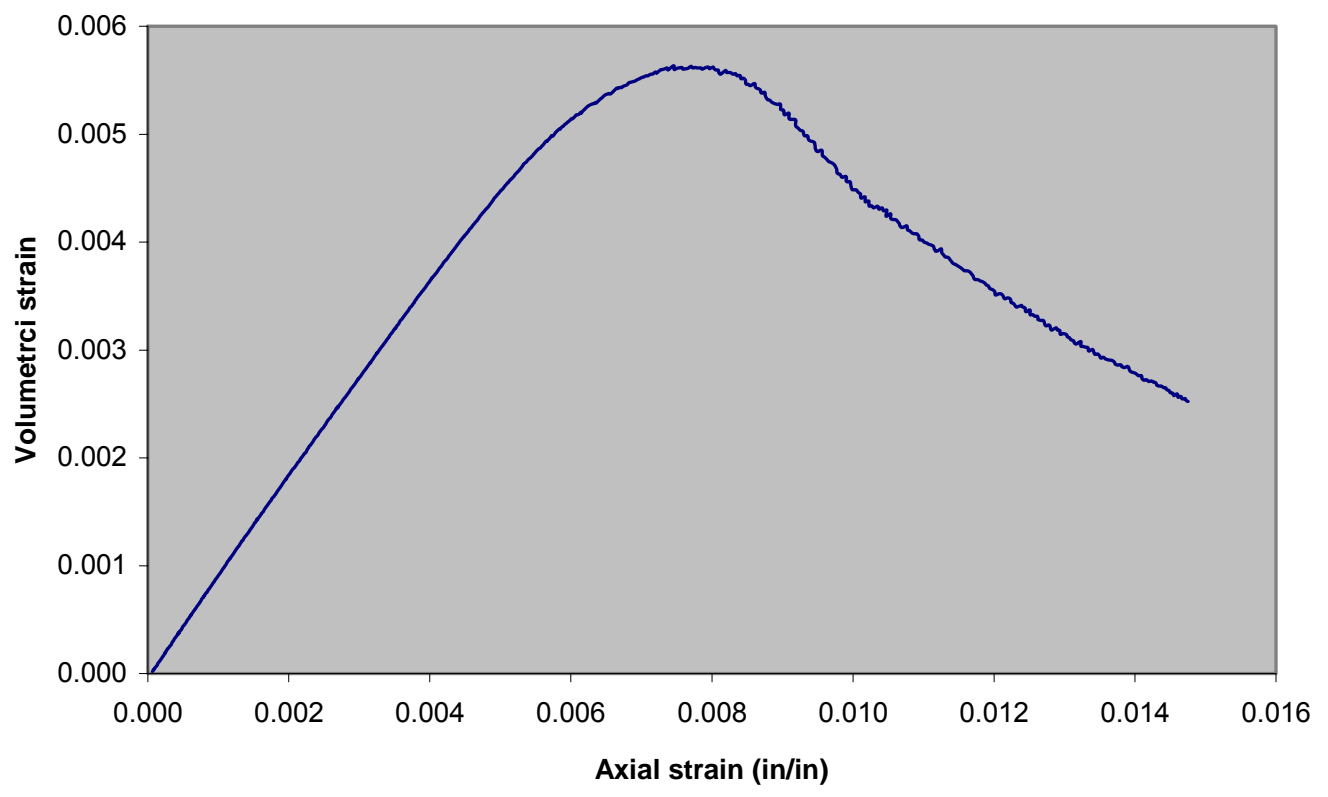

Figure B38 Volumetric strain vs. axial strain for cylinder with 1.4" x 1.4" air-filled debond wrapped with CFRP composite $\left(0^{\circ} / \pm 45^{\circ} / 90^{\circ}\right)$ 


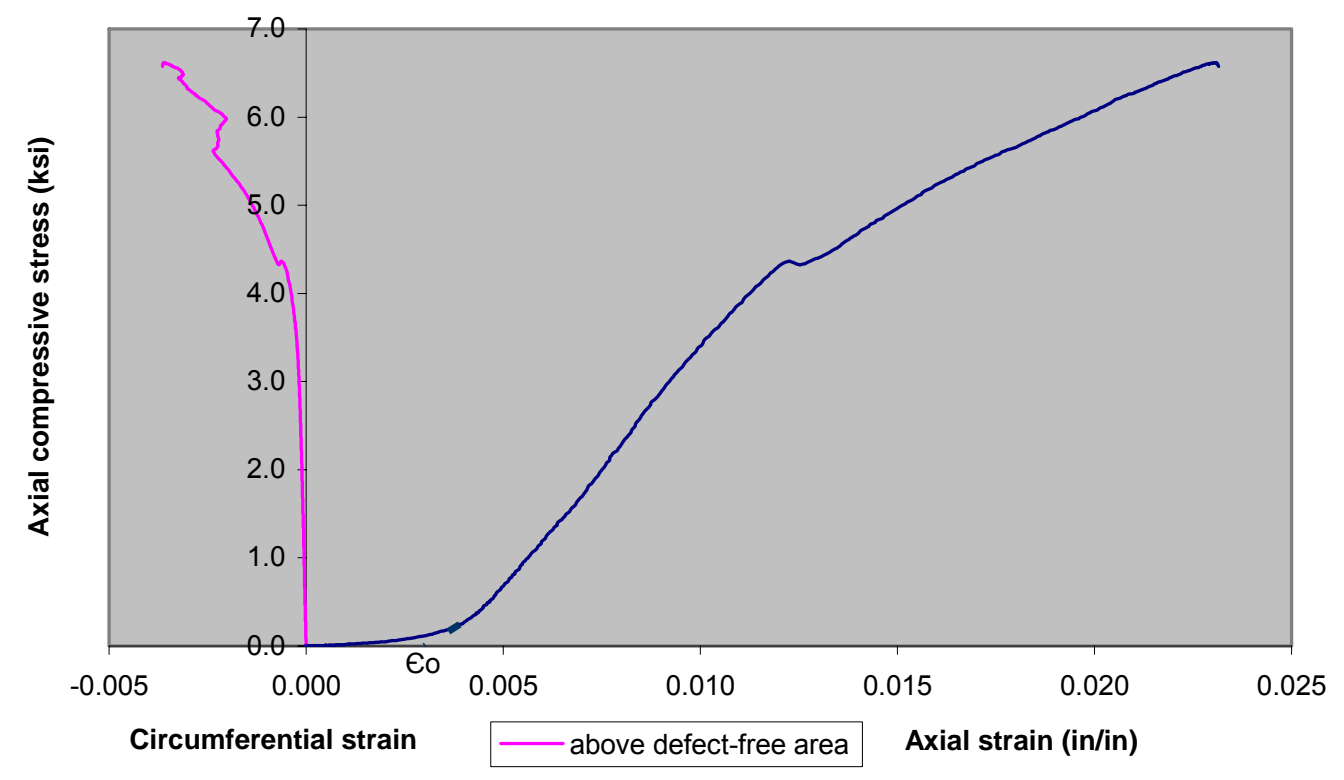

Figure B39 Axial compressive stress vs. strain for cylinder with 2" x 2" air-filled debond wrapped with CFRP composite $\left(0^{\circ} / \pm \mathbf{4 5}^{\circ} / 90^{\circ}\right)$

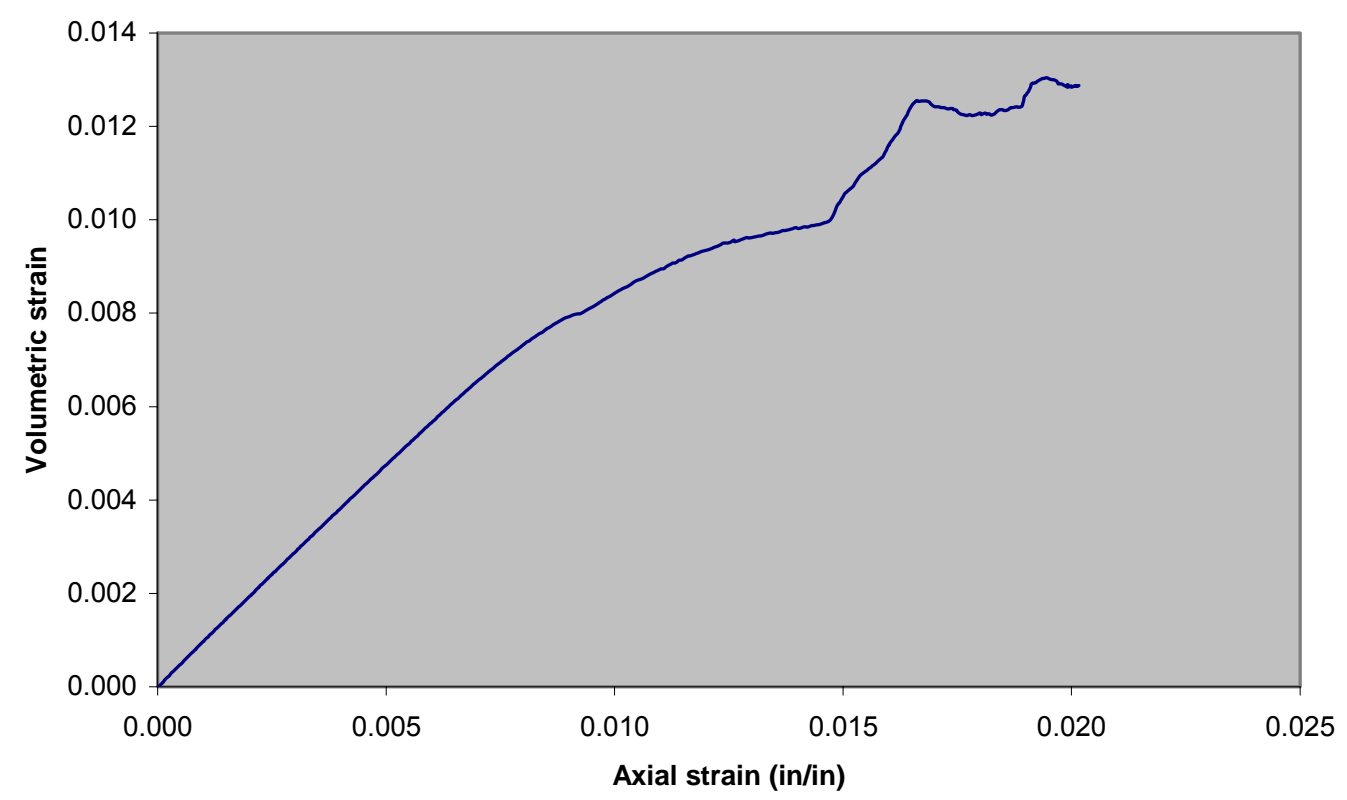

Figure B40 Volumetric strain vs. axial strain for cylinder with 2" x 2" air-filled debond wrapped with CFRP composite $\left(0^{\circ} / \pm 45^{\circ} / 90^{\circ}\right)$ 


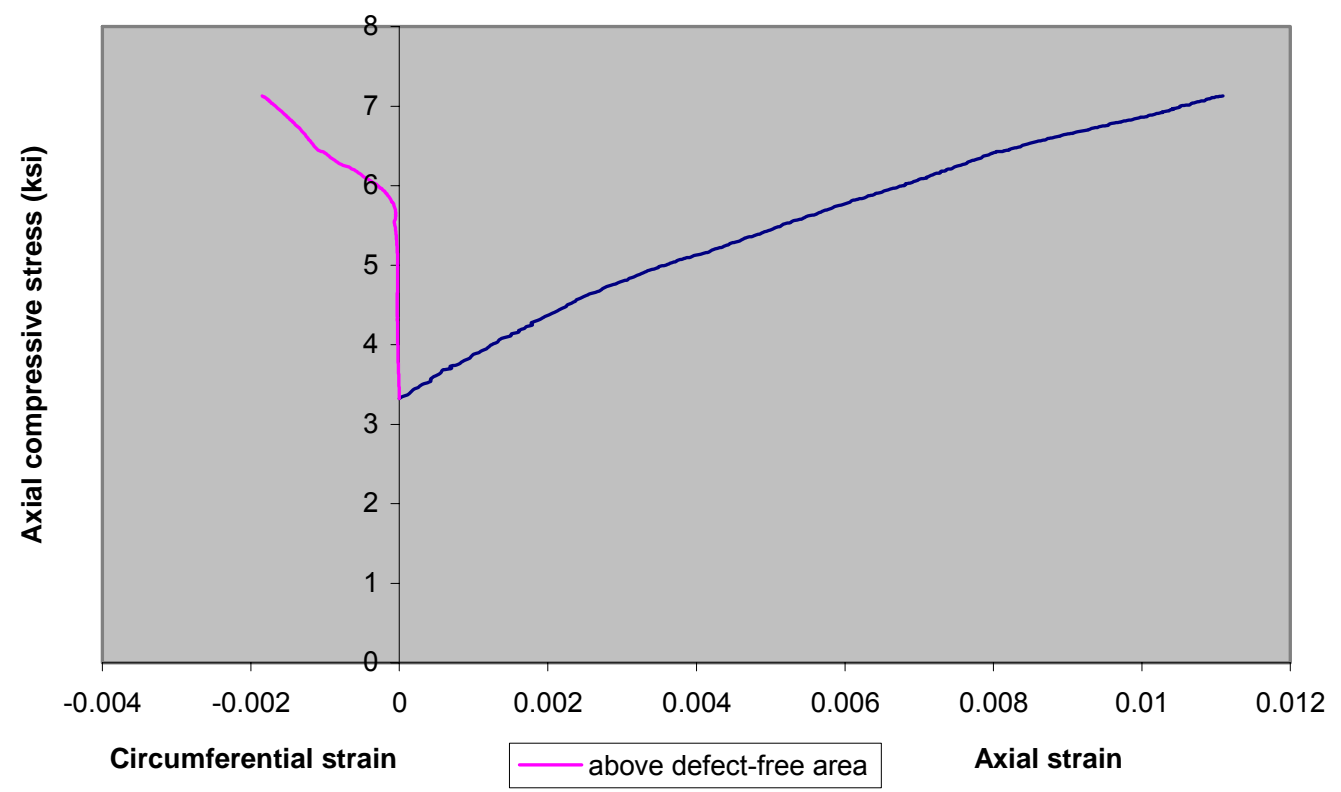

Figure B41 Axial compressive stress vs. strain for cylinder with 3" x 3 " air-filled debond wrapped with CFRP composite $\left(0^{\circ} / \pm \mathbf{4 5}^{\circ} / \mathbf{9 0}^{\circ}\right)$

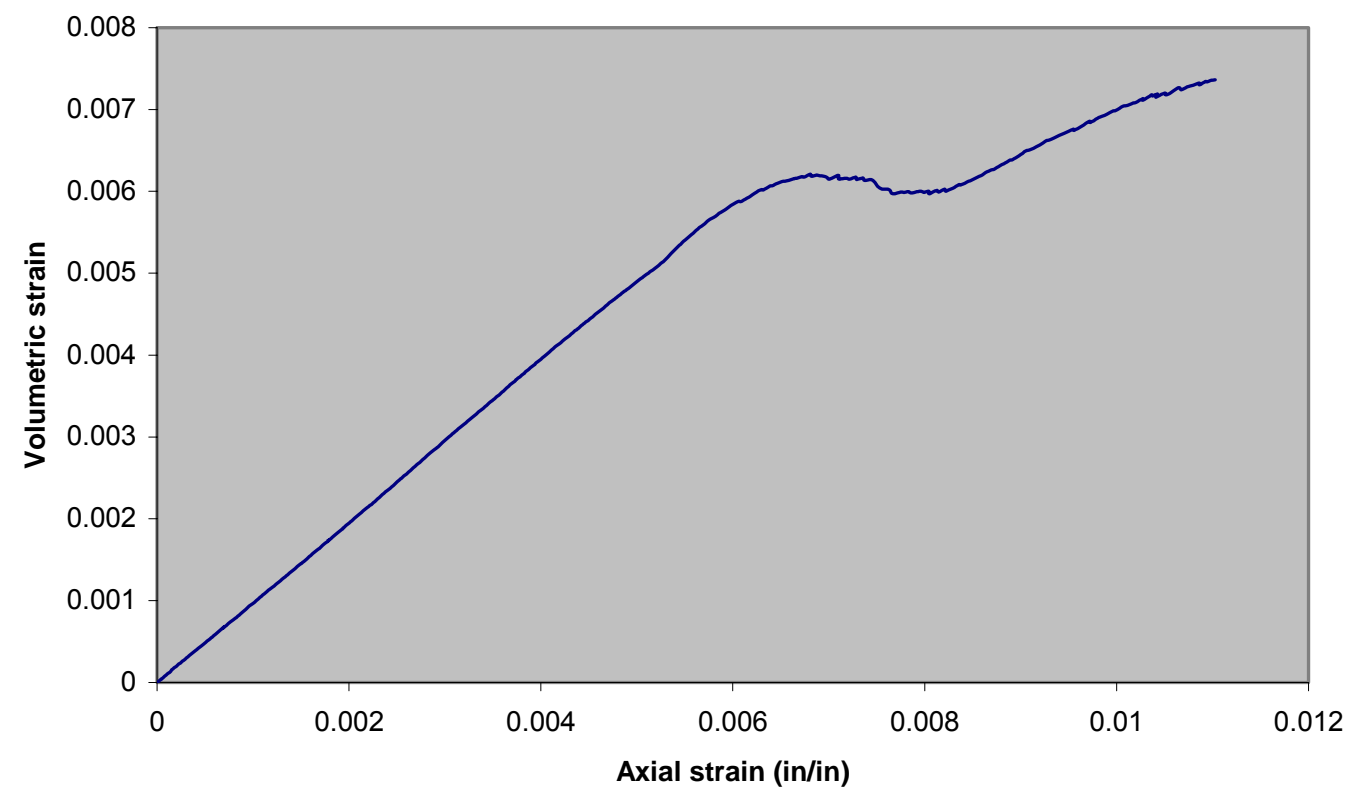

Figure B42 Volumetric strain vs. axial strain for cylinder with 3 " $x 3$ " air-filled debond wrapped with CFRP composite $\left(0^{\circ} / \pm 45^{\circ} / 90^{\circ}\right)$ 


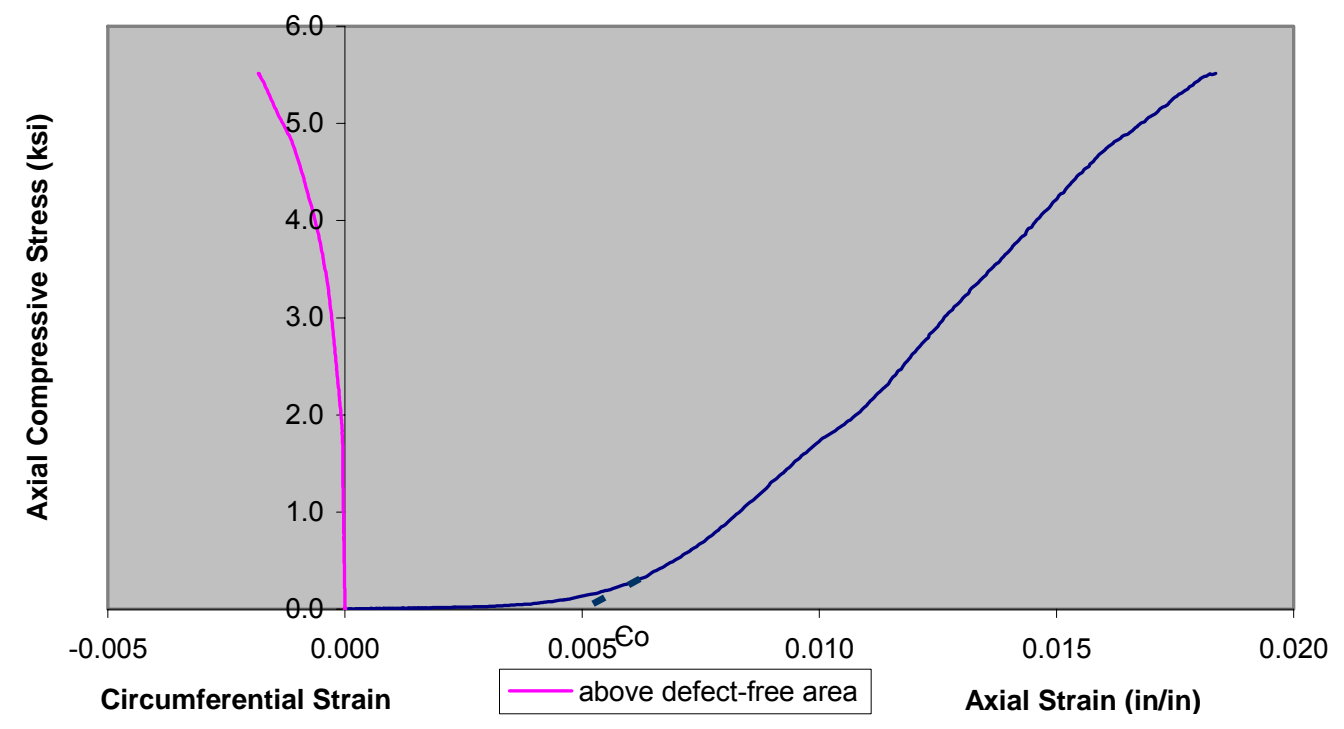

Figure B43 Axial compressive stress vs. strain for cylinder with 1" x 1" water-filled debond wrapped with CFRP composite $\left(0^{\circ} / \pm 45^{\circ} / 90^{\circ}\right)$

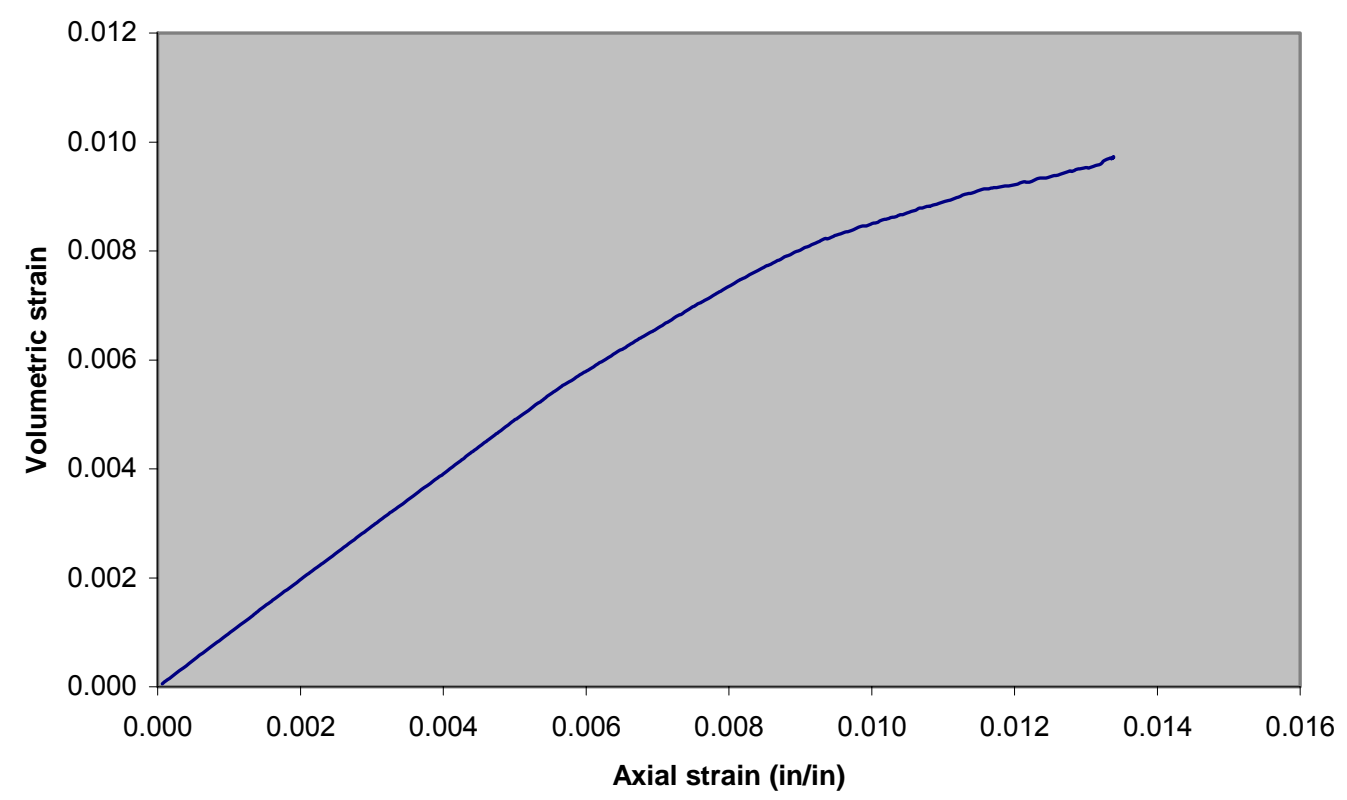

Figure B44 Volumetric strain vs. axial strain for cylinder with 1" $x 1$ " water-filled debond wrapped with CFRP composite $\left(0^{\circ} / \pm 45^{\circ} / 90^{\circ}\right)$ 


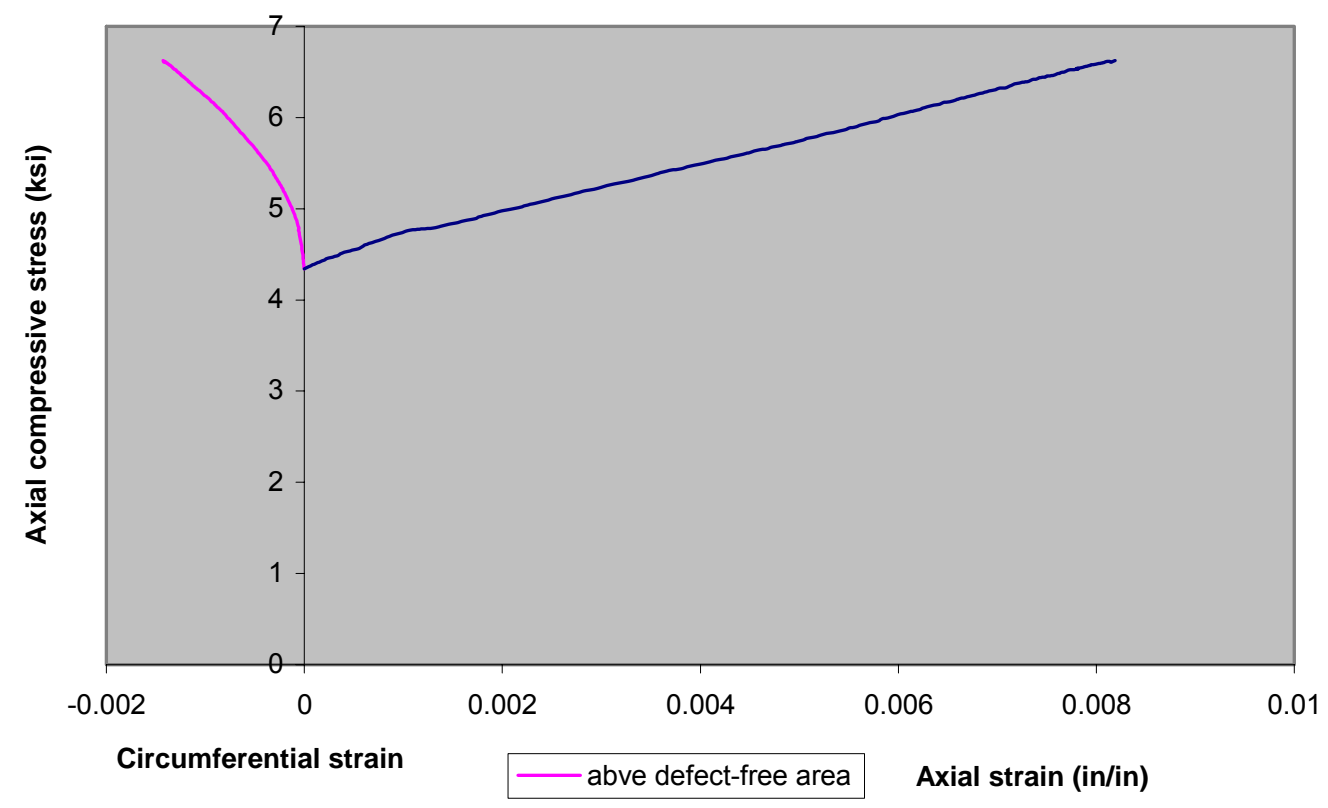

Figure B45 Axial compressive stress vs. strain for cylinder with 1.4" x 1.4" waterfilled debond wrapped with CFRP composite $\left(0^{\circ} / \pm \mathbf{4 5}^{\circ} / \mathbf{9 0}^{\circ}\right)$

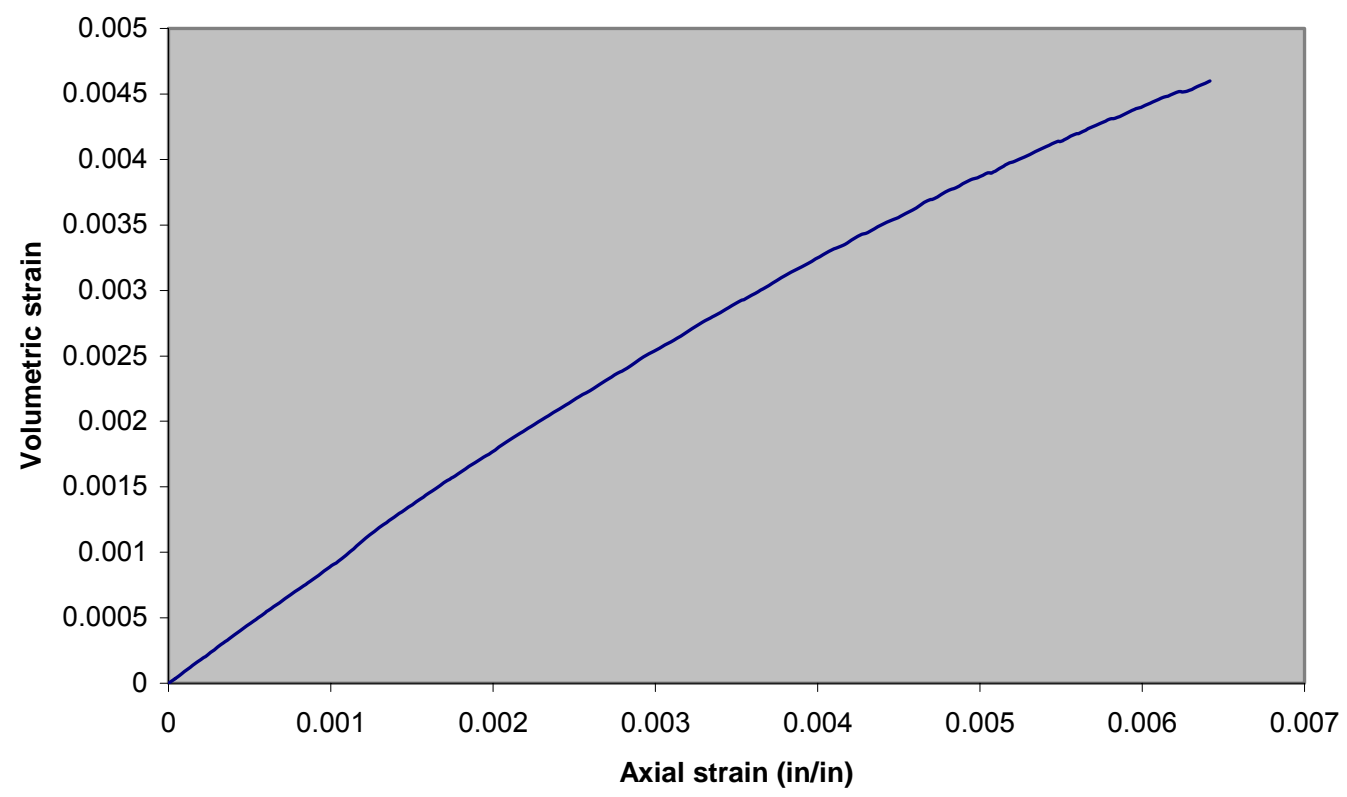

Figure B46 Volumetric strain vs. axial strain for cylinder with 1.4" $x$ 1.4" waterfilled debond wrapped with CFRP composite $\left(0^{\circ} / \pm \mathbf{4 5}^{\circ} / 90^{\circ}\right)$ 


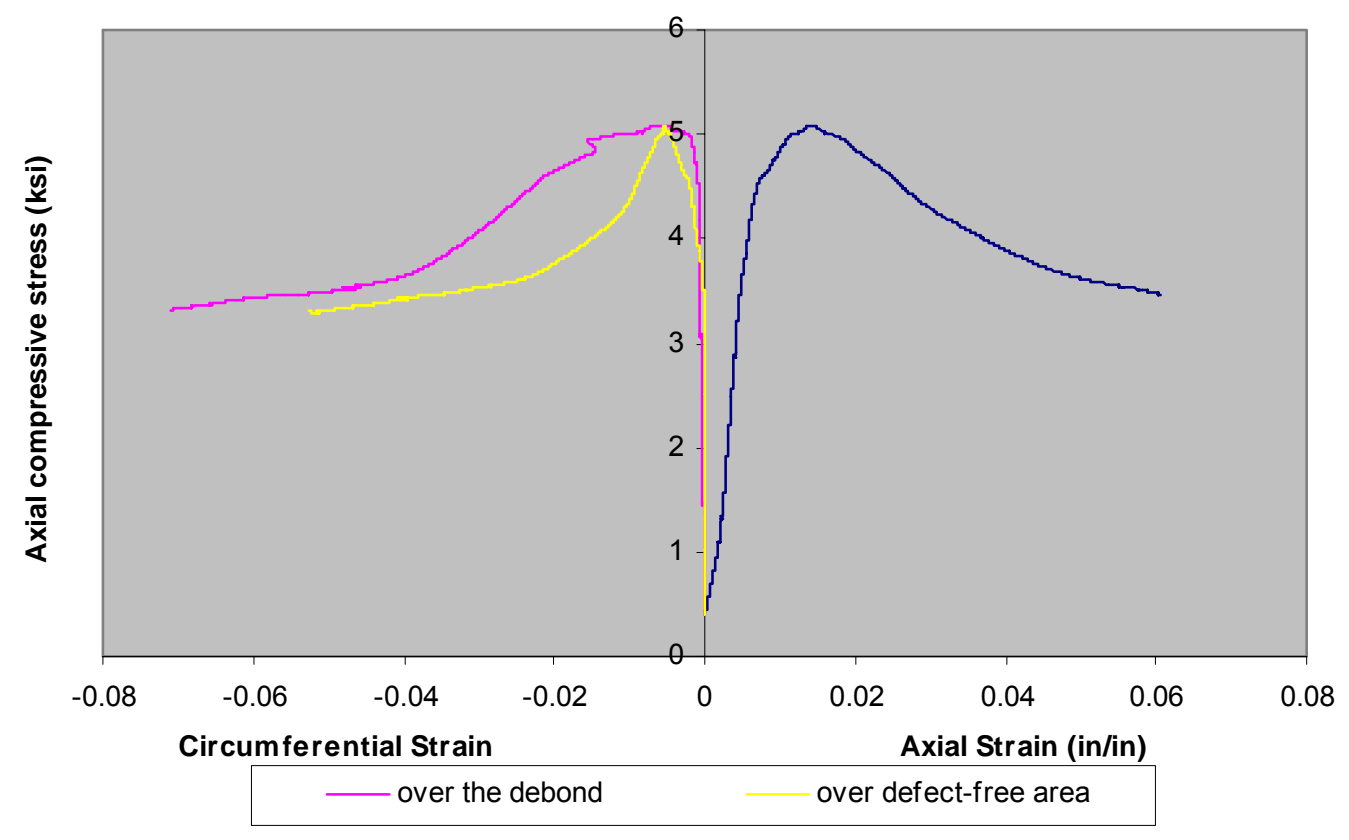

Figure B47 Axial compressive stress vs. strain for cylinder with 2" x 2" water-filled debond wrapped with CFRP composite $\left(0^{\circ} / \pm 4^{\circ} / \mathbf{9 0}^{\circ}\right)$

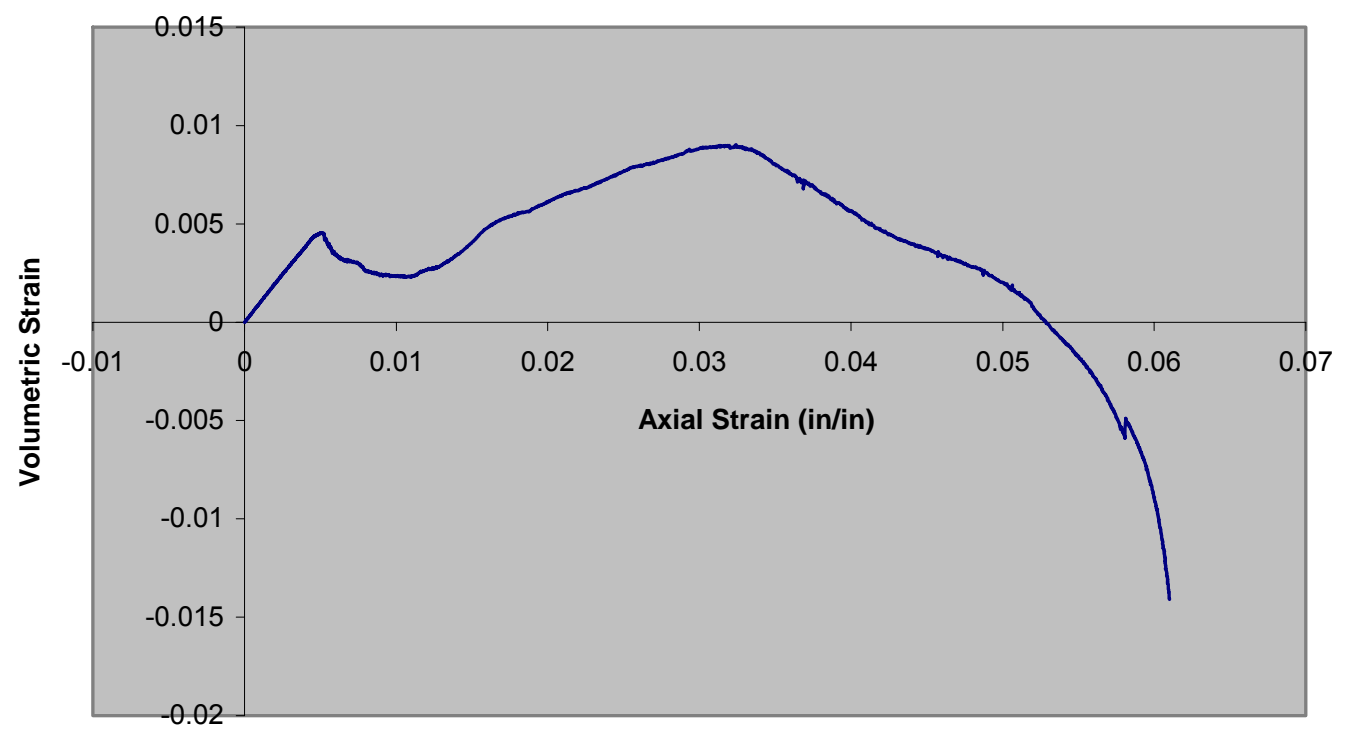

Figure B48 Volumetric strain vs. axial strain for cylinder with 2" x 2" water-filled debond wrapped with CFRP composite $\left(0^{\circ} / \pm 4^{\circ} / 9^{\circ}\right)$ 


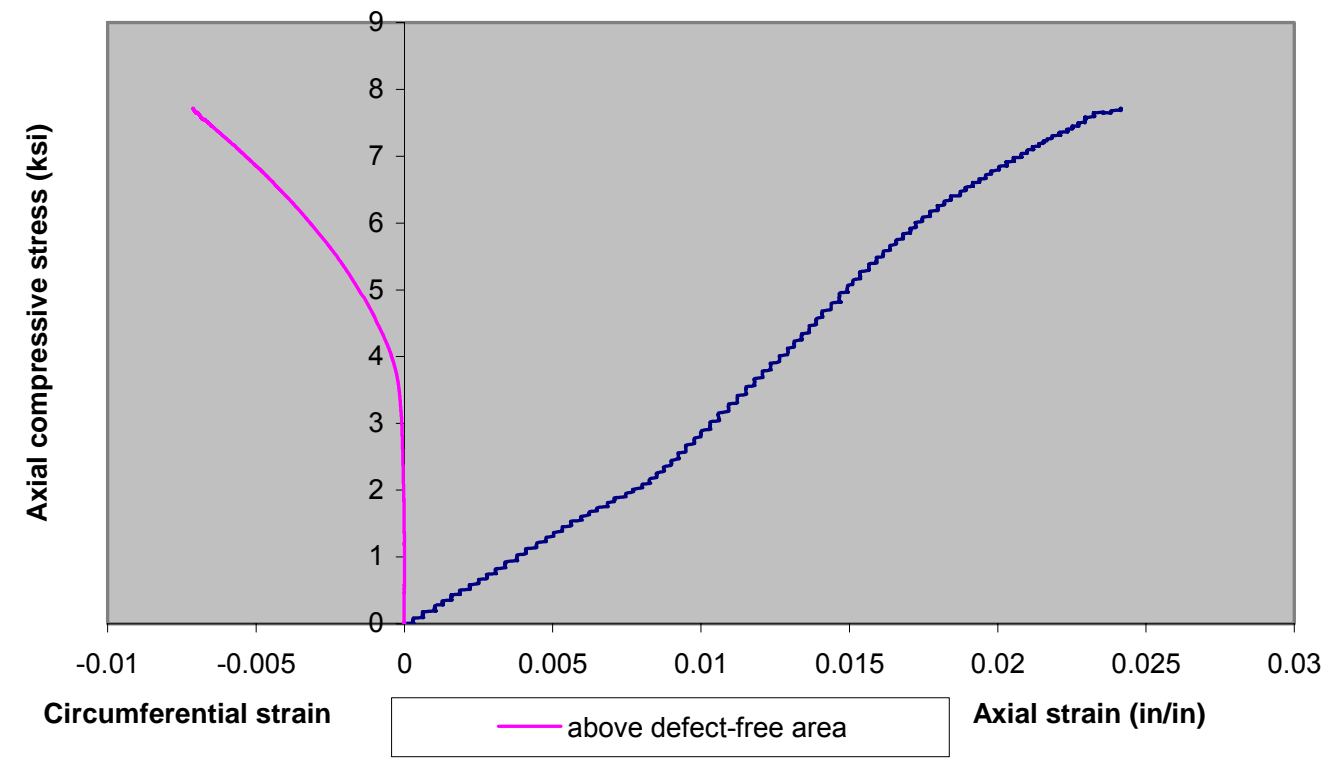

Figure B49 Axial compressive stress vs. strain for cylinder with 3" $x$ 3" water-filled debond wrapped with CFRP composite $\left(0^{\circ} / \pm 45^{\circ} / \mathbf{9 0}^{\circ}\right)$

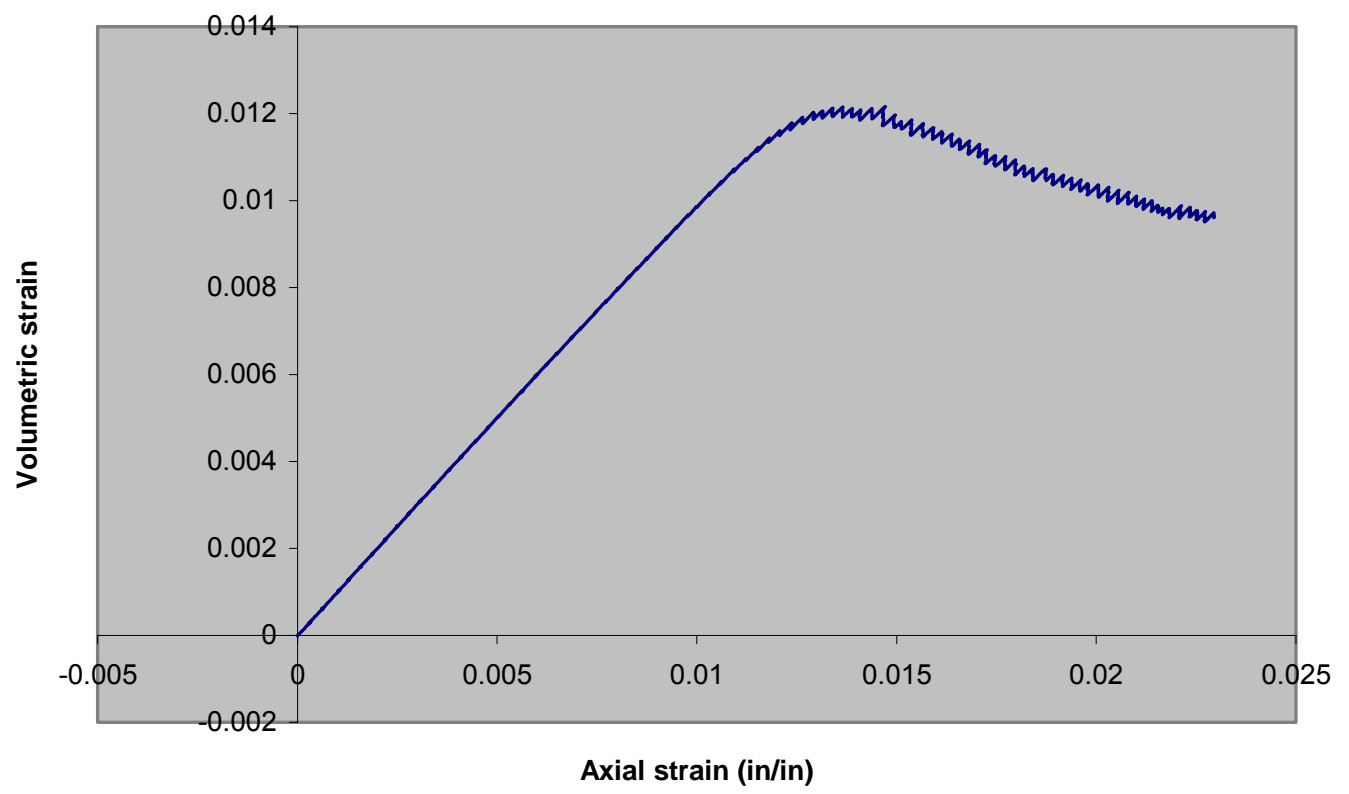

Figure B50 Volumetric strain vs. axial strain for cylinder with 3" x 3" water-filled debond wrapped with CFRP composite $\left(0^{\circ} / \pm 45^{\circ} / 90^{\circ}\right)$ 


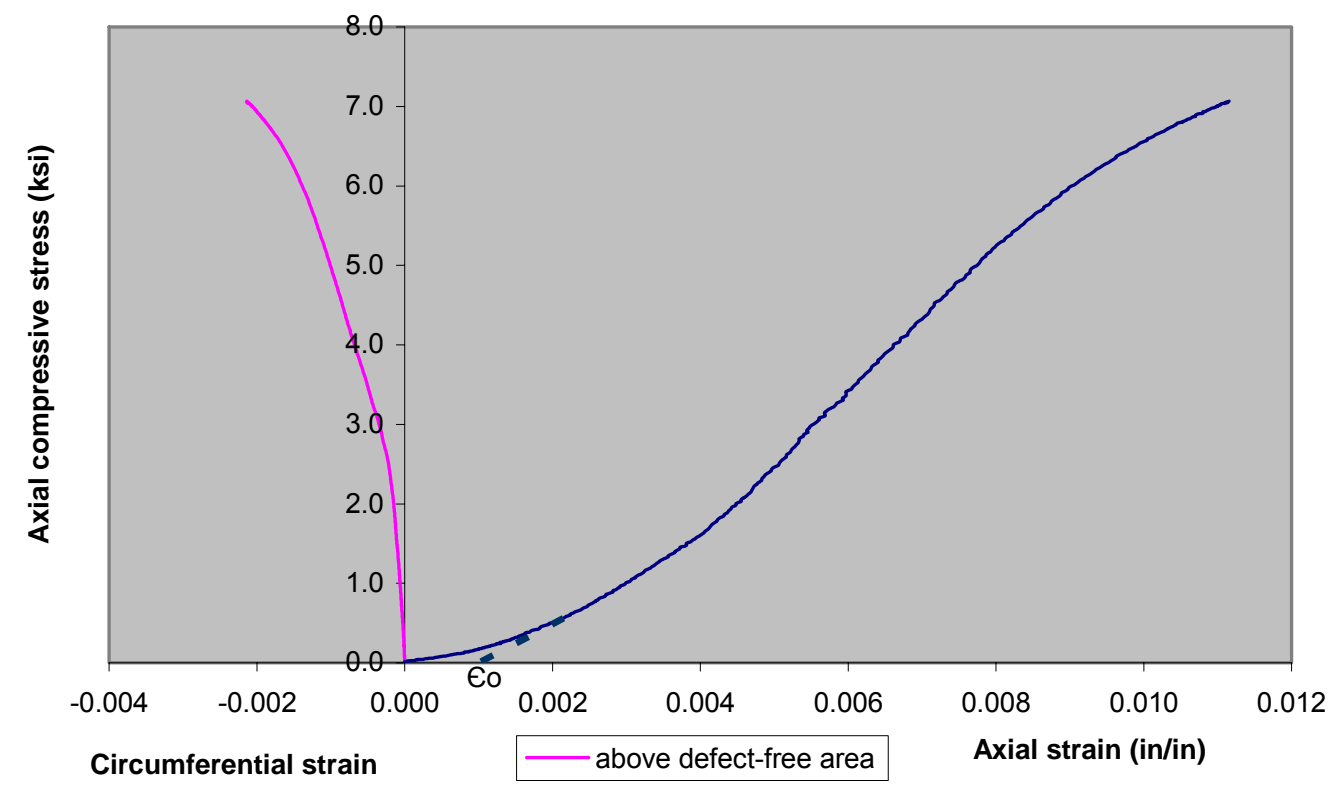

Figure B51 Axial compressive stress vs. strain for cylinder with 1" x 1" Teflon sheet wrapped with CFRP composite $\left(0^{\circ} / \pm 45^{\circ} / 90^{\circ}\right)$

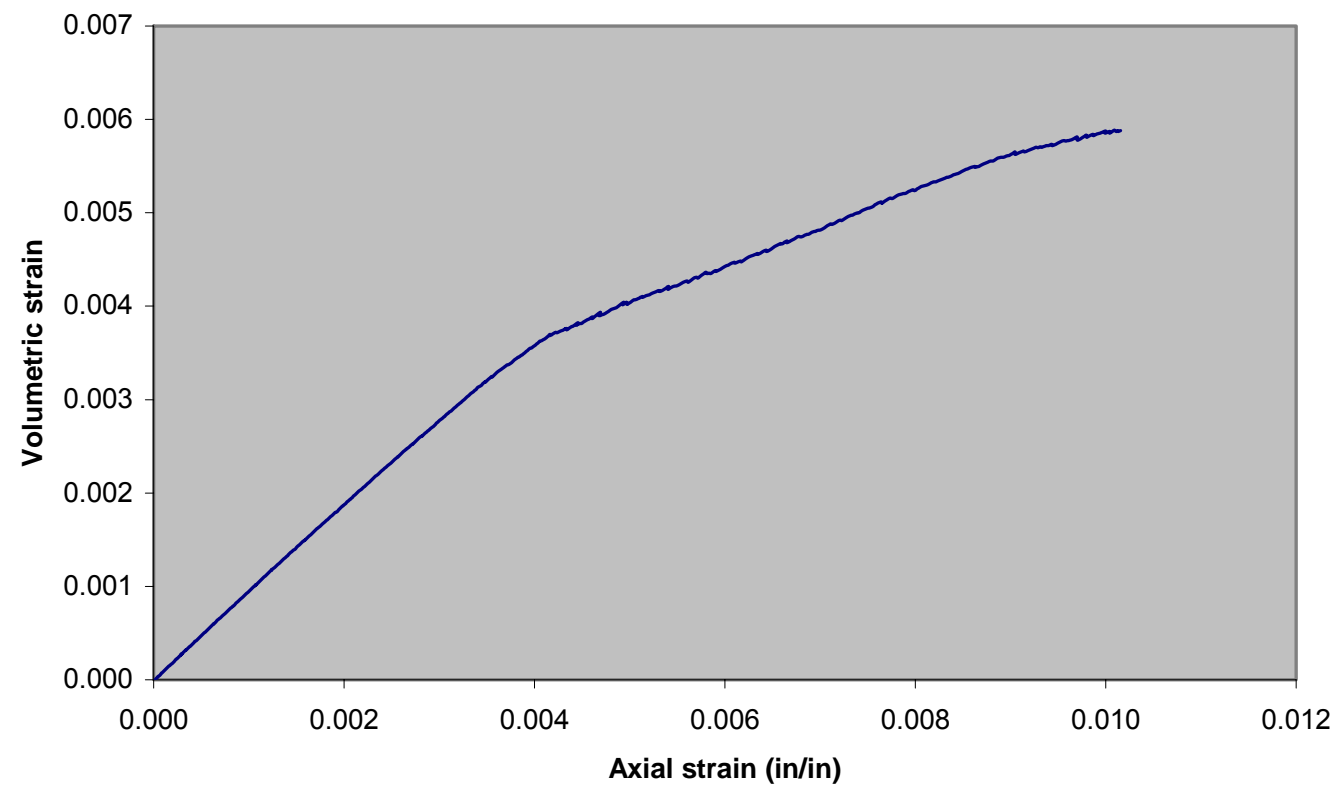

Figure B52 Volumetric strain vs. axial strain for cylinder with 1" x 1" Teflon sheet wrapped with CFRP composite $\left(0^{\circ} / \pm 45^{\circ} / 90^{\circ}\right)$ 


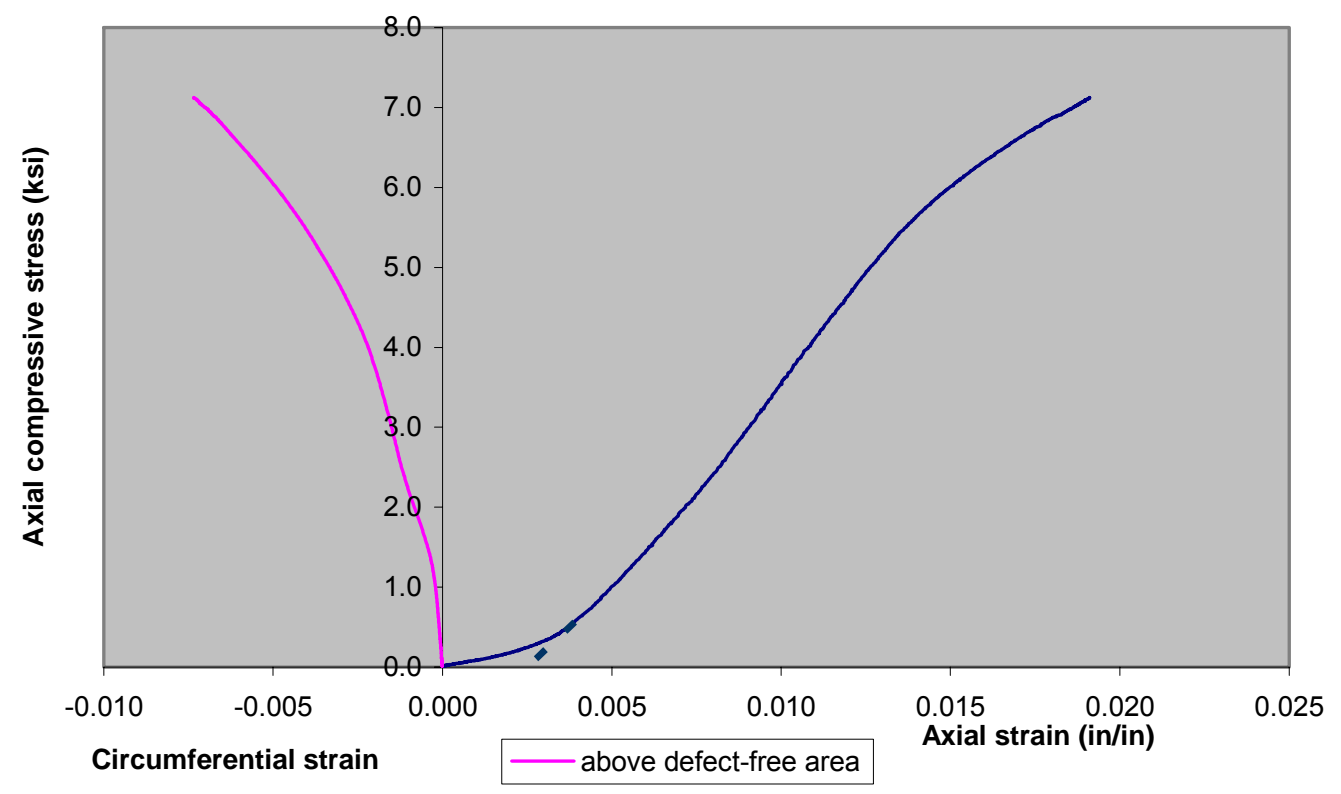

Figure B53 Axial compressive stress vs. strain for cylinder with 1.4" x 1.4" Teflon sheet wrapped with CFRP composite $\left(0^{\circ} / \pm 4^{\circ} / 90^{\circ}\right)$

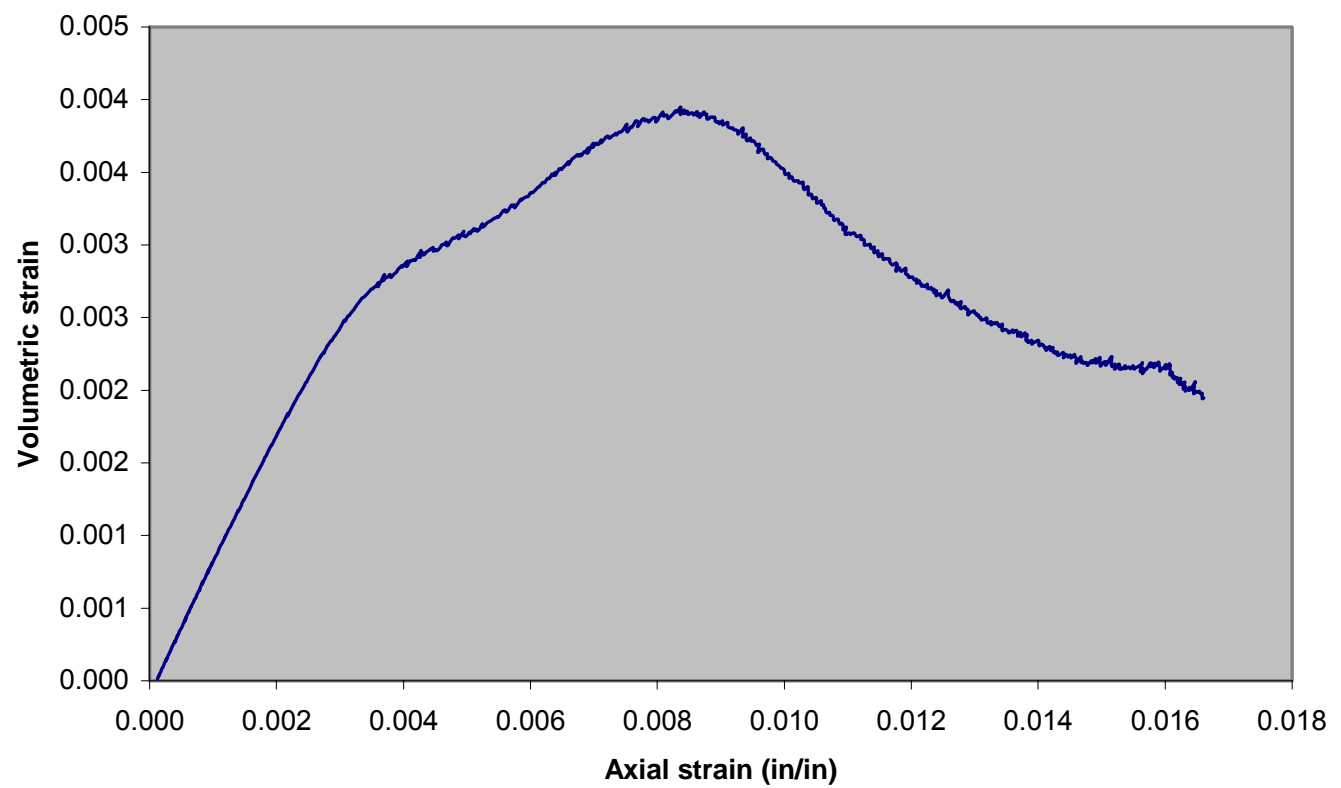

Figure B54 Volumetric strain vs. axial strain for cylinder with 1.4" x 1.4" Teflon sheet wrapped with CFRP composite $\left(0^{\circ} / \pm 4^{\circ} / 9^{\circ}\right)$ 


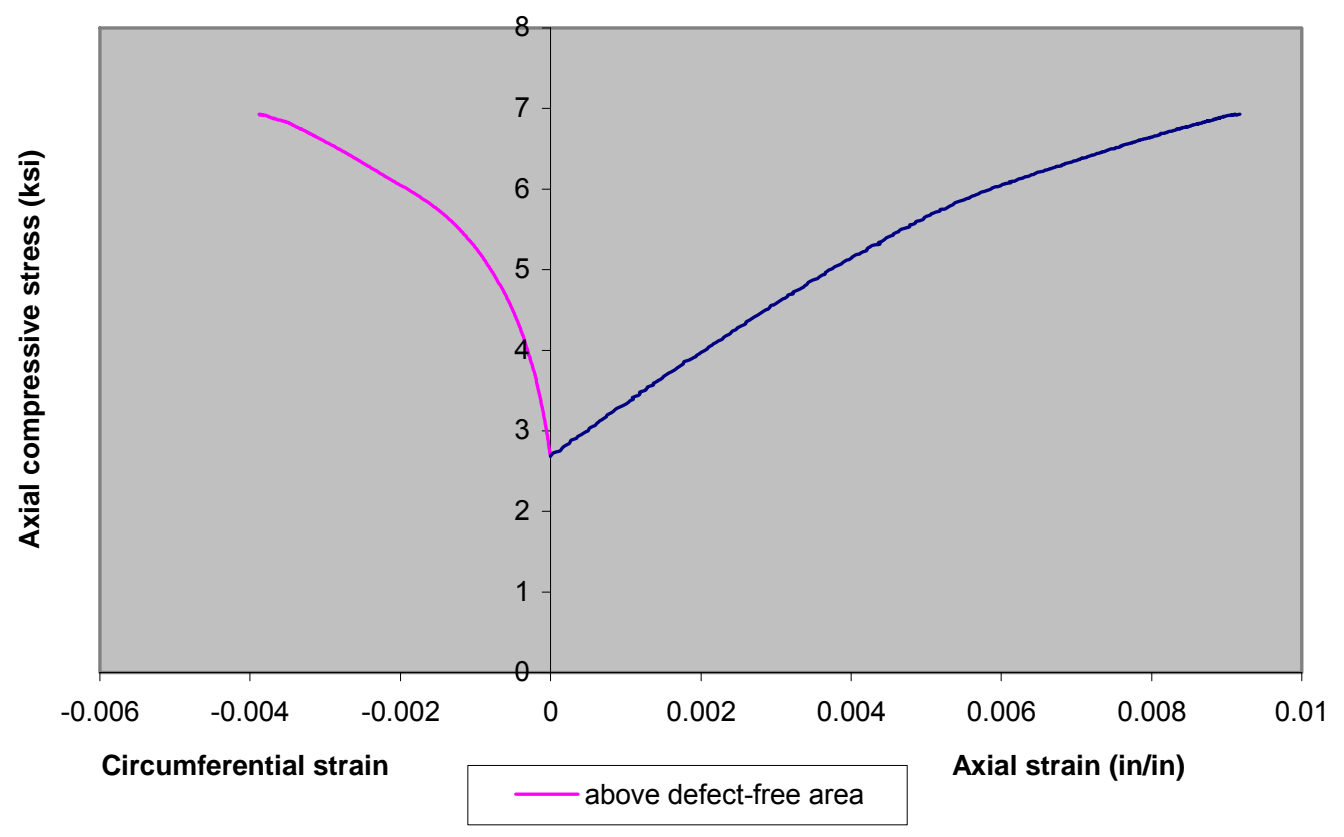

Figure B55 Axial compressive stress vs. strain for cylinder with 2" x 2" Teflon sheet wrapped with CFRP composite $\left(0^{\circ} / \pm \mathbf{4 5}^{\circ} / \mathbf{9 0}^{\circ}\right)$

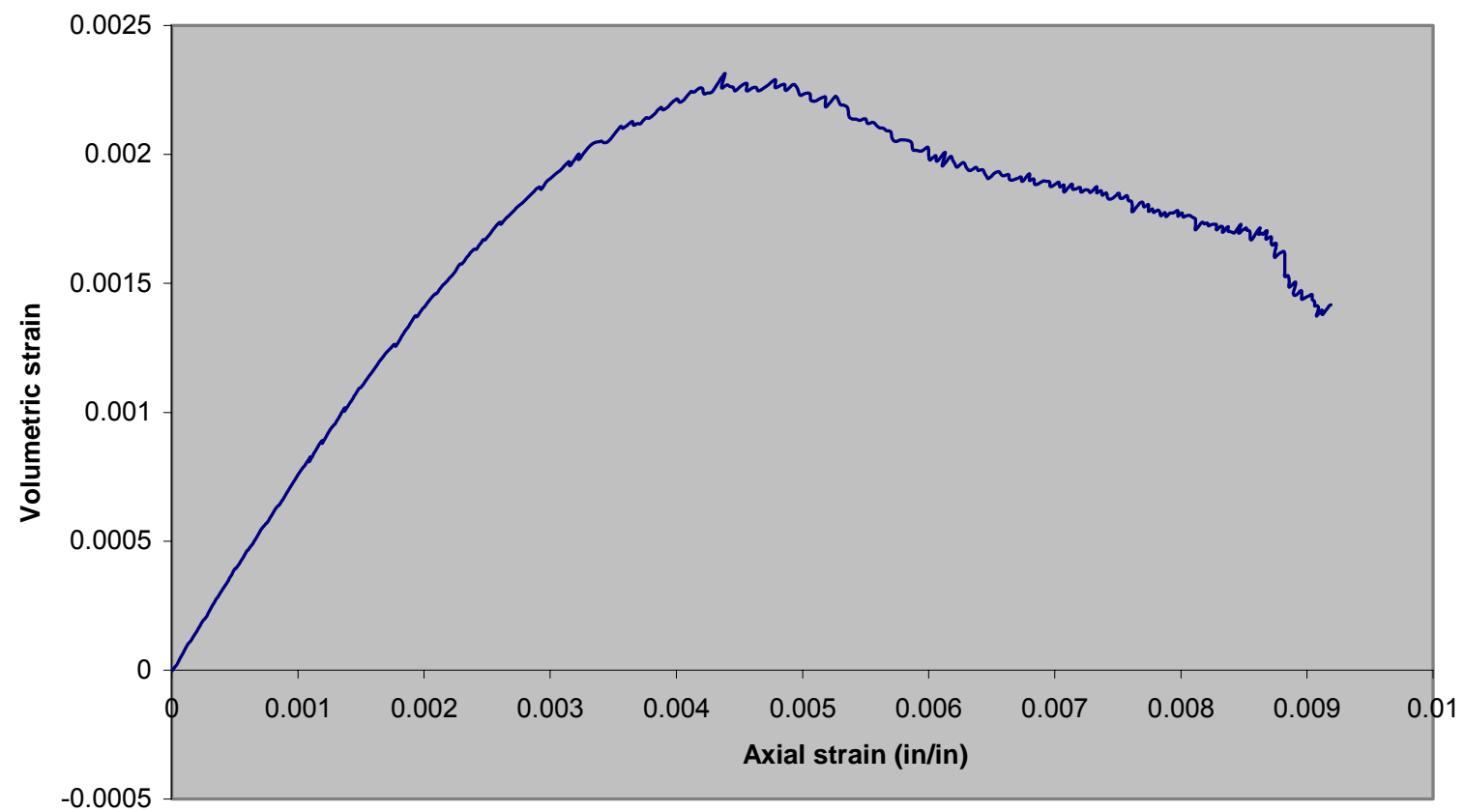

Figure B56 Volumetric strain vs. axial strain for cylinder with 2" x 2" Teflon sheet wrapped with CFRP composite $\left(0^{\circ} / \pm \mathbf{4 5}^{\circ} / \mathbf{9 0}^{\circ}\right)$ 


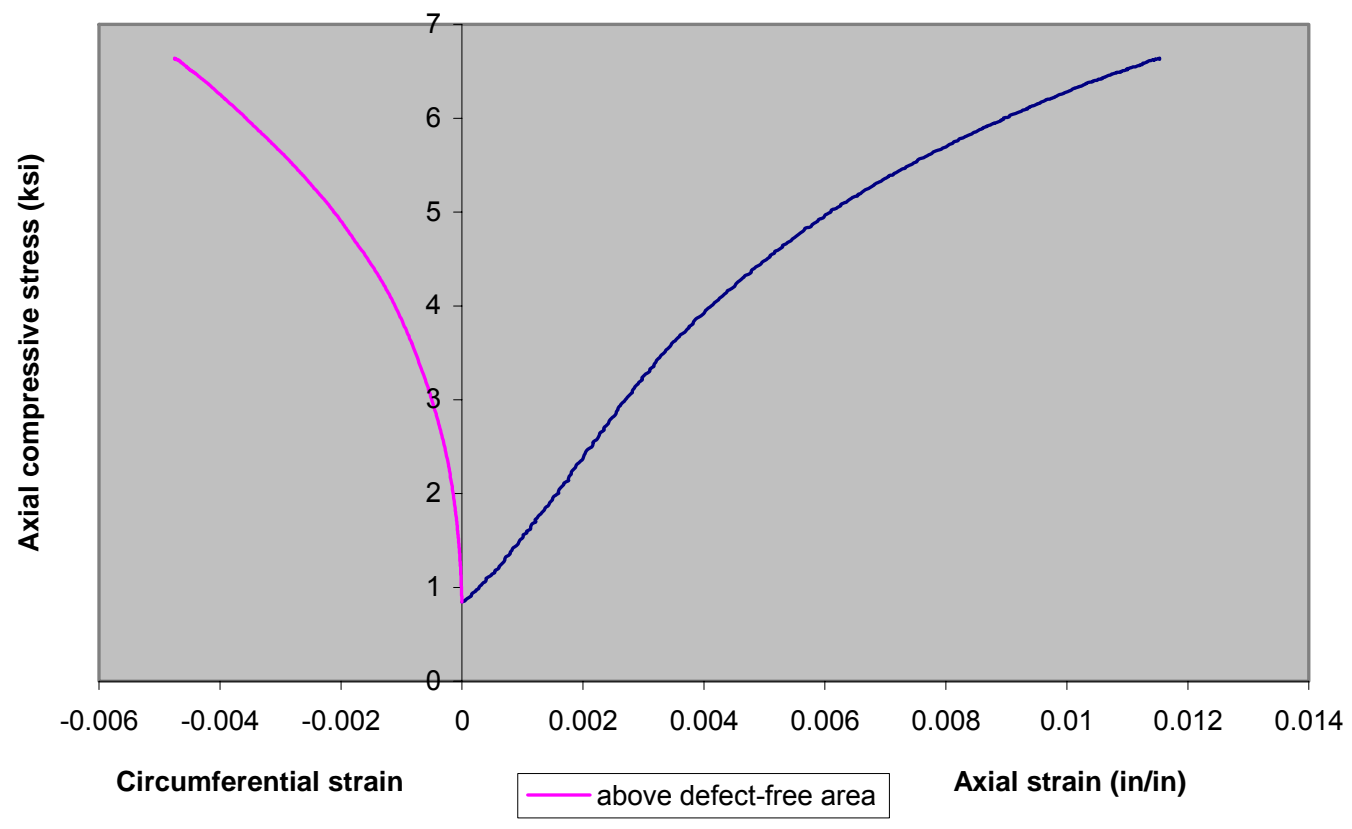

Figure B57 Axial compressive stress vs. strain for cylinder with 3" x 3" Teflon sheet wrapped with CFRP composite $\left(0^{\circ} / \pm \mathbf{4 5}^{\circ} / \mathbf{9 0}^{\circ}\right)$

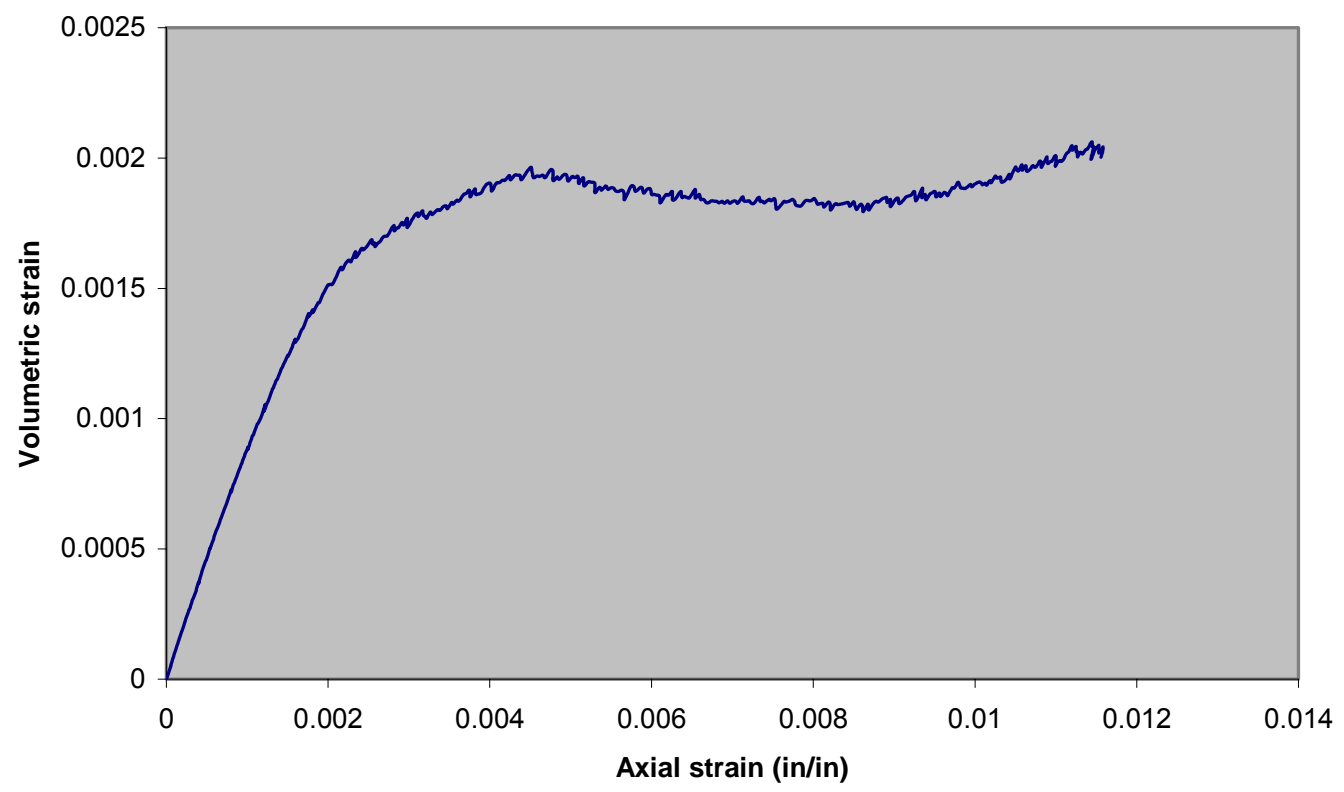

Figure B58 Volumetric strain vs. axial strain for cylinder with 3" $x$ 3" Teflon sheet wrapped with CFRP composite $\left(0^{\circ} / \pm 45^{\circ} / 9^{\circ}\right)$

John $\mathrm{H}$. 